\title{
Bridging the gap - the Sustainable Development Goals and climate change mitigation
}

\author{
Sperling, Frank ; Granoff , Ilmi; Northrop , Eliza; Olhoff, Anne; Gale, Andrew Scott
}

Published in:

The Emissions Gap Report 2016

Publication date:

2016

Document Version

Publisher's PDF, also known as Version of record

Link back to DTU Orbit

Citation (APA):

Sperling, F., Granoff , I., Northrop , E., Olhoff, A., \& Gale, A. S. (2016). Bridging the gap - the Sustainable Development Goals and climate change mitigation. In The Emissions Gap Report 2016: A Unep Synthesis Report (pp. 40-47). UNEP DTU Partnership.

\section{General rights}

Copyright and moral rights for the publications made accessible in the public portal are retained by the authors and/or other copyright owners and it is a condition of accessing publications that users recognise and abide by the legal requirements associated with these rights.

- Users may download and print one copy of any publication from the public portal for the purpose of private study or research.

- You may not further distribute the material or use it for any profit-making activity or commercial gain

- You may freely distribute the URL identifying the publication in the public portal 


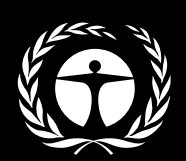

UNEP

\section{The Emissions Gap Report 2016}

A UNEP Synthesis Report

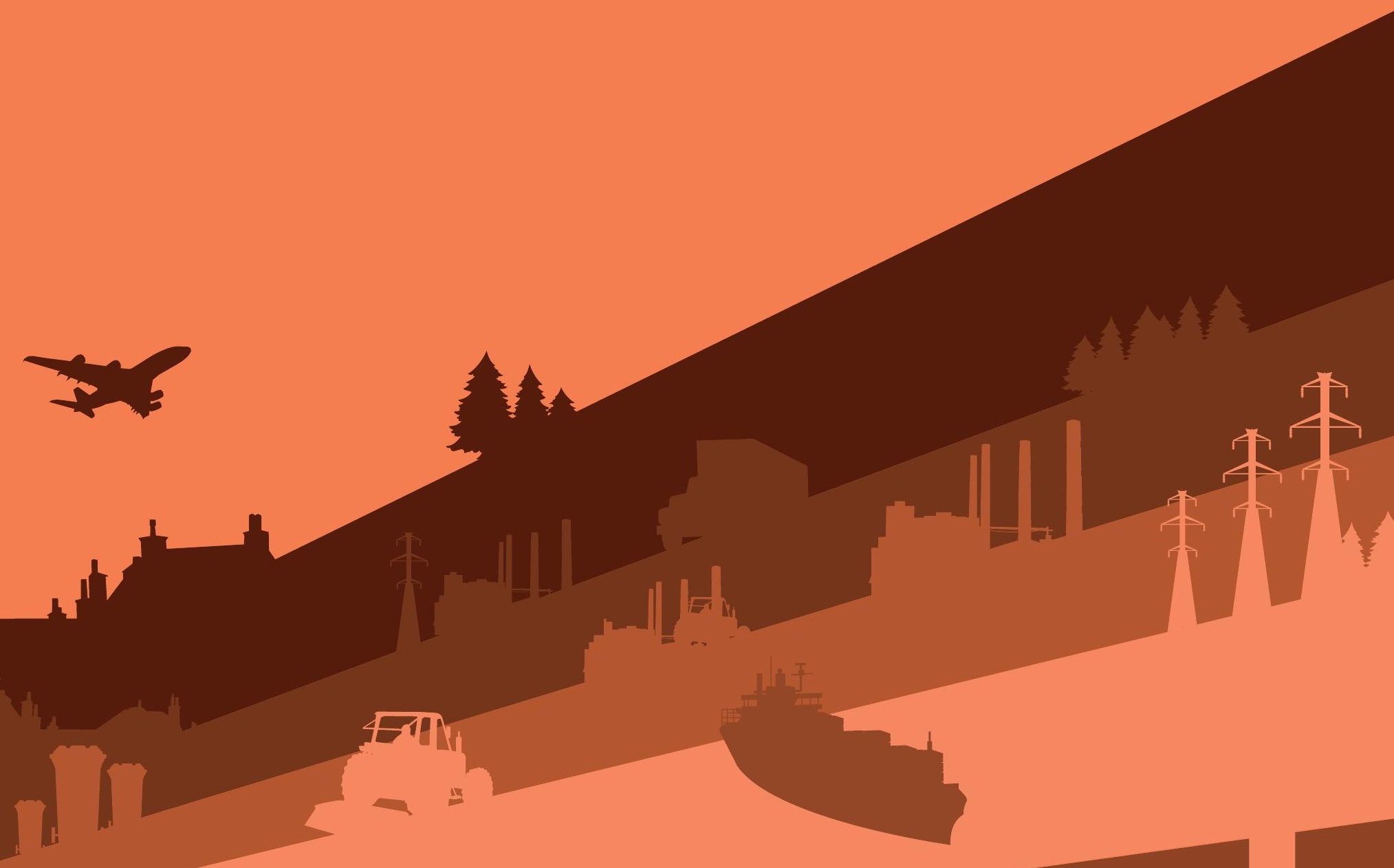


Published by the United Nations Environment Programme (UNEP), November 2016

Copyright @ UNEP 2016

ISBN: 978-92-807-3617-5

Job Number: DEW/2061/NA

This publication may be reproduced in whole or in part and in any form for educational or non-profit services without special permission from the copyright holder, provided acknowledgement of the source is made. UNEP would appreciate receiving a copy of any publication that uses this publication as a source.

No use of this publication may be made for resale or any other commercial purpose whatsoever without prior permission in writing from the United Nations Environment Programme. Applications for such permission, with a statement of the purpose and extent of the reproduction, should be addressed to the Director, Communication Division, UNEP, P. O. Box 30552, Nairobi 00100, Kenya.

\section{Disclaimers}

Mention of a commercial company or product in this document does not imply endorsement by UNEP or the authors. The use of information from this document for publicity or advertising is not permitted. Trademark names and symbols are used in an editorial fashion with no intention on infringement of trademark or copyright laws.

The views expressed in this publication are those of the authors and do not necessarily reflect the views of the United Nations Environment Programme. We regret any errors or omissions that may have been unwittingly made.

(C) Images and illustrations as specified.

\section{Citation}

This document may be cited as: UNEP (2016). The Emissions Gap Report 2016. United Nations Environment Programme (UNEP), Nairobi

A digital copy of this report along with supporting appendices are available at http://uneplive.unep.org/theme/index/13\#egr

Supported by:
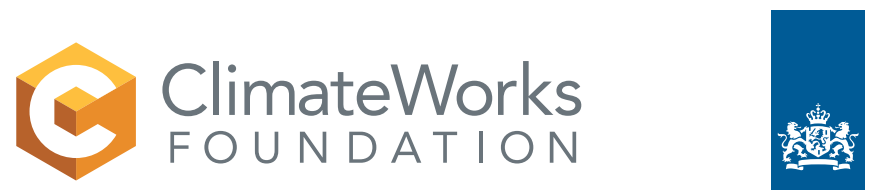

Ministry of Infrastructure and the Environment 


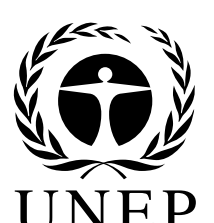

UNEP

The Emissions Gap Report 2016 A UNEP Synthesis Report

November 2016 


\section{Acknowledgements}

The United Nations Environment (UNEP) would like to thank the members of the steering committee, the lead and contributing authors, reviewers and the secretariat for their contribution to the preparation of this assessment report.

Authors and reviewers have contributed to the report in their individual capacities. Their affiliations are only mentioned for identification purposes.

\section{Project steering committee}

Jacqueline McGlade (United Nations Environment), John Christensen (UNEP DTU Partnership), Mónica Araya (Nivela), Navroz K. Dubash (Centre for Policy Research, India), Simon Maxwell (Climate and Development Knowledge Network), Surabi Menon (ClimateWorks Foundation), Bert Metz (European Climate Foundation), Yacob Mulugetta (University College London), Bouzekri Razi (Ministry of Environment, Morocco), Katia Simeonova (United Nations Framework Convention on Climate Change), Merlyn van Voore (United Nations Environment)

\section{Chapter 1}

Lead authors: Anne Olhoff (UNEP DTU Partnership), John Christensen (UNEP DTU Partnership)

\section{Chapter 2}

Lead authors: Taryn Fransen (World Resources Institute), Michel den Elzen (PBL Netherlands Environmental Assessment Agency), Takeshi Kuramochi (NewClimate Institute)

Contributing authors: Greet Janssens-Maenhout (Joint Research Centre, European Commission), Anne Olhoff (UNEP DTU Partnership), Jos Olivier (PBL Netherlands Environmental Assessment Agency)

\section{Chapter 3}

Lead authors: Michel den Elzen (PBL Netherlands Environmental Assessment Agency), Niklas Höhne (NewClimate Institute), Joeri Rogelj (International Institute for Applied Systems Analysis)

Contributing authors: Taryn Fransen (World Resources Institute), Mark Roelfsema (PBL Netherlands Environmental Assessment Agency), Sebastian Sterl (NewClimate Institute)

\section{Chapter 4}

Lead authors: Niklas Höhne (NewClimate Institute), Philip Drost (United Nations Environment)

Contributing authors: Fatemeh Bakhtiari (UNEP DTU Partnership), Sander Chan (German Development Institute), Ann Gardiner (Ecofys), Thomas Hale (University of Oxford Blavatnik School of Government), Angel Hsu (Yale University - Yale School of Forestry and Environmental Studies), Takeshi Kuramochi (NewClimate Institute), Daniel Puig (UNEP DTU Partnership), Mark Roelfsema (PBL Netherlands Environmental Assessment Agency), Sebastian Sterl (NewClimate Institute)

\section{Chapter 5}

Lead authors: Subash Dhar (UNEP DTU Partnership), Timothy Clifford Farrell (UNEP DTU Partnership), Rana Ghoneim (United Nations Industrial Development Organization), Diana Urge-Vorsatz (Central European University)

Contributing authors: Elisabeth Boles (Massachusetts Institute of Technology), Benigna Boza-Kiss (Central European University), Marco Matteini (United Nations Industrial Development Organization), Jyoti Painuly (UNEP DTU Partnership), Minal Pathak (Center for Environmental Planning and Technology University), Ksenia Petrichenko (UNEP DTU Partnership), Bettina Schreck (United Nations Industrial Development Organization), PR Shukla (Indian Institute of Management, Ahmedabad)

\section{Chapter 6}

Lead authors: Frank Sperling (University of Oxford), IImi Granoff (Overseas Development Institute)

Contributing authors: Eliza Northrop (World Resources Institute), Anne Olhoff (UNEP DTU Partnership), Andrew Scott (Overseas Development Institute)

\section{Reviewers}

Swati Agarwal (The Energy and Resources Institute), Jennifer Bansard (University of Potsdam), Maria Belenky (Climate Advisers), Thomas Black Arbeláez (Centro Andino para la Economía en el Medio Ambiente), Tyler Bryant (International Energy Agency), Laura Cozzi (International Energy Agency), Steffen Dockweiler (Danish Energy Agency), 
Patty Fong (European Climate Foundation), Brendan Guy (Natural Resources Defense Council), Matthew Hoffmann (University of Toronto - Munk School of Global Affairs), Angel Hsu (Yale University - Yale School of Forestry and Environmental Studies), Jan Kersting (Fraunhofer Institute for Systems and Innovation Research), Gary Kleiman (World Bank Group), Rob Kool (Netherlands Enterprise Agency), Benoit Lebot (International Partnership for Energy Efficiency Cooperation), Franck Lecocq (Centre International de Recherche sur l'Environnement et le Développement), Perry Miles (European Commission), Karsten Neuhoff (German Institute for Economic Research), Lars J. Nilsson (Lund University - Environmental and Energy Systems Studies), He Ping (Energy Foundation China), lan Ponce (United Nations Framework Convention on Climate Change), Céline Ramstein (World Bank Group), Oliver Rapf (Building Performance Institute Europe), David Reidmiller (US Department of State), Lisa Ryan (University College Dublin), Yamina Saheb (OpenExp), Reed Schuler (US Department of State), Laura Segafredo ( $2^{\circ}$ Investing Initiative), Jigar Shah (Institute for Industrial Productivity), Ralph Sims (Massey University), Robert Tromop (Efficient Energy International), Harro van Asselt (Stockholm Environment Institute), Lutz Weischer (Germanwatch), Oscar Widerberg (Vrije University Amsterdam - Institute for Environmental Studies), William Wills (Instituto Alberto Luiz Coimbra de Pós-Graduação e Pesquisa de Engenharia - Universidade Federal do Rio de Janeiro), Jim Wolfe (independent consultant)

\section{Chief scientific editors}

Anne Olhoff (UNEP DTU Partnership), John Christensen (UNEP DTU Partnership)

\section{Editorial team}

Daniel Puig (UNEP DTU Partnership), Lars Christiansen (UNEP DTU Partnership), Cecilie Larsen (UNEP DTU Partnership)

\section{Project coordination}

Lars Christiansen (UNEP DTU Partnership), Cecilie Larsen (UNEP DTU Partnership), Anne Olhoff (UNEP DTU Partnership), Volodymyr Demkine (United Nations Environment)

\section{INDC assessment and gap calculations}

Michel den Elzen (PBL Netherlands Environmental Assessment Agency), Hanna Fekete (NewClimate Institute), Niklas Höhne (NewClimate Institute), Joeri Rogelj (International Institute for Applied Systems Analysis)

\section{External global and national modelling data contributors}

Climate Analytics, Climate Action Tracker (Marcia Rocha, Bill Hare and Michiel Schaeffer)

Climate Interactive (Lori Siegel and Elisabeth Sawin) Danish

Energy Agency (Steffen Dockweiler)

Ecofys (Pieter van Breevoort)

Energy Research Institute, China

(Chenmin He and Kejun Jiang)

International Energy Agency

(Laura Cozzi and Fabian Kesicke)

International Institute for Applied Systems Analysis

(Nicklas Forsell)

Joint Research Centre, European Commission (Alban Kitous, Kimon Keramidas and Giacomo Grassi)

London School of Economics and Political Science (Joe

Cranston Turner and Rodney Boyd)

National Center for Climate Change Strategy and

International Cooperation, China (Fu Sha)

PBL Netherlands Environmental Assessment Agency

(Annemiek Admiraal and Heleen van Soest)

Pacific Northwest National Laboratory (Gokul lyer)

Potsdam Institute for Climate Impact Research

(Louise Jeffery)

United Nations Framework Convention on Climate

Change Secretariat

University of Melbourne (Malte Meinshausen)

\section{Media and launch support}

Shereen Zorba (United Nations Environment), Mette Annelie Rasmussen (UNEP DTU Partnership), Evelyn Ongige (United Nations Environment), Sami Dimassi (United Nations Environment), UNEP World Conservation Monitoring Centre

\section{Design, layout and printing}

Caren Weeks (independent consultant), Kailow, Virginia Njoroge (United Nations Environment)

\section{Translation of Executive summary}

Strategic Agenda

\section{Financial contributors}

Climate Works Foundation, The Netherlands Ministry of Infrastructure and the Environment

\section{Thanks also to}

Astrid Solvej Lund Andersen (UNEP DTU Partnership), Thomas Hebo Larsen (UNEP DTU Partnership) 


\section{Contents}

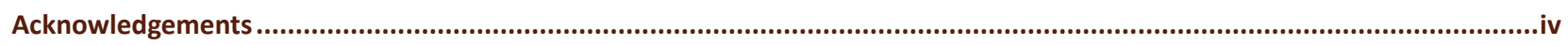

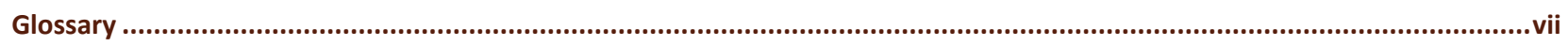

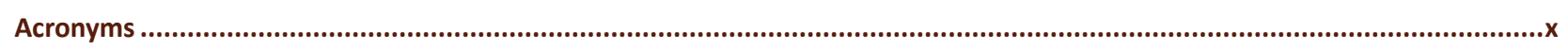

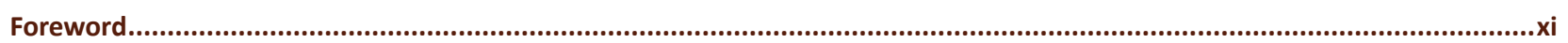

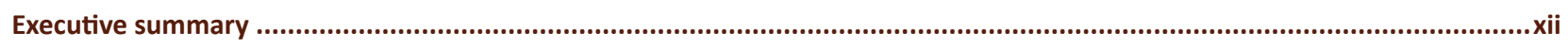

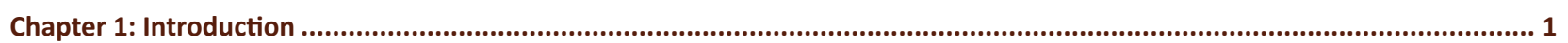

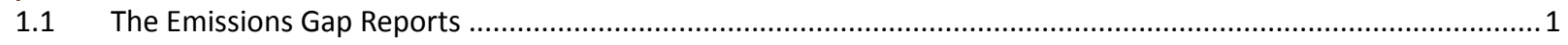

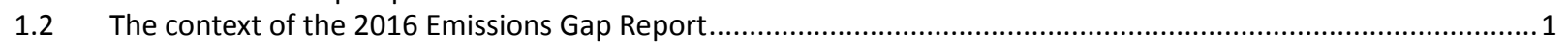

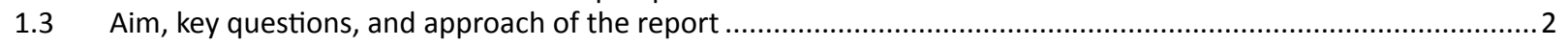

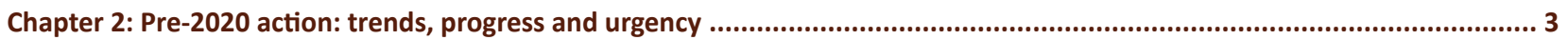

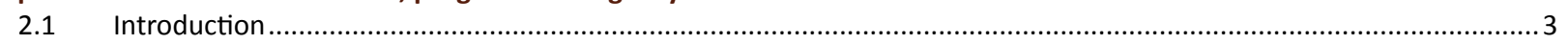

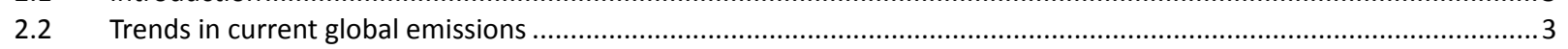

2.3 Progress towards achieving the Cancun Pledges: an update focusing on G20 members ..........................................

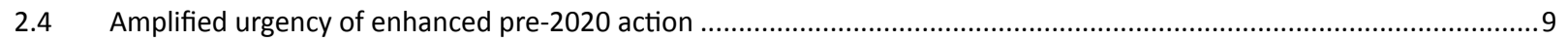

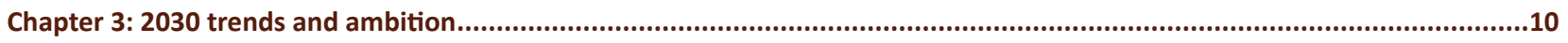

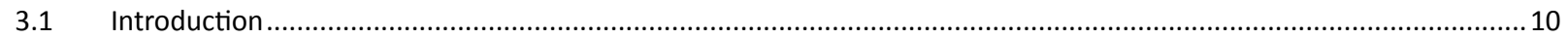

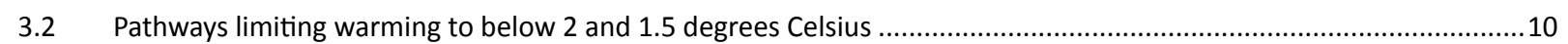

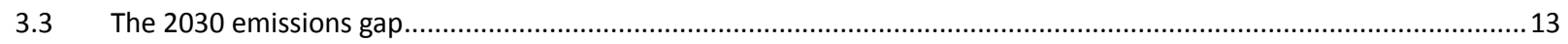

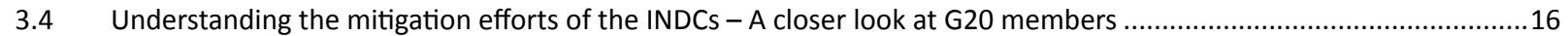

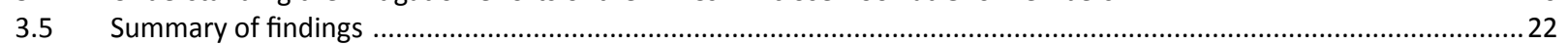

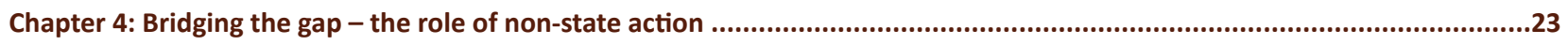

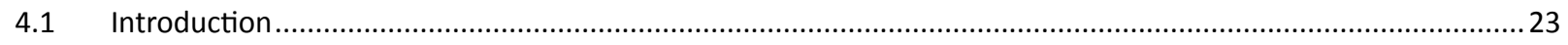

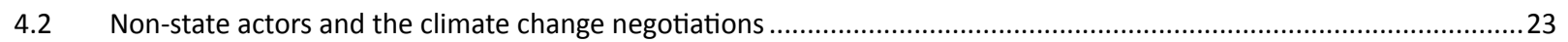

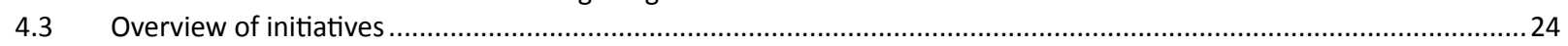

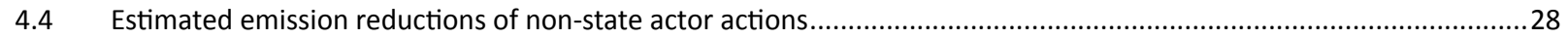

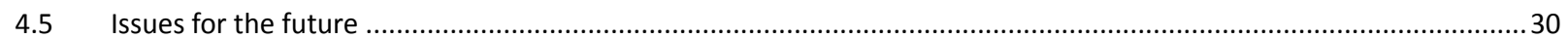

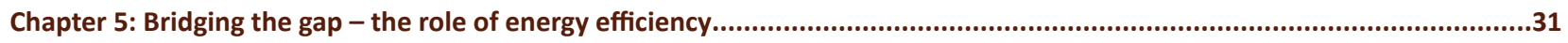

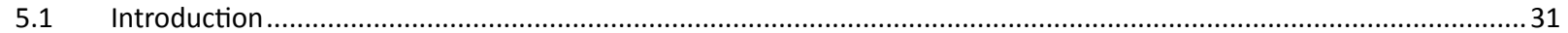

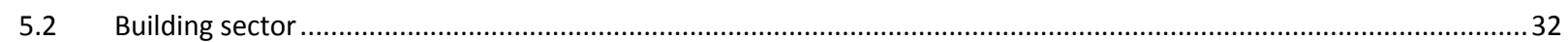

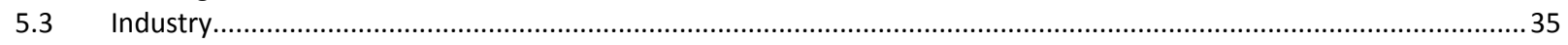

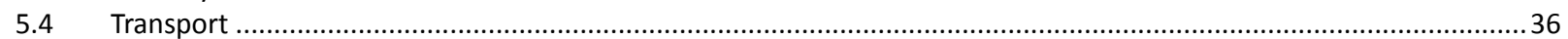

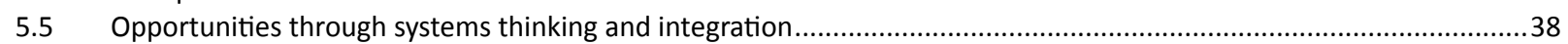

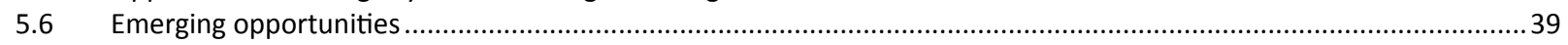

Chapter 6: Bridging the gap - the Sustainable Development Goals and climate change mitigation ..........................................40

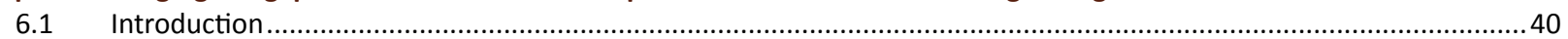

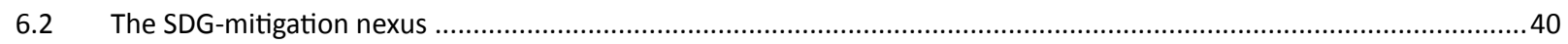

6.3 The role of the SDGs in reducing greenhouse gas emissions: path-alignment and path-contingency ...........................42

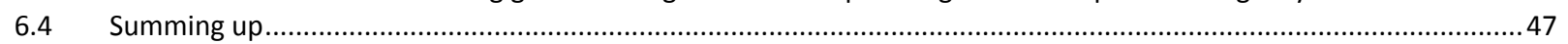

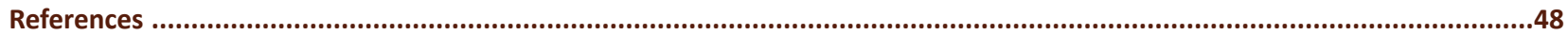




\section{Glossary}

This glossary is compiled according to the Lead Authors of the Report drawing on glossaries and other resources available on the websites of the following organizations, networks and projects: Intergovernmental Panel on Climate Change, Non-State Actor Zone for Climate Action, United Nations Environment, United Nations Framework Convention on Climate Change and World Resources Institute (United States).

Adaptation: The process of adjustment to actual or expected climate and its effects. In human systems, adaptation seeks to moderate or avoid harm or exploit beneficial opportunities. In some natural systems, human intervention may facilitate adjustment to expected climate and its effects.

Avoid Shift Improve: A framework proposed for mitigation from the transport sector. Avoid refers to the need to improve the efficiency of the transport system such as through integrated land-use planning. Shift involves servicing demand using low-carbon modes like using public transport instead of motorized private vehicles. Improve relies on vehicle efficiency improvement or alternative vehicle technologies to reduce emissions such as using a vehicle powered by alternative fuels.

Baseline/reference: The state against which change is measured. In the context of transformation pathways, the term 'baseline scenarios' refers to scenarios that are based on the assumption that no mitigation policies or measures will be implemented beyond those that are already in force and/ or are legislated or planned to be adopted. Baseline scenarios are not intended to be predictions of the future, but rather counterfactual constructions that can serve to highlight the level of emissions that would occur without further policy effort. Typically, baseline scenarios are then compared to mitigation scenarios that are constructed to meet different goals for greenhouse gas emissions, atmospheric concentrations or temperature change. The term 'baseline scenario' is used interchangeably with 'reference scenario' and 'no policy scenario'. In much of the literature the term is also synonymous with the term 'business as usual (BAU) scenario', although the term 'BAU' has fallen out of favour because the idea of 'business as usual' in century-long socioeconomic projections is hard to fathom.
Bottom-up model: In the context of this assessment, a model that represents a system by looking at its detailed underlying parts. Compared to so-called top-down models, which focus on economic interlinkages, bottom-up models of energy use and emissions can provide greater resolution with regards to sectors or mitigation technologies.

Cancun Pledge: During 2010, many countries submitted their existing plans for controlling greenhouse gas emissions to the Climate Change Secretariat and these proposals were formally acknowledged under the United Nations Framework Convention on Climate Change (UNFCCC). Developed countries presented their plans in the shape of economy-wide targets to reduce emissions, mainly up to 2020, while developing countries proposed ways to limit their growth of emissions in the shape of plans of action.

Carbon dioxide budget (or carbon budget): For a given temperature rise limit, for example a $1.5^{\circ} \mathrm{C}$ or $2^{\circ} \mathrm{C}$ longterm limit, the corresponding carbon budget reflects the total amount of carbon emissions that can be emitted for temperatures to stay below that limit. Stated differently, a carbon budget is the area under a carbon dioxide $\left(\mathrm{CO}_{2}\right)$ emission trajectory that satisfies assumptions about limits on cumulative emissions estimated to avoid a certain level of global mean surface temperature rise.

Carbon dioxide equivalent $\left(\mathrm{CO}_{2} \mathrm{e}\right)$ : A way to place emissions of various radiative forcing agents on a common footing by accounting for their effect on climate. It describes, for a given mixture and amount of greenhouse gases, the amount of $\mathrm{CO}_{2}$ that would have the same global warming ability, when measured over a specified time period. For the purpose of this report, greenhouse gas emissions (unless otherwise specified) are the sum of the basket of greenhouse gases listed in Annex A to the Kyoto Protocol, expressed as $\mathrm{CO}_{2} \mathrm{e}$ assuming a 100 -year global warming potential.

Carbon intensity: The amount of emissions of $\mathrm{CO}_{2}$ released per unit of another variable such as gross domestic product, output energy use or transport.

Carbon offset: See Offset. 
Carbon price: The price for avoided or released $\mathrm{CO}_{2}$ or $\mathrm{CO}_{2} \mathrm{e}$ emissions. This may refer to the rate of a carbon tax or the price of emission permits. In many models that are used to assess the economic costs of mitigation, carbon prices are used as a proxy to represent the level of effort in mitigation policies.

Carbon sequestration: The process of removing carbon from the atmosphere and depositing it in a reservoir.

Carbon stock: The quantity of carbon contained in a carbon pool or reservoir.

Carbon tax: A levy on the carbon content of fossil fuels. Because virtually all of the carbon in fossil fuels is ultimately emitted as $\mathrm{CO}_{2}$, a carbon tax is equivalent to an emission tax on $\mathrm{CO}_{2}$ emissions.

Co-benefits: The positive effects that a policy or measure aimed at one objective might have on other objectives, without yet evaluating the net effect on overall social welfare. Co-benefits are often subject to uncertainty and depend on, among others, local circumstances and implementation practices. Co-benefits are often referred to as ancillary benefits.

Conditional INDC: INDC proposed by some countries that are contingent on a range of possible conditions, such as the ability of national legislatures to enact the necessary laws, ambitious action from other countries, realization of finance and technical support, or other factors.

Conference of the Parties (COP): The supreme body of the Convention. It currently meets once a year to review the Convention's progress.

Current policy trajectory: This trajectory is based on estimates of 2020 emissions considering projected economic trends and current policy approaches including policies at least through 2012. Estimates may be based on either official data or independent analysis.

Double counting: In the context of this assessment, double counting refers to a situation in which the same emission reductions are counted towards meeting two countries' pledges.

Emissions gap: The difference between the greenhouse gas emission levels consistent with having a likely chance ( $>66$ per cent) of limiting the mean global temperature rise to below $2^{\circ} \mathrm{C} / 1.5^{\circ} \mathrm{C}$ in 2100 above pre-industrial levels and the GHG emission levels consistent with the global effect of the INDCs, assuming full implementation from 2020.

Emission pathway: The trajectory of annual greenhouse gas emissions over time.

Global warming potential: An index representing the combined effect of the differing times greenhouse gases remain in the atmosphere and their relative effectiveness in absorbing outgoing infrared radiation.

Greenhouse gases: The atmospheric gases responsible for causing global warming and climatic change. The major greenhouse gases are carbon dioxide $\left(\mathrm{CO}_{2}\right)$, methane $\left(\mathrm{CH}_{4}\right)$ and nitrous oxide $\left(\mathrm{N}_{2} \mathrm{O}\right)$. Less prevalent, but very powerful, GHGs are hydrofluorocarbons (HFCs), perfluorocarbons (PFCs) and sulphur hexafluoride $\left(\mathrm{SF}_{6}\right)$.

Gross domestic product: The sum of gross value added, at purchasers' prices, by all resident and non-resident producers in the economy, plus any taxes and minus any subsidies not included in the value of products in a country or geographic region for a given period, normally one year. Gross domestic product is calculated without deducting for depreciation of fabricated assets or depletion and degradation of natural resources.

Integrated Assessment Models: Models that seek to combine knowledge from multiple disciplines in the form of equations and/or algorithms in order to explore complex environmental problems. As such, they describe the full chain of climate change, from production of greenhouse gases to atmospheric responses. This necessarily includes relevant links and feedbacks between socio-economic and biophysical processes.

Intended Nationally Determined Contribution (INDC): Submissions by Parties which identify actions each national government intends to take under the Paris Agreement. INDCs are, in effect, the basis of post-2020 global emission reduction commitments included in the Paris Agreement.

International Cooperative Initiatives (ICls): Initiatives outside the UNFCCC aimed at reducing emissions of climate forcers by, for example, promoting actions that are less greenhouse gas intensive, compared to prevailing alternatives. Cooperative initiatives also involve national and sub-national partners (they are often referred to as, simply, 'cooperative initiatives').

Kyoto Protocol: An international agreement, standing on its own, and requiring separate ratification by governments, but linked to the UNFCCC. The Kyoto Protocol, among other things, sets binding targets for the reduction of greenhouse gas emissions by industrialized countries.

Land use, land-use change and forestry (LULUCF): A greenhouse gas inventory sector that covers emissions and removals of greenhouse gases resulting from direct humaninduced land use, land use change and forestry activities.

Likely chance: A likelihood greater than 66 per cent chance. Used in this assessment to convey the probabilities of meeting temperature limits.

Lock-in: Lock-in occurs when a market is stuck with a standard even though participants would be better off with an alternative.

Medium chance: A likelihood of 50-66 per cent chance. Used in this report to convey the probabilities of meeting temperature limits.

Mitigation: In the context of climate change, a human intervention to reduce the sources, or enhance the sinks of greenhouse gases. Examples include using fossil fuels more efficiently for industrial processes or electricity generation, 
switching to solar energy or wind power, improving the insulation of buildings and expanding forests and other 'sinks' to remove greater amounts of $\mathrm{CO}_{2}$ from the atmosphere.

Monitoring, reporting and verification: A process/concept that potentially supports greater transparency in the climate change regime.

Montreal Protocol: The Montreal Protocol on Substances that Deplete the Ozone Layer is an international treaty that was designed to reduce the production and consumption of ozone-depleting substances in order to reduce their abundance in the atmosphere, and thereby protect the Earth's ozone layer.

Nationally Determined Contribution (NDC): By its decision 1/CP.21, paragraph 22, the Conference of the Parties (COP) invited Parties to communicate their first NDC no later than when the Party submits its respective instrument of ratification, acceptance, approval or accession of the Paris Agreement. In the same paragraph, the COP further stated that if a Party has communicated an INDC prior to joining the Agreement, that Party shall be considered to have satisfied the provision of decision $1 /$ CP.21, paragraph 22 , unless that Party decides otherwise.

Non-state actor: In the context of climate action, 'non-state actor' includes companies, cities, subnational regions and investors. More broadly, non-state actors have been defined as entities that participate or act in international relations. They are organizations with sufficient power to influence and cause a change even though they do not belong to any state institution.

Offset (in climate policy): A unit of $\mathrm{CO}_{2} \mathrm{e}$ emissions that is reduced, avoided, or sequestered to compensate for emissions occurring elsewhere.

Party: A state (or regional economic integration organization such as the EU) that agrees to be bound by a treaty and for which the treaty has entered into force.

Pledge case: This case identifies the maximum level of greenhouse gas emissions that each country or Party could emit in 2020 and still meet its pledge - without considering the use of offsets.

Scenario: A description of how the future may unfold based on 'if-then' propositions. Scenarios typically include an initial socio-economic situation and a description of the key driving forces and future changes in emissions, temperature or other climate change-related variables.

Source: Any process, activity or mechanism that releases a greenhouse gas, an aerosol or a precursor of a greenhouse gas or aerosol into the atmosphere.

Sustainable development: Development that meets the needs of the present without compromising the ability of future generations to meet their own needs.
Tipping point: A level of change in system properties beyond which a system reorganizes, often abruptly, and does not return to the initial state even if the drivers of the change are abated. For the climate system, it refers to a critical threshold when global or regional climate changes from one stable state to another stable state. The tipping point event may be irreversible.

Top-down model: A model that applies macroeconomic theory, econometric and/or optimization techniques to aggregate economic variables. Using historical data on consumption, prices, incomes, and factor costs, topdown models assess demand and emissions for goods and services from main sectors, such as energy conversion, transportation, buildings, agriculture and industry.

Uncertainty: A cognitive state of incomplete knowledge that can result from a lack of information or from disagreement about what is known or even knowable. It may have many types of sources, from imprecision in the data to ambiguously defined concepts or terminology, or uncertain projections of human behaviour. Uncertainty can therefore be represented by quantitative measures (for example a probability density function) or by qualitative statements (for example reflecting the judgement of a team of experts).

Unconditional INDCs: INDCs proposed by countries without conditions attached.

2020 pledge: See Cancun Pledge. 


\section{Acronyms}

\begin{tabular}{ll}
${ }^{\circ} \mathrm{C}$ & degrees Celsius \\
$\mathrm{BAU}$ & business as usual \\
$\mathrm{CO}_{2}$ & carbon dioxide \\
$\mathrm{CO}_{2} \mathbf{e}$ & carbon dioxide equivalent \\
$\mathbf{C O P}$ & Conference of the Parties to the UNFCCC \\
EJ & exajoules \\
EU & European Union \\
GHG & greenhouse gas \\
Gt & gigatonne \\
ICI & international cooperative initiative \\
INDC & Intended Nationally Determined Contribution \\
IPCC & Intergovernmental Panel on Climate Change \\
km & kilometre \\
kt & kilotonne \\
kWh & kilowatt hour \\
LULUCF & Land use, land-use change and forestry \\
m & square metres \\
Mt & megatonne \\
NDC & Nationally Determined Contribution \\
OECD & Organisation for Economic Cooperation and Development \\
SDG & Sustainable Development Goal \\
UNFCCC & United Nations Framework Convention on Climate Change \\
USA/US & United States of America \\
\hline
\end{tabular}




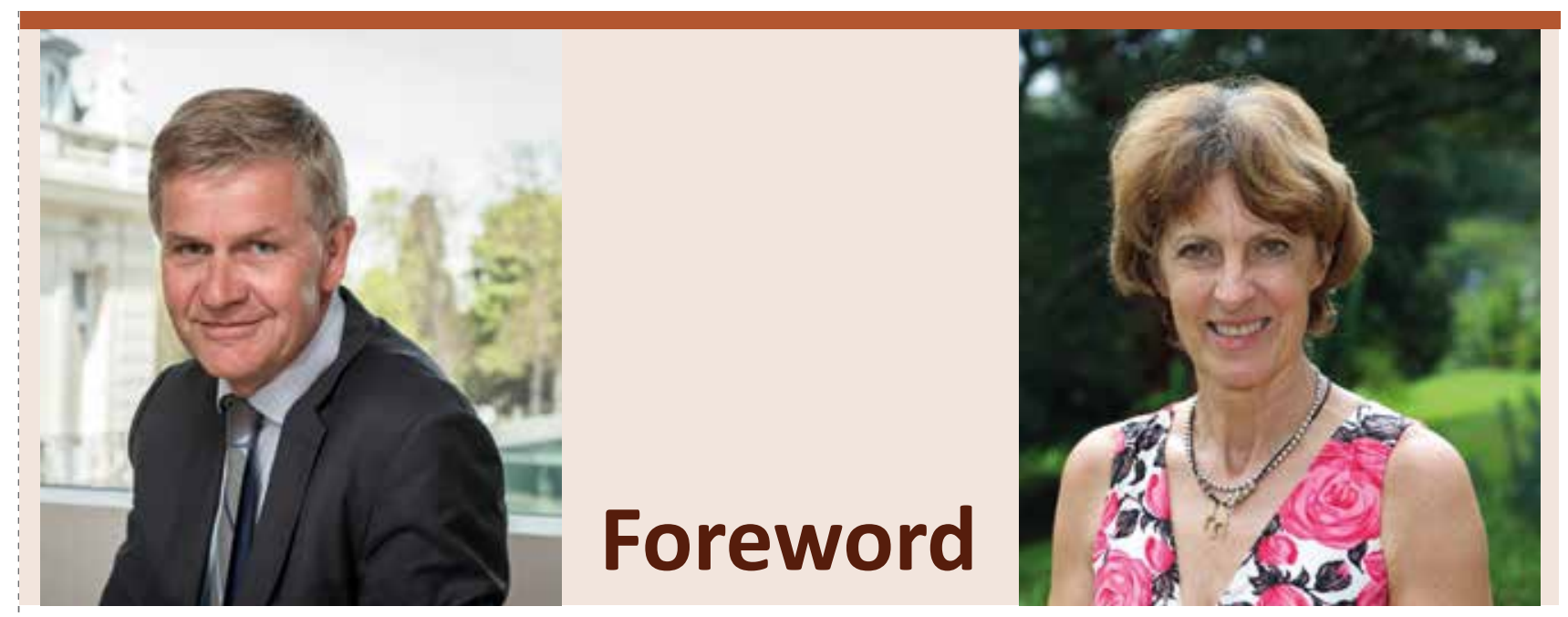

There is a troubling paradox at the heart of climate policy. On the one hand, nobody can doubt the historic success of the Paris Agreement. On the other hand, everybody willing to look can see the impact of our changing climate. People already face rising seas, expanding desertification and coastal erosion. They take little comfort from agreements to adopt mitigation measures and finance adaptation in the future. They need action today.

That is why the Emissions Gap Report tracks our progress in restricting global warming to 1.5 - 2 degrees Celsius above pre-industrial levels by the end of this century.

This year's data shows that overall emissions are still rising, but more slowly, and in the case of carbon dioxide, hardly at all. The report foresees further reductions in the short term and increased ambition in the medium term. Make no mistake; the Paris Agreement will slow climate change. The recent Kigali Amendment to the Montreal Protocol will do the same.

But not enough: not nearly enough and not fast enough. This report estimates we are actually on track for global warming of up to 3.4 degrees Celcius. Current commitments will reduce emissions by no more than a third of the levels required by 2030 to avert disaster. The Kigali Amendment will take off 0.5 degrees Celcius, although not until well after 2030. Action on short-lived climate pollutants, such as black carbon, can take off a further 0.5 degrees Celcius. This means we need to find another one degree from somewhere to meet the stronger, and safer, target of 1.5 degrees Celcius warming.

So, we must take urgent action. If we don't, we will mourn the loss of biodiversity and natural resources. We will regret the economic fallout. Most of all, we will grieve over the avoidable human tragedy; the growing numbers of climate refugees hit by hunger, poverty, illness and conflict will be a constant reminder of our failure to deliver.
None of this will be the result of bad weather. It will be the result of bad choices by governments, private sector and individual citizens. Because there are choices. This report highlights plenty of them. For example, it shows how UN Environment can help governments to ensure that every dollar they invest and every regulation they introduce will help to increase the scale and speed with which those choices deliver results.

Even beyond government, the report shows many regions, cities and industrial sectors are choosing to target emissions reductions above those pledged by governments. Investors and bankers are choosing a more inclusive green economy. Authorities and legislators are choosing to improve energy efficiency, building codes and operating standards. While small scale businesses, farmers and families are choosing better production and consumption habits, like less waste and smarter travel.

So, the choices are ours. The historic deals of last year are within reach, but we must redouble our effort. That's why today, as the Paris Agreement legally enters into force, we sincerely hope this report will be a wakeup call to the world.

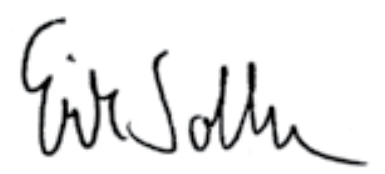

Erik Solheim

Head of UN Environment

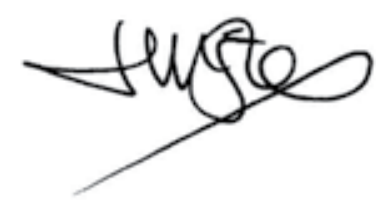

Jacqueline McGlade

UN Environment Chief Scientist 


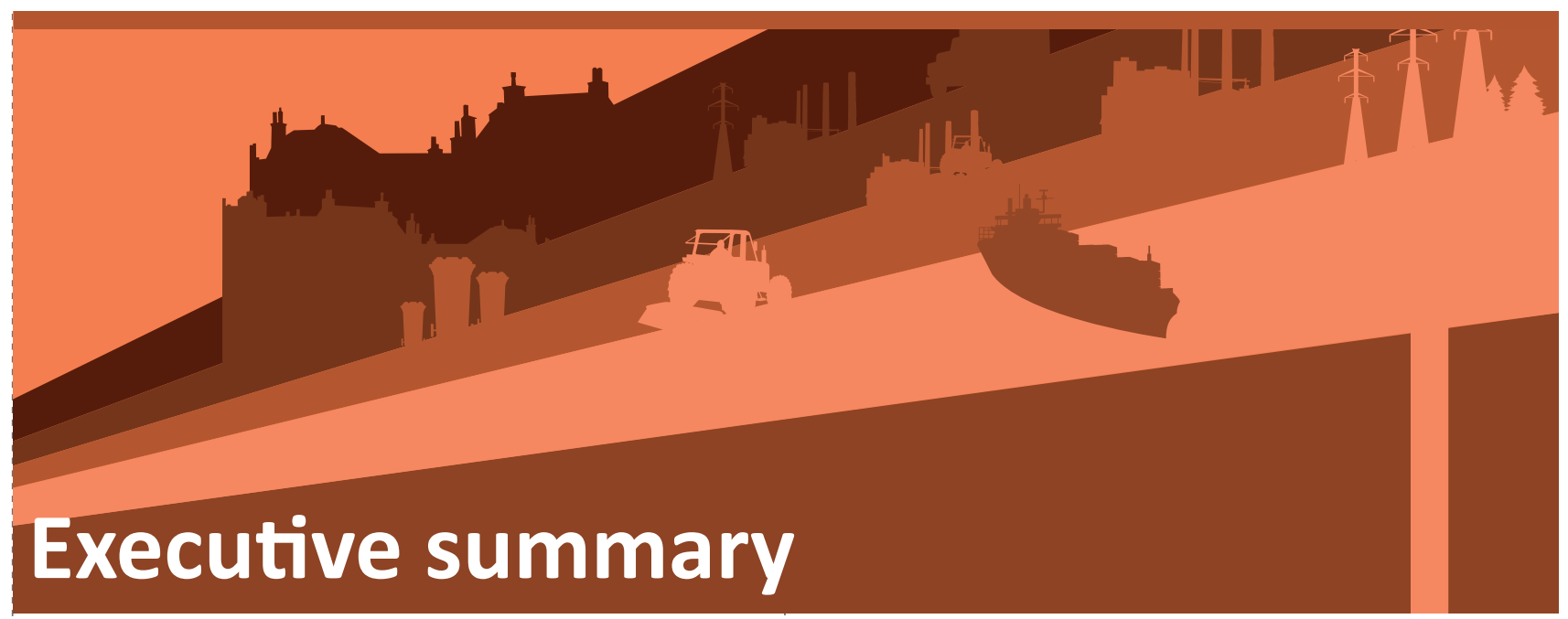

1. The strengthened long-term objectives of the Paris Agreement require even stronger actions than previously identified, calling for accelerated efforts pre-2020, as well as increasing the ambition of the Nationally Determined Contributions

The Paris Agreement has very specific language about the long-term goals and how to get there, including:

- A long-term goal of keeping the increase in global average temperature to well below 2 degrees Celsius $\left({ }^{\circ} \mathrm{C}\right)$ above pre-industrial levels.

- An aim to limit the temperature increase to $1.5^{\circ} \mathrm{C}$, as this would significantly reduce the risks and impacts of climate change.

- The need for global emissions to peak as soon as possible, followed by a rapid decline - recognising that this will take longer for developing countries.

Compared to the $2^{\circ} \mathrm{C}$ goal that was the reference point of earlier Emissions Gap Reports, these new objectives require stronger short-term action and deeper cuts in the medium and longer term, as the remaining carbon dioxide budget is now considerably lower. Against the background of the large emissions gap that was identified in previous reports, this further amplifies the need for ambitious early action that accelerates and strengthens the Nationally Determined Contributions of countries.

Enhanced pre-2020 and pre-2030 action will reduce the so-called transitional challenges associated with the necessary shift in emissions pathways, and:

- Reduce the lock-in of carbon and energy intensive infrastructure in society and the energy system, encourage the rapid deployment of state of the art technologies, and spur near-term learning and development of technologies that will be essential in the long term.
- Reduce the overall costs and economic challenges during the transitional period, for example, in terms of upscaling energy investments.

- Reduce future dependence on unproven technologies, including negative emissions technologies, and increase the options to achieve stringent emission reductions.

- Reduce climate risks, for example, by reducing the pace of the global temperature increase.

- Realise immediate co-benefits through enhanced early action on climate change mitigation, such as improved public health as a result of lower air pollution, improved energy security, and reduced crop yield losses.

Additional early action will be essential to keeping the door open to limit warming to below $1.5^{\circ} \mathrm{C}$ by 2100 .

\section{Record speed of entry into force of the Paris Agreement signals strong commitment to action}

The adoption of the Paris Agreement on climate change by 195 countries and the global agreement on the Sustainable Development Goals, made 2015 a landmark year. The Paris Agreement is the first climate deal with universal contributions to mitigation action. With ratification having surpassed the agreed minimum of 55 countries, representing at least 55 per cent of global emissions, the Agreement will enter into force before the Conference of Parties to the United Nations Framework Convention on Climate Change in Marrakesh (COP 22). This sends a strong signal that countries are committed to action.

The need for urgent action has been reinforced by the fact that 2015 was the hottest year since modern record keeping began. Although high temperatures were exacerbated by the effect of El Niño, it is notable that ten of the warmest years on record have occurred since 2000 , and the trend continues, with the first six months of 2016 all being the warmest ever recorded. 


\section{Focus of the 2016 Emissions Gap Report}

The United Nations Environment (UNEP) Emissions Gap Report 2016 provides an authoritative assessment of the extent to which the current and planned national emissions reductions, as specified in the submitted Intended Nationally Determined Contributions, will contribute towards the Paris Agreement goals. It does so by providing an estimate of the additional reductions - the gap - required by 2030 to be on a least-cost path that is likely to ensure the global temperature goals.

The assessment focuses on the $2^{\circ} \mathrm{C}$ goal, as well as on the implications for limiting the temperature increase to $1.5^{\circ} \mathrm{C}$.

The key new features and results of the 2016 Report are:

- The assessment is based on Intended Nationally Determined Contributions submitted by almost all countries in the world, and a large number of studies supporting robustness of the estimates.

- The key quantitative results stay within the ranges presented in the 2015 assessment.

- The results underpin the urgency of immediate and strong action, and the need to build on the momentum of the entry into force of the Paris Agreement. Since the results are not likely to change in the next two years, enhanced action need not wait for the facilitative dialogue in 2018.

- The report identifies where solutions are available to deliver low-cost emission reductions at scale, including three major areas of action: contributions by non-state actors, energy efficiency acceleration, and synergies with achievement of the sustainable development goals.
The report has been prepared by an international team of leading scientists who assessed all available information, including those reviewed by the Intergovernmental Panel on Climate Change in its fifth assessment report, as well as more recent scientific literature. The assessment production process has been transparent and participatory, and governments of the countries with specific mention in the report have been invited to comment on the assessment findings before finalization.

\section{Global greenhouse gas emissions continue to increase}

Total global greenhouse gas (GHG) emissions continue to show a steady increase, reaching approximately 52.7 gigatonnes carbon dioxide equivalent $\left(\mathrm{GtCO}_{2} \mathrm{e}\right)$ in 2014. There have been small variations around this longer trend. Notably, the rate of global greenhouse gas emissions increase during the period 2000 to 2010 was faster (2.2 per cent per year) than during the period 1970 to 2000 (1.3 per cent per year), increasing in 2010 and 2011 (3.5 per cent per year) and then slowing in 2012 to 2013 (1.8 per cent per year).

\section{Global carbon dioxide emissions from fossil fuel use and industry seem to stabilize}

Global carbon dioxide emissions from fossil fuel combustion, cement production and other industrial processes are the major source of total global greenhouse gas emissions. Currently, they account for about 68 per cent of total global greenhouse gas emissions, and were estimated to be $36.2 \mathrm{GtCO}_{2}$ in 2015. Figure ES1 presents a detailed overview of the development in global carbon dioxide emissions from fossil fuel use and industry for the period 1970 to 2015.

Figure ES1: Carbon dioxide emissions from fossil-fuel use and industry.

$\mathrm{GtCO}_{2} /$ year

40

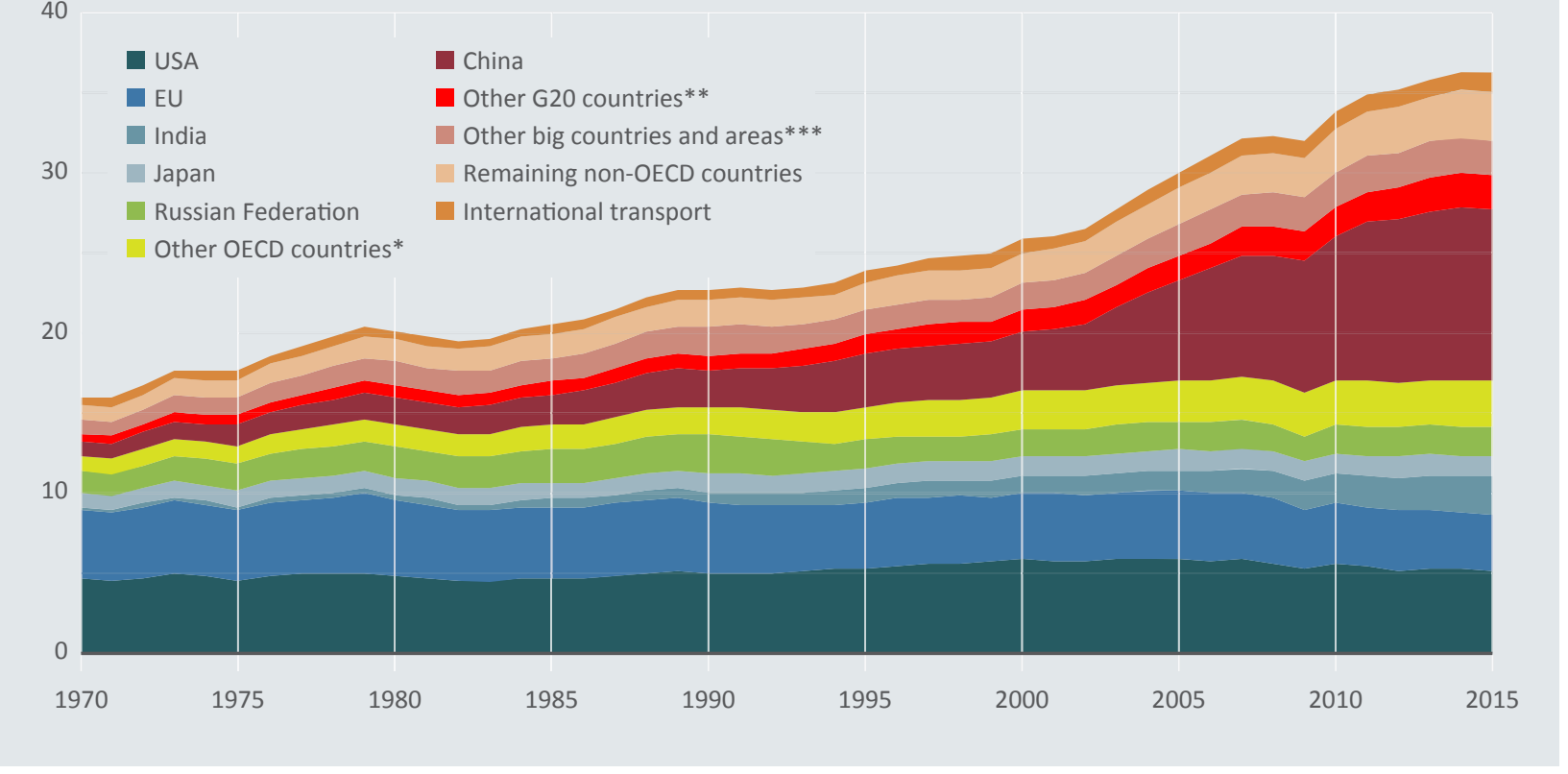

* Other OECD countries include Australia; Canada; Mexico; Republic of Korea and Turkey.

** Other G20 countries include Argentina; Brazil; Indonesia; Saudi Arabia; South Africa and Turkey.

*** Other big countries and areas include Egypt; Iran; Kazakhstan; Malaysia; Nigeria; Taiwan, Province of China; Thailand and Ukraine. 
In 2015, global carbon dioxide emissions from these sources stagnated for the first time and showed signs of a weak decline. Prior to 2015, global carbon dioxide emissions increased by roughly 1.3 per cent per year for the period 2012 to 2014, which was significantly slower than that of the 12 preceding years, where the average increase was 2.9 per cent per year (2000-2011), but higher than the average growth rate of around 1 per cent per year during the 1990s. These findings are in line with other studies on trends in global energy-related carbon dioxide emissions.

In summary, global greenhouse gas emissions continue to grow, and while the indications are encouraging that the growth rate of global carbon dioxide emissions from fossil fuel use and industry is slowing, it is still too early to say whether this is likely to be permanent.

The continued growth of global emissions and the underlying trends show that the world is not yet on a trajectory that allows for a transition to stringent low emissions development pathways consistent with the stated temperature goals.

\section{Collectively, members of the $\mathbf{G} 20$ are on a likely track to meet their Cancun Pledges for 2020, but these pledges do not deliver the necessary early emission reductions}

From a global perspective, early action is especially important for the major economies of the world; crucially these countries, as members of the G20, account for approximately three quarters of global emissions. Most of the G20 members at COP 16 in Cancun formalised the emission reduction pledges they had put forward as a follow up to the Copenhagen Accord. Since then, the annual Emissions Gap Reports have consistently assessed the progress countries are making towards delivering on these pledges, as they represent the main formalised early action commitment, and their timely achievement will send very positive signals to other countries.

It should be noted that not all pledges demand the same level of effort. A country currently on track to achieve its pledge has not necessarily made a greater effort to mitigate emissions than a country not yet on track. The projections assessed are subject to the uncertainty associated with macroeconomic trends, such as changes in gross domestic product, and population trends, as well as the impact of each country's climate policy action. The emission trajectories analysed here do not quantify the potential impact of using offsets to achieve pledges, which is considered to be quite limited.

The assessment shows that according to all available estimates three of the G20 members - China, the European Union, and India - are on track to meet their pledges without purchasing offsets. Three more - Brazil, Japan, and Russia are on track according to most estimates.

According to both government and independent estimates, Canada, Mexico, and the United States of America are likely to require further action, possibly supplemented by purchased offsets, in order to meet their pledges. Mexico's Cancun Pledge is conditional on the provision of adequate financial and technological support from developed countries as part of a global agreement, and the fulfilment of this condition has not been assessed.

Government and independent sources have found a gap between Australia's projected 2020 emissions and its target level for that year. However, Australia's latest official projections find that for the budget period, and including carry-over from its first commitment period under the Kyoto Protocol, the country is now on track to meet its Kyoto target.

According to independent analysis, the Republic of Korea will also require further action to meet its pledge. This cannot be verified using available official projections. The Republic of Korea has domestically abandoned its 2020 target, replacing it with the Intended Nationally Determined Contributions target in the amended Green Growth Act. However, its earlier pledge has not been officially withdrawn.

Sufficient information is currently unavailable to determine whether Indonesia and South Africa are on track to meet their pledges. In the case of Indonesia, independent projections span a wide range, and official projections reflecting current policies are unavailable.

Finally, Argentina, Saudi Arabia and Turkey have not made greenhouse gas reduction pledges for 2020. All three countries submitted post-2020 pledges to the United Nations Framework Convention on Climate Change as part of their Intended Nationally Determined Contributions.

Overall, there is general progress on pledge achievement, but several countries will need to accelerate action to meet their Cancun Pledge by 2020. It must be underlined that, collectively, these pledges are not ambitious enough to have a better starting point in $\mathbf{2 0 2 0}$ to meet the $\mathbf{2 0 3 0}$ levels of global greenhouse gas emissions consistent with the longer-term goals of below 2 or $1.5^{\circ} \mathrm{C}$.

The urgency of enhancing pre-2020 mitigation action is, therefore, indisputable:

- It strengthens the likelihood that countries will meet and exceed their Cancun Pledges.

- It provides a more solid foundation for implementing the Nationally Determined Contributions from 2020, and for continuously strengthening their ambition.

- It supports the transition towards a least-cost emissions reduction trajectory after 2020 that is consistent with the $2^{\circ} \mathrm{C}$ goal.

- It is likely the last chance to keep the option of limiting global warming to $1.5^{\circ} \mathrm{C}$ in 2100 open, as all available scenarios consistent with the $1.5^{\circ} \mathrm{C}$ goal imply that global greenhouse gas emissions peak before 2020 . 
6. Pathways for staying well below 2 and $1.5^{\circ} \mathrm{C}$ require deep emission reductions after, and preferably also before, 2020 and lower levels of emissions in $\mathbf{2 0 3 0}$ than earlier assessed $2^{\circ} \mathrm{C}$ pathways

The central aim of the Paris Agreement is to keep the global temperature increase by the end of the century to well below $2^{\circ} \mathrm{C}$ compared to pre-industrial levels, with an ambition to limit the temperature increase even further to $1.5^{\circ} \mathrm{C}$. While these global goals are quite clear, there is a need to interpret what they mean. For example, what if the global average temperature exceeds these goals during the century, but is below the goals by end of it? Similarly, it is necessary to define an acceptable probability for achieving the goals, which in the end is a political rather than scientific question, as it requires value judgments about what is acceptable and desirable to society. In line with the Intergovernmental Panel on Climate Change's definition of "likely", this report generally uses a 66 per cent or higher probability.

A large body of literature is available on least-cost pathways that limit warming to below $2^{\circ} \mathrm{C}$ with a 66 per cent or higher probability. This issue has been covered extensively by the Intergovernmental Panel on Climate Change and earlier Emissions Gap Reports. For a $1.5^{\circ} \mathrm{C}$ goal, the body of literature is much more sparse and there are no published scenarios that meet the $1.5^{\circ} \mathrm{C}$ limit permanently with more than 66 per cent probability. Therefore, the studies assessed operate with a 50 per cent probability, which in Intergovernmental Panel on Climate Change terminology is considered "about as likely as not". The 2018 Special report on the impacts of global warming of $1.5^{\circ} \mathrm{C}$ above pre-industrial levels and related global greenhouse gas emission pathways by the Intergovernmental Panel on Climate Change will provide a more comprehensive picture as it will cover new studies. Table ES1 presents the pathway characteristics for achieving the two different temperature goals, showing the median acceptable emission levels for key years between 2020 and 2100 .

As in the earlier Emissions Gap Reports, it is important to highlight that most scenarios that are available in the literature, and that limit warming to below 2 or $1.5^{\circ} \mathrm{C}$, assume the use of so-called negative emissions technologies in the second half of the century -- that is the active and permanent removal of carbon dioxide from the atmosphere. This can be achieved, for example, through sustainable afforestation and reforestation, enhanced soil carbon absorption, biochar, and the combination of bio-energy with carbon capture and storage. Important challenges have been identified for large-scale application of negative emissions technologies. For example, with biomass there is a challenge to produce enough biomass without harming biodiversity and a potential for competition between energy and food production over land and water resources.

Table ES1: Overview of pathway characteristics for two global temperature targets.

\begin{tabular}{|c|c|c|c|c|c|}
\hline $1.5^{\circ} \mathrm{C}(>50 \%$ in 2100$)$ & \multicolumn{5}{|c|}{$\begin{array}{l}\text { Pathways limiting warming to below } 1.5^{\circ} \mathrm{C} \text { by } 2100 \text { with }>50 \% \text { probability } \\
\text { Limited action until } 2020 \text { and cost-optimal mitigation afterwards }\end{array}$} \\
\hline \multicolumn{6}{|c|}{$\begin{array}{l}\text { Number of available scenarios: } \mathbf{6} \text {; Number of contributing modelling frameworks: } \mathbf{2} \\
\text { Year of global annual emissions becoming net zero' for: } \\
\text { Kyoto-GHGs: (2060-2080); total } \mathrm{CO}_{2} \text { (including LULUCF): (2045-2050); } \mathrm{CO}_{2} \text { from energy and industry: (2045-2055) } \\
\end{array}$} \\
\hline & \multicolumn{5}{|c|}{ Annual emissions of global total greenhouse gases $\left[\mathrm{GtCO}_{2} \mathrm{e} /\right.$ year] } \\
\hline Year & 2020 & 2025 & 2030 & 2050 & 2100 \\
\hline median* & 56 & 47 & 39 & 8 & -5 \\
\hline range and spread** & $53(-/-) 56$ & $46(-/-) 48$ & $37(-/-) 40$ & $4(-/-) 14$ & $-5(-/-)-3$ \\
\hline & \multicolumn{5}{|c|}{$\mathrm{CO}_{2}$ carbon budgets [global total cumulative $\mathrm{CO}_{2}$ emissions in $\mathrm{GtCO}_{2}$ ] } \\
\hline Time period & 2015-2030 & $2030-2050$ & $2050-2075$ & $2075-2100$ & $2015-2100$ \\
\hline median* & 552 & 236 & -199 & -353 & 217 \\
\hline range and spread** & $503(-/-) 567$ & $178(-/-) 259$ & $-146(-/-)-277$ & $-288(-/-)-372$ & $71(-/-) 383$ \\
\hline $2^{\circ} \mathrm{C}(>66 \%$ in 2100$)$ & \multicolumn{5}{|c|}{$\begin{array}{l}\text { Pathways limiting warming to below } 2^{\circ} \mathrm{C} \text { by } 2100 \text { with }>66 \% \text { probability } \\
\text { Limited action until } 2020 \text { and cost-optimal mitigation afterwards }\end{array}$} \\
\hline \multicolumn{6}{|c|}{$\begin{array}{l}\text { Number of available scenarios: 10; Number of contributing modelling frameworks: } 4 \\
\text { Year of global annual emissions becoming net zero' for: } \\
\text { Kyoto-GHGs: } 2085 \text { (2080-2090); total } \mathrm{CO}_{2} \text { (including LULUCF): } \mathbf{2 0 7 0} \text { (2060-2075); } \mathrm{CO}_{2} \text { from energy and industry: } \mathbf{2 0 7 0} \text { (2060-2075) }\end{array}$} \\
\hline & \multicolumn{5}{|c|}{ Annual emissions of global total greenhouse gases $\left[\mathrm{GtCO}_{2} \mathrm{e} /\right.$ year] } \\
\hline Year & 2020 & 2025 & 2030 & 2050 & 2100 \\
\hline median* & 52 & 48 & 42 & 23 & -3 \\
\hline \multirow[t]{2}{*}{ range and spread ${ }^{* *}$} & $49(49 / 53) 55$ & $44(46 / 50) 53$ & $29(31 / 44) 44$ & $17(18 / 27) 29$ & $-11(-9 /-1) 0$ \\
\hline & \multicolumn{5}{|c|}{$\mathrm{CO}_{2}$ carbon budgets [global total cumulative $\mathrm{CO}_{2}$ emissions in $\mathrm{GtCO}_{2}$ ] } \\
\hline Time period & 2015-2030 & $2030-2050$ & $2050-2075$ & $2075-2100$ & 2015-2100 \\
\hline median* & 533 & 362 & 70 & -288 & 553 \\
\hline range and spread** & 481(499/582)572 & $242(258 / 431) 447$ & $-97(-52 / 175) 187$ & $-120(-146 /-327)-342$ & $483(490 / 934) 988$ \\
\hline \multicolumn{6}{|c|}{$\begin{array}{l}\text { * Rounded to the nearest } 1 \mathrm{GtCO}_{2} \mathrm{e} / \text { year } \\
\text { ** Rounded to the nearest } 1 \mathrm{GtCO}_{2} \mathrm{e} / \text { year. Format: minimum value }\left(20^{\text {th }} \text { percentile/ } 80^{\text {th }} \text { percentile) maximum value }- \text { no percentiles are provided if less than }\right. \\
10 \text { scenarios are available. } \\
+ \text { Rounded to nearest } 5 \text { years. Format: median }\left(20^{\text {th }} \text { percentile }-80^{\text {th }} \text { percentile); (minimum - maximum) if less than } 10 \text { scenarios are available. }\right.\end{array}$} \\
\hline
\end{tabular}


Some studies have examined options for hedging against emissions more steeply in the very near-term that is over the a strong reliance on negative emissions in the long-term. coming 5 to 15 years.

These studies find that this is only possible by reducing

Table ES2: Global total greenhouse gas emissions in 2025 and 2030 under different scenarios.

\begin{tabular}{|c|c|c|c|}
\hline Scenario & Global total emissions in 2025 & Global total emissions in 2030 & Number of scenarios in set \\
\hline Baseline & $61.0(56.7-64.3)$ & $64.7(59.5-69.5)$ & 179 \\
\hline Current policy trajectory & $56.2(54.8-59.4)$ & $59.4(57.9-63.1)$ & 3 \\
\hline Unconditional INDCs & $53.9(50.6-56.3)$ & $55.5(51.9-57.5)$ & 10 \\
\hline Conditional INDCs & $53.0(49.3-54.9)$ & $53.4(49.5-54.7)$ & $10(6+4)$ \\
\hline $2^{\circ} \mathrm{C}$ pathways (least-cost from 2020) & $47,7(46.2-50.2)$ & $41.8(30.6-43.5)$ & 10 \\
\hline $1.5^{\circ} \mathrm{C}$ pathways (least-cost from 2020 ) & $47.2(45.8-48.2)$ & $38.8(37.7-40.0)$ & 6 \\
\hline
\end{tabular}

Figure ES2: Global greenhouse gas emissions under different scenarios and the emissions gap in 2030.

Annual Global Total Greenhouse Gas Emissions $\left(\mathrm{GtCO}_{2} \mathrm{e}\right)$

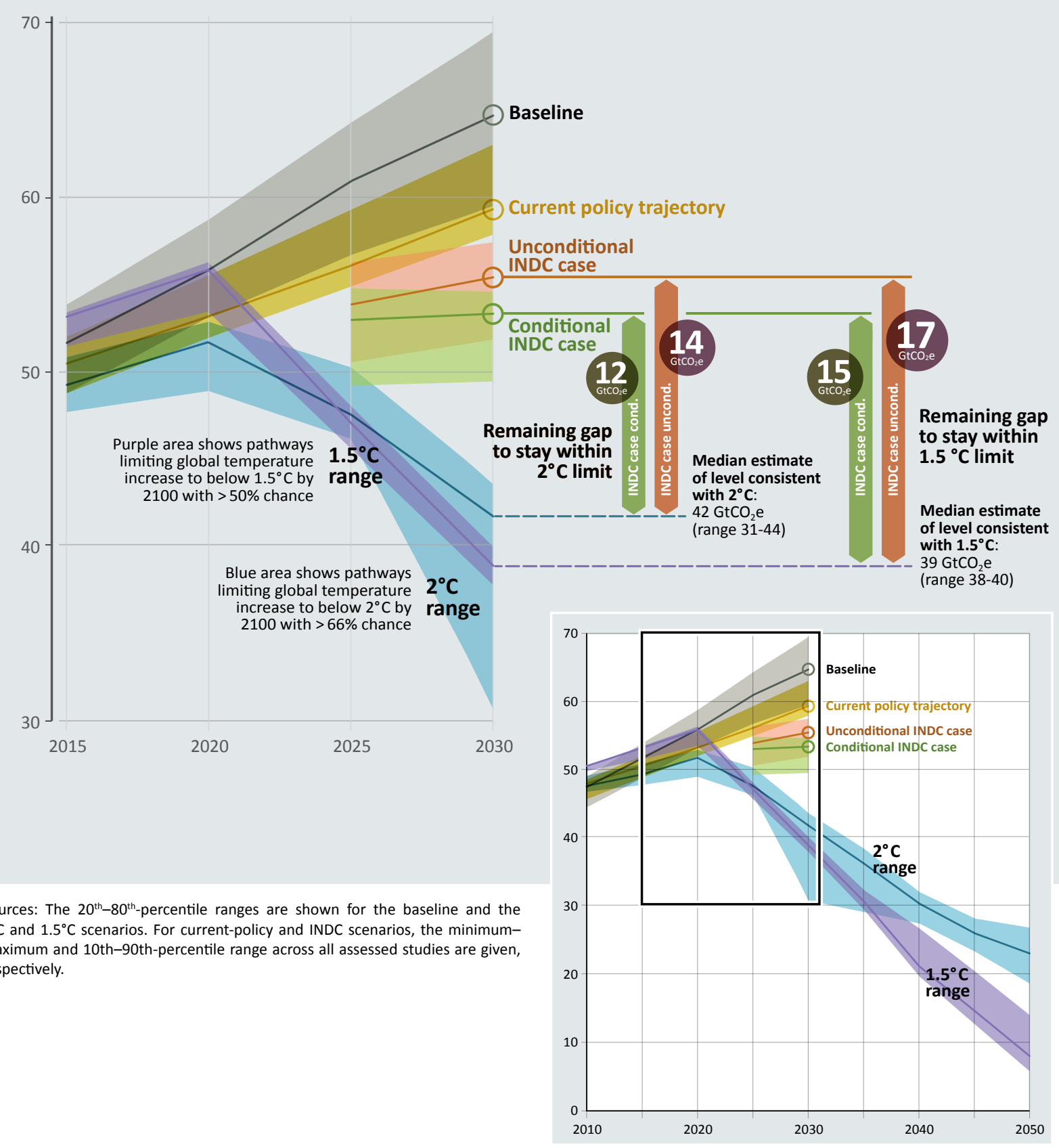


7. The emissions gap for $\mathbf{2 0 3 0}$ is $\mathbf{1 2}$ to $14 \mathrm{GtCO}_{2}$ e compared with $2^{\circ} \mathrm{C}$ scenarios, for $1.5^{\circ} \mathrm{C}$ the gap is $3 \mathrm{GtCO}_{2} \mathrm{e}$ larger. Even if fully implemented, the unconditional Intended Nationally Determined Contributions are only consistent with staying below an increase in temperature of $3.2^{\circ} \mathrm{C}$ by 2100 and $3.0^{\circ} \mathrm{C}$, if conditional Intended Nationally Determined Contributions are included

In the period up to COP 21 in Paris, United Nations Environment had, as part of the preparation of the Emissions Gap Report 2015, engaged a team of independent experts to assess the mitigation impacts of the Intended Nationally Determined Contributions. The results were presented as a key part of the Emissions Gap Report and covered the 118 countries having submitted an Intended Nationally Determined Contribution by 1 October 2015. This year, new international studies are available that include the 160 Intended Nationally Determined Contributions submitted, representing 187 out of 195 Parties to the United Nations Framework Convention on Climate Change. The assessment is based on 10 different global level Intended Nationally Determined Contribution studies that all provide analysis of the unconditional contributions and six that cover both conditional and unconditional pledges. The scenarios presented describe the following cases:

- The baseline scenario reflects emission projections that assume no additional climate policies have been put in place from 2005 onwards.

- The current policy trajectory scenario reflects the best estimates of global emissions taking into account currently adopted and implemented policies.

- The Intended Nationally Determined Contribution describe how global greenhouse gas emissions might evolve under full implementation of two Intended Nationally Determined Contribution cases:

- Unconditional Intended Nationally Determined Contribution case: assuming full implementation of unconditional Intended Nationally Determined Contributions.

- Conditional Intended Nationally Determined Contribution case: assuming full implementation of both unconditional and conditional Intended Nationally Determined Contributions.

The $1.5^{\circ} \mathrm{C}$ and $2^{\circ} \mathrm{C}$ scenarios represent least-costs global scenarios consistent with a likely chance of limiting warming to below $2^{\circ} \mathrm{C}$ and $1.5^{\circ} \mathrm{C}$ above pre-industrial levels consistent with the estimates presented in table ES2.

Figure ES2 shows that full implementation of the unconditional Intended Nationally Determined Contributions - using rounded numbers - will reduce global greenhouse gas emissions in 2030 by $9 \mathrm{GtCO}_{2} \mathrm{e}$ (range: 7-13) relative to the median in the no-policy baseline scenario, and by $4 \mathrm{GtCO}_{2} \mathrm{e}$ (range: $2-7$ ) relative to the median in the current policy trajectory. Comparing the cost-optimal $2^{\circ} \mathrm{C}$ and $1.5^{\circ} \mathrm{C}$ scenarios to the unconditional Intended Nationally Determined Contribution projections shows a gap in 2030
Figure ES3: Comparison of projected emissions by 2030 and alltime $1.5^{\circ} \mathrm{C}$ and $2^{\circ} \mathrm{C}$ carbon budgets. Cumulative global total carbon dioxide emissions for the conditional INDC case, the unconditional INDC case and the current policies scenario, and carbon budgets from the Fifth Assessment Report of the Intergovernmental Panel on Climate Change (IPCC AR5) (IPCC, 2014a). The carbon budget ranges show the values based on the range of scenarios assessed by Working Group III (IPCC, 2014b). The solid horizontal line at $1,000 \mathrm{GtCO}_{2}$ shows the estimate based on complex Earth-System Models, assessed by Working Group I (IPCC, 2014a).

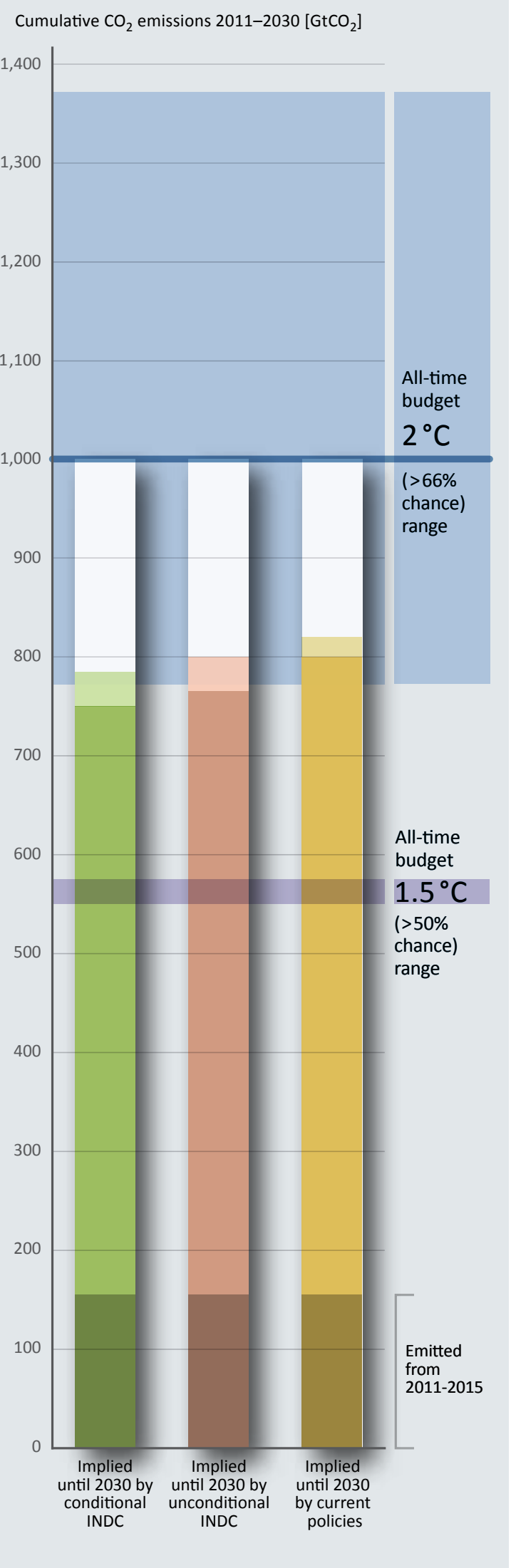


of $14 \mathrm{GtCO}_{2} \mathrm{e}$ (range: 10-16) between the unconditional Intended Nationally Determined Contribution scenario and the $2^{\circ} \mathrm{C}$ scenario. Comparing the unconditional Intended Nationally Determined Contribution scenario with the $1.5^{\circ} \mathrm{C}$ scenario would further increase the gap by $3 \mathrm{GtCO}_{2} \mathrm{e}$, as shown in figure ES2.

If countries were to fully implement the conditional Intended Nationally Determined Contributions, the estimated global greenhouse gas emissions in 2030 would be about $2.4 \mathrm{GtCO}_{2} \mathrm{e}$ (range: 1.2-4.8) lower in 2030 compared to the unconditional Intended Nationally Determined Contribution scenario case. This leaves a gap in 2030 of 12 (range: 8-13) $\mathrm{GtCO}_{2} \mathrm{e}$ between the conditional Intended Nationally Determined Contribution scenario and the cost-optimal $2^{\circ} \mathrm{C}$ scenario. When comparing with the $1.5^{\circ} \mathrm{C}$ scenario, the gap would increase by an additional $3 \mathrm{GtCO}_{2} \mathrm{e}$.

Interestingly, a number of countries have Intended Nationally Determined Contribution targets suggesting emission levels in 2030 above their estimated no-policy baseline or current policy scenario. These countries are, thus, assumed to overachieve on their Intended Nationally Determined Contribution targets, and the different model teams treat this issue in different ways, which adds an uncertainty of $1 \mathrm{GtCO}_{2} \mathrm{e}$ (range: $0-1$ ) by 2030 , to the estimated Intended Nationally Determined Contribution and gap projections.

Compared to last year's report, the estimates of the emission levels that would be realised under full implementation of the Intended Nationally Determined Contributions have not changed significantly. In summary, the Intended Nationally Determined Contributions represent a first start to initiate the required transition, but are far from being consistent with the agreed upon long-term temperature goals.

The full implementation of the unconditional Intended Nationally Determined Contributions is consistent with staying below an increase in temperature of $3.2^{\circ} \mathrm{C}$ (median, range: $2.9-3.4^{\circ} \mathrm{C}$ ) by 2100 relative to pre-industrial levels with greater than 66 per cent probability. This is lower than current policies, which imply staying below warming of $3.6^{\circ} \mathrm{C}$ (median, range: $3.4-3.7^{\circ} \mathrm{C}$ ) by 2100 with greater than 66 per cent probability. Full implementation of the conditional Intended Nationally Determined Contributions would lower the temperature projections relative to the unconditional Intended Nationally Determined Contributions by about $0.2^{\circ} \mathrm{C}$.

Under the Intended Nationally Determined Contribution scenarios, the carbon dioxide budget estimated by the

Figure ES4: Greenhouse gas emissions (all gases and sectors) of the G20 economies, and G20 as a whole, by 2030 for the business as usual (BAU) emissions projection from the INDC submission (third bar), for the current policies scenario from official and national studies (fourth bar), from global model studies used for our analysis (fifth bar), for the unconditional INDC scenario (sixth bar), and for the conditional INDC scenario (seventh bar). The uncertainty ranges are explained in the main text. For reporting reasons, the emissions projections for China, EU, India and USA are shown in panel (a), and the other countries in panel (b), with different vertical axes. The Figure also shows the number of studies underlying the estimate (if available) for the last four bars: current policies (national studies), current policies (all studies) and the unconditional INDC and conditional INDC (all studies).

\section{Figure ES4a}

Emissions $\left(\mathrm{GtCO}_{2} \mathrm{e} /\right.$ year)

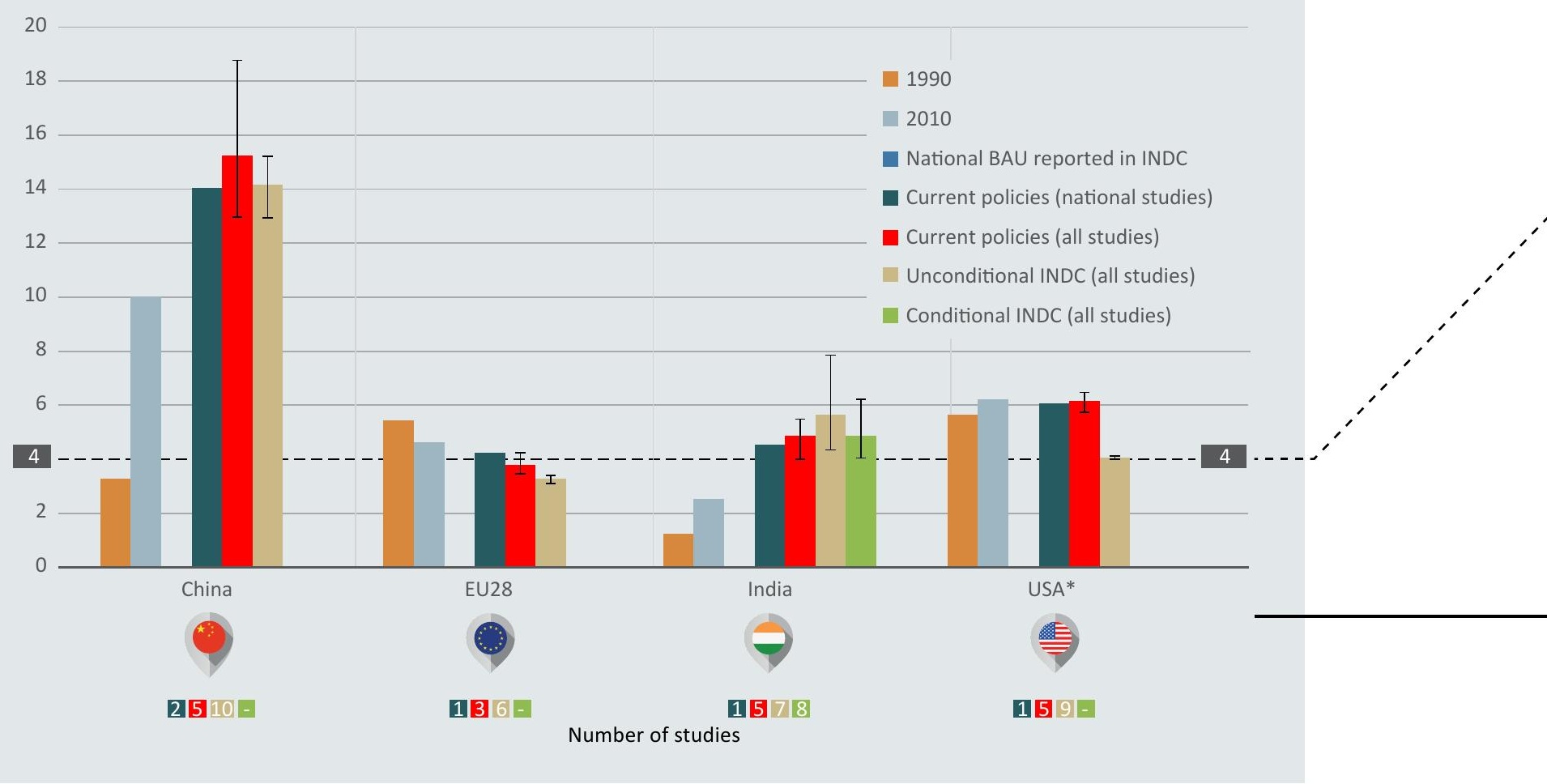


Intergovernmental Panel on Climate Change for limiting warming to below $2^{\circ} \mathrm{C}$ with at least 66 per cent probability will be close to depleted by 2030 , and the similar budget aligned with limiting warming to below $1.5^{\circ} \mathrm{C}$ with at least 50 per cent probability will already be well exceeded by 2030. Figure ES3 shows the cumulative carbon dioxide emissions implied by the Intended Nationally Determined Contribution scenarios.

\section{Assessments of Intended Nationally} Determined Contributions from individual G20 members show ambition, but also reveal that for some countries current policies are estimated to deliver greater reductions than the Intended Nationally Determined Contributions. This indicates that there might be room for strengthening the ambition of Intended Nationally Determined Contributions, noting that the analytical uncertainties are fairly large

Reflecting on the dominant share of global emissions coming from the G20 members, this year's Emissions Gap Report presents a more detailed assessment of the Intended Nationally Determined Contributions from this group of countries.
The calculation of the $\mathrm{G} 20$ members' median emission projections resulting from full implementation of the Intended Nationally Determined Contribution is based on the same data as the 2015 Emissions Gap Report, complemented with: a) the data from two new studies, and b) the estimates for the three G20 economies, Argentina, Saudi Arabia and Turkey, that were not included in the previous report.

Results of this assessment are presented for all the individual countries and the European Union in figure ES4, noting that data is not available for all countries.

The figure shows that for many countries the implementation of the Intended Nationally Determined Contribution would lead to lower emissions than the current policies scenario that is additional policies would have to be implemented to meet the Intended Nationally Determined Contribution. It is interesting to note that for some countries the Intended Nationally Determined Contribution is above the current policies scenario, indicating that it should be possible to enhance ambition quite easily. However, additional research is necessary because for many countries the uncertainty ranges overlap, and the number of studies for the current policies and Intended Nationally Determined Contribution cases vary significantly.

Figure ES4b

Emissions $\left(\mathrm{GtCO}_{2} \mathrm{e} /\right.$ year)

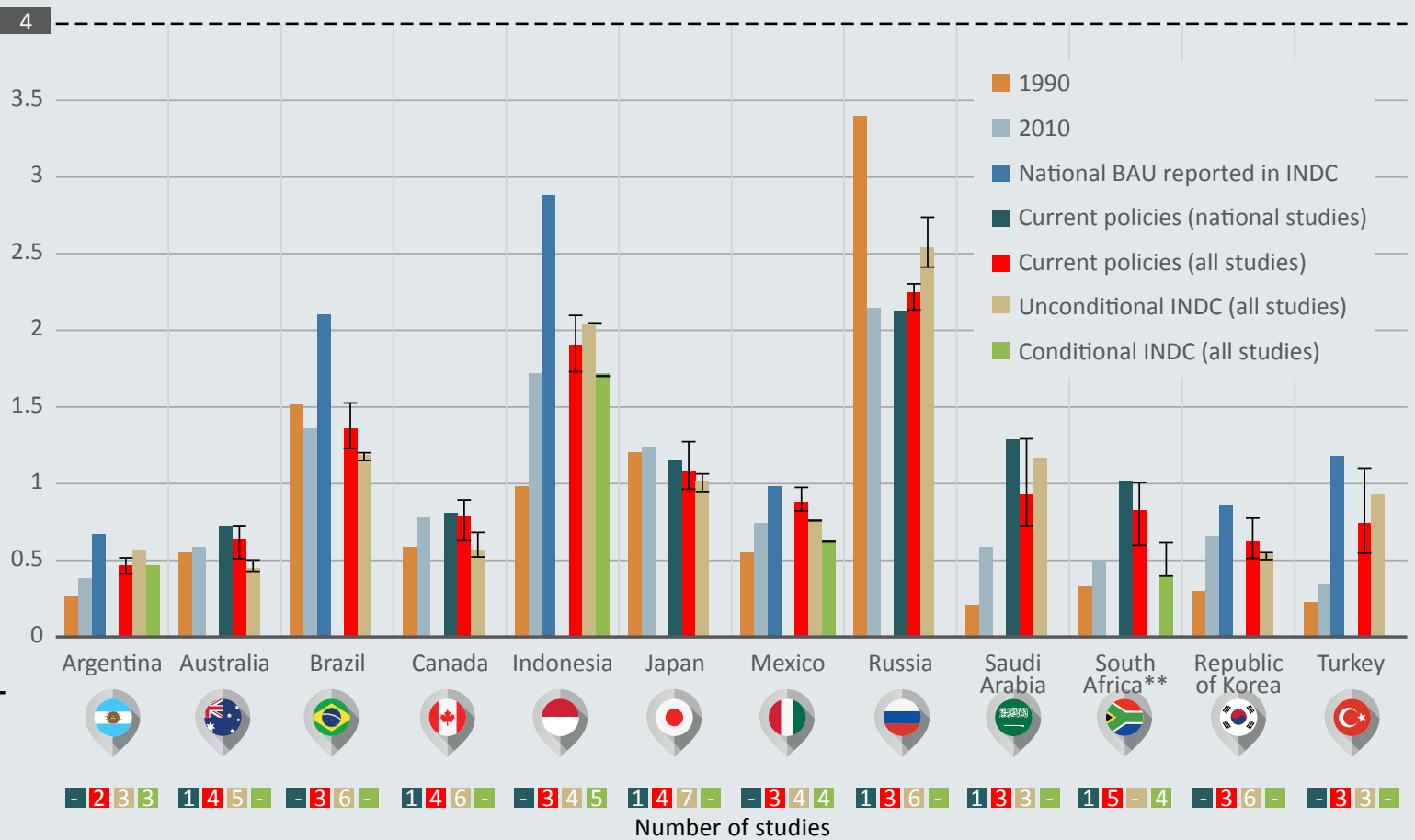

** South Africa's INDC is based on an emissions trajectory with an emissions range of 398-614 MtCO 2 e including LULUCF over the period $2025-2030$. 
9. Non-state actor initiatives could likely reduce emissions in 2020 and 2030 with a few additional gigatonnes. It is difficult to assess the overlap with Intended Nationally Determined Contributions as these are often not detailed enough. State and non-state actions can both overlap and mutually reinforce each other

Global climate governance has become substantially more diverse, with many actors other than national governments undertaking climate actions. Such actors include: the private sector, cities and regions and other subnational actors like citizen groups, referred to here as "non-state actors". Their actions could be both individual (for example, a company or city taking on a particular target), as well as cooperative (for example, an international cooperative initiative for city action). In some instances, national governments also participate and sometimes even drive the action. Figure ES5 shows the broad sector engagement of major cooperative mitigation initiatives.

During COP 20 in 2014, the Non-state Actor Zone for Climate Action was launched - an online platform to showcase non-state climate actions, both by individual and cooperative entities. It currently contains more than 11,000 commitments, mostly from individual actors. The Lima-Paris Action Agenda was also launched in 2014, by Peru, France, the United Nations Framework Convention on Climate Change Secretariat and the office of the United Nations Secretary General, and was given a prominent position during COP 21 to showcase the commitment of both state and non-state actors. These initiatives have now been integrated, for COP 22, as part of a new Global Climate Action Agenda to boost commitments and cooperative action between governments, cities, businesses, investors and citizens to cut emissions and help vulnerable nations adapt to climate impacts and build their own clean energy and sustainable future. More emphasis is put on increasing transparency, tracking results and demonstrating credibility of non-state action.

Some open questions remain, for example how can the international process best formally recognise, support, and catalyse non-state action? Equally important will be how non-state action relates to national governments' efforts to implement their Nationally Determined Contributions, and to the development of future Nationally Determined Contributions.

National action and Intended Nationally Determined Contributions, on the one hand, and non-state actions, on the other, can reinforce each other and together create a virtuous cycle of increasing ambition. Many initiatives address issues like financing, technology deployment and capacity building that may have important indirect effects on emissions. They can go hand-in-hand with policies of national governments.

In relation to the emissions gap, the interest is focused on the potential and actual contribution of actions by non-state actors to enhance global efforts to reduce greenhouse gas emissions.

A growing number of studies are available, estimating the potential contribution from actions by non-state actors to global efforts of reducing greenhouse gas emissions. Figure ES6 illustrates the results from eight different studies. The data still has significant gaps concerning actual impacts, overlaps and relation with Intended Nationally Determined Contributions; the figure is, therefore, only indicative of information about the potential of non-state action. The arrows showing the emission reductions potential start at different levels, because the individual studies use different baselines, and the last three studies explicitly estimate the impact additional to Intended Nationally Determined Contributions.

Figure ES5: Overview of sectoral distribution of 203 mitigation-focused International Cooperative Initiatives.

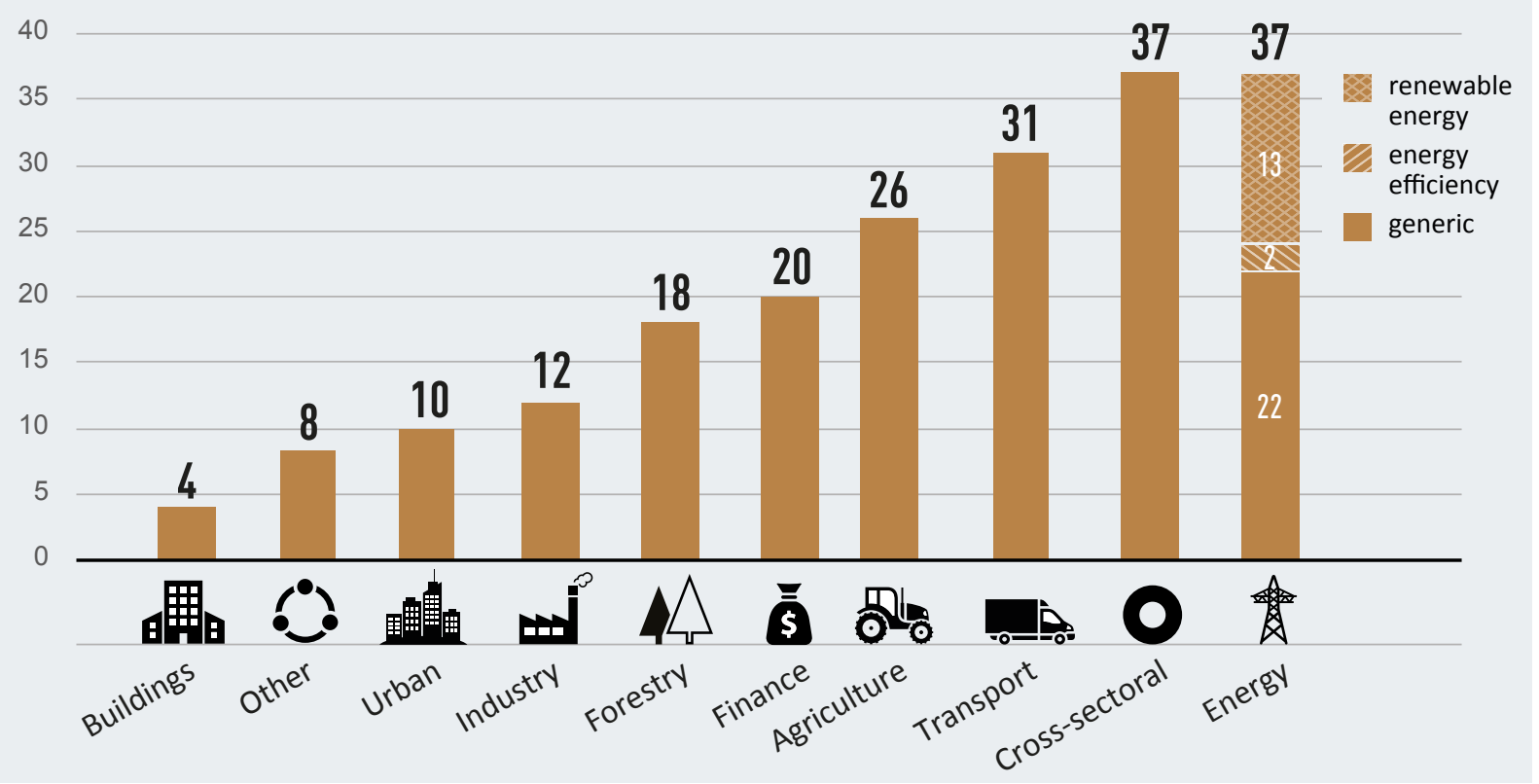

Note: Some initiatives cover more than one sector 
The data indicates that the aggregated impact of the initiatives are in the order of a few $\mathrm{GtCO}_{2} \mathrm{e}$ in $\mathbf{2 0 3 0}$ beyond the current Intended Nationally Determined Contributions that is potentially a significant contribution to closing the gap, if the initiatives reach their stated goals and if these reductions do not displace actions elsewhere. At the same time, many initiatives, in addition to their direct actions and contributions, provide political momentum and exercise pressure on governments to take further action.

\section{Ambitious action on energy efficiency} becomes more urgent given that the longterm objective in the Paris Agreement is more stringent. Well-documented opportunities exist to strengthen national policies and deliver deeper reductions through more effective delivery of energy efficiency policies

When examining the Intended Nationally Determined Contributions, it is evident that $\mathbf{1 6 7}$ countries have included energy efficiency as one of their priority action areas. It is also important to note that despite generally declining fossil energy prices, global investments in energy efficiency increased by 6 per cent to US\$221 billion in 2015, indicating that action is already happening.

Energy efficiency has been included in earlier Emissions Gap Reports reflecting the significant potential for emission reductions. This year's report presents policies that have proven to accelerate energy efficiency gains in three key sectors: buildings, industry and transport (see figure ES7). About 40 per cent of global greenhouse gas emissions are generated from direct energy use in these three sectors, while an additional 25 per cent are related to the power generation providing electricity to these end users.

If scaled-up, globally, the assessed energy efficiency policies can dramatically reduce energy use and greenhouse gas emissions in these key sectors. Sector-specific estimates of emission reduction potentials are highly dependent on the underlying assumptions and approaches. Studies based on the Fourth Assessment Report of the Intergovernmental Panel on Climate Change show that for a cost range of between US\$20 and 100 per tonne of carbon dioxide, the estimates of both direct and indirect emissions reduction potentials in 2030 are (in $\mathrm{GtCO}_{2} \mathrm{e}$ ): 5.9 for buildings, 4.1 for industry and 2.1 for transport. The study notes that these estimates are conservative and the real potential in each sector is likely bigger.

A more recent analysis by the International Energy Agency indicates that the cumulative direct and indirect emissions estimates to 2035 are (in $\mathrm{GtCO}_{2} \mathrm{e}$ ): 30 for buildings, 22 for industry and 12 for transport. The two studies are not comparable due to basic differences in approaches, but, collectively, illustrate the significant potential in the three sectors.

Beyondmitigation, improvedenergyefficiencyalsooffersmany other benefits like reduced air pollution and improved local employment. Energy efficiency is an integral part of Sustainable Development Goal 7, which aims to 'ensure access to affordable, reliable, sustainable and modern energy for all'. The energy efficiency target is to double the global rate of improvement in energy efficiency by 2030 , from 1.3 per cent per year to 2.6 per cent. The achievement of this goal will be important for achieving many of the other goals.

Figure ES6: Illustration of impact of initiatives by study.

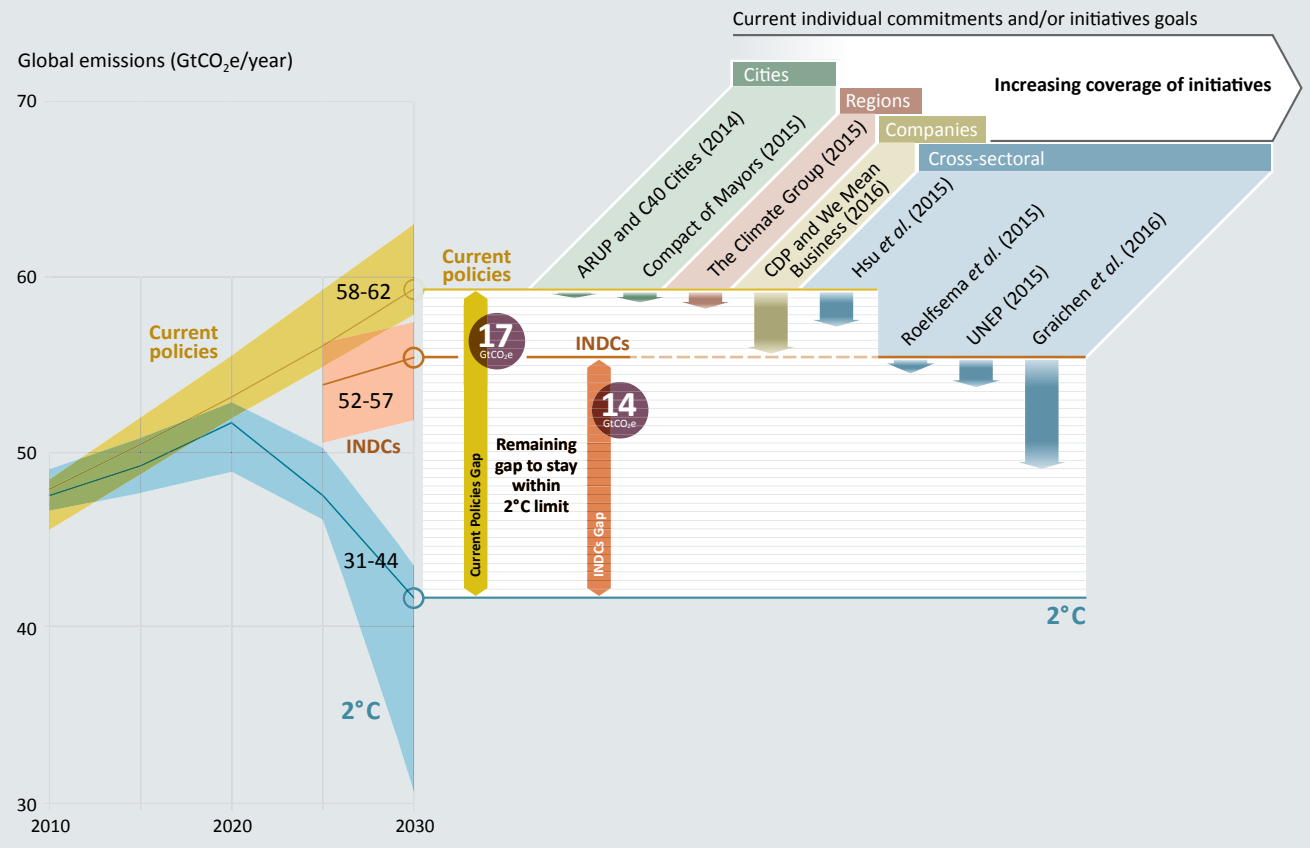

Note: The arrows showing the emission reductions potential start at different levels because the individual studies use different baselines (the last three studies explicitly estimate the impact additional to INDCs). 


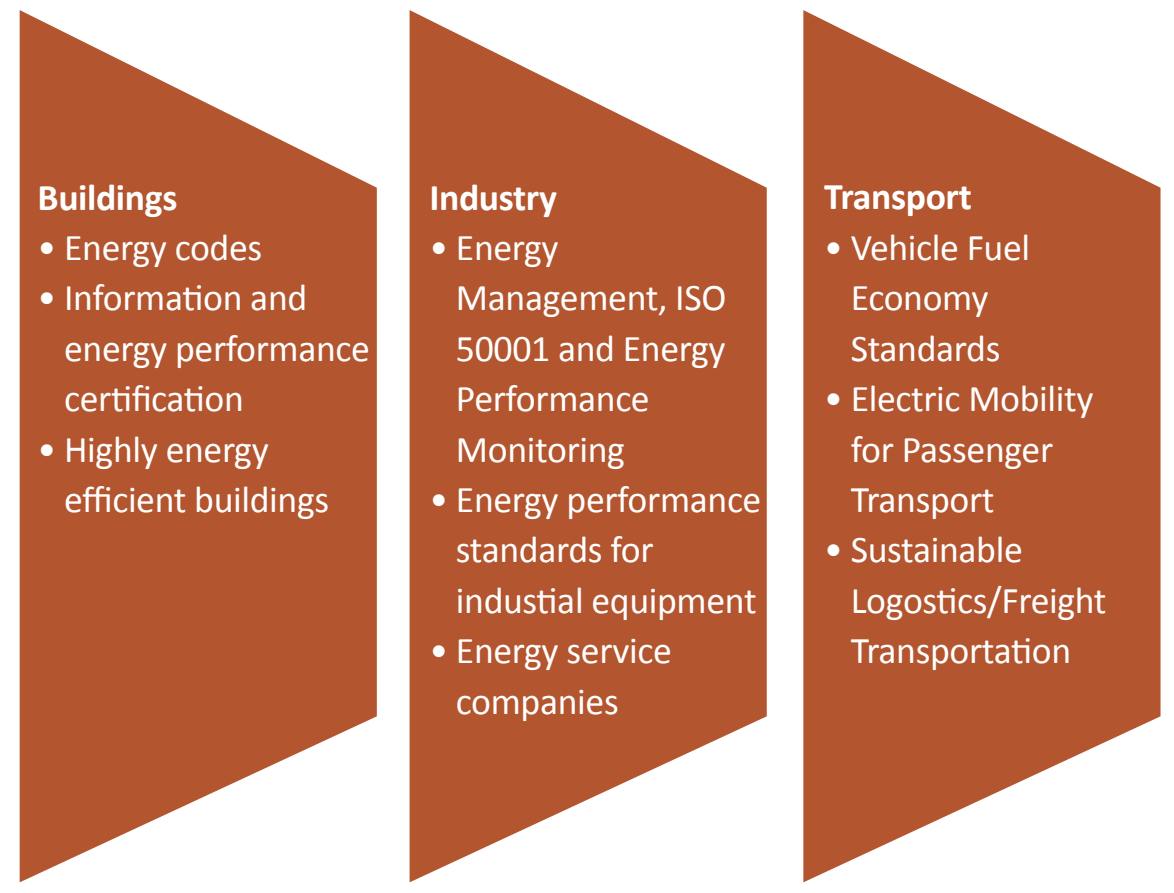

Many policy options exist in the three sectors; this assessment has focused on a small number of policies already implemented or under implementation in many countries where good results have been achieved.

Not all mitigation options can be associated with individual sectors, and it is important to consider the wider energy system as an integration between different elements. For example, design of housing efficiency needs to be closely integrated with the selection of heating and cooling technologies and lighting.

While most emissions in cities originate from the building, industry and transport sectors, a sizeable share of these emissions could be avoided through city-level mitigation options, such as spatial planning, improving transit options, increasing and co-locating employment and residential densities, and increasing green spaces.

More sustainable lifestyles, behaviours, cultures and consumption patterns are equally important to consider when designing policies - for example, for transport, building and appliance efficiency. While traditional policymaking has focused on technological and economic solutions, changes in energy behaviour are increasingly recognised as a key focus area when aiming for transformative action.

11. The Paris Agreement defines the Sustainable Development Goal (SDG) on climate change. Making the right choices in implementing all goals will be crucial to achieving the Paris Agreement objectives and the 2030 Agenda for Sustainable Development

The 2030 Agenda for Sustainable Development, adopted in 2015, defines the international development agenda of the next 15 years. The 2030 Agenda expressly recognizes the
United Nations Framework Convention on Climate Change as the authoritative body for defining the sustainable development goal thirteen on climate change, providing a direct link between the Paris Agreement and the goal on climate change.

Climate action is not only a sustainable development goal in its own right; it also directly affects and is affected by efforts to achieve many of the other goals. In some cases, interactions between the different goals may be mutually reinforcing, or path-aligned, while in other cases they may be conflicting, or path-contingent. This means that strategic choices matter. Successful implementation of both the United Nations Framework Convention on Climate Change and the Sustainable Development Goal agendas will, therefore, depend on the ability of national governments to develop and implement a set of national targets that serve both agendas, optimise benefits, exploit synergies, and reconcile trade-offs.

Among the key findings of analyses to date is that the earliest impacts of climate change may undermine our ability to deliver the goals by 2030, and that failure to deliver on the climate action goals will have even larger implications for maintaining development progress post-2030.

Exploring a complementary approach, the nature of the relationship between seven Sustainable Development Goals, selected based on their relevance for mitigation in key sectors, and the mitigation action required under the Paris Agreement is investigated. Table ES3 presents an overview of the findings. Of the four path-aligned goals, three directly relate to sustainability and ecosystems and would, therefore, be expected to align well with climate change mitigation goals. Encouragingly, the report additionally finds that achieving universal access to energy is compatible with emission reduction targets, as this is associated with 
low energy demands and, in most cases, best achieved While it is too early to provide an assessment of the through expansion and reliance on low-carbon distributed quantitative emissions implications of pursuing the technologies.

Sustainable Development Goals, and vice versa, emerging results from integrated assessment models provide For the path-contingent goals, there is often general or insights into the available "solution space" that allows for even specific knowledge of how to overcome many of the simultaneous achievement of multiple goals and targets. challenges, as well as longstanding experience of particular An emphasis on measures that reduce energy and policies and practices that can help to minimize trade-offs other consumption demands generally benefits overall $\begin{array}{lll}\text { and maximize synergies between different interests. } & \text { development concerns by freeing up the solution space for }\end{array}$ other goals, for example, food security and infrastructure.

Table ES3: Overview of path-aligned and path-contingent Sustainable Development Goals (SDG) covered in the report.

\begin{tabular}{|lll|}
\hline Alignment & SDG & Topic \\
\hline Path-aligned & SDG7 & Sustainable energy access \\
& SDG11 & Sustainable cities \\
& SDG12 & Sustainable consumption and production \\
& SDG15 & Terrestrial ecosystems \\
\hline Path-contingent & SDG2 & Hunger and food security \\
& SDG8 & Growth and employment \\
& SDG9 & Infrastructure, industrialization, and innovation \\
\hline
\end{tabular}





\section{Chapter 1}

\section{Introduction}

Lead authors: Anne Olhoff (UNEP DTU Partnership) and John Christensen (UNEP DTU Partnership)

\subsection{The Emissions Gap Reports}

Since 2010, United Nations Environment (UNEP) has produced annual Emissions Gap Reports based on requests by countries for an independent scientific assessment of how actions and pledges by countries affect the global greenhouse gas emissions trend, and how this compares to emissions trajectories consistent with the long-term goal of the United Nations Framework Convention on Climate Change (UNFCCC). The difference has become known as the emissions gap. In addition to estimating the emissions gap, the reports focus on key options for achieving the emissions reductions necessary to bridge the gap, and provide an assessment of how these can be accelerated and scaled up. Countries have found these emissions gap assessments useful in informing the political process. This seventh Emissions Gap Report is based on requests by countries for an update that focuses on some of the key issues emerging with the adoption of the Paris Agreement and its specific long-term temperature goal.

\subsection{The context of the 2016 Emissions Gap Report}

The adoption of the Paris Agreement - the first agreement on climate change with universal contributions on mitigation - at the twenty-first session of the Conference of the Parties (COP 21) to the UNFCCC has been called a landmark in international efforts to address climate change. The objective of the Paris Agreement of "holding the increase in the global average temperature to well below $2^{\circ} \mathrm{C}$ above pre-industrial levels and to pursue efforts to limit the temperature increase to $1.5^{\circ} \mathrm{C}$ above pre-industrial levels" (UNFCCC, 2015a, p. 22) translates directly into urgency of enhanced and immediate mitigation action.

The Paris Agreement has been ratified with record speed and will enter into effect on 4 November 2016, 30 days after the threshold of more than 55 Parties, representing at least 55 per cent of global emissions, ratified or otherwise joined the agreement. This threshold was achieved on 5 October 2016.
Together with the September 2015 unanimous adoption by United Nations member countries of the Sustainable Development Goals (SDGs) to be achieved by 2030, the Paris Agreement provides a new, strengthened framework for global climate change action. Moreover, the Agreement accentuates the urgency of action and the context of sustainable development and poverty eradication.

The Paris Agreement builds on the Intended Nationally Determined Contributions (INDCs) submitted by countries in advance of COP 21 as requested in the Lima Call for Climate Action (UNFCCC, 2014). The 2015 Emissions Gap Report (UNEP, 2015) undertook a thorough assessment of the aggregate effect of the INDCs on global greenhouse gas emissions in 2025 and 2030, based on the INDCs submitted by 1 October 2015. It concluded that while the INDCs represent a real increase in ambition compared to global greenhouse gas emission levels resulting from a projection of current policies, the contributions are far from what is required for an emissions pathway consistent with staying below $2^{\circ} \mathrm{C}$. More specifically, the 2015 Emissions Gap Report estimated that full implementation of both unconditional and conditional INDCs would imply an emissions gap of 12 gigatonnes of carbon dioxide equivalent $\left(\mathrm{GtCO}_{2} \mathrm{e}\right)$ in 2030 between what the INDCs contribute and the least-cost emission level for a pathway to stay below $2^{\circ} \mathrm{C}$. This estimate is in line with the findings of the synthesis report of the aggregate effects of the INDCs by the UNFCCC (2015b).

Recognising the need to bridge the significant gap between the ambition levels in the Intended Nationally Determined Contributions (INDCS) and the level of ambition required to meet the Paris Agreement goal of staying well below $2^{\circ} \mathrm{C}$ and pursuing a $1.5^{\circ} \mathrm{C}$ target, Article 4 of the Paris Agreement specifies that "Each Party shall communicate a nationally determined contribution every five years" (UNFCCC 2015a, p. 23) and, furthermore, that "Each Party's successive nationally determined contribution will represent a progression beyond the Party's then current nationally determined contribution and reflect its highest possible ambition" (UNFCCC 2015a, p. 22). The Agreement 
also decides to convene a facilitative dialogue among Parties in 2018, "to take stock of the collective efforts of Parties in relation to progress towards the long-term goal... and to inform the preparation of nationally determined contributions" (UNFCCC 2015a, p. 4). The Intergovernmental Panel on Climate Change (IPCC) was invited to produce a special report by 2018 on the impacts of global warming of $1.5^{\circ} \mathrm{C}$ above pre-industrial levels and related global greenhouse gas emission pathways. The facilitative dialogue and special report by the IPCC means that 2018 presents important opportunities to strengthen the nationally determined contributions and the global mitigation ambition by 2020 .

Two recent events have provided additional momentum to the acceleration of global mitigation efforts. Under the auspices of the International Civil Aviation Organization, governments, with the support of industry, and civil society representatives have agreed in early October on a new global market-based Carbon Offsetting and Reduction Scheme for International Aviation, which will begin with a pilot phase from 2021 through 2023, followed by a first phase from 2024 through 2026. A few weeks later, the 197 governments meeting as parties to the Montreal Protocol reached an agreement on the so-called Kigali Amendment, under which developed countries will start to phase down the use of hydrofluorocarbons by 2019. Developing countries will follow with a freeze of consumption levels in 2024, with some countries freezing consumption in 2028. By the late 2040s, all countries are expected to consume no more than 15-20 per cent of their respective baselines.

Studies on the impact of these agreements on emissions and future temperature increase are still scarce. However, early indications are that the contributions will be significant; although with the stipulated timeframes for implementation the short-term impacts on the 2030 emissions gap will be limited. The two agreements do, however, send strong signals on the willingness to take political action.

\subsection{Aim, key questions, and approach of the report}

In line with previous reports, the objective of the 2016 Emissions Gap Report is to provide an up-to-date scientific assessment of the global progress towards the emissions reductions required to be on track to meet the long-term goal of the UNFCCC. In particular, this year the report emphasizes the implications of the Paris Agreement's strengthened goal of holding the increase in the global average temperature to well below $2^{\circ} \mathrm{C}$, and to pursue efforts to limit the temperature increase to $1.5^{\circ} \mathrm{C}$ above pre-industrial levels for immediate and longer-term mitigation action (Chapters 2 and 3 ).

In line with previous years, the report assesses actions in selected areas that can contribute to bridging the emissions gap, and how these can be accelerated and scaled up. Previous reports have covered a wide range of areas, including agriculture, forestry, and renewable energy. The areas selected this year are non-state action (Chapter 4); energy efficiency (Chapter 5); and the nexus between the Sustainable Development Goals and climate change mitigation (Chapter 6).

Non-state action and energy efficiency have been examined in earlier reports, but increased political focus on these options and availability of new studies that provide better understanding of their large emissions reduction potential, in combination, provides a strong rationale for revisiting these options.

The report asks four principal questions:

1. What is the current status of pre-2020 mitigation action?

2. What is the gap between the estimated level of global emissions in 2030 if the Intended Nationally Determined Contributions are fully implemented, and the range consistent with the well below $2^{\circ} \mathrm{C}$ or $1.5^{\circ} \mathrm{C}$ temperature goal?

3. What are the possible emissions reduction contributions of non-state action and increased energy efficiency, and how can action in these areas be accelerated to enhance the ambition of nationally determined contributions?

4. What do we know about the nexus between the Sustainable Development Goals and mitigation, and areas of alignment and conflict between the two?

This year, the assessment is based on submissions of Intended Nationally Determined Contributions by almost all countries in the world, and more international studies now support the robustness of the Gap estimates. The conclusion is that the results remain within the ranges of the 2015 assessment, and that countries should not wait for further evidence but start to act immediately.

As in previous years, the report adopts an assessment approach and has been prepared by a wide range of scientists from around the world. This year, 34 scientists from 18 institutions in 17 countries have contributed to the report.

United Nations Environment hopes that this seventh edition of the Emissions Gap Report will help inform discussions at COP 22 and support the enhanced and accelerated mitigation ambition required to meet the goal of the Paris Agreement. 


\section{Chapter 2}

\section{Pre-2020 action: trends, progress and urgency}

Lead authors: Taryn Fransen (World Resources Institute), Michel den Elzen (PBL Netherlands Environmental Assessment Agency) and Takeshi Kuramochi (NewClimate Institute)

Contributing authors: Greet Janssens-Maenhout (Joint Research Centre, European Commission), Anne Olhoff (UNEP DTU Partnership) and Jos Olivier (PBL Netherlands Environmental Assessment Agency)

\subsection{Introduction}

The strengthened language of the Paris Agreement of holding the increase in the global average temperature to well below $2^{\circ} \mathrm{C}$ above pre-industrial levels, and to pursue efforts to limit the temperature increase to $1.5^{\circ} \mathrm{C}$ above preindustrial levels translates into a need for even stronger and more immediate mitigation action than previously assessed.

This chapter looks into pre-2020 action, focusing on trends, progress and urgency. It provides an overview of the state of play of global emission trends and progress towards achieving the Cancun Pledges by G20 members as two key indicators of the level of pre-2020 action. Trends in current performance and progress are, furthermore, likely to influence the extent to which parties are positioned to implement their Nationally Determined Contributions (NDCs), and transition to the stringent least-cost emissions reduction trajectories after 2020, required to reach the temperature target of the United Nations Framework Convention on Climate Change (UNFCCC). The chapter presents an update, based on the latest available scientific literature, on the following critical topics:

- Do emissions show signs of peaking? Section 2.2 gives an overview of current trends in total global emissions of greenhouse gases, and of energy-related carbon dioxide $\left(\mathrm{CO}_{2}\right)$ emissions from fossil fuels and industry as a major driver of total greenhouse gas emissions.

- Are G20 members on track to meet their Cancun Pledges? Section 2.3 provides an update of the 2015 assessment (UNEP, 2015), based on current policy portfolios of $\mathrm{G} 20$ members, and plausible assumptions regarding macroeconomic trends and offsets.
- What are the implications for urgency of action? Based on the two preceding sections, Section 2.4 reiterates the urgency of immediately enhancing mitigation actions to facilitate a transition towards least-cost emission reduction trajectories after 2020 that are aligned with $2^{\circ} \mathrm{C}$ and $1.5^{\circ} \mathrm{C}$ targets.

\subsection{Trends in current global emissions}

Total global greenhouse gas emissions continue to increase. In 2014, they reached approximately 52.7 gigatonnes $\mathrm{CO}_{2} \mathrm{e}$ $\left(\mathrm{GtCO}_{2} \mathrm{e}\right.$ ) (range: 47.9-57.5') (UNEP, 2015)2. Over the past decades the trend in global greenhouse gas emissions has been one of steady increase with small variations around this longer-term trend. Notably, global greenhouse gas emissions increased at a faster rate (2.2 per cent per year) during the period 2000 to 2010 than they did during the period 1970 to 2000, where the growth rate was 1.3 per cent per year (IPCC, 2014b). Considering the period from 2010, the emissions growth slowed to 1.8 per cent on average in 2012 to 2013, from a 3.5 per cent increase in 2010 and 2011 (JRC/PBL, 2014).

Global $\mathrm{CO}_{2}$ emissions from fossil fuels and industry ${ }^{3}$ are the major source of total global greenhouse gas emissions. Currently, they account for about 68 per cent of total global greenhouse gas emissions, and were estimated at a total of $36.2 \mathrm{GtCO}_{2}$ for 2015 (range: 32.7-39.9) (Olivier et al.,

190 per cent confidence interval based on the uncertainty range assessed in The Fifth Assessment Report of the Intergovernmental Panel on Climate Change (IPCC) Working Group III (IPCC, 2014b).

2 Data for this year is available from EDGAR and PRIMAP. Sources: JRC/PBL (2014), Potsdam Institute for Climate Impact Research (2016).

3 It covers the $\mathrm{CO}_{2}$ emissions from fossil fuel combustion and cement production and other processes, including flaring of waste gas during gas and oil production, cement clinker production and other limestone uses, feedstock and other non-energy uses of fuels, and several other small sources. 
$\mathrm{GtCO}_{2} /$ year

40

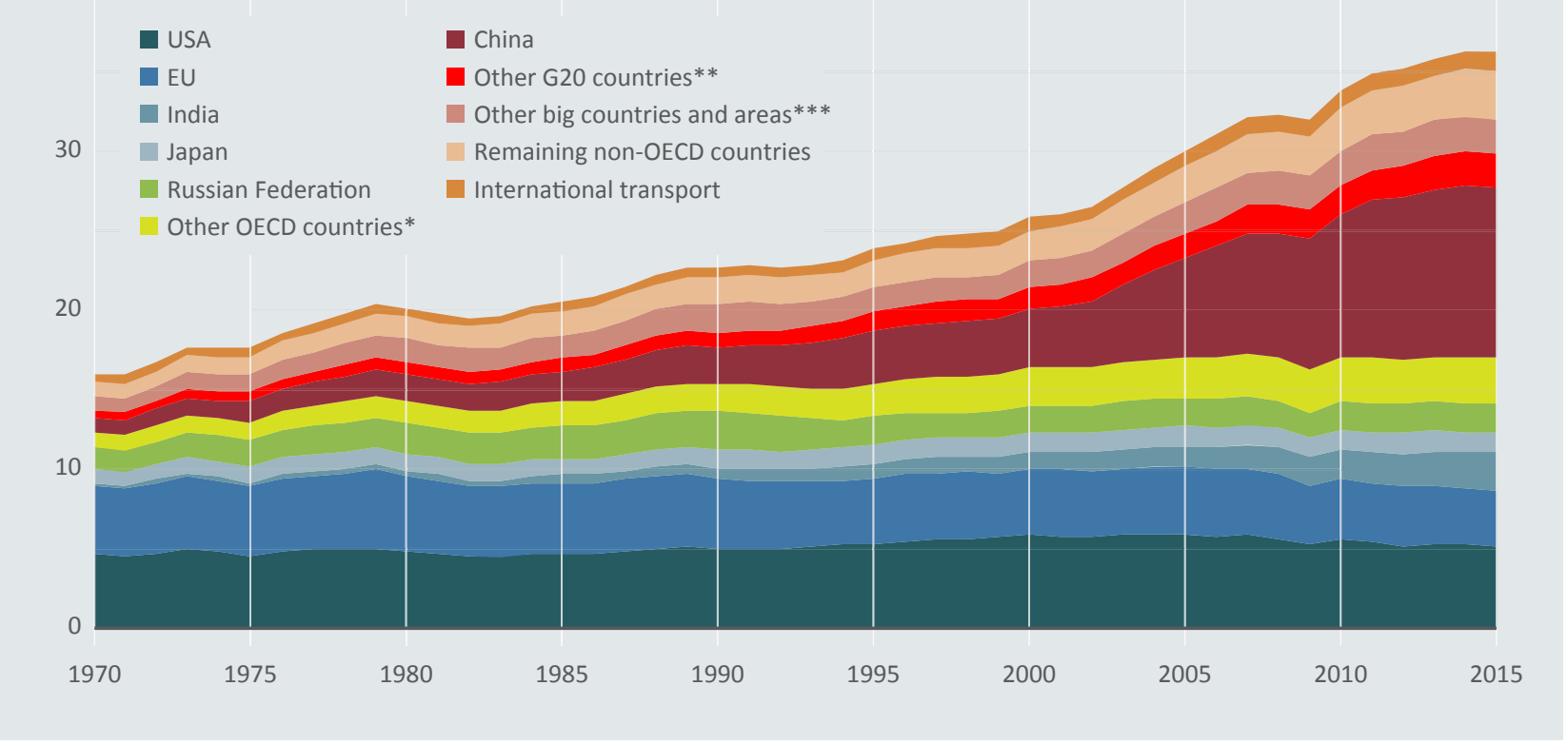

* Other OECD countries include Australia; Canada; Mexico; Republic of Korea and Turkey.

** Other G20 countries include Argentina; Brazil; Indonesia; Saudi Arabia; South Africa and Turkey.

*** Other big countries and areas include Egypt; Iran; Kazakhstan; Malaysia; Nigeria; Taiwan, Province of China; Thailand and Ukraine.

forthcoming $)^{4}$. Given their share of total greenhouse gas emissions, it is relevant to look more closely at the trend in $\mathrm{CO}_{2}$ emissions from fossil fuels and industry. Figure 2.1 shows the development in global $\mathrm{CO}_{2}$ emissions from fossil fuels and industry for the period 1970 to 2015.

In 2015 global $\mathrm{CO}_{2}$ emissions stagnated for the first time and showed signs of a weak decline compared to 2014 (-0.1 per cent). This was preceded by a slowdown in the growth rate of $\mathrm{CO}_{2}$ emissions, from 2.0 per cent in 2013 to 1.1 per cent in 2014 (Olivier et al., forthcoming). These findings are in line with the studies of the Global Carbon Project on trends in global energy-related $\mathrm{CO}_{2}$ emissions (Le Quéré et al., 2015; Jackson et al., 2016) $)^{5}$.

Global $\mathrm{CO}_{2}$ emissions increased by roughly 1.3 per cent annually for the period 2012 to 2014, a pace significantly slower than that of the 12 preceding years, where the average annual increase was 2.9 per cent (2000-2011), but higher than the average annual growth rate of around 1 per cent during the 1990s.

In summary, global greenhouse gas emissions continue to grow, and while there is an encouraging indication of a halting of the growth rate of global $\mathrm{CO}_{2}$ emissions from fossil fuels and industry, it is still too early to say whether this is likely to be permanent.

4 These results are based on IEA (2016) statistics and preliminary estimates based on the latest BP statistics, including the recent revision of coal statistics in China.

5 The changes in the growth rate of global $\mathrm{CO}_{2}$ emissions in 2015 compared to 2014 comprise very different growth rates and show differences amongst top $\mathrm{CO}_{2}$ emitters. For example, growth rates in $\mathrm{CO}_{2}$ emissions decreased in China and the US in 2015, compared to 2014, whereas they increased in the EU and India in 2015, compared to 2014. Olivier et al. (forthcoming) provide additional insights into whether the changes in growth rate for the top emitters are of a structural, and therefore more permanent, nature or not.

\subsection{Progress towards achieving the Cancun Pledges: an update focusing on G20 members}

As the Emissions Gap Report has done since 2013, this section provides an update on the progress towards achieving the Cancun Pledges, focusing on members of the $\mathrm{G}^{2} \mathrm{O}^{6}$. These economies, collectively, generate around three quarters of global greenhouse gas emissions ${ }^{7}$. Although it is critical that all countries advance as far as possible towards achieving - and ideally exceeding - their Cancun Pledges this is particularly the case for the highest-emitting economies, given their large share of total global greenhouse gas emissions.

\subsubsection{Assessment of G20 members' 2020 emissions under three cases}

To assess G20 members' progress towards their Cancun Pledges, this section compares current emissions trajectories with those associated with the achievement of these parties' pledges. Three cases are considered: a pledge case, based on official data; a current policy trajectory case, based on official data; and a current policy trajectory case, based on independent analysis. These three cases are further described in box 2.1, while the findings are presented in table 2.1 .

The members of the G20 are: Argentina, Australia, Brazil, Canada, China, France, Germany, India, Indonesia, Italy, Japan, Republic of Korea, Mexico, Russia, Saudi Arabia, South Africa, Turkey, the UK, the United States of America (USA), and the European Union (EU). In our analysis, the EU including all its Member States (regardless of G20 status) is considered as a single Party, and EU Member States are not considered individually. In general, evaluating the pledges of other countries is limited by a lack of data.

7 In 2012, these parties accounted for 77 per cent of global emissions, excluding land use, land-use change and forestry (LULUCF), and 75 per cent of global greenhouse gas emissions, including LULUCF (CAIT WRI, 2015). 


\section{Box 2.1: Assumptions of the assessment of progress towards Cancun Pledges}

For each G20 member, table 2.1 compares estimates for 2020 emissions under three cases:

1. Pledge case (official data): Identifies the maximum level of greenhouse gas emissions that each country or Party could emit in 2020 and still meet its pledge - without considering the use of offsets. If a pledge is presented as a range (Australia, Brazil, China, India), the less ambitious end of the range is adopted as the official pledge estimate. If a country has both a conditional and an unconditional pledge (Indonesia), only the unconditional pledge is used. If a country has only a conditional pledge (Mexico, South Africa), the conditional pledge is used. For countries whose pledges are framed relative to a baseline scenario, it is assumed that baselines are not adjusted in the future. For countries whose pledges are framed as greenhouse gas intensity targets, economic growth consistent with official projections is assumed ${ }^{8}$. Where available, the 2020 emission level described by the country or Party as the pledge level is used; alternatively, these levels are calculated working from official base-year or baseline data.

2. Current policy trajectory case (official data): Identifies official estimates of 2020 emissions, considering projected economic trends and current policy approaches, as identified by each modelling study cited in our analysis, including policies at least through 2012.

3. Current policy trajectory case (independent analysis): Similarly identifies estimates of 2020 emissions considering the best current estimates of projected economic trends and current policy approaches, but is based on independent analysis rather than official data. Figures are drawn from the Climate Action Tracker (CAT, 2015) and den Elzen et al. (2015) for all countries, as well as other country-specific sources, where noted. Current policy trajectory (independent analysis) supplements the official sources described in point two by providing data that aims for consistency across countries and political independence.

Projections considering only a limited subset of sectors and gases, for example $\mathrm{CO}_{2}$ emissions from fossil fuels, are omitted, as they cannot be compared to projections and targets that include the full set of greenhouse gases across the entire economy.

Source: UNEP (2015).

\subsubsection{Summary of progress of $\mathbf{G} 20$ members $^{9}$}

According to the assessment presented in table 2.1, six G20 members are on track to meet their Cancun Pledges according to the most available analyses. Four members are likely to require further action, to purchase offsets or use a combination of the two to meet their targets. For two 20 members there is currently insufficient information to assess whether they are on track to meet their pledges, illustrating that better data is necessary to adequately track progress in some countries. For another member, no conclusion is drawn due to differing interpretations of what would constitute pledge attainment. The three remaining G20 members have no Cancun Pledges. Further details are provided below. As highlighted in box 2.2, three important caveats should be kept in mind when assessing country progress towards the Cancun Pledges.

\section{Box 2.2: Assessing progress towards achieving the Cancun Pledges: three caveats}

1. Pledges do not necessarily demand the same level of effort to achieve. In other words, a country currently on track to achieve its pledge has not necessarily made a greater effort to mitigate emissions than a country not yet on track.

2. Projections are subject to uncertainty associated with macroeconomic trends, such as changes in gross domestic product, and population trends, as well as the impact of each country's climate policy action.

3. The potential impact of using offsets to achieve pledges is not quantified for the emission trajectories considered. If offsets are traded internationally, and are counted towards the pledges of both buying and selling parties, the global impact of the pledges will be weakened. Most countries have not clarified their intentions concerning their use of offsets to meet their Cancun Pledges. G20 members, Australia, Brazil, Canada, the EU, and the USA have explicitly not excluded the possibility; other members have not formally commented (CAIT WRI, 2015).

Source: UNEP (2015).

8 For China, the gross domestic product is assumed to reach 61.6 trillion yuan in 2020, consistent with China's National Communication (People's Republic of China, 2012). For India, the gross domestic product is assumed to reach 120.41 trillion rupees (2006-2007 rupee value) in 2020, consistent with the average of the scenarios presented in Planning Commission Government of India (2014).

9 This section builds on Section 2.3.2 of UNEP (2015). Updates are included where these are available. 
Table 2.1: Emissions in 2020 under Cancun pledge case and current policy trajectory cases for $\mathrm{G} 20$ members categorised alphabetically by status of progress in million tonnes $\mathrm{CO}_{2}$ equivalent $\left(\mathrm{MtCO}_{2} \mathrm{e}\right)^{10}$.

\begin{tabular}{|c|c|c|c|c|}
\hline Parties & $\begin{array}{l}\text { Cancun Pledge case } \\
\text { (based on official } \\
\text { data) }\end{array}$ & $\begin{array}{l}\text { Current policy } \\
\text { trajectory } \\
\text { (based on } \\
\text { official data) }\end{array}$ & $\begin{array}{l}\text { Current policy trajectory } \\
\text { (based on independent } \\
\text { estimates) }^{11}\end{array}$ & Mitigation pledge and current policy trajectory details \\
\hline \multicolumn{5}{|c|}{ G20 members assessed to be on track to meet their Cancun Pledges } \\
\hline Brazil & $\begin{array}{l}2,070^{\mathrm{a}} \\
\text { (Government of } \\
\text { Brazil, 2010) }\end{array}$ & N/A & $\begin{array}{l}1,750-2,075^{\mathrm{a}}(\mathrm{CAT}, 2014)^{12} \\
1,470-1,520^{\mathrm{a}} \text { (den Elzen et } \\
\text { al., 2015) }\end{array}$ & Baseline scenario pledge \\
\hline China* & $\begin{array}{l}14,500^{\mathrm{a}} \\
\text { (People's Republic of } \\
\text { China, 2012) }\end{array}$ & N/A & $\begin{array}{l}12,200-12,600^{\mathrm{a}} \text { (CAT, 2015) } \\
12,535-13,420^{\mathrm{a}} \text { (den Elzen } \\
\text { et al., 2015) }\end{array}$ & $\begin{array}{l}\text { Intensity pledge } \\
\text { Cancun Pledge case assumes } 40 \% \text { reduction in } \\
\text { greenhouse gas intensity calculated based on the } 2020 \\
\text { gross domestic product cited in People's Republic of } \\
\text { China (2012). The } \mathrm{CO}_{2} \text { projection is complemented for } \\
\text { non- } \mathrm{CO}_{2} \text { projections from CAT (2015). }\end{array}$ \\
\hline $\begin{array}{l}\text { European } \\
\text { Union }\end{array}$ & $\begin{array}{l}4,500^{b} \\
(E E A, 2014)\end{array}$ & $\begin{array}{l}4,235^{\mathrm{b}, \mathrm{c}} \\
\text { (EEA, } \\
\text { forthcoming) }\end{array}$ & $\begin{array}{l}4,115-4,375^{\mathrm{b}} \text { (CAT, 2015) } \\
4,105-4,370^{\mathrm{b}} \text { (den Elzen et } \\
\text { al., 2015) }\end{array}$ & Base year pledge \\
\hline India* & $\begin{array}{l}3,815^{\mathrm{b}} \\
\text { (Planning Commission } \\
\text { Government of India } \\
2011,2014)\end{array}$ & N/A & $\begin{array}{l}\text { 3,575-3,610 (CAT, 2015) } \\
3,535-3,960^{\mathrm{a}} \text { (den Elzen et } \\
\text { al., 2015) }\end{array}$ & $\begin{array}{l}\text { Intensity pledge } \\
\text { Cancun Pledge case is calculated based on an assumed } \\
20 \% \text { reduction in greenhouse gas intensity (Planning } \\
\text { Commission Government of India, 2011), the } 2020 \\
\text { gross domestic product from Planning Commission } \\
\text { Government of India (2014), and exclusion of the } \\
\text { emissions from agriculture and land use, land-use } \\
\text { change and forestry (LULUCF) (Planning Commission } \\
\text { Government of India, 2011). }\end{array}$ \\
\hline Japan & $\begin{array}{l}1,345^{b, c} \\
\text { (Government of } \\
\text { Japan, 2016) }{ }^{13}\end{array}$ & N/A & $\begin{array}{l}1,230-1,330^{\mathrm{b}} \text { (CAT, 2015) } \\
1,135-1,330^{\mathrm{b}} \text { (den Elzen et } \\
\text { al., 2015) } \\
1,350-1,400^{\mathrm{b}} \text { (Kuramochi, } \\
2014)\end{array}$ & Base year pledge \\
\hline $\begin{array}{l}\text { Russian } \\
\text { Federation }\end{array}$ & $\begin{array}{l}2,515^{\mathrm{b}} \\
\text { (Government of } \\
\text { Russia, 2014) }\end{array}$ & $\begin{array}{l}2,410^{\mathrm{b}} \\
\text { (Government of } \\
\text { Russia, 2015) }\end{array}$ & $\begin{array}{l}\text { 2,415-2,455 }(\text { CAT, 2015) } \\
2,295-2,375^{b} \text { (den Elzen et } \\
\text { al., 2015) }\end{array}$ & $\begin{array}{l}\text { Base year pledge } \\
\text { Cancun Pledge case reflects } 25 \% \text { reduction calculated } \\
\text { based on national inventory data (Government of } \\
\text { Russia, 2014). }\end{array}$ \\
\hline \multicolumn{5}{|c|}{ G20 members likely to require further action or purchased offsets } \\
\hline Canada & $\begin{array}{l}620^{\mathrm{b}, \mathrm{c}} \\
\text { (Government of } \\
\text { Canada, 2016) }\end{array}$ & $\begin{array}{l}770^{\mathrm{b}, \mathrm{c}} \\
\text { (Government of } \\
\text { Canada, 2016) }\end{array}$ & $\begin{array}{l}745^{\mathrm{b}}(\mathrm{CAT}, 2015) \\
720-760^{\mathrm{b}} \text { (den Elzen et al., } \\
2015)\end{array}$ & Base year pledge \\
\hline Mexico & $\begin{array}{l}670^{\mathrm{a}} \\
\text { (NCCS, 2013) }\end{array}$ & $\begin{array}{l}830^{\mathrm{a}} \\
\text { (Government of } \\
\text { Mexico, 2012; } \\
\text { NCCS, 2013) }\end{array}$ & $\begin{array}{l}785-800^{\mathrm{a}} \text { (CAT, 2015) } \\
770-810^{\mathrm{a}} \text { (den Elzen et al., } \\
2015)\end{array}$ & $\begin{array}{l}\text { Baseline scenario pledge } \\
\text { In the Intended Nationally Determined Contribution } \\
\text { (INDC) (Government of Mexico, 2015), Mexico has } \\
\text { updated its baseline }{ }^{14} \text { to } 792 \text {, and if the Cancun Pledge } \\
\text { is calculated based on this baseline, it would be: } 555^{2} \text {. } \\
\text { Current Policy Trajectory (Official Data) is based on } \\
\text { Government of Mexico (2012), adjusted per NCCS } \\
\text { (2013). }\end{array}$ \\
\hline $\begin{array}{l}\text { Republic of } \\
\text { Korea }\end{array}$ & $\begin{array}{l}550^{\mathrm{a}} \\
\text { (Republic of Korea, } \\
2015) \\
545^{\mathrm{a}} \\
\text { (Republic of Korea, } \\
2014)\end{array}$ & N/A & $\begin{array}{l}745-755^{b} \text { (CAT, 2015) } \\
585-620^{b} \text { (den Elzen et al., } \\
2015)\end{array}$ & $\begin{array}{l}\text { Baseline scenario pledge } \\
\text { Cancun Pledge case of } 550^{a} \text { is calculated from INDC } \\
\text { (Republic of Korea, 2015) baseline of } 783 .\end{array}$ \\
\hline $\begin{array}{l}\text { United } \\
\text { States of } \\
\text { America }\end{array}$ & $\begin{array}{l}\text { 5,345 a,c } \\
\text { (U.S. Department of } \\
\text { State, 2015) }\end{array}$ & $\begin{array}{l}5,450-5,600^{a, c} \\
\text { (U.S. } \\
\text { Department of } \\
\text { State, 2015) }\end{array}$ & $\begin{array}{l}\text { 6,360-6,600 (CAT, 2015) } \\
5,445-6,170^{\mathrm{a}} \text { (den Elzen et } \\
\text { al., 2015) } \\
5,340-5,610^{\mathrm{a}, \mathrm{c}} \text { (Belenky, } \\
2016) \\
5,225-5,815^{\mathrm{a}, \mathrm{c}} \text { (Larsen et } \\
\text { al., 2016) }\end{array}$ & Base year pledge \\
\hline
\end{tabular}




\begin{tabular}{|c|c|c|c|c|}
\hline Parties & $\begin{array}{l}\text { Cancun pledge case } \\
\text { (based on official } \\
\text { data) }\end{array}$ & $\begin{array}{l}\text { Current policy } \\
\text { trajectory } \\
\text { (based on } \\
\text { official data) }\end{array}$ & $\begin{array}{l}\text { Current policy trajectory } \\
\text { (based on independent } \\
\text { estimates) }{ }^{11}\end{array}$ & Mitigation pledge and current policy trajectory details \\
\hline \multicolumn{5}{|c|}{ G20 members for which no conclusion is drawn regarding Cancun Pledge alignment } \\
\hline Australia & $\begin{array}{l}520^{a, c} \\
\text { (Department of } \\
\text { Environment and } \\
\text { Energy Australia, } \\
2016 \text { ) }\end{array}$ & $\begin{array}{l}580^{\mathrm{a}, \mathrm{c}} \\
\text { (Department } \\
\text { of Environment } \\
\text { Australia, } \\
2016)^{15}\end{array}$ & $\begin{array}{l}575^{\mathrm{b}} \text { (CAT, 2015) } \\
600^{\mathrm{a}} \text { (Kuramochi et al., } \\
2016 \text { ) } \\
570 \text { (Reputex, 2016) }\end{array}$ & Base year pledge \\
\hline Indonesia & $\begin{array}{l}\text { 1,335 } \\
\text { (BAPPENAS, 2015) } \\
2,185^{a} \\
\text { (Ministry of } \\
\text { Environment } \\
\text { Indonesia, 2010; } \\
\text { Ministry of } \\
\text { Environment and } \\
\text { Forestry Indonesia, } \\
\text { 2015) }\end{array}$ & N/A & $\begin{array}{l}820^{\mathrm{b}}(\mathrm{CAT}, 2015) \\
1,910-1,950^{\mathrm{a}} \text { (den Elzen et } \\
\text { al., 2015) }\end{array}$ & $\begin{array}{l}\text { Baseline scenario pledge } \\
\text { Cancun Pledge case of } 1,335^{\mathrm{a}} \text { is calculated based on } \\
\text { the baseline from BAPPENAS }(2015)^{16} \text {. } \\
2,185^{\mathrm{a}} \text { is calculated based on the baseline from the } \\
\text { Ministry of Environment Indonesia ( } 2010) \text { and the } \\
\text { Ministry of Environment and Forestry Indonesia } \\
\text { (2015). }\end{array}$ \\
\hline $\begin{array}{l}\text { South } \\
\text { Africa }\end{array}$ & $\begin{array}{l}585^{a} \\
\text { (Department of } \\
\text { Environmental Affairs } \\
\text { Republic of South } \\
\text { Africa, 2011a, 2011b) }\end{array}$ & N/A & $\begin{array}{l}730^{\mathrm{b}}(\mathrm{CAT}, 2015) \\
560-885^{\mathrm{b}}(\mathrm{PBL}, 2015)\end{array}$ & Baseline scenario pledge \\
\hline \multicolumn{5}{|c|}{ G20 members with no Cancun Pledge } \\
\hline Argentina & No pledge & $\begin{array}{l}465 \text { (Ministry } \\
\text { of the } \\
\text { Environment } \\
\text { and Sustainable } \\
\text { Development } \\
\text { Argentina, } \\
\text { 2015) }\end{array}$ & $365-460^{\mathrm{b}}$ (CAT, 2015) & \\
\hline $\begin{array}{l}\text { Saudi } \\
\text { Arabia }\end{array}$ & No pledge & N/A & $840^{\mathrm{b}}$ (CAT, 2015) & \\
\hline Turkey & No pledge & $\begin{array}{l}600^{\mathrm{a}, \mathrm{c}} \\
670^{\mathrm{b}, \mathrm{c}} \\
\text { (Republic of } \\
\text { Turkey Ministry } \\
\text { of Environment } \\
\text { and } \\
\text { Urbanization, } \\
\text { 2016) }\end{array}$ & $\begin{array}{l}625^{\mathrm{b}}(\mathrm{CAT}, 2015) \\
485-690^{\mathrm{b}} \text { (den Elzen et al., } \\
2015)\end{array}$ & \\
\hline
\end{tabular}

\section{Notes:}

aFigures including LULUCF

${ }^{b}$ Figures excluding LULUCF

'Figures based on global warming potentials from IPCC (2007)

*China and India have greenhouse gas intensity targets based on the ratio of greenhouse gas emissions to gross domestic product. For consistency, we have converted these to absolute emission numbers based on the official documentation cited above, but a determination of whether each country has achieved its pledge should be based on intensity rather than absolute emissions.

Estimates are rounded to the nearest $5 \mathrm{MtCO}_{2} \mathrm{e}$.

10 Figures do not consider the possible purchase or sale of offsets. Figures including LULUCF indicated witha, excluding LULUCF indicated with ${ }^{\mathrm{b}}$.

11 References to den Elzen et al. (2015) in this column represent PBL estimates based on the method of den Elzen et al. (2015). Some numbers presented here have been updated per latest estimates available from http://infographics.pbl.nl/indc/ [Accessed 19 October 2016].

12 The most recent Climate Action Tracker (November 2015) (CAT, 2015) analysis does not include LULUCF.

13 In the revised 2nd Biennial Report (Government of Japan, 2016), Japan revised its accounting approach on LULUCF, which is now accounted for not only the target year but also the base year

14 The INDC baseline is based on a new methodology with global warming potentials from IPCC (2014a); it is, therefore, not comparable to any other sources cited here. All other sources use global warming potentials from IPCC (1995); the NCCS (2013) also uses a previous methodology.

15 Due to conflicting information, Australia is placed under the category "G20 members for which no conclusion is drawn regarding Cancun Pledge alignment".

16 The INDC baseline is based on a revised national inventory that shows significantly lower 2010 emissions than those shown in the National Communication and assumed by other studies cited here. See BAPPENAS (2015) for a comparison of 2010 emissions. 


\section{G20 members that are on track to meet their Cancun Pledges}

Three of the G20 parties - China, the EU, and India - are on track to meet their pledges without purchasing offsets, according to all available analyses. Three more - Brazil, Japan, and Russia - are on track, according to most estimates.

China and India's pledges are framed in terms of greenhouse gas intensity reductions from 2005 levels, and several sources indicate that both countries are currently on track to achieve them. Studies indicate that China, which pledged a reduction of 40-45 per cent in emissions intensity, is on track to achieve a reduction of at least 42 per cent (CAT, 2015; PBL, 2015; Sha et al., 2015). India reports that it achieved a 12 per cent reduction in emissions intensity from 2005 to 2010 (Ministry of Environment, Forest and Climate Change India, 2015), while Garg et al. (2014) show a 17 per cent reduction from 2005 to 2012 (out of a pledged reduction of 20-25 per cent from 2005 to 2020). The CAT (2015) and PBL (2015) show India on track for intensity reductions of 36 per cent and 28 per cent by 2020 , respectively ${ }^{17}$.

Japan announced an adjustment to its pledge in November 2013 from a 25 per cent reduction on 1990 levels to a 3.8 per cent reduction on 2005 levels - similar to an increase of about 6 per cent on 1990 levels. There is no official current policy projections available, but CAT (2015) shows Japan on track to meet its revised pledge, whereas den Elzen et al. (2015) estimates a range in 2020 from slightly below to slightly above the pledge level. Japan's actual trajectory, however, will depend significantly on the respective roles of nuclear power and coal-fired power to meet future needs ${ }^{18}$.

\section{G20 members that are likely to require further action or purchased offsets}

Canada, Mexico, and the United States are likely to require further action and/or purchase offsets in order to meet their pledges, according to government and independent estimates. Mexico's Cancun Pledge is conditional on the provision of adequate financial and technological support from developed countries as part of a global agreement (Government of Mexico, 2015).

According to independent analysis, the Republic of Korea will also require further action to meet its pledge, but this cannot be verified based on publicly available official projections. Independent estimates of 2020 emissions range from well below to well above the pledge level (CAT,

17 Calculated for China based on an assumed gross domestic product growth rate of 8.5 per cent (PBL, 2015) and 7.0 per cent (CAT, 2015), and for India based on an assumed gross domestic product growth rate of 7.5 per cent (PBL, 2015) and 6.4 per cent (CAT, 2015).

18 A study commissioned by Japan's Ministry of Environment (Ministry of Environment Japan, 2015) projected that by 2030, the share of renewable energy in the electricity sector could reach around 25-30 per cent in a 'medium deployment' case and 30-35 per cent in a 'high deployment' case.
2015; den Elzen et al., 2015) ${ }^{19}$. The Republic of Korea has domestically abandoned the 2020 target by replacing it with the Intended Nationally Determined Contribution (INDC) target in the amended Green Growth Act (The Law National Information Center, 2016). As of August 2016, the country's 2020 mitigation target submitted to the UNFCCC has not been withdrawn.

\section{G20 members for which no conclusion is drawn regarding pledge attainment}

Government and independent sources also find a gap between Australia's projected 2020 emissions and its target level for that year. In accordance with the Kyoto Protocol, Australia uses a carbon budget approach that accounts for cumulative emissions over the period of 2013 to 2020 in order to assess progress against its target. Australia's latest official projections (Department of Environment Australia, 2016) find that for the budget period, including carry-over from its first commitment period under the Kyoto Protocol, Australia is now on track to meet its Kyoto target.

Insufficient information is currently available to determine whether Indonesia and South Africa are on track to meet their pledges. In the case of Indonesia, independent projections span a wide range, and official projections reflecting current policies are unavailable. The Ministry of Environment and Forestry Indonesia (2015) identifies baseline 2020 emissions as $2.95 \mathrm{GtCO}_{2} \mathrm{e}$, and the abatement necessary to achieve the unilateral 26 per cent reduction target as $0.767 \mathrm{GtCO}_{2} \mathrm{e}$. It further identifies a suite of mitigation activities both under and outside of Perpres No. 61/2011. A subset of these activities has reported abatement of $46.38 \mathrm{MtCO}_{2} \mathrm{e}$ (of which 41.29 $\mathrm{MtCO}_{2} \mathrm{e}$ occurred under Perpres No. 61/2011) from 2010-2012, or an average of $15.46 \mathrm{MtCO}_{2}$ e per year. The remainder of the activities, however, have not reported their emissions reductions, nor have future emissions reductions been forecast.

In the case of South Africa, independent estimates of 2020 emissions vary widely, from well below the pledge level to well above it. Moreover, these projections exclude land use, land-use change and forestry (LULUCF), whereas South Africa's pledge includes LULUCF. Official projections are not available. South Africa's pledge is conditional.

\section{G20 members with no Cancun Pledge}

Three G20 member states, Argentina, Saudi Arabia and Turkey, have not proposed greenhouse gas reduction pledges for 2020. However, all three countries have submitted post-2020 Pledges to the UNFCCC as part of their INDCs. In addition, Turkey has submitted a Biennial Report including its projected emissions for 2020 (Republic of Turkey Ministry of Environment and Urbaniation, 2016).

19 It has been reported that the 2020 target was abandoned domestically (Carbon Pulse, 2016), but to date there is no report that the Republic of Korea abandoned its pre-2020 Pledge made under the UNFCCC. 
To summarize, this section has examined the extent to which $\mathrm{G} 20$ members are proceeding towards the minimum level of their Cancun Pledges. The cumulative impact of the progress of $\mathrm{G} 20$ members towards achieving their Cancun Pledges is not calculated, as there is limited information on the $\mathrm{CO}_{2}$ emission projections for the current policies scenario. However, as Chapter 3 shows, 2020 emissions under current global policy trajectories - which take progress by the $\mathrm{G} 20$ members into account - roughly align with those associated with implementation of the high end of the estimated $52-54 \mathrm{GtCO}_{2}$ e emissions range of the Cancun Pledges (UNEP, 2014).

\subsection{Amplified urgency of enhanced pre-2020 action}

The strengthened long-term objective of the Paris Agreement amplifies the urgency of enhancing early mitigation action. Enhanced early action facilitates a transition to the stringent, long-term emission reductions required to hold the increase in the global average temperature to well below $2^{\circ} \mathrm{C}$ above pre-industrial levels (Rogelj et al., 2013; Clarke et al., 2014). Furthermore, it is critical for pursuing the $1.5^{\circ} \mathrm{C}$ target (see also Section 3.2).

The previous sections clearly demonstrate that although there are encouraging signs of mitigation action, the current level of action is very far from what is required to move towards alignment with the strengthened objective of the Paris Agreement. Total global greenhouse gas emissions continue to increase, and although the growth in global $\mathrm{CO}_{2}$ emissions - a major contributor to total global greenhouse gas emissions - has shown encouraging signs of levelling out over the past two years, it is too soon to tell whether this is likely to be permanent. G20 member countries and states continue to make progress towards achieving their Cancun Pledges, but current trends indicate that, overall, the continuation of current levels of action is likely to result in total global greenhouse gas emissions in $\mathbf{2 0 2 0}$ that are in line with the weakest Cancun Pledge scenario considered in previous Emissions Gap Reports (see for example UNEP (2013)).

The urgency of enhancing pre-2020 mitigation action is, thus, indisputable:

- It bolsters the likelihood that countries meet and exceed their Cancun Pledges.

- It provides a more solid foundation for implementing the Nationally Determined Contributions and for continuously strengthening their ambition.

- It supports the transition towards a least-cost emissions reduction trajectory after 2020 that is consistent with the well below $2^{\circ} \mathrm{C}$ target.

- It is likely the last chance to keep the option of limiting global warming to $1.5^{\circ} \mathrm{C}$ in 2100 open, as all available scenarios consistent with the $1.5^{\circ} \mathrm{C}$ target imply that global greenhouse gas emissions peak before 2020 .
In addition to these critical aspects of pre-2020 action, enhanced early action (both pre-2020 and pre-2030) is associated with a number of other important outcomes and a wide range of additional economic, technological, societal, and climate outcome benefits. For example, enhanced early action will reduce climate risks and impacts. It will, furthermore, enable the realization of near-term co-benefits of climate change mitigation, including health-related benefits associated with lower air pollution; improved energy security; and reduced crop yield losses. These, and other benefits and trade-offs between immediate and delayed mitigation action, have been assessed in detail in previous Emissions Gap Reports (UNEP, 2012, 2013, 2014, 2015). Building on these, the most important implications of failing to respond to the increased urgency of early action include:

- Delaying action implies that significantly higher rates of global emission reductions are required in the medium- and long-term to meet the well below $2^{\circ} \mathrm{C}$ target. The order of magnitude of these rates is without historic precedent.

- Delaying action reduces the 'solution space' and options available to society to achieve stringent emission reductions.

- Delaying action will result in greater lock-in of carbon- and energy-intensive infrastructure in the energy system and society, as a whole. It will also be a disincentive for near-term learning and technology development that will be essential in the long-term.

- Delaying action translates into greater dependence on negative emissions technologies in the mediumterm - technologies that so far are unproven on a larger scale.

- Delaying action increases the costs of mitigation in the medium- and long-term, and implies greater risks of economic disruption.

- Importantly, delaying action is associated with greater risks of failing to meet the well below $2^{\circ} \mathrm{C}$ target and is likely to be incompatible with meeting a $1.5^{\circ} \mathrm{C}$ target. 


\section{Chapter 3}

\section{0 trends and ambition}

Lead authors: Michel den Elzen (PBL Netherlands Environmental Assessment Agency), Niklas Höhne (NewClimate Institute) and Joeri Rogelj (International Institute for Applied Systems Analysis)

Contributing authors: Taryn Fransen (World Resources Institute), Mark Roelfsema (PBL Netherlands Environmental Assessment Agency) and Sebastian Sterl (NewClimate Institute)

\subsection{Introduction}

The Paris Agreement aims at limiting global average temperature increase to well below $2^{\circ} \mathrm{C}$ relative to pre-industrial levels, and to pursue efforts to further limit global average temperature increase to $1.5^{\circ} \mathrm{C}$. This chapter provides an update of the mitigation challenge associated with the temperature goal of the Paris Agreement, and the estimated global emission levels under various assumptions regarding the implementation of policies and Intended Nationally Determined Contributions (INDCs).

\subsection{Pathways limiting warming to below 2 and 1.5 degrees Celsius}

The Paris Agreement is clear about its aim to keep warming well below 2 degrees Celsius $\left({ }^{\circ} \mathrm{C}\right)$ and pursue efforts to limit it to $1.5^{\circ} \mathrm{C}$, but it does not provide a specific probability with which these limits are to be avoided. Deciding on the appropriate level of probability is a political rather than scientific question, as it requires value judgments about what is acceptable and desirable to society (Schleussner et al., 2016). However, clarity regarding the working assumptions about these probabilities is required to enable comparable quantification and exploration of pathways consistent with the Paris Agreement's temperature target. Therefore, all results in this report are accompanied by unambiguous descriptions of the quantitative temperature goals they inform, acknowledging that other interpretations are possible and valid. In line with last year's Emissions Gap Report (UNEP, 2015), the scenarios considered are least-cost pathways starting in 2020 that limit warming to below $2^{\circ} \mathrm{C}$, with at least 66 per cent probability by 2100 (never resulting in a probability of below 60 per cent), and which return warming to below $1.5^{\circ} \mathrm{C}$ with at least 50 per cent probability by 2100 , respectively (table 3.1 ).
A large body of literature is available on pathways that limit warming to below $2^{\circ} \mathrm{C}$ with 66 per cent or higher probabilities. This has been covered extensively by the Intergovernmental Panel on Climate Change (IPCC) (Clarke et al., 2014) and earlier Emissions Gap Reports. Summary statistics for least-cost pathways starting from 2020, in line with limiting warming to below $2^{\circ} \mathrm{C}$ with at least 66 per cent probability, are provided in table 3.1.

The Fifth Assessment Report of the IPCC also covered $1.5^{\circ} \mathrm{C}$ pathways to a limited extent (IPCC, 2014a; IPCC 2014b). These included least-cost pathways starting from 2010 in line with a 66 per cent probability of limiting warming to below $1.5^{\circ} \mathrm{C}$ in $2100^{1}$. Currently, there are no scenarios available that assume least-cost pathways starting from 2020 that can return warming to below $1.5^{\circ} \mathrm{C}$ by 2100 with at least 66 per cent probability. Therefore, this report describes the characteristics of scenarios that assume least-cost pathways starting from 2020 and return warming to below $1.5^{\circ} \mathrm{C}$ in 2100 with a lower, 50 per cent probability.

Following the Fifth Assessment Report of the IPCC, a dedicated review of the $1.5^{\circ} \mathrm{C}$ scenarios appeared in the literature (Rogelj et al., 2015), and other reports, including the United Nations Framework Convention on Climate Change (UNFCCC) Synthesis Report on the Aggregate Effect of Intended Nationally Determined Contributions (INDCs) (UNFCCC, 2016e), have additionally provided more specific information about global emission pathways in line with

1 The IPCC reports that global $\mathrm{CO}_{2}$ equivalent $\left(\mathrm{CO}_{2} \mathrm{e}\right)$ emissions in these $1.5^{\circ} \mathrm{C}$ scenarios are reduced by 70-95 per cent and $110-120$ per cent below 2010 levels in 2050 and 2100, respectively. $\mathrm{CO}_{2}$ equivalence in the Fifth Assessment Report of the IPCC was computed using 100-year Global Warming Potentials reported in the Second Assessment Report of the IPCC. $\mathrm{CO}_{2}$ e emissions include all greenhouse gases and are derived from Integrated Assessment Model scenarios which also include consistent evolutions of radiatively active air pollutants. 
Table 3.1: Overview of pathway characteristics for two global temperature targets. A detailed overview of scenario names is provided in Annex A.1. available online. Source: UNEP (2015) and additional calculations.

\begin{tabular}{|c|c|c|c|c|c|}
\hline $1.5^{\circ} \mathrm{C}(>50 \%$ in 2100$)$ & \multicolumn{5}{|c|}{$\begin{array}{l}\text { Pathways limiting warming to below } 1.5^{\circ} \mathrm{C} \text { by } 2100 \text { with }>50 \% \text { probability } \\
\text { Limited action until } 2020 \text { and cost-optimal mitigation afterwards }\end{array}$} \\
\hline \multicolumn{6}{|c|}{$\begin{array}{l}\text { Number of available scenarios: 6; Number of contributing modelling frameworks: } 2 \\
\text { Year of global annual emissions becoming net zerot for: } \\
\text { Kyoto greenhouse gases (GHGs): (2060-2080); total } \mathrm{CO}_{2} \text { (including land use, land-use change and forestry (LULUCF)): (2045-2050); CO } \text { from } \\
\text { energy and industry: (2045-2055) }\end{array}$} \\
\hline \multicolumn{6}{|c|}{ Annual emissions of global total GHGs $\left[\mathrm{GtCO}_{2} \mathrm{e} / \mathrm{year}\right]$} \\
\hline Year & 2020 & 2025 & 2030 & 2050 & 2100 \\
\hline median* & 56 & 47 & 39 & 8 & -5 \\
\hline range and spread** & $53(-/-) 56$ & $46(-/-) 48$ & $37(-/-) 40$ & $4(-/-) 14$ & $-5(-/-)-3$ \\
\hline \multicolumn{6}{|c|}{$\mathrm{CO}_{2}$ carbon budgets [global total cumulative $\mathrm{CO}_{2}$ emissions in $\mathrm{GtCO}_{2}$ ] } \\
\hline Time period & $2015-2030$ & $2030-2050$ & $2050-2075$ & $2075-2100$ & $2015-2100$ \\
\hline median* & 552 & 236 & -199 & -353 & 217 \\
\hline range and spread** & $503(-/-) 567$ & $178(-/-) 259$ & $-146(-/-)-277$ & $-288(-/-)-372$ & $71(-/-) 383$ \\
\hline $2^{\circ} \mathrm{C}(>66 \%$ in 2100$)$ & \multicolumn{5}{|c|}{$\begin{array}{l}\text { Pathways limiting warming to below } 2^{\circ} \mathrm{C} \text { by } 2100 \text { with }>66 \% \text { probability } \\
\text { Limited action until } 2020 \text { and cost-optimal mitigation afterwards }\end{array}$} \\
\hline \multicolumn{6}{|c|}{ 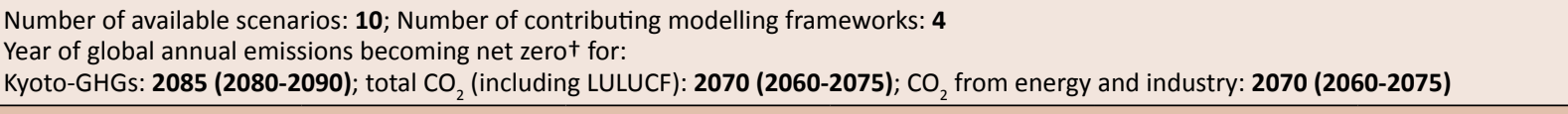 } \\
\hline & \multicolumn{5}{|c|}{ Annual emissions of global total GHGs $\left[\mathrm{GtCO}_{2} \mathrm{e} /\right.$ year] } \\
\hline Year & 2020 & 2025 & 2030 & 2050 & 2100 \\
\hline median* & 52 & 48 & 42 & 23 & -3 \\
\hline \multirow[t]{2}{*}{ range and spread** } & $49(49 / 53) 55$ & $44(46 / 50) 53$ & $29(31 / 44) 44$ & $17(18 / 27) 29$ & $-11(-9 /-1) 0$ \\
\hline & \multicolumn{5}{|c|}{$\mathrm{CO}_{2}$ carbon budgets [global total cumulative $\mathrm{CO}_{2}$ emissions in $\mathrm{GtCO}_{2}$ ] } \\
\hline Time period & $2015-2030$ & $2030-2050$ & $2050-2075$ & $2075-2100$ & $2015-2100$ \\
\hline median* & 533 & 362 & 70 & -288 & 553 \\
\hline range and spread** & $481(499 / 582) 572$ & $242(258 / 431) 447$ & $-97(-52 / 175) 187$ & $-120(-146 /-327)-342$ & $483(490 / 934) 988$ \\
\hline
\end{tabular}

$1.5^{\circ} \mathrm{C}$. Each of these publications draws upon scenarios published earlier (Luderer et al., 2013; Rogelj et al., 2013a; Rogelj et al., 2013b).

More literature is forthcoming and will be assessed in the framework of a Special Report on the impacts of global warming of $1.5^{\circ} \mathrm{C}$ above pre-industrial levels and related global greenhouse gas emission pathways by the IPCC. This report will be finalized by 2018 , in time to inform the facilitative dialogue under the UNFCCC.

Based, on the available literature, it is possible to identify four key characteristics of $1.5^{\circ} \mathrm{C}$ scenarios that start a leastcost pathway from 2020 and limit warming to below $1.5^{\circ} \mathrm{C}$ in 2100 with greater than 50 per cent probability. These are:

(1) Immediate mitigation action: all available scenarios consistent with this definition, peak global greenhouse gas emissions around 2020.

(2) The rapid up-scaling of the full portfolio of mitigation technologies: this includes widespread adoption of renewables, the phase-out of unabated fossil fuels, and the use of negative emissions technologies that allow for the active removal of carbon dioxide $\left(\mathrm{CO}_{2}\right)$ from the atmosphere.

(3) Development along a low-energy demand trajectory.
(4) Temperature overshoot: almost all available scenarios consistent with this definition, temporarily exceed the $1.5^{\circ} \mathrm{C}$ limit during the $21^{\text {st }}$ century.

The issues of negative emissions and temperature overshoot are discussed in more detail in the following.

A large proportion of the scenarios that limit warming to below $2^{\circ} \mathrm{C}$, available in the literature, assume the use of so-called negative emissions technologies (Tavoni and Socolow, 2013; Williamson, 2013; UNEP, 2014; UNEP, 2015; Smith et al., 2016) - the active removal and permanent sequestration of $\mathrm{CO}_{2}$ from the atmosphere. This can be achieved, for example, through the combination of bio-energy with carbon capture and storage (Obersteiner et al., 2001). Scenarios with significantly lower amounts of negative emissions exist, but the exclusion of this mitigation option at times renders ambitious climate goals unattainable (IPCC, 2014a; Riahi et al., 2015). The IPCC (2014a) reported that all scenarios currently available that limit warming to below $1.5^{\circ} \mathrm{C}$ by 2100 , require $\mathrm{CO}_{2}$ removal in the second half of the century (see table 3.1). Furthermore, virtually all scenarios currently available in the literature for limiting warming to below $1.5^{\circ} \mathrm{C}$ by 2100 temporarily exceed the $1.5^{\circ} \mathrm{C}$ limit during the $21^{\text {st }}$ century, and, thus, peak and decline temperatures in order to again fall below $1.5^{\circ} \mathrm{C}$ in 
2100. For this to happen at the scale and rate required, global negative emissions are required. A large overshoot can be avoided through strong near-term action.

Important challenges have been identified for negative emissions technologies (Smith et al., 2016) which have to be addressed, for example, the potential competition between biomass and food production over land and water (Bonsch et al., 2016). In most cases, the amounts of bio-energy assumed in scenarios limiting median warming to below $1.5^{\circ} \mathrm{C}$ in 2100 are within the assessed limits of estimated sustainable biomass production, that is, they do not impede on sufficient global food production (Creutzig et al., 2015; Bonsch et al., 2016). However, this can change over time, for example, if local climate impacts happen to be more severe than currently anticipated. Furthermore, in absence of strong local institutions that can provide good governance and prevent illegal deforestation and illegal expropriation, the sustainable potentials might be lower.
Because of uncertainties in availability of future technology, studies have explored how the absence of a specific technology would influence the attainability of temperature goals (Kriegler et al., 2013; Luderer et al., 2013; Rogelj et al., 2013b; Krey et al., 2014; Riahi et al., 2015). These studies focus on a $2^{\circ} \mathrm{C}$ temperature goal, but found that a limitation or absence of bio-energy with carbon capture and storage significantly limits the feasibility of keeping temperature rise to low levels. At the same time, hedging against a strong reliance on bio-energy with carbon capture and storage in the long-term is possible by reducing emissions more steeply in the very near-term, that is, over the coming 5 to 15 years.

Further research that explores the trade-offs and synergies of negative emissions technologies in relation to limiting warming to $1.5^{\circ} \mathrm{C}$ would be extremely valuable.

\section{Box 3.1: Integrated Assessment Models' strengths and opportunities.}

The IPCC defines Integrated Assessment as "a method of analysis that combines results and models from the physical, biological, economic, and social sciences, and the interactions among these components in a consistent framework to evaluate the status and the consequences of environmental change and the policy responses to it" (IPCC, 2014b). Integrated Assessment Models are the models used in such a scientific exercise.

For the study of climate change mitigation scenarios, Integrated Assessment Models often include a representation of: (1) the socioeconomic driving forces, (2) the level of climate change mitigation and, (3) the physics of the climate system to estimate the impact on global temperature rise. To systematically explore socioeconomic driving forces, the research community recently developed a set of five narratives that describe worlds with very differing adaptation and mitigation challenges. These are referred to as the "Shared Socioeconomic Pathways" (O'Neill et al., 2014; O'Neill et al., 2015). Subsequently, these narratives are used to explore if and how stringent mitigation targets can be reached (Riahi et al., in Press).

Most commonly, Integrated Assessment Models are used to create scenarios, which attempt to achieve global mitigation at minimum cost. Such "cost-optimal" (or "least-cost") scenarios let the model decide when (now, in a decade, or at the end of the century) and where (in which geographical region and/or in which sector) emissions are reduced. The model user can also add additional constraints regarding which mitigation technologies are available in the model. Ultimately, the model chooses between different alternatives based on their relative cost, and the social discount rate, which makes investing in the near-term more expensive than in the longer term.

Integrated Assessment Models are powerful tools, which allow the assessment of trade-offs and synergies between various mitigation options. Importantly, Integrated Assessment Model scenarios provide the costs of reducing emissions, for example, the costs to transform the energy system or limit the emissions from land-use and land-use change. However, they typically do not cover the economic and social costs of avoided climate change impacts or side effects. Recent studies have shown that these benefits can be significant and easily outweigh the costs of reducing emissions (West et al., 2013). Furthermore, Integrated Assessment Model scenarios provide detailed technological transformation pathways that allow keeping emissions within a specific limit. Such transformation is often based on our understanding of transformations that took place in the past, like the transition of horse carriages to cars. However, Integrated Assessment Models typically do not contain much information on how to achieve the required pace of transformation in the future. Social science research can help to further understand the determinants and the key steps required to achieve a global low-carbon transition (Geels et al., 2016). 


\subsection{The 2030 emissions gap}

\subsubsection{Overview of scenarios}

To assess the impact of the INDCs ${ }^{2}$ on future global greenhouse gas emissions, global greenhouse gas emissions in 2025 and 2030 are compared under four scenarios (Rogelj et al., 2016). The assessment draws on multiple individual scenarios from the published literature. Each scenario is global in scope, reflecting possible actions from all countries.

- The baseline scenario reflects emission projections that assume no additional climate policies are put in place from 2005 onwards. It is the medium projection estimate from around 180 baseline scenarios from the scenario database that accompanied the Fifth Assessment Report of the IPCC (Clarke et al., 2014).

- The current policy trajectory scenario reflects the best estimates of the global emissions - taking currently adopted and implemented policies into account. Current policy trajectory scenarios assume that no additional mitigation action is taken beyond current climate policies - regardless of whether this results in 2020 Pledges not being achieved or being overachieved. Current policy trajectories reflect all adopted and implemented policies, which for the purpose of this report are defined as legislative decisions, executive orders, or their equivalent. This implies that publicly announced plans or strategies alone would not qualify, while individual executive orders to implement such plans or strategies would qualify. Ultimately, however, these definitions may be interpreted differently in the different underlying studies. This assessment is bound by the interpretations used by individual research groups. The current policy trajectory scenario is based on the current policies scenarios from four ${ }^{3}$ of the ten available global INDC analyses that provide such current policy trajectory scenarios, as detailed in table 3.2.

- The INDC scenario portrays how global greenhouse gas emissions might evolve under full implementation of INDCs. It is sourced from ten global INDC analyses, which updates the work of UNEP (2015), and is described in more detail in Rogelj et al. (2016). The number of INDCs considered by the studies that were assessed here ranges from the 118 INDCs submitted by 1 October 2015 to the 160 INDCs submitted by 12 December 2015 (UNFCCC, 2015a) (table 3. 2). These 118 to 160 INDCs cover emissions from 145 to 187 out of 195 Parties to the UNFCCC, which in turn were responsible for roughly 88 to more than 96 per cent of global greenhouse gas emissions in 2012 (JRC/PBL, 2014). Here, the INDC scenario draws on individual INDC

2 INDCs were submitted before the Paris summit; under the Paris Agreement, future mitigation contributions will be referred to as National Determined Contributions (NDCs), without the 'Intended'.

3 These four groups with current policy scenarios are: (i) the Climate Action Tracker by Climate Analytics, NewClimate Institute, Ecofys and Potsdam Institute for Climate Impact Research; (ii) International Energy Agency; (iii) Joint Research Centre; and (iv) PBL Netherlands Environmental Assessment Agency. The groups from London School of Economics and Danish Energy Agency also have current policy scenarios that are calibrated at the International Energy Agency current policies scenario. scenarios from the ten global analyses (table 3.2). The resulting composite INDC scenario comprises the median, $10^{\text {th }}$ percentile, and $90^{\text {th }}$ percentile global estimates for 2025 and 2030 from all of these sources. Compared to the previous Emissions Gap Report (UNEP, 2015), three new studies have been included (JRC, PNNL and the UNFCCC synthesis Report - see table 3.2), while global estimates of the official or independent country-specific sources have been excluded, since for many countries there was no data available. The official or independent country-specific sources are now only used for the national estimates (Section 3.4).

The INDC scenario comprises unconditional and conditional INDC cases. As discussed in the 2015 Gap Report (UNEP, 2015), some countries place conditions on all or part of their INDCs. Of the INDCs submitted by 12 December 2015, roughly 45 per cent came with both conditional and unconditional components; about a third was conditional only and the remainder did not specify conditions (WRI, 2015). Consequently, two cases are explored in this assessment: unconditional INDCs and conditional INDCs. In the unconditional INDC case, Parties with INDCs are assumed to implement only those portions of their targets without conditions, while Parties that solely have a conditional target are assumed to follow a current policy trajectory. In the conditional INDC case, all Parties with INDCs are assumed to implement their conditional targets, and Parties that only have an unconditional target are assumed to implement that target. In both the unconditional and conditional INDC cases, it is assumed that for any traded international offsets, each unit is counted towards the INDC of a single country only - either the buyer or the seller ${ }^{4}$.

- The $1.5^{\circ} \mathrm{C}$ and $2^{\circ} \mathrm{C}$ scenario represent least-costs global scenarios consistent with a likely chance of limiting warming to below $2^{\circ} \mathrm{C}$ and $1.5^{\circ} \mathrm{C}$ above preindustrial levels. The $2^{\circ} \mathrm{C}$ scenario comprises the subset of scenarios from the Fifth Assessment Report of the IPCC scenario database (Clarke et al., 2014) that: (i) have a greater than 66 per cent chance of keeping global temperature increase to below $2^{\circ} \mathrm{C}$ by 2100 compared to pre-industrial levels, (ii) are consistent with full implementation of 2020 Pledges that are anchored in the Cancun Agreement, and (iii) distribute emission reductions across regions, gases and sectors after 2020 in such a way that global mitigation costs of necessary reductions are minimised. The $1.5^{\circ} \mathrm{C}$ scenario data is selected from the literature and comprises scenarios which: (i) have a greater than 50 per cent chance of keeping

4 This is in line with the intention of countries not to double the count of offsets, which is consistent with the Paris Agreement. 
Table 3.2: Overview of global INDC studies included in the Gap assessment (in alphabetical order). Source: Rogelj et al. (2016).

\begin{tabular}{|c|c|c|c|c|c|}
\hline Reference & $\begin{array}{l}\text { Sector and } \\
\text { gas coverage }\end{array}$ & $\begin{array}{l}\text { Cut-Off Date for } \\
\text { Analysis and } \\
\text { Countries Included }\end{array}$ & $\begin{array}{l}\text { Scenario } \\
\text { coverage }\end{array}$ & $\begin{array}{l}\text { Unconditional } \\
\text { INDC case }\end{array}$ & $\begin{array}{l}\text { Conditiona } \\
\text { INDC case }\end{array}$ \\
\hline $\begin{array}{l}\text { Climate Action Tracker (Climate Action Tracker, } \\
\text { 2015) }\end{array}$ & All & 8 Dec. 2015 & $\begin{array}{l}\text { Current policy } \\
\text { trajectory, INDC }\end{array}$ & $\mathrm{x}$ & $x$ \\
\hline $\begin{array}{l}\text { Climate \& Energy College / University of } \\
\text { Melbourne dataset (Meinshausen, 2015) }\end{array}$ & All & 15 Dec. 2015 & INDC & $x$ & $x$ \\
\hline Climate Interactive (Climate Interactive, 2015) & All & 20 Oct. 2015 & INDC & $x$ & - \\
\hline Danish Energy Agency (DEA, 2015) & All & 8 Dec. 2015 & INDC & $\mathrm{x}$ & - \\
\hline $\begin{array}{l}\text { International Energy Agency - World Energy } \\
\text { Outlook (IEA, 2015) }\end{array}$ & $\mathrm{All}^{\mathrm{a}}$ & 15 Dec. 2015 & $\begin{array}{l}\text { Current policy } \\
\text { trajectory, INDC }\end{array}$ & $x$ & - \\
\hline $\begin{array}{l}\text { Joint Research Centre (JRC) (Kitous and } \\
\text { Keramidas, 2015; Kitous et al., 2016) }\end{array}$ & All & Mid-Oct. 2015 & $\begin{array}{l}\text { Current policy } \\
\text { trajectory, INDC }\end{array}$ & $\mathrm{x}$ & $\mathrm{x}$ \\
\hline $\begin{array}{l}\text { London School of Economics and Political } \\
\text { Science (LSE) (Boyd et al., 2015) }\end{array}$ & All & Mid-Oct. 2015 & INDC & $x$ & $x$ \\
\hline $\begin{array}{l}\text { Pacific Northwest National Laboratory (PNNL) } \\
\text { (Fawcett et al., 2015) }\end{array}$ & All & Mid-Oct. 2015 & INDC & $x$ & - \\
\hline $\begin{array}{l}\text { PBL Netherlands Environmental Assessment } \\
\text { Agency (den Elzen et al., 2016) }\end{array}$ & All & 15 Dec. 2015 & $\begin{array}{l}\text { Current policy } \\
\text { trajectory, INDC }\end{array}$ & $x$ & $\mathrm{x}$ \\
\hline $\begin{array}{l}\text { UNFCCC Synthesis Report on the Aggregate } \\
\text { Effect of INDCs (UNFCCC, 2016e) }\end{array}$ & All & 4 April 2016 & INDC & $\mathrm{x}$ & $\mathrm{x}$ \\
\hline
\end{tabular}

a Only available at the global level. Here the International Energy Agency current policies scenario is used.

global temperature increase to below $1.5^{\circ} \mathrm{C}$ by 2100 compared to pre-industrial levels, (ii) have emissions in 2020 above 53 gigatonnes $\mathrm{CO}_{2}$ equivalent $\left(\mathrm{GtCO}_{2} \mathrm{e}\right)$ per year, and (iii) distribute emission reductions across regions, gases and sectors after 2020 in such a way that global mitigation costs of necessary reductions are minimised (Rogelj et al., 2015).

The studies from which the current policy trajectory scenario and the INDC scenario are drawn differ in a number of ways, such as: conditional versus unconditional INDCs; assumptions regarding non-covered sectors and gases; treatment of land use, land-use change and forestry (LULUCF) and surplus emission units; different bases for calculating Global Warming Potentials (table 3.2). The methodological differences between the groups cannot be fully harmonized, which leads to some uncertainty as indicated in the results presented in Section 3.4, where the implications of the differences between studies are also further explored.

Table 3.3: Global total greenhouse gas emissions in 2025 and 2030 under different scenarios (median and $10^{\text {th }}$ to $90^{\text {th }}$ percentile range). Ranges are computed as described in Rogelj et al. (2016). In cases where estimates are based on less than 10 scenarios, the minimum-maximum range is provided. The row of "Conditional INDCs" is only provided for information, as a direct comparison with the "Unconditional INDCs" ranges is not possible due to arbitrary model sampling differences. Source: Rogelj et al. (2016).

\begin{tabular}{|l|l|l|l|}
\hline Emissions estimates $\left(\mathrm{GtCO}_{2} \mathrm{e} /\right.$ year) & Global total emissions in $\mathbf{2 0 2 5}$ & Global total emissions in $\mathbf{2 0 3 0}$ & Number of scenarios in set \\
\hline Scenario & $61.0(56.7-64.3)$ & $64.7(59.5-69.5)$ & 179 \\
\hline Baseline & $56.2(54.8-59.4)$ & $59.4(57.9-63.1)$ & 3 \\
\hline Current policy trajectory & $53.9(50.6-56.3)$ & $55.5(51.9-57.5)$ & 10 \\
\hline Unconditional INDCs & $53.0(49.3-54.9)$ & $53.4(49.5-54.7)$ & $10(6+4)$ \\
\hline Conditional INDCs $^{\mathrm{a}}$ & $47,7(46.2-50.2)$ & $41.8(30.6-43.5)$ & 10 \\
\hline $\mathbf{2}^{\circ}$ p pathways $^{\mathrm{b}}$ (least-cost from 2020) & $47.2(45.8-48.2)$ & $38.8(37.7-40.0)$ & 6 \\
\hline $\mathbf{1 . 5}^{\circ} \mathrm{C}^{\text {pathways }}{ }^{\mathrm{c}}$ (least-cost from 2020) & & & \\
\hline
\end{tabular}

a Assuming full implementation of both unconditional and conditional INDCs. Six studies provided an estimate for the conditional INDC case. The median estimate of influence derived from these six studies is used to adjust the unconditional INDC estimate of the four remaining studies that did not include conditional INDC estimates. The estimated improvement of moving from the unconditional to the conditional case is in the range of $2.4\left(1.2-4.8 \mathrm{GtCO}_{2}\right.$ e per year full range).

${ }^{b}$ As in UNEP (2015): limiting global average temperature increase to below $2^{\circ} \mathrm{C}$ with greater than 66 per cent probability in 2100 (probabilities never drop below 60 per cent during the entire century).

As in UNEP (2015): limiting global average temperature increase to below $1.5^{\circ} \mathrm{C}$ with greater than 50 per cent probability in 2100 (allowing median temperatures to exceed the $1.5^{\circ} \mathrm{C}$ limit during some period before 2100 ). 


\subsubsection{The effect of INDCs on global greenhouse gas emissions}

This section presents the findings regarding the aggregate effect on total global greenhouse gas emissions of full implementation of the INDCs in 2025 and 2030, compared to the emissions implied by baseline, current policy trajectory, and $2^{\circ} \mathrm{C}$ and $1.5^{\circ} \mathrm{C}$ scenarios. The results are shown in table 3.3 and figure 3.1 .
It is apparent from figure 3.1 that current policies lead to emissions that are markedly lower than the baseline, which assumes that no additional climate policies are put in place from 2005. This indicates that the baseline will become increasingly less useful as a reference case.

Figure 3.1: Global greenhouse gas emissions under different scenarios and the emissions gap in 2030.

Annual Global Total Greenhouse Gas Emissions $\left(\mathrm{GtCO}_{2} \mathrm{e}\right)$

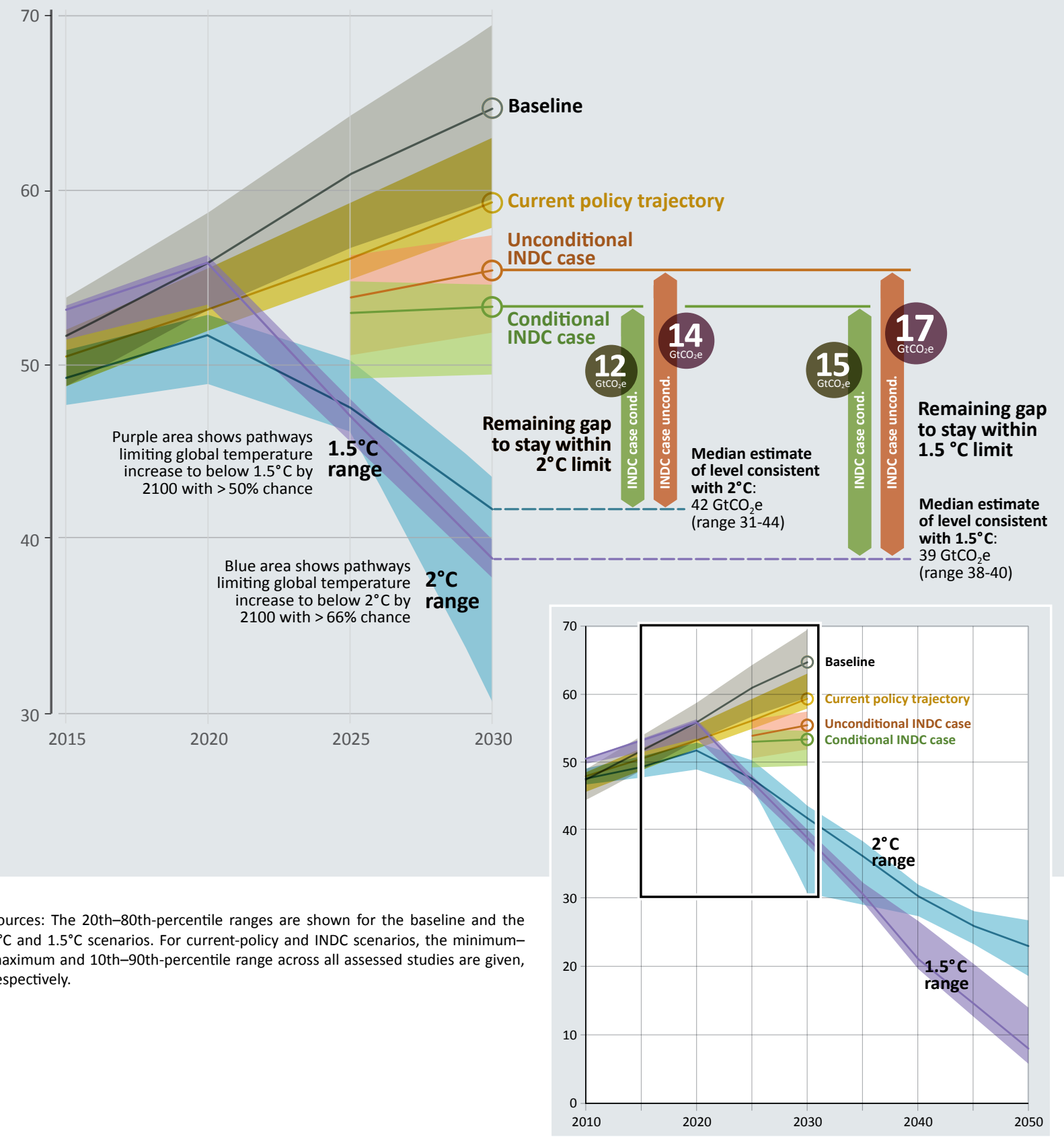


Figure 3.1 shows that full implementation of the unconditional INDCs will reduce global greenhouse gas emissions in 2030 by $9 \mathrm{GtCO}_{2} \mathrm{e}$ (range: 7-13) relative to the median no-policy baseline, and by $4 \mathrm{GtCO}_{2} \mathrm{e}^{5}$ (range: 2-7) relative to the median current policy trajectory. Comparing these cost-optimal $2^{\circ} \mathrm{C}$ and $1.5^{\circ} \mathrm{C}$ scenarios to the unconditional INDC projections shows a large discrepancy. More specifically, there is a gap in 2030 of $14 \mathrm{GtCO}_{2} \mathrm{e}$ (range: 10-16) between the unconditional INDC scenario and the $2^{\circ} \mathrm{C}$ scenario. Comparing the unconditional INDC scenario with the $1.5 \mathrm{C}$ scenario further increases the gap by $3 \mathrm{GtCO}_{2} \mathrm{e}$, which is in the same order as found in UNFCCC (2016e).

In comparison, if countries were to also fully implement the conditional INDCs, estimated global greenhouse gas emissions in 2030 would end up about $2.4 \mathrm{GtCO}_{2}$ e (range: 1.2-4.8) lower in 2030 compared to the unconditional INDC scenario case. This leaves a gap in 2030 of 12 (8-13) $\mathrm{GtCO}_{2} \mathrm{e}$ between the conditional INDC scenario and the cost-optimal $2^{\circ} \mathrm{C}$ scenario. Comparing the conditional INDC scenario with the $1.5^{\circ} \mathrm{C}$ scenario increases the gap by $3 \mathrm{GtCO}_{2} \mathrm{e}$.

For a number of countries, the INDC targets suggest emission levels above their estimated no-policy baseline or current policy scenario. These countries are, thus, expected to overachieve their INDC targets (see Section 3.4 for further details on G20 members). Different model teams treat these surpluses in different ways, which adds an uncertainty of $1 \mathrm{GtCO}_{2} \mathrm{e}$ (range: $0-1$ ) by 2030 to the estimated INDC and gap projections here.

The gap calculations assume that there is no double counting of reductions. In other words, transferred reductions are only counted towards the achievement of one country's INDCs, not towards both the country buying and selling. However, as the Paris Agreement allows the possibility of voluntary use of "internationally transferred mitigation outcomes", it is possible that a system of trading offset credits will be developed and used. This could imply a risk of double counting, which could increase the global emissions by 2030 by $0.8 \mathrm{GtCO}_{2} \mathrm{e}$ in the unconditional and conditional INDC case $^{6}$.

\subsubsection{The carbon budget implications of INDCs}

To give an indication of the carbon budget implications of the INDC scenarios, figure 3.2 shows the cumulative $\mathrm{CO}_{2}$ emissions implied by the INDC scenarios until 2030. Figure 3.2 shows that under the INDC scenarios, the IPCC $\mathrm{CO}_{2}$ budget for limiting warming to below $2^{\circ} \mathrm{C}$ with at least 66 per cent probability will be close to depleted by 2030 , and the IPCC $\mathrm{CO}_{2}$ budget in line with limiting warming to below $1.5^{\circ} \mathrm{C}$ with at least 50 per cent probability will already be well exceeded by 2030 . The figure also illustrates the limited $\mathrm{CO}_{2}$ budget

5 The gap numbers and ranges in the text are rounded to the nearest gigatonne.

6 Consistent with the earlier analysis of double counting in the UNEP 2014 Emissions Gap Report, for the INDC cases it is assumed that international emission offsets could account for 33 per cent of the difference between current policies trajectory and emission levels for the INDC cases by 2030 for the Organisation for Economic Cooperation and Development (OECD) countries. This is an arbitrary, conservative estimate, as many Parties have yet to specify any limits to the use of transferable units. implications of the INDC scenarios compared to the current policy scenario. If the $\mathrm{CO}_{2}$ budget is exceeded, negative emissions at a global scale are required to capture the excess $\mathrm{CO}_{2}$. As highlighted in Section 3.2, limitations or absence of negative emissions technologies would significantly limit the feasibility of keeping temperature rise to low levels in 2100. Steep emission reductions would be required over the coming 5 to 15 years to hedge against a strong reliance on negative emissions technologies later in this century.

\subsubsection{The global temperature effect of INDCS}

Estimates of what level of temperature increase the implementation of the INDCs would result in depends on the assumptions made about what happens after 2030, and the probability assigned to the temperature increase. The Paris Agreement indicates that consecutive National Determined Contributions (NDCs) have to represent a progression over time. Here, the same approach is adopted as in a recent study (Rogelj et al., 2016) which assumes that, as a minimum, this entails that the level of climate mitigation effort implied by the actions to achieve INDCs by 2030 is continued after 2030, until the end of the century ${ }^{7}$. Under these assumptions, the full implementation of the unconditional INDCs is consistent with staying below an increase in temperature of $3.2^{\circ} \mathrm{C}$ (median, range: $2.9-3.4^{\circ} \mathrm{C}$ ) by 2100 relative to pre-industrial levels with greater than 66 per cent probability. This is lower than current policies, which imply staying below an increase of $3.6^{\circ} \mathrm{C}$ (median, range: $3.4-3.7^{\circ} \mathrm{C}$ ) by 2100 with greater than 66 per cent probability. Full implementation of the conditional INDCs would lower the temperature projections relative to the unconditional INDCs by about $0.2^{\circ} \mathrm{C}$.

\subsection{Understanding the mitigation efforts of the INDCs - A closer look at G20 members}

This section presents country-specific findings for the members of the $\mathrm{G}^{2} \mathrm{O}^{8}$. As mentioned in Chapter 2, these economies, collectively, generate around three quarters of global greenhouse gas emissions, and their emission levels and INDCs have the largest impact on the aggregate, global findings of this assessment.

\subsubsection{Overview of scenarios}

For each of the $\mathrm{G} 20$ members, median emission projections resulting from the full implementation of the INDC are calculated. The calculation is based on the same data as in the 2015 Emissions Gap Report (UNEP, 2015), complemented with data from two new studies of the Joint Research Centre (Kitous et al., 2016) and Pacific Northwest National

7 "Continued effort" in this context is approximated by estimating the global carbon price implied by the INDCs in 2030 and projecting this price further until the end of the century in a way consistent with the scenarios available in the Fifth Assessment Report of the IPCC Working Group III Scenario Database. See Rogelj et al. (2016) for a detailed description of the method.

8 The members of the G20 are: Argentina, Australia, Brazil, Canada, China, France, Germany, India, Indonesia, Italy, Japan, Republic of Korea, Mexico, Russia, Saudi Arabia, South Africa, Turkey, the United Kingdom (UK), the United States of America (USA), and the European Union (EU). In our analysis, the EU including all its Member States (regardless of G20 status) is considered as a single Party, and EU Member States are not considered individually. 
Figure 3.2: Comparison of projected emissions by 2030 and alltime $1.5^{\circ} \mathrm{C}$ and $2{ }^{\circ} \mathrm{C}$ carbon budgets. Cumulative global total carbon dioxide emissions for the conditional INDC case, the unconditional INDC case and the current policies scenario, and carbon budgets from the Fifth Assessment Report of the Intergovernmental Panel on Climate Change (IPCC AR5) (IPCC, 2014a). The carbon budget ranges show the values based on the range of scenarios assessed by Working Group III (IPCC, 2014b). The solid horizontal line at $1,000 \mathrm{GtCO}_{2}$ shows the estimate based on complex Earth-System Models, assessed by Working Group I (IPCC, 2014a). Historical emissions until 2015 are based on Le Quéré et al. (2015).
Cumulative $\mathrm{CO}_{2}$ emissions 2011-2030 $\left[\mathrm{GtCO}_{2}\right]$

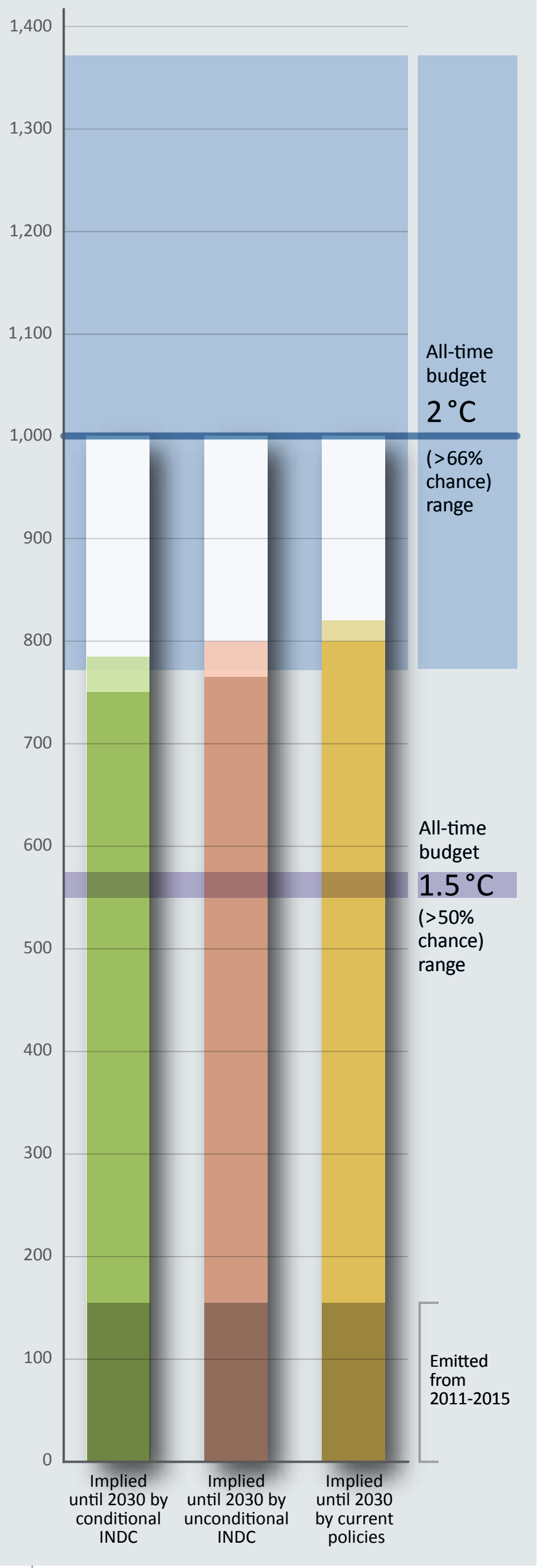


Laboratory (Fawcett et al., 2015), and with estimates for the three G20 economies, Argentina, Saudi Arabia and Turkey, that were not included in the previous Emissions Gap Report. More specifically, the data is sourced from:

(i) The official estimates included in the INDCs (UNFCCC, 2016a).

(ii) Calculations based on the INDCs and other documents submitted by countries to the UNFCCC (such as national greenhouse gas inventories, national communications, biennial reports, and biennial update reports).

(iii) Estimates published in country-specific studies.

(iv) Eight independent global analyses ${ }^{9}$, described further in detail in table 3.4.

Figure 3.3 presents the greenhouse gas emission projections for G20 economies for current policy trajectories, and for unconditional and conditional (in the case of India, Indonesia and Mexico) INDC cases for 2030, noting that for the United States of America (USA), the 2025 unconditional
INDC is shown. The Figure provides an indication of whether or not a country needs to implement policies additional to the current policy trajectory to meet its INDC target, but does not attempt to indicate the level of ambition of the INDC targets. It is also important to note that the current policy trajectory scenarios, which attempt to reflect the most recent mitigation policies, differ from the baseline or business as usual (BAU) scenarios employed by some countries, which typically assume that no new policies are adopted or implemented after a given cut-off year.

Figure 3.3 shows that for many countries the implementation of their INDC would lead to lower emissions than the current policies scenario, or in other words that additional policies would have to be implemented to meet the INDC target.

However, it should be noted that additional research is necessary, as the uncertainty ranges overlap for many countries and since the number of studies available for the current policy trajectory case and the INDC cases vary significantly.

Figure 3.3: Greenhouse gas emissions (all gases and sectors) of the G20 economies, and G20 as a whole, by 2030 for the business as usual (BAU) emissions projection from the INDC submission (third bar), for the current policies scenario from official and national studies (fourth bar), from global model studies used for our analysis (fifth bar), for the unconditional INDC scenario (sixth bar), and for the conditional INDC scenario (seventh bar). The uncertainty ranges are explained in the main text. For reporting reasons, the emissions projections for China, EU, India and USA are shown in panel (a), and the other countries in panel (b), with different vertical axes. The Figure also shows the number of studies underlying the estimate (if available) for the last four bars: current policies (national studies), current policies (all studies) and the unconditional INDC and conditional INDC (all studies).

\section{Figure 3.3a}

Emissions ( $\mathrm{GtCO}_{2} \mathrm{e} /$ year)

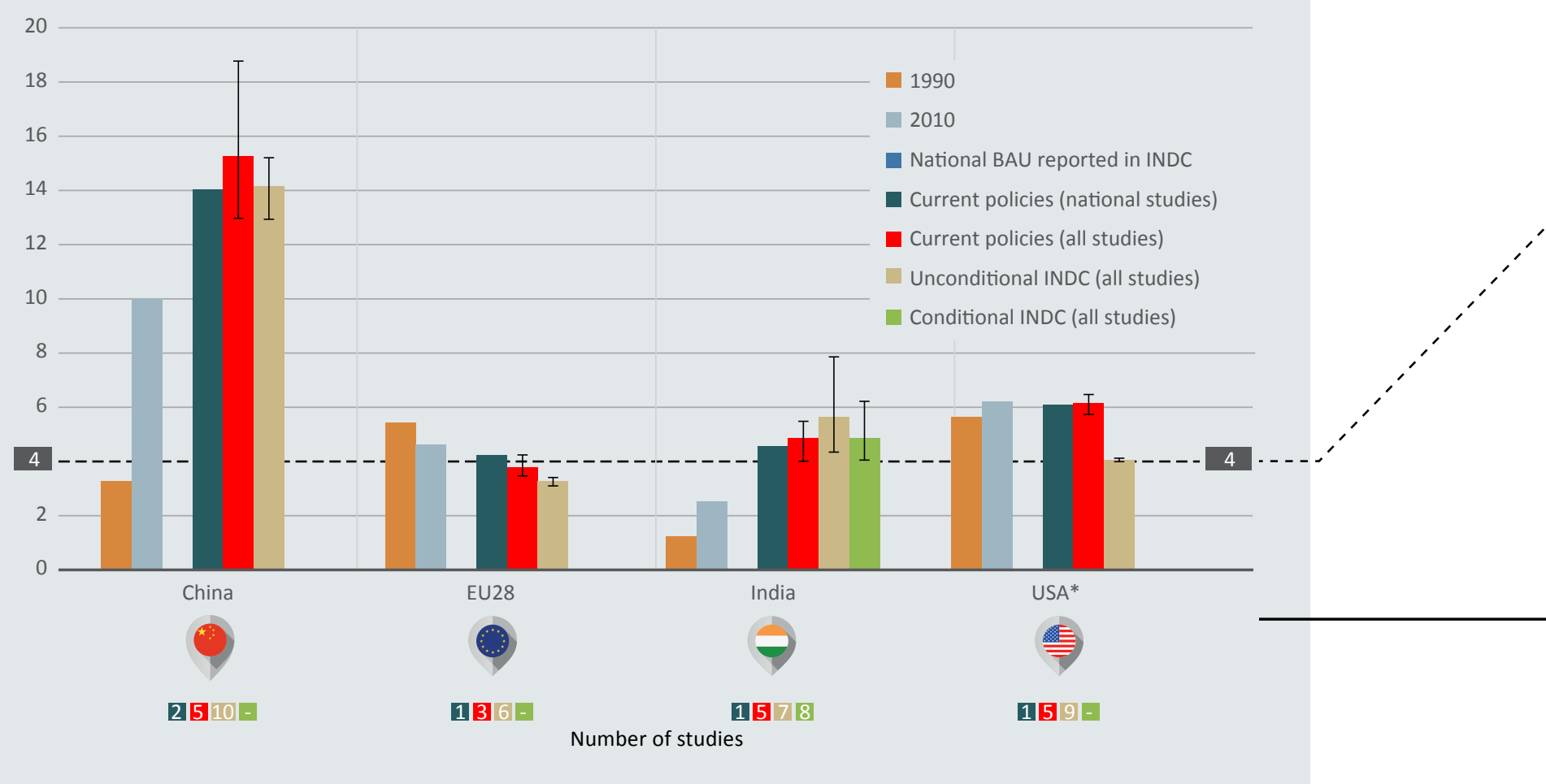

* For USA unconditional INDC is for 2025.

9 The UNFCCC synthesis report and the Danish Energy Agency study are excluded here, as these studies do not provide national estimates. 


\subsubsection{The effect of INDCs on G20 members' greenhouse gas emissions}

Cross-cutting information regarding national emissions (relative to various base years), emissions per gross domestic product and emissions per capita for G20 economies is summarised in figures $3.4 \mathrm{a}-\mathrm{c}$. The projections of the latter two indicators are influenced by many factors. For example, economic and population growth will generally result in an increase in emissions, while energy intensity improvements in the global economy and reductions of carbon intensity in energy production will generally result in a decrease in emissions. The population and the gross domestic product projections are based on the medium UN population scenario and the International Energy Agency World Energy Outlook Report 2014 (IEA, 2014) - if available for the selected countries - and the Shared Socioeconomic Pathways database (scenario SSP2) (Dellink et al., 2016), which is consistent with the current policies scenarios.

Figure 3.4a illustrates the change in emissions by 2030 compared to different historical years - 1990 and 2010, the most recent year for which comprehensive data is available. It indicates that the various countries have had different phases of rapid emissions increase.

Figure 3.4b illustrates the wide range of likely per capita emissions in 2030. It also illustrates a general trend that countries starting from a lower base level in 2010 tend to increase more by 2030.
Figure $3.4 \mathrm{c}$ shows the emissions intensity of the economies. This is useful as an indicator of the extent to which INDCs lead to a convergence in emissions intensity among countries, and to a decoupling of economic growth and emissions. As figure 3.4b shows, emissions per capita are projected to decline between 2010 and 2030 in all G20 economies except Argentina, China, India, the Russian Federation, Saudi Arabia and Turkey, as a result of the implementation of unconditional INDCs. At the same time, income levels are projected to increase in this time period, indicating a decoupling of economic growth and greenhouse gas emissions. In total, decoupling is projected for 15 to 16 of the $\mathrm{G} 20$ economies, depending on the conditionality of their INDCs. Only Turkey shows an increase in emission per gross domestic product. The largest reductions are projected for countries with the highest emission intensities in 2010, such as Brazil, China, and Indonesia. Furthermore, emission intensities of all G20 economies are projected to lead to levels between about 200 and 900 tonnes $\mathrm{CO}_{2} \mathrm{e}$ per million US\$ in 2030, independent of these countries' emission intensity levels in 2010 and income levels in 2030. This convergence, again, reflects a decoupling of economic growth and greenhouse gas emissions.

Providing an assessment of whether the magnitude of change in these indicators as a result of INDCS is consistent with ambition and fairness requires explicit benchmarking across alternative normative indicators of burden-sharing, and is beyond the scope of the Emissions Gap Report.

\section{Figure 3.3b}

Emissions $\left(\mathrm{GtCO}_{2} \mathrm{e} /\right.$ year)

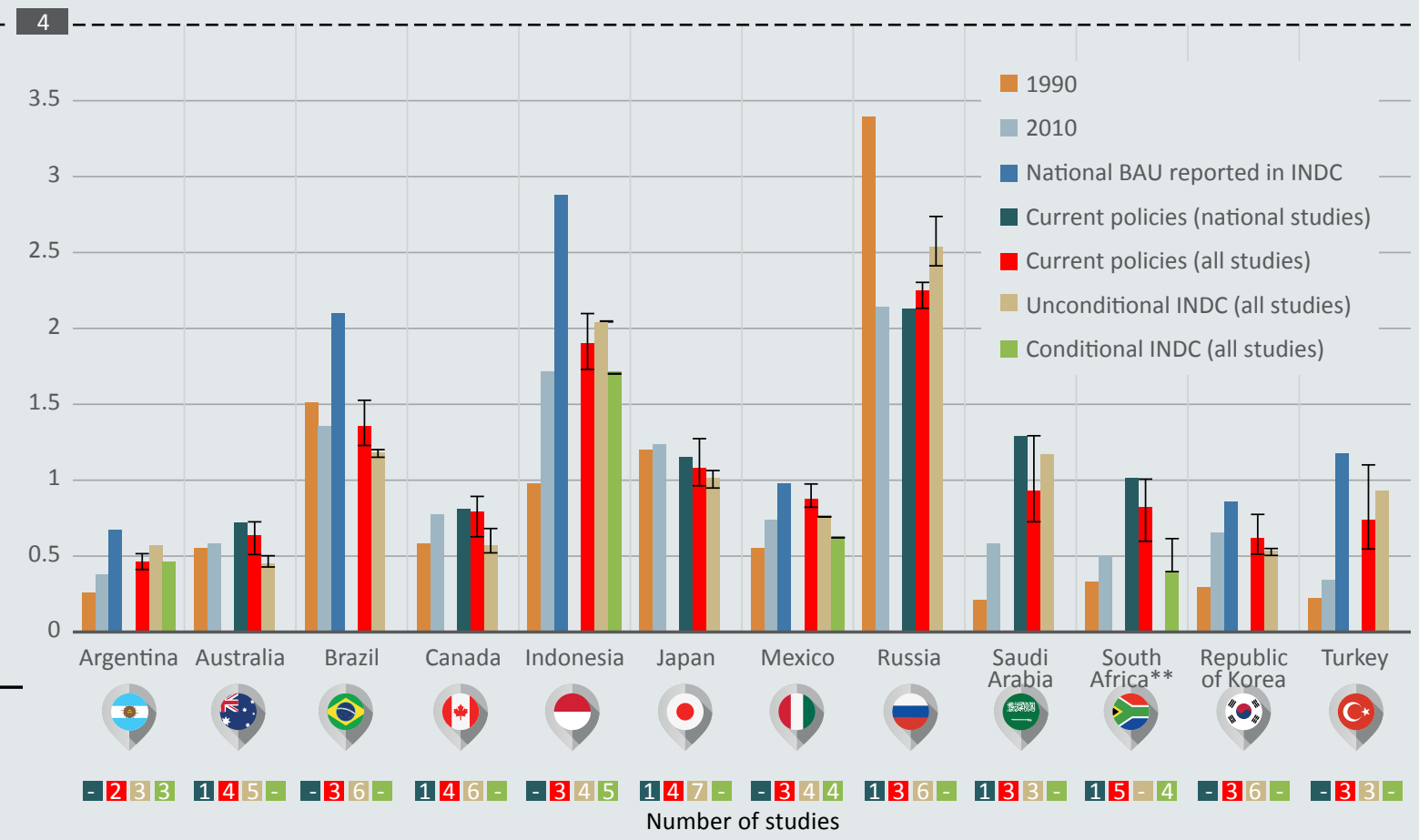

** South Africa's INDC is based on an emissions trajectory with an emissions range of 398-614 MtCO e including LULUCF over the period $2025-2030$. 
Table 3.4: Overview of INDC studies included in the G20 member assessment by type of source (in alphabetical order).

\begin{tabular}{|c|c|c|c|}
\hline Reference & Geographic coverage & $\begin{array}{l}\text { Sector and } \\
\text { gas coverage }\end{array}$ & $\begin{array}{l}\text { Scenario } \\
\text { coverage }\end{array}$ \\
\hline \multicolumn{4}{|l|}{ Global INDC analyses } \\
\hline $\begin{array}{l}\text { Climate Action Tracker (Climate Action Tracker, } \\
\text { 2015) }\end{array}$ & All G20 economies included & All & $\begin{array}{l}\text { Current policy } \\
\text { trajectory, INDC }\end{array}$ \\
\hline $\begin{array}{l}\text { Climate \& Energy College / University of } \\
\text { Melbourne dataset (Meinshausen, 2015) }\end{array}$ & All G20 economies included & All & INDC \\
\hline Climate Interactive (Climate Interactive, 2015) & $\begin{array}{l}\text { About nine countries, that is: Australia, Canada, EU, } \\
\text { India, Japan, Mexico, Russia, Republic of Korea, USA }\end{array}$ & All & INDC \\
\hline $\begin{array}{l}\text { International Energy Agency - World Energy } \\
\text { Outlook (IEA, 2015) }\end{array}$ & China, India & $\begin{array}{l}\mathrm{CO}_{2} \text { from } \\
\text { energy use }^{\mathrm{b}}\end{array}$ & $\begin{array}{l}\text { Current policy } \\
\text { trajectory, INDC }\end{array}$ \\
\hline $\begin{array}{l}\text { Joint Research Centre (JRC) (Kitous and } \\
\text { Keramidas, 2015; Kitous et al., 2016) }\end{array}$ & All G20 economies included & All & $\begin{array}{l}\text { Current policy } \\
\text { trajectory, INDC }\end{array}$ \\
\hline $\begin{array}{l}\text { London School of Economics and Political } \\
\text { Science (LSE) (Boyd et al., 2015) }\end{array}$ & All G20 economies, except Australia & All & INDC \\
\hline $\begin{array}{l}\text { Pacific Northwest National Laboratory (PNNL) } \\
\text { (Fawcett et al., 2015) }\end{array}$ & China, India, Russia ${ }^{c}$ & All & INDC \\
\hline $\begin{array}{l}\text { PBL Netherlands Environmental Assessment } \\
\text { Agency (den Elzen et al., 2016) }\end{array}$ & All G20 economies included & All & $\begin{array}{l}\text { Current policy } \\
\text { trajectory, INDC }\end{array}$ \\
\hline \multicolumn{4}{|l|}{ Official country-specific data sources } \\
\hline Australian Government (2015) & Australia & All & $\begin{array}{l}\text { Current policy } \\
\text { trajectory }\end{array}$ \\
\hline $\begin{array}{l}\text { Biennial Report/Biennial Update Report } \\
\text { (UNFCCC, 2016b) }^{\text {a }}\end{array}$ & $\begin{array}{l}\text { Brazil, Japan, Norway, Republic of Korea, Russia and } \\
\text { Switzerland }\end{array}$ & Varies & $\begin{array}{l}\text { Current policy } \\
\text { trajectory }\end{array}$ \\
\hline Department of Environmental Affairs (2014) & South Africa & All & $\begin{array}{l}\text { Current policy } \\
\text { trajectory, INDC }\end{array}$ \\
\hline EEA (2014) & EU & All & $\begin{array}{l}\text { Current policy } \\
\text { trajectory }\end{array}$ \\
\hline Government of Canada (2014) & Canada & All & $\begin{array}{l}\text { Current policy } \\
\text { trajectory }\end{array}$ \\
\hline INDCs (UNFCCC, 2016a) & $\begin{array}{l}\text { Argentina, Brazil, Japan, Mexico, Republic of Korea, } \\
\text { South Africa, Turkey and the USA }\end{array}$ & Varies & INDC \\
\hline National Climate Change Strategy (2013) & Mexico & All & $\begin{array}{l}\text { Current policy } \\
\text { trajectory }\end{array}$ \\
\hline $\begin{array}{l}\text { National Communications (UNFCCC, 2016c; } \\
\text { UNFCCC 2016d) }\end{array}$ & Indonesia, USA & Varies & INDC \\
\hline \multicolumn{4}{|l|}{ Independent country-specific data sources } \\
\hline $\begin{array}{l}\text { Centre for Policy Research (Dubash et al., } \\
\text { 2015) }\end{array}$ & India & $\mathrm{CO}_{2}$ & $\begin{array}{l}\text { Current policy } \\
\text { trajectory }\end{array}$ \\
\hline Climate Advisers (Belenky, 2015) & USA $^{\mathrm{a}}$ & All & $\begin{array}{l}\text { Current policy } \\
\text { trajectory, INDC }\end{array}$ \\
\hline $\begin{array}{l}\text { Energy Research Institute Low carbon } \\
\text { scenarios (based on Jiang et al., 2013) }\end{array}$ & China & $\mathrm{CO}_{2}{ }^{\mathrm{d}}$ & $\begin{array}{l}\text { Current policy } \\
\text { trajectory, INDC }\end{array}$ \\
\hline $\begin{array}{l}\text { Indian Institute of Management, Ahmedabad } \\
\text { (Garg et al., 2014) }\end{array}$ & India & All & $\begin{array}{l}\text { Current policy } \\
\text { trajectory }\end{array}$ \\
\hline $\begin{array}{l}\text { Institut du Développement Durables et des } \\
\text { Relations Internationales (Garg et al., 2014) }\end{array}$ & Japan & All & INDC \\
\hline $\begin{array}{l}\text { King Abdullah University of Science and } \\
\text { Technology, (2014) }\end{array}$ & Saudi Arabia & $\mathrm{CO}_{2}^{\mathrm{d}}$ & $\begin{array}{l}\text { Current policy } \\
\text { trajectory }\end{array}$ \\
\hline $\begin{array}{l}\text { National Center for Climate Strategy and } \\
\text { International Cooperation (Sha et al., 2015) }\end{array}$ & China & $\mathrm{CO}_{2}^{\mathrm{d}}$ & INDC \\
\hline World Resources Institute (Kuramochi, 2014) & Japan & All & INDC \\
\hline $\begin{array}{l}\text { World Resources Institute (Hausker et al., } \\
\text { 2015) }\end{array}$ & USA & All & $\begin{array}{l}\text { Current policy } \\
\text { trajectory, INDC }\end{array}$ \\
\hline
\end{tabular}

${ }^{a}$ Compared to last year, we have deleted the INDC estimate of China for the studies Climate Interactive and Climate Advisers because of data inconsistency, but this does not affect the INDC estimate of China, as the number of studies included is still 10 (instead of 12).

${ }^{b}$ Augmented with US Environmental Protection Agency (2012), JRC/PBL (2014) and den Elzen et al. (2015) to produce economy-wide figures.

${ }^{C}$ Not all countries' projections of the studies are included for this analysis.

${ }^{d}$ Augmented with Tavoni et al. (2015) and Government of China (2012) to produce economy-wide figures. 
Figure 3.4: Greenhouse gas emissions for the INDCs for G20 members relative to 2010 levels (a), per capita emissions (b), emission intensity of the economy (that is, emissions per unit of real gross domestic product - US\$2005) (c).

Figure 3.4a: Greenhouse gas emissions relative to base year (in percentage) for G20 members under the INDCs in 2030.

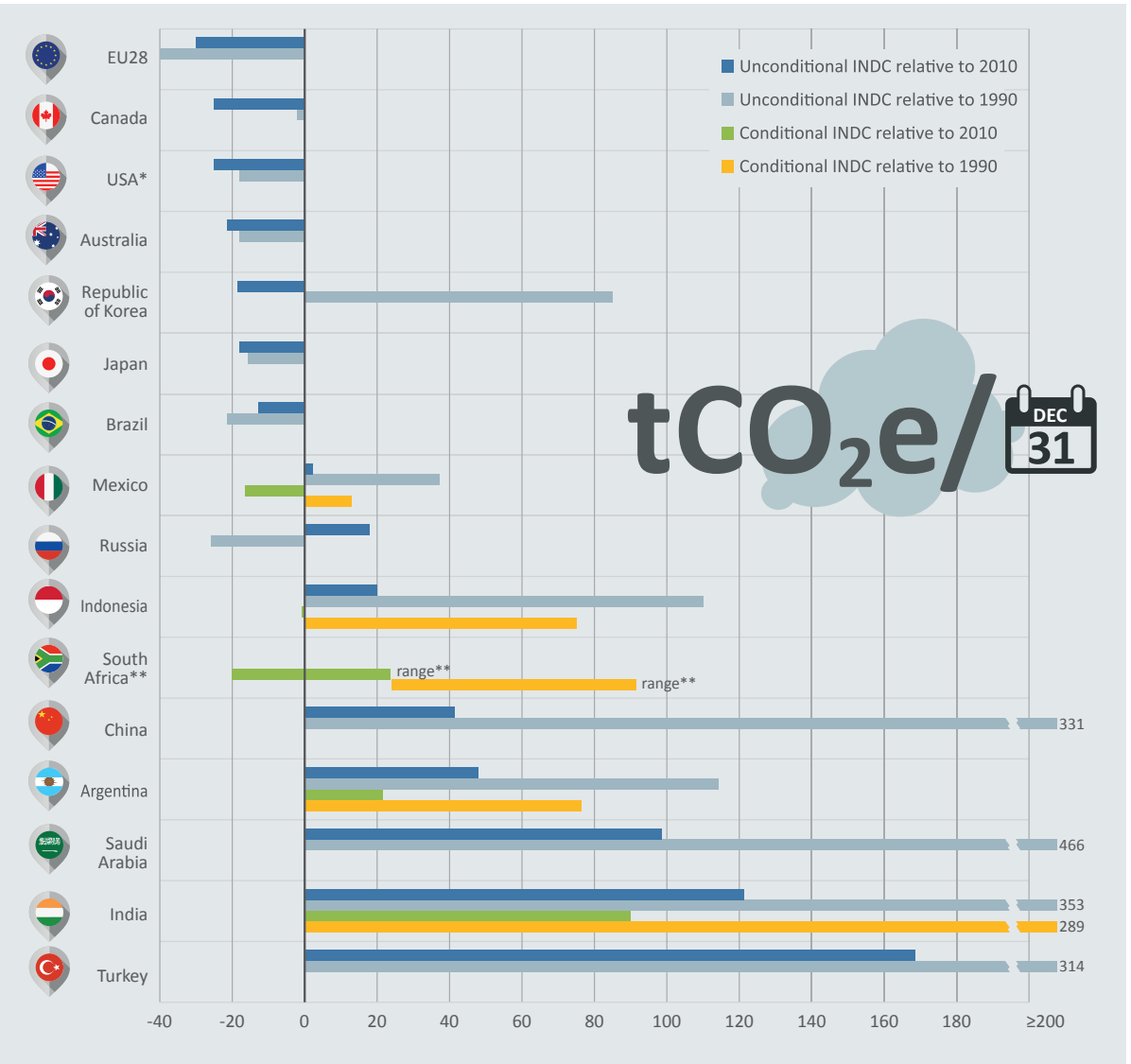

Figure 3.4b: Greenhouse gas emissions per capita for $\mathrm{G} 20$ members under the INDCs in 2030 ( $\left.\mathrm{tCO}_{2} \mathrm{e} / \mathrm{capita}\right)$.

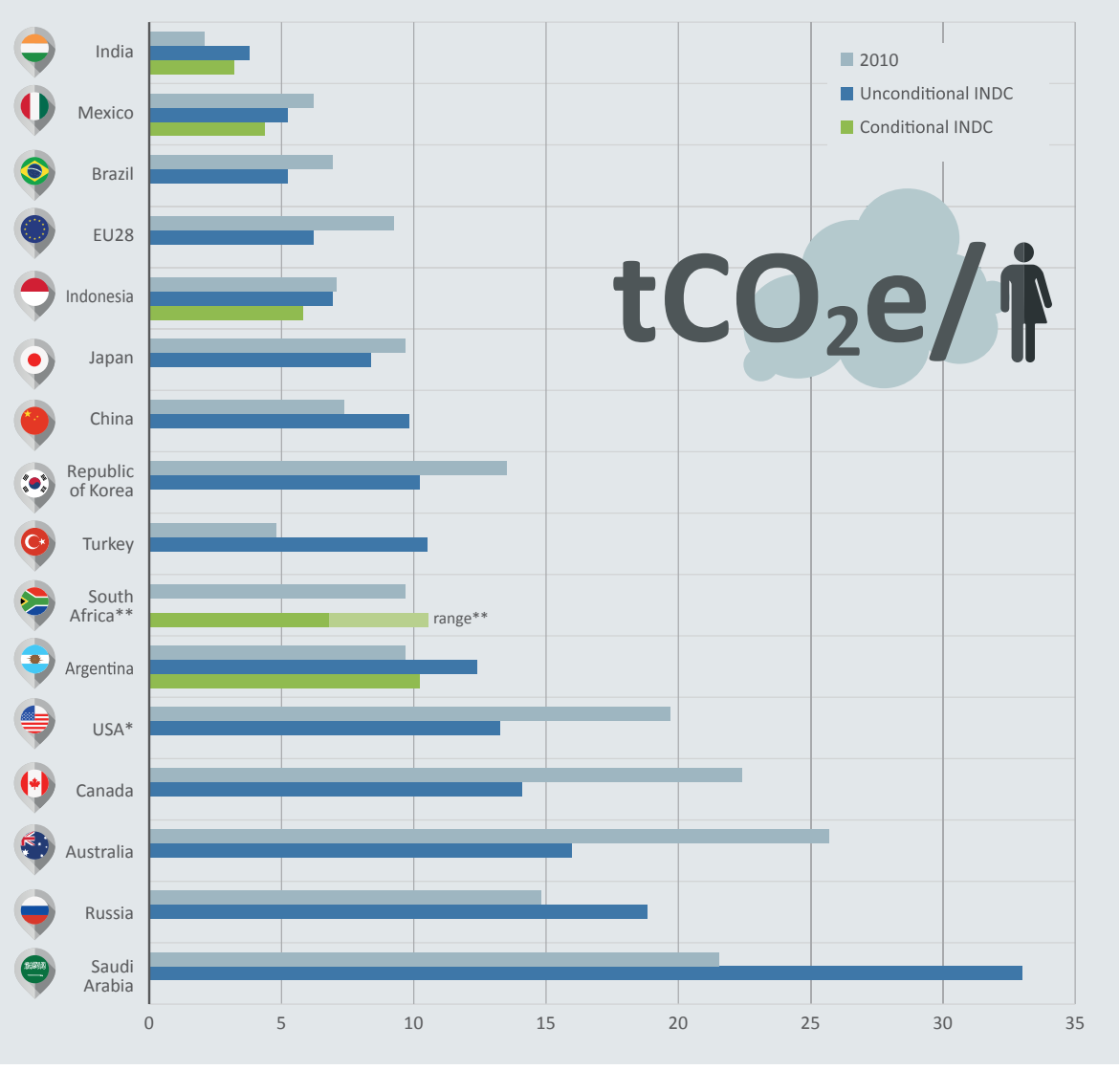

* For USA unconditional INDC is for 2025.

** South Africa's INDC is based on an emissions trajectory with an emissions range of $398-614 \mathrm{MtCO}_{2} \mathrm{e}$ including LULUCF over the period 2025-2030. 
Figure 3.4c: Greenhouse gas emissions per unit of gross domestic product (US\$2005) for G20 members under the INDCs in 2030 (in $\mathrm{MtCO}_{2} \mathrm{e} /$ US\$ billion).

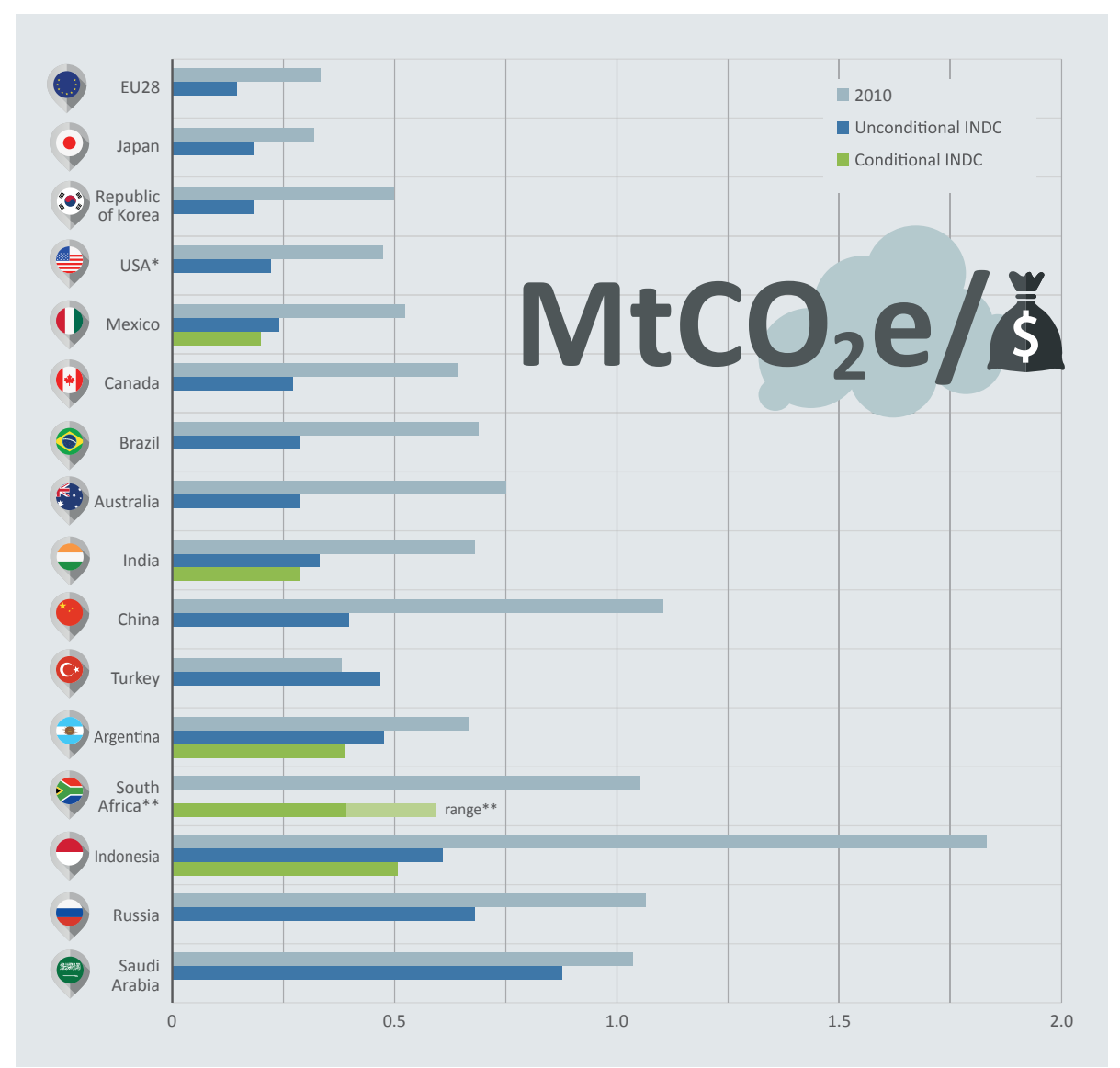

* For USA unconditional INDC is for 2025.

** South Africa's INDC is based on an emissions trajectory with an emissions range of 398-614 $\mathrm{MtCO}_{2} \mathrm{e}$ including LULUCF over the period $2025-2030$.

However, a number of recent studies attempt this task using a range of different effort-sharing allocations according to different equity principles (Climate Action Tracker, 2015; Climate Equity Reference Project, 2015; Meinshausen et al., 2015; Hof et al., 2016). These include studies that explicitly draw on the data from the IPCC effort-sharing allocation database (Höhne et al., 2014), which comprises data from many effort-sharing studies reviewed for the IPCC.

\subsection{Summary of findings}

The decisions of the Paris Agreement on "well below $2^{\circ} \mathrm{C}$ " and "pursuing efforts to limit temperature increase to $1.5^{\circ} \mathrm{C}$ " requires a redefinition of the emissions gap. Moving from $2^{\circ} \mathrm{C}$ to $1.5^{\circ} \mathrm{C}$ increases the gap by around $3 \mathrm{GtCO}_{2} \mathrm{e}$ in 2030 with significantly more stringent emissions reductions required afterwards.

INDCs are a first start to initiate this required transition, but are still far from being in line with the agreed long-term goals. Ambition of the existing INDCs, with target years through 2030, would have to be increased. Continuing on the emissions trajectory implied by the current INDCs would mean that the budget for $1.5^{\circ} \mathrm{C}$ is already overspent by 2030 , and the budget for $2^{\circ} \mathrm{C}$ is almost depleted. Due to the pathdependence of technology and the risk of lock-in, the earlier these targets are enhanced, the easier and less costly it will be to achieve them. The more ambitious early mitigation is, the less the world will have to rely on socially contested negative emissions technologies and high-cost emission reduction options in the future.

The estimates of the emission levels that would be realised under full implementation of the INDCs have not changed significantly compared to last year's report. Countries show wide differences in the need to implement additional policies to meet their INDCs. In general, differences of per capita emissions and emission intensity narrow (with some exceptions), but these levels are still well above the global average level needed to be compatible with a $1.5^{\circ} \mathrm{C}$ or $2^{\circ} \mathrm{C}$ temperature target. 


\section{Chapter 4}

\section{Bridging the gap - the role of non-state action}

Lead authors: Niklas Höhne (NewClimate Institute) and Philip Drost (United Nations Environment Programme)

Contributing authors: Fatemeh Bakhtiari (UNEP DTU Partnership), Sander Chan (German Development Institute), Ann Gardiner (Ecofys), Thomas Hale (University of Oxford - Blavatnik School of Government), Angel Hsu (Yale University - Yale School of Forestry and Environmental Studies), Takeshi Kuramochi (NewClimate Institute), Daniel Puig (UNEP DTU Partnership), Mark Roelfsema (PBL Netherlands Environmental Assessment Agency) and Sebastian Sterl (NewClimate Institute)

\subsection{Introduction}

Global climate change governance is becoming increasingly diverse, with many actors, other than national governments, undertaking climate change management actions. In this chapter, the focus is on actors like the private sector, civil society organizations, cities and regions, and other subnational actors, often referred to as non-state actors. Their actions could be either individual or cooperative ${ }^{1}$.

The 2015 Conference of the Parties (COP) to the United Nations Framework Convention on Climate Change (UNFCCC) showed a growing institutionalization of processes aimed at engaging non-state actors in efforts to manage climate change. This chapter assesses the role of non-state actors in bridging the emissions gap and summarises the role of their actions in the UNFCCC process. The chapter describes key features of a sample of around 200 cooperative initiatives, and provides a synthesis of recent estimates of emission reduction potentials by non-state actor actions. Finally, it highlights a number of issues where additional research is required.

\subsection{Non-state actors and the climate change negotiations}

Over the past decades, non-state actors have been taking measures to reduce emissions of greenhouse gases
(Andonova et al., 2009; Bulkeley et al., 2012; Bulkeley et al., $2014)^{2}$. While they unarguably played a key role in putting climate change issues firmly on the international agenda, their place within the international climate regime has long been limited to roles as observers and lobbyists ${ }^{3}$. Over the years, the role of non-state actors in international climate change negotiations has shifted towards a more structural, long-term engagement.

\subsubsection{Non-state actor actions in recent years}

Early efforts include the Momentum for Change campaign by the UNFCCC secretariat, to "shine a light on the enormous groundswell of activities underway across the globe that are moving the world toward a highly resilient, low-carbon future" (UNFCCC, 2016c)

The Peruvian government, in collaboration with the UNFCCC secretariat, launched the Non-State Actor Zone for Climate Action, an online platform to showcase non-state commitments, both by individual and cooperative entities. The Non-State Actor Zone for Climate Action provides the broadest overview of non-state and subnational climate action to date, and includes data from multiple partner organizations (UNEP, 2015)

2 These efforts go back at least 25 years, with the launch of the Rainforest Alliance in 1980, and fall under the broader pattern of international governance schemes, which emerged in the mid-1970s, partly as a result of the increasing globalization spurred by the liberalization of international financial markets.

3 In some instances, representatives from non-state actor initiatives have joined a UNFCCC party delegation team. This may have helped raise awareness among UNFCCC Parties about the breadth of actions undertaken by non-state actors.

4 Additional information about the campaign is available online at: http:// unfccc.int/secretariat/momentum_for_change/items/6214.php [Accessed 11 October 2016]

5 The Non-State Actor Zone for Climate Action database is available online at: http://climateaction.unfccc.int/ [Accessed 11 October 2016] 
The so-called Technical Examination Process on Mitigation, a multi-stakeholder forum within the UNFCCC negotiation process, was started in 2014 and expert meetings have been organized around specific themes such as transport, renewable energy and land use. Relevant non-state actors are engaged in the process ${ }^{6}$.

At the UNFCCC COP 20 in Peru, the host government, the government of France (as host of the 2015 conference), the UNFCCC secretariat, and the office of the UN SecretaryGeneral launched the Lima-Paris Action Agenda7. Focusing on 12 thematic areas, the Agenda seeks to: (i) mobilize "robust global action towards low carbon and resilient societies", (ii) provide "enhanced support to existing initiatives", and (iii) mobilize "new partners" and provide "a platform for the visibility of their actions" (UNFCCC, 2016b).

France declared the Lima-Paris Action Agenda to be the 'fourth pillar' of the Paris climate conference, together with a universal legal agreement, Nationally Determined Contributions (NDCs) from UNFCCC Parties, and finance and technology ${ }^{8}$.

\subsubsection{The Paris outcomes and beyond}

There is little doubt that the growing engagement of nonstate actors has contributed to the successful conclusion of the Paris Agreement (Jacobs, 2016) ${ }^{9}$. Section IV of the decision that accompanies the Paris Agreement (decision 1/CP.21) illustrates the growing institutionalization of non-state actor engagement within the climate regime. Addressing pre-2020 action, the decision introduces changes on previous ad hoc mobilization efforts, with a view to ensuring a more structured engagement (UNFCCC, 2016h). The main changes are:

- The Non-State Actor Zone for Climate Action platform is anchored in the decision (paragraph 117).

- High-level events for state and non-state climate action until 2020 are expected to further ensure the visibility and recognition at the highest level of non-state climate actions (paragraph 121).

- The Technical Examination Process on mitigation is maintained (paragraph 109), with a view to broadening the interface between state and non-state actors within the UNFCCC process $^{10}$.

- UNFCCC Parties and non-party stakeholders are encouraged to continue catalysing efforts to strengthen climate change action (paragraph 118).

6 Additional information about the forum is available online at: http://unfccc. int/focus/mitigation/technical_expert_meetings/items/8179.php [Accessed 11 October 2016]

7 http://newsroom.unfccc.int/lpaa/about/[Accessed 11 October 2016]

8 The speech of Laurent Fabius, the conference's president, is available online at: http://newsroom.unfccc.int/lima/laurent-fabius-scientific-conferenceclosing-speech-our-common-future/ [Accessed 11 October 2016]

9 Hale (2016) argues that "following the Copenhagen summit of 2009, the [international climate change] regime has been shifting from a "regulatory" model of binding, negotiated emissions targets to a "catalytic and facilitative" model that seeks to create conditions under which actors progressively reduce their emissions through coordinated policy shifts." He further suggests that "the December 2015 Paris Agreement and related decisions confirm this evolution" (p. 12).

10 In paragraph 12, the document calls for the launch of a parallel process on adaptation.
- Ensuring a degree of continuity of the Lima-Paris Action Agenda by establishing two high-level champions, who are tasked to "facilitate through strengthened high-level engagement in the period 2016-2020 the successful execution of existing efforts and the scalingup and introduction of new or strengthened voluntary efforts, initiatives and coalitions" (UNFCCC, 2016, p. 18) (paragraph 121).

Building on the above decision, and drawing on the multiplicity of previous efforts it echoes, a Global Climate Action Agenda was launched in May 2016 ${ }^{11}$. The Global Climate Action Agenda has two priorities ${ }^{12}$ :

- Engage with interested parties and non-party stakeholders, including furthering the voluntary initiatives of the Lima-Paris Action Agenda.

- Provide guidance to the UNFCCC secretariat on the organization of technical expert meetings focused on specific policies, practices and actions, and coordinate annual high-level events.

The process around COP 21 has brought a much higher level of recognition than before to the role of non-state actors' in the intergovernmental climate change process. However, many open questions remain related to how the international process can best recognise, support, and catalyse non-state actor actions. Furthermore, how do non-state actor actions relate to national governments' efforts to implement their NDCs, and to the development of future NDCs? Regarding the latter question, it has been argued that some kind of formal coordination mechanism could be implemented (Betsill et al., 2015).

\subsection{Overview of initiatives}

Non-state climate action comes in many forms. One category that has attracted particular attention is the so-called International Cooperative Initiatives (ICls). The reason is that the high number of participants in ICls can lead to a considerable emission reduction impact.

There is no single definition of what constitutes an $\mathrm{ICl}^{13}$. What is clear, however, is that over the past two decades the number of ICls has grown significantly, and has experienced a renewed impetus ahead of COP $21^{14}$.

11 The Road Map for Global Climate Action is available online at: http:// newsroom.unfccc.int/media/658505/high-level-champions-climate-actionroadmap.pdf [Accessed 11 October 2016]

12 The climate change champions will present a report of their work at the 2016 Conference of the Parties to the UNFCCC.

13 Most often, ICls are characterised as initiatives outside the United Nations Framework Convention on Climate Change aimed at reducing emissions of climate forcers by, for example, promoting actions that are less GHG intensive, compared to prevailing alternatives. Cooperative initiatives also involve national and sub-national partners.

14 Note, for example, that between September 2014 and December 2015, the number of local government signatories to the Compact of Mayors increased from 228 to 428 (and up to 568 when this report went to press). Similarly, between May 2015 and December 2015, more than 400 investors, representing US\$2 25 trillion in assets, joined the Investor Platform for Climate Action. 
Figure 4.1: Number of initiatives launched per year between 2000 and 2015. Source: Climate Initiatives Platform database.

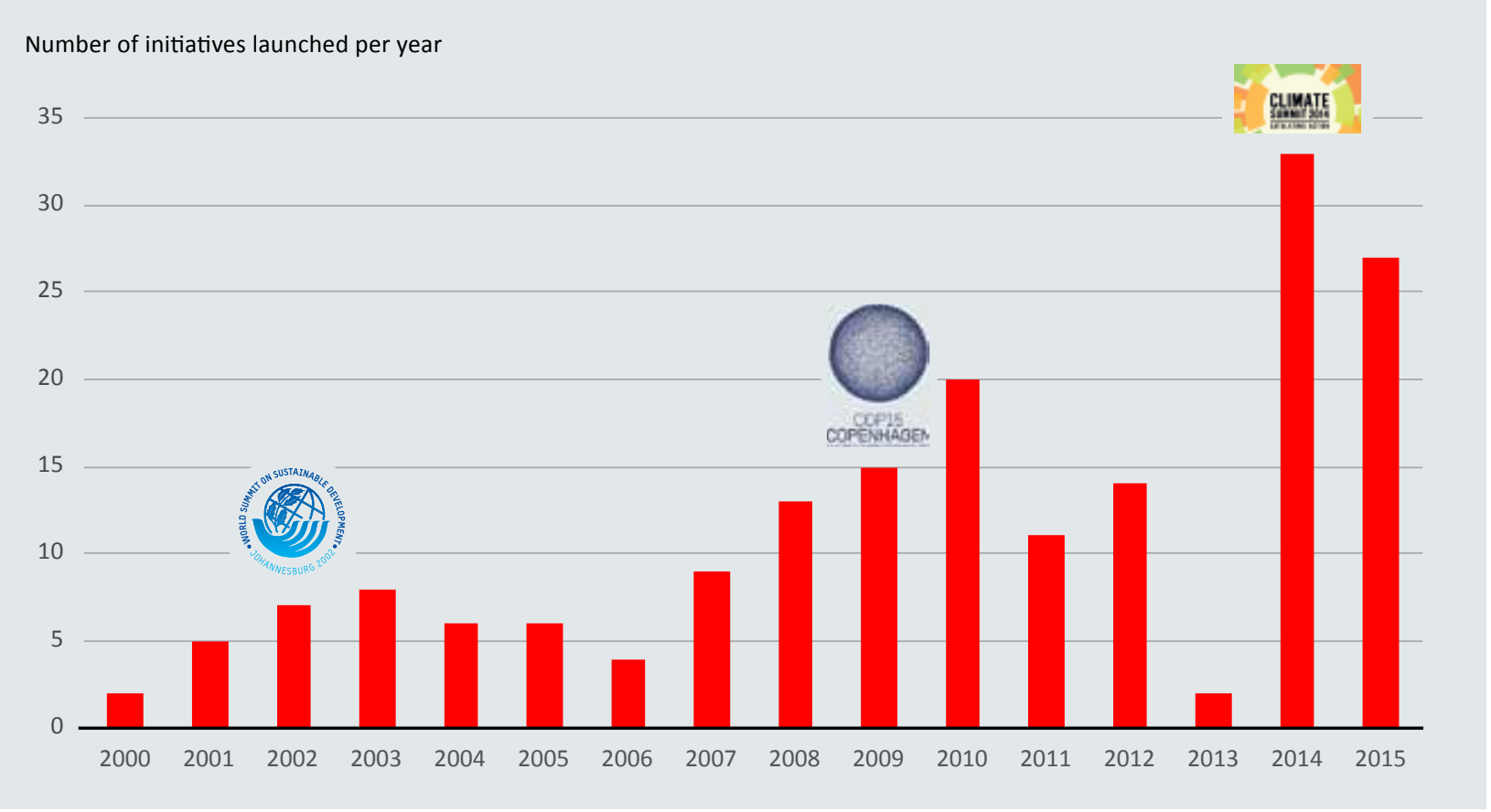

Table 4.1: Overview of features of 203 mitigation-focussed ICls.

\begin{tabular}{|l|l|}
\hline Features & Observed trends \\
\hline Sectoral focus & $\begin{array}{l}\text { Some initiatives (37) focus on more than one sector. For single-sector ICls, the dominant sectors are transport } \\
(31) \text {, agriculture (22), and energy (20). }\end{array}$ \\
\hline Geographic scope & $\begin{array}{l}\text { Most initiatives (163) are global in scope. By region, the number of ICls is highest in Europe (15), and Asia and } \\
\text { the Pacific (14), and lowest in West Asia (7), and Latin America and the Caribbean (6). }\end{array}$ \\
\hline Permanent secretariat & $\begin{array}{l}\text { Most initiatives (178) have a permanent secretariat. In many instances the secretariat is hosted by a related, } \\
\text { larger organization. }\end{array}$ \\
\hline Regular reporting & $\begin{array}{l}\text { The extent to which initiatives report regularly on their activities is unclear in half (102) of the initiatives. Regular } \\
\text { reporting occurs in 73 instances (and irregular reporting in 28). }\end{array}$ \\
\hline Type of commitment & $\begin{array}{l}\text { Only some initiatives (61) have quantitative commitments. Twice as many (128) have qualitative commitments. } \\
\text { The nature of the commitment is unclear in all other instances (14). }\end{array}$ \\
\hline Type of activities ${ }^{16}$ & $\begin{array}{l}\text { Climate Initiatives Platform registers three types of activities: technical dialogue, political dialogue, and } \\
\text { implementation. Many initiatives conduct more than one such activity. Implementation is the most common } \\
\text { activity (125), followed by technical dialogue (109), and political dialogue (49). }\end{array}$ \\
\hline Type of membership & $\begin{array}{l}\text { Industry is involved in over half (112) of the initiatives, followed by intergovernmental organizations (94), } \\
\text { national-level government agencies (91), non-governmental organizations (78), subnational-level government } \\
\text { agencies (51), and academia (37). }\end{array}$ \\
\hline Creation of ICls & $\begin{array}{l}\text { The annual creation of new initiatives rose from only a handful (4) in 2006, to a first peak in 2010 (20). It } \\
\text { reached a low point in 2013 (2), and swelled again in 2014 (33) and 2015 (27). }\end{array}$ \\
\hline
\end{tabular}

Throughout 2016, the number of non-state commitments and actions continued to increase. The Non-State Actor Zone for Climate Action platform currently records over 11,000 climate commitments, mostly from individual cities, regions and companies, but also from investors, civil society organizations, and cooperative initiatives.

A number of databases collect information on ICls. Because definitions vary, the various databases record very different numbers of entries ${ }^{17}$. On the basis of their own set of criteria

15 Regular reporting refers to planned reporting, irrespective of its periodicity

16 Implementation refers to actions that directly lead to emission reductions (as opposed to the indirect impact on emissions that technical or political dialogues are expected to have).

17 The purpose of the database and the level of effort devoted to keeping it upto-date are further reasons why the number of entries differ. which an ICI database should meet, Widerberg and Stripple (2016) identified and reviewed five such databases ${ }^{18+19}$. These are: the Non-state Action Zone for Climate Action, the Climate Initiatives Platform ${ }^{20}$, the Portal on Cooperative

18 The criteria used by Widerberg and Stripple require that the database: (i) collects information on ICls and their participants, (ii) focus on transnational initiatives, and (iii) focus on initiatives that have climate change mitigation as their main focus (Widerberg and Stripple, 2016).

19 The databases were created for different purposes and, therefore, differ in their criteria for including a specific initiative. For example, the Non-state Action Zone for Climate Action database intends to showcase the breadth of non-state actor actions, whereas the Transnational Climate Change Governance database was created for academic purposes, to analyse a welldefined, small selection of initiatives. The Global Aggregator for Climate Actions serves a dual, political and academic purpose.

20 The Climate Initiatives Platform database is available online at: http:// climateinitiativesplatform.org/index.php/Welcome [Accessed 11 October 2016] 
Figure 4.2a: Regional distribution of initiatives in percentage

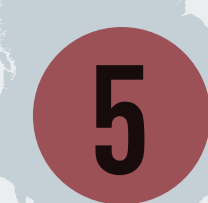

North America

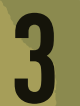

Latin America and the Caribbean
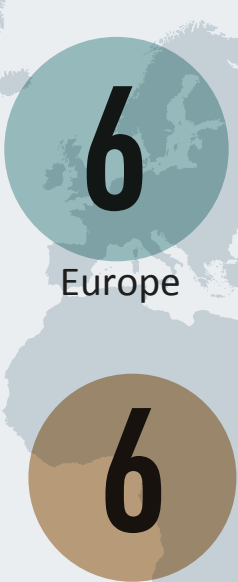

Africa

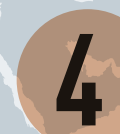

West Asia

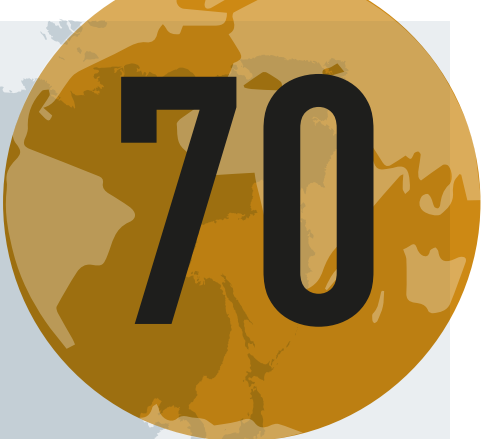

Global

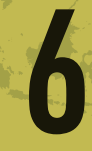

Asia and the Pacific

Figure 4.2b: Sectoral distribution of initiatives

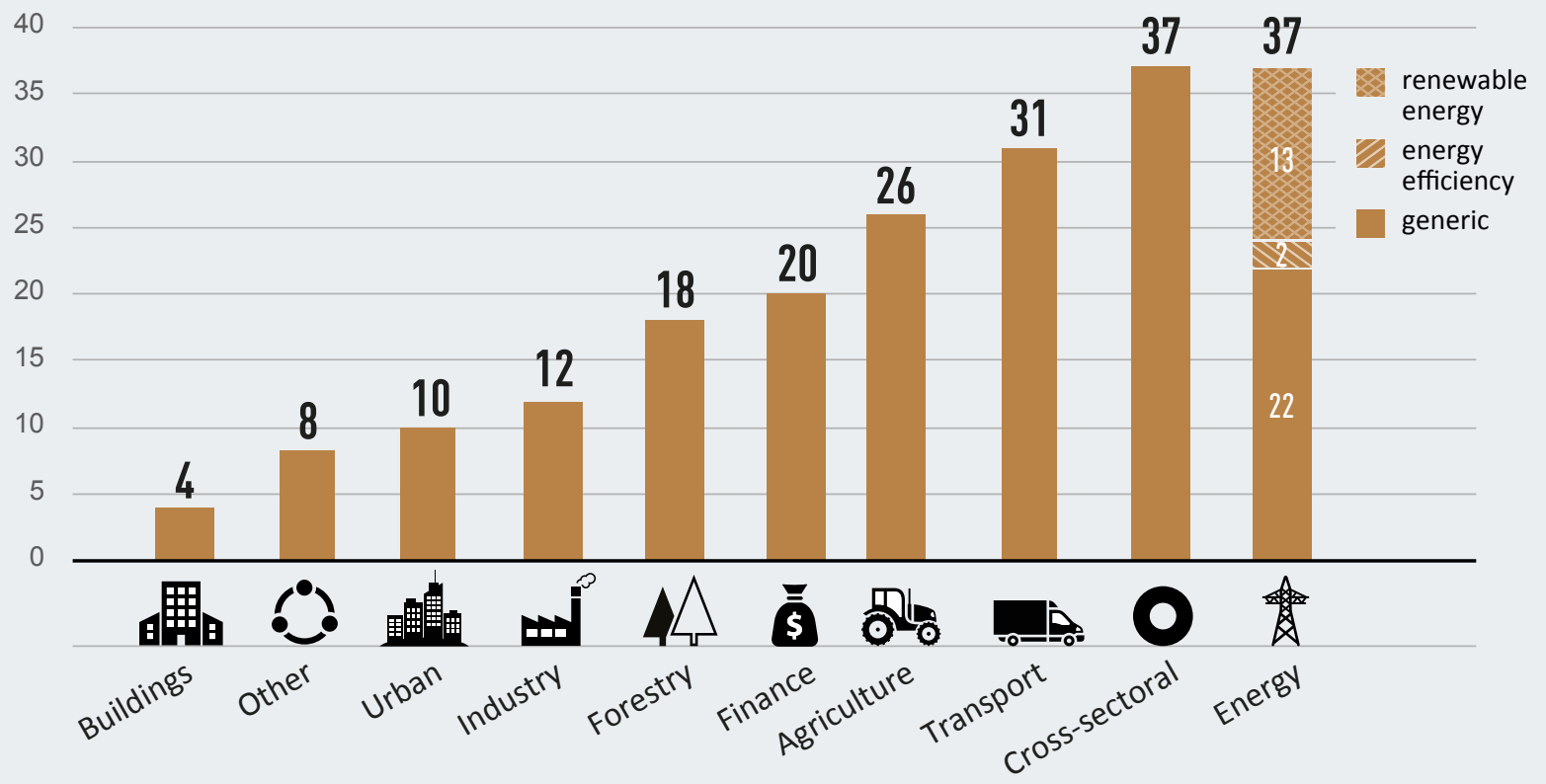

Note: Some initiatives cover more than one sector.

\section{Figure 4.2c:}

Permanent secretariat

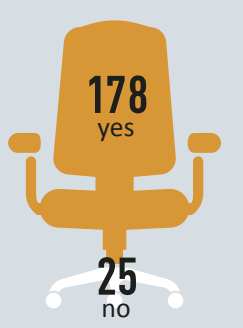

Figure 4.2d:

Regular reporting

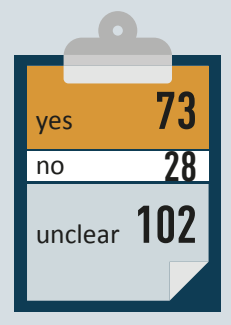

Figure 4.2e:

Type of commitment

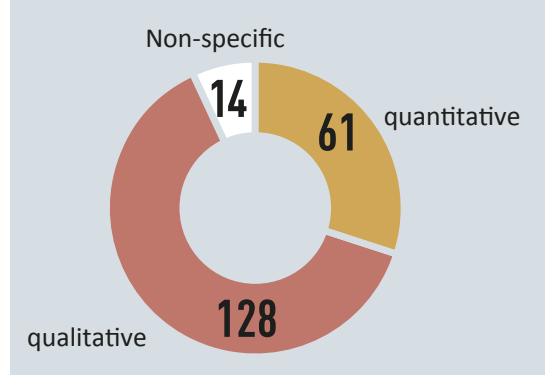


Table 4.2: Greenhouse gas emission reduction impacts of selected initiatives (in million tonnes of $\mathrm{CO}_{2}$ equivalent $\left(\mathrm{MtCO}_{2} \mathrm{e}\right)$ per year, by study).

\begin{tabular}{|c|c|c|c|c|c|c|c|c|}
\hline \multicolumn{2}{|c|}{ Actors and sectors } & \multicolumn{7}{|c|}{ Current individual commitments and/or initiatives' goals } \\
\hline & & \multirow{3}{*}{$\begin{array}{l}\text { UNEP, 2015) } \\
2020 \\
1,080\end{array}$} & \multirow{3}{*}{$\begin{array}{l}\text { (Hsu et al., } \\
2015 \text { ) } \\
2020 \\
454^{i}\end{array}$} & \multirow{2}{*}{\begin{tabular}{|l} 
(CISL and \\
Ecofys, 2015) \\
$\mathbf{2 0 2 0}$ \\
\end{tabular}} & \multicolumn{2}{|c|}{ (Roelfsema et al., 2015) } & \multicolumn{2}{|c|}{ (Graichen et al., 2016) } \\
\hline \multicolumn{2}{|l|}{ Target year } & & & & 2020 & 2030 & 2020 & 2030 \\
\hline \multirow{3}{*}{$\begin{array}{l}\text { Initiatives for } \\
\text { individual } \\
\text { entities }\end{array}$} & Cities and municipalities & & & & $600^{i \prime}$ & 700 & $55^{i i i}$ & 55 \\
\hline & Regions & 760 & & & & & $360^{\mathrm{iv}}$ & 270 \\
\hline & Individual companies & 630 & & $\begin{array}{l}51-100^{v} \\
10-30^{v i}\end{array}$ & $800^{\text {vii }}$ & 1,400 & $540^{\text {viii }}$ & 660 \\
\hline \multirow{9}{*}{$\begin{array}{l}\text { Sector-wide } \\
\text { initiatives }\end{array}$} & Energy efficiency & $60^{0 \mathrm{ix}}$ & $1,750^{x}$ & 60 & & & $280^{x i}$ & 1,180 \\
\hline & Efficient cook stoves & 120 & & & & & $270^{\times i}$ & 270 \\
\hline & Renewable energy & & $0.2^{2^{\mathrm{xii}}}$ & & & & $460^{\text {xiv }}$ & 1,360 \\
\hline & Transport & & & & $200^{\mathrm{xv}}$ & 500 & $240^{\mathrm{xii}}$ & 520 \\
\hline & $\begin{array}{l}\text { Methane and other short- } \\
\text { lived climate pollutants }\end{array}$ & 90 & & & $500^{\text {xvii }}$ & 1,300 & oxvii & 1,400 \\
\hline & Fluorinated gases & & & $0.0-0.7^{\mathrm{xix}}$ & 0 & $700^{2 x}$ & $50^{2 \times x i}$ & 140 \\
\hline & $\begin{array}{l}\text { Reduced deforestation and } \\
\text { afforestation }\end{array}$ & $100^{x \times i i}$ & $331^{\text {xiii }}$ & $20-200$ & $300^{\text {xiv }}$ & 700 & $800^{x x y}$ & $2,380^{x \times x i}$ \\
\hline & Agriculture & 300 & & & & & & \\
\hline & Shipping and aviation & & & & $200^{\text {xxvi }}$ & 500 & & \\
\hline \multicolumn{2}{|c|}{ Overlap between initiatives } & 200 & & & 200 & 300 & $\sim 100-1,000$ & $\sim 100-1,000$ \\
\hline \multirow{2}{*}{$\begin{array}{l}\text { Total expected } \\
\text { reduction below } \\
\text { study's baseline }\end{array}$} & Midpoint & 2,900 & 2,540 & No total| ${ }^{x \times v i i i}$ & 2,500 & 5,500 & & \\
\hline & Range & $2,500-3,300$ & & & & & & \\
\hline \multicolumn{2}{|c|}{$\begin{array}{l}\text { Part which is already covered by } \\
\text { national pledges / (I)NDCs }\end{array}$} & $33 \%$ & $\begin{array}{l}\text { Not } \\
\text { quantified }\end{array}$ & $\begin{array}{l}\text { Not } \\
\text { quantified }\end{array}$ & $70 \%$ & $\begin{array}{l}\text { Not } \\
\text { quantified }\end{array}$ & $\begin{array}{l}\text { Not } \\
\text { quantified dxix }\end{array}$ & $\begin{array}{l}\text { Not } \\
\text { quantified }\end{array}$ \\
\hline \multicolumn{2}{|c|}{$\begin{array}{l}\text { Total expected reduction below } \\
\text { national pledges / (I)NDCs }\end{array}$} & $1,700-2,200$ & $\begin{array}{l}\text { Not } \\
\text { quantified }\end{array}$ & $\begin{array}{l}\text { Not } \\
\text { quantified }\end{array}$ & 750 & $\begin{array}{l}\text { Not } \\
\text { quantified }\end{array}$ & $\begin{array}{l}2,800 \text { (range } \\
1,600-4,000 \text { ) }\end{array}$ & $\begin{array}{l}8,000 \text { (range } \\
5,400-10,600 \text { ) }\end{array}$ \\
\hline
\end{tabular}

Note: The table summarises findings from studies that include more than one sector or actor.

Initiatives ${ }^{21}$, initiatives collected in the context of the Transnational Climate Change Governance ${ }^{22}$ project, and the Global Aggregator for Climate Actions ${ }^{23}$. A further overview is presented in Graichen et al. (2016).

Widerberg and Stripple (2016) found that both the NonState Actor Zone for Climate Action and the Portal on Cooperative Initiatives lack clear criteria, and noted that the Global Aggregator for Climate Actions is no longer active ${ }^{24}$. Moreover, the Non-State Actor Zone for Climate Action covers relatively few ICls. The analysis presented here draws on the Climate Initiatives Platform, because this database is updated more regularly and is publicly accessible ${ }^{25}$. At present, the Climate Initiatives Platform records 203 initiatives focussed on mitigation. The remainder of this

21 The Portal on Cooperative Initiatives database is available online at: http:// unfccc.int/focus/mitigation/items/7785.php [Accessed 11 October 2016]

22 The Transnational Climate Change Governance database is available online at: http://community.dur.ac.uk/tccg/downloads/ [Accessed 11 October 2016, password protected]

23 The Global Aggregator for Climate Actions database is available online at: http://www.climategroundswell.org/blog-test/2015/7/16/galvanizing-agroundswell-of-solutions-to-support-cop21 [Accessed 11 October 2016]

24 The Global Aggregator for Climate Actions records all initiatives announced during the 2014 United Nations Climate Summit.

25 The Climate Initiatives Platform database is continuously being updated, with the goal of inventorying all initiatives that meet the following criteria: i Irrespective of what its main focus might be, the initiative contributes to reducing emissions of greenhouse gases (that is, initiatives that have no discernible climate change goals - and approaches to reach them - are not included).

ii The initiative is international in scope (that is, initiatives promoting emission reductions in only one country are not included).

iii The initiative involves cooperation between two or more non-state parties (that is, initiatives involving only one party, or only state actors, are not included). section summarises trends observed in the selection of initiatives currently inventoried in the Climate Initiatives Platform database (Figure 4.1, Figure 4.2 and Table 4.1).

Compact of Mayors (currently "Global Covenant of Mayors for Climate \& Energy") The Carbon Disclosure Project (CDP) - Top 500 Companies and Cement Sustainability Initiatives

C40

Under2MOU

Cement Sustainability Initiative (WBCSD)

The World Wildlife Fund's Climate Savers programme

vii C40 and Covenant of Mayors (currently "Global Covenant of Mayors for Climate \& Energy")

viii American Business Act on Climate Pledge (ABAOCP), Caring for Climate, RE100; does not take into account that these initiatives are expected to grow by $2020 / 2030$.

ix En.lighten initiative

$x \quad$ Energy Efficiency Accelerator

xi Global Buildings Performance Network (GBPN) and Super-Efficient Equipment and Appliance Deployment Initiative

xii Global Alliance for Clean Cookstoves (GACC)

xiii Small Island Developing States (SIDS) Lighthouse Initiative

xiv European Wind Initiative, Solar Europe Industry Initiative, US Wind Program, SunShot Initiative

xv Global Fuel Economy Initiative (GFEI)

xvi International Union of Railways (UIC) Low Carbon Rail Transport Challenge and Global Fuel Economy Initiative (GFEI)

xvii Global Methane Initiative and Zero Routine Flaring by 2030

xviii Clime and Clean Air Coalition (CCAC) and Global Methane Initiative (GMI)

xix Refrigerants Naturally!

xx North American 2013 HFC Submission to the Montreal Protocol

xxi Clime and Clean Air Coalition (CCAC)

xxii Tropical Forestry Alliance

xxiii New York Declaration on Forests

xxiv New York Declaration on Forests

xxv Bonn Challenge and Governor's Climate and Forest Task Force (GCFTF)

xxvi New York Declaration on Forests and Governor's Climate and Forest Task Force (GCFTF)

xxvii International Maritime Organization and International Civil Aviation Organization xxviii No total given as study was not intended to be exhaustive. xxix All numbers were calculated with respect to an INDC baseline. 
Several initiatives were launched in $2015^{26}$. These include, for example, the Africa Renewable Energy Initiative, and the Zero Deforestation Commitments from Commodity Producers and Traders.

Geographically, ICl engagement is rather unbalanced: $70-90$ per cent of them are led by developed country actors (Chan et al., 2015; Galvanizing the Groundswell of Climate Actions, 2015; Widerberg and Pattberg, 2015; Bansard et al., 2016; Hsu et al., 2016). Participants based in the Middle East and North Africa, Africa, Oceania, South East Asia, and China, are particularly underrepresented (Bulkeley et al., 2014; Hsu et al., 2016).

Most initiatives that set quantitative commitments propose a target and time frame to which - in principle - all members should commit, provide guidance and coordination support, and conduct outreach campaigns to recruit additional members ${ }^{27}$.

Most of the initiatives that report regularly on their activities bring together governmental agencies - at the local or national level - with one or more of the following actors: industry, intergovernmental organizations, and non-governmental environmental organizations. Typically, industry provides some form of technical support, while intergovernmental organizations and non-governmental environmental organizations provide legitimacy (through endorsement). In some instances, intergovernmental organizations provide financial support ${ }^{28}$.
Some of the initiatives that report regularly on their activities entail industry-only partnerships of European or global reach, in which members impose reporting duties on themselves. In these partnerships, reporting is seldom verified by a third party ${ }^{29}$.

A small number of the initiatives that report regularly on their activities are long-established efforts that were created with a very specific purpose, climate change mitigation only being an ancillary benefit of the activity. Typically, they are organizations with well-developed governance mechanisms, which require regular reporting beyond financial reporting ${ }^{30}$.

\subsection{Estimated emission reductions of non-state actor actions}

A growing number of analyses are available, which seek to estimate the potential and actual contribution of non-state actor action to the global effort of reducing greenhouse gas emissions. However, the evidence base remains fragmented, as outlined in this section.

National action, Intended Nationally Determined Contributions (INDCS) and non-state actions may reinforce each other and, together, create a virtuous cycle of raising ambition. Many initiatives address issues like financing, technology deployment, and capacity building, which may have important indirect effects on emissions.

However, for analysing the overall global impact it is important to analyse the ambition level of both actions to

Table 4.3: Greenhouse gas emission reduction impacts of selected initiatives (in $\mathrm{MtCO}_{2}$ e per year, by study).

\begin{tabular}{|c|c|c|c|c|c|c|c|c|c|c|c|}
\hline \multirow{2}{*}{\multicolumn{2}{|c|}{ Actors and sectors }} & \multicolumn{6}{|c|}{ Current individual commitments and/or initiatives' goals } & \multicolumn{4}{|c|}{ Systemic impact } \\
\hline & & \multirow[t]{2}{*}{ 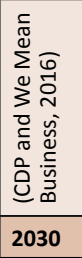 } & \multicolumn{2}{|l|}{ 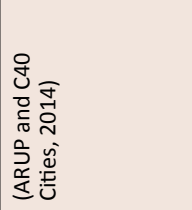 } & \multicolumn{2}{|l|}{ 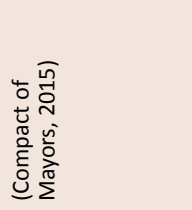 } & \multirow{2}{*}{ 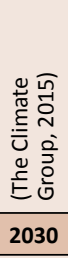 } & \multirow[t]{2}{*}{ 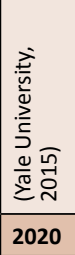 } & \multirow[t]{2}{*}{ 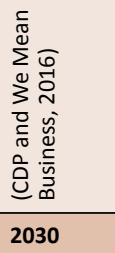 } & \multirow[t]{2}{*}{ 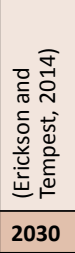 } & \multirow[t]{2}{*}{ 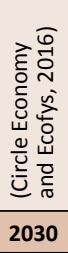 } \\
\hline \multicolumn{2}{|l|}{ Target year } & & 2020 & 2030 & 2020 & 2030 & & & & & \\
\hline \multirow{2}{*}{$\begin{array}{l}\text { Initiatives for } \\
\text { individual } \\
\text { entities }\end{array}$} & $\begin{array}{l}\text { Cities and } \\
\text { municipalities }\end{array}$ & & 454 & 402 & 500 & 740 & & \multirow[t]{2}{*}{1,000} & & 3,700 & \\
\hline & Regions & & & & & & 1,200 & & & & \\
\hline \multirow[t]{2}{*}{$\begin{array}{l}\text { Sector-wide } \\
\text { initiatives }\end{array}$} & Business sector & $\begin{array}{l}3,900- \\
4,900^{i} \\
\end{array}$ & & & & & & & $>10,000^{\mathrm{ii}}$ & & \\
\hline & Circular economy & & & & & & & & & & $\begin{array}{l}6,000- \\
7,500 \\
\end{array}$ \\
\hline \multicolumn{2}{|c|}{ Overlap between initiatives } & 700 & & & & & & None & $\begin{array}{l}\text { Not } \\
\text { quantified }\end{array}$ & & \\
\hline \multicolumn{2}{|c|}{$\begin{array}{l}\text { Total expected impact below } \\
\text { study's baseline }\end{array}$} & $\begin{array}{l}3,200- \\
4,200\end{array}$ & 454 & 402 & 500 & 740 & 1,200 & 1,000 & 10,000 & 3,700 & $\begin{array}{l}6,000- \\
7,500\end{array}$ \\
\hline
\end{tabular}

Note: The table summarises findings from studies that include only one sector or actor

Science-Based Targets, RE100, EP100, Zero-deforestation pledges; taking into account that these initiatives are expected to grow by $2020 / 2030$.

Overlaps between initiatives mean the impact is smaller than the sum of the individual initiatives, as initiatives are complementary to each other. In this study, they were not estimated in detail.

26 At the time of writing, the Climate Initiatives Platform database did not contain any initiatives launched in 2016 (that is, 2015 was the latest year for which the database had any entries).

27 Examples include the Zero Routine Flaring by 2030 Partnership, RE100, and the Lima Challenge.

28 Examples include the Climate Group's States and Regions Alliance and the Asia Forest Partnership.

29 Examples include the Airport Accreditation initiative and the Ultra-Low $\mathrm{CO}_{2}$ Steelmaking initiative.

30 Examples include the Forest Stewardship Council and the Global Reporting Initiative. 


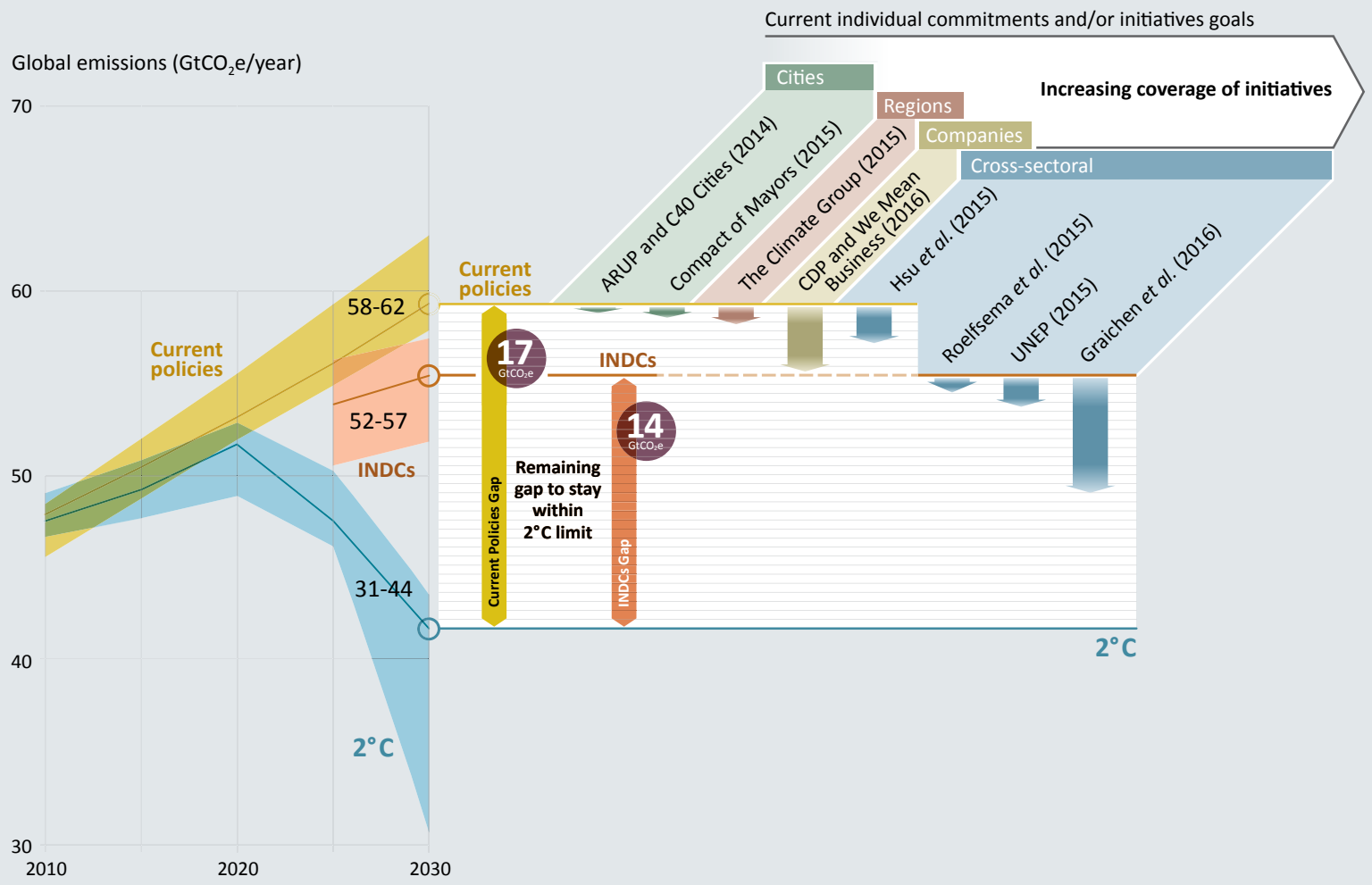

Note: The arrows showing the emission reductions potential start at different levels because the individual studies use different baselines (the last three studies explicitly estimate the impact additional to INDCs).

understand if one adds more ambition than the other and, therefore, helps close the emissions gap (Hale, 2016). While doing so is analytically challenging, a number of studies have made some inroads (see, for example, Höhne et al., 2015; Graichen et al., 2016). ${ }^{31}$ Tables 4.2 and 4.3 and figure 4.3 provide overviews of the estimates available.

The studies vary significantly in scope, in particular which kind of impact they analyse. We identified several categories of impact, but studies are not always clear about which impact they estimate:

Individual commitments: Reductions that would occur if all participants of the initiatives (individual companies, cities, etcetera) fulfil their individually set targets.

Initiatives' goals: Reductions that would occur if the initiatives achieve their stated collective goals (in terms of participants of companies and cities).

31 Analyses of the actual performance of non-state actor actions (as opposed to simply analysing the targets, in the assumption that they will be met) are emerging, but remain limited in number (see, for example, Khan and Sovacool, 2016). Additional emission reductions that could potentially be achieved by non-state actors, should they receive support from national governments, have not been studied to date.
Systemic impact: Reductions that would occur if the initiatives achieve a transformative impact at sector level or economy-wide level beyond the participants of the initiatives themselves.

Studies on the actual performance of non-state actors in meeting their voluntarily set targets (not only analysing the targets themselves) are emerging, but are very limited in number (for example Khan and Sovacool, 2016). Moreover, to the authors' knowledge, additional reductions that can potentially be delivered by initiatives through supporting measures by national governments have not been studied to date.

The compilation of available studies shows:

- Aggregated impact of individual non-state action, initiatives, and national efforts cannot yet be estimated with precision. More studies are available compared to last year, in particular on cities, but large data gaps remain as not all sectors are sufficiently studied, and the overlaps and relation with INDCs are still unclear. Key data shortcomings include:

- While emissions reductions are published, assumptions about greenhouse gas emission baseline scenarios are often missing, as are 
the baseline scenario projections. This makes comparisons across studies challenging.

- All studies assume full implementation. This assumption leads to overestimates, if full implementation is not achieved (Khan and Sovacool, 2016). It follows that transparent data on implementation levels, and the capacity to verify the data, are needed (IVM and FORES, 2015).

- The evidence available suggests that both activity levels and actual emission reductions are increasing. This trend is especially marked in the area of cities, and ambitious plans of company initiatives are also emerging.

- The limited evidence available indicates that the aggregated impact of the initiatives to closing the emissions gap can be in the order of a few gigatonnes of carbon dioxide equivalents $\left(\mathrm{GtCO}_{2} \mathrm{e}\right)$ in 2030. This would represent a major contribution, if the initiatives reach their stated goals and the emission reductions do not displace actions elsewhere.

\subsection{Issues for the future}

This section summarises a number of issues where additional research is needed.

\subsubsection{Integrate state and non-state action}

To capture the full impact of non-state actor action, and to maximise complementarity action, national governments should take into account the potential impact of non-state actor actions and initiatives. This would help national governments obtain a better understanding of the size of the mitigation opportunities, while promoting heightened ambition and capacity to realise those opportunities ${ }^{32}$.

In areas where state and non-state actions overlap, non-state actor actions may be able to "reinforce, implement, and give credibility to the national pledges" (Hale, 2016, p. 20). The reverse may also be true: non-state actor actions could benefit from enhanced national government support - for example through the removal of barriers, and supportive legislation ${ }^{33}$.

32 Not least, non-state actor actions can also serve as important vehicles for policy experimentation and knowledge diffusion.

33 Development of guidance is underway, to help governments and initiatives engage with each other more effectively (see, for example, the Initiative for Climate Action Transparency, available online at: http://www. climateactiontransparency.org/ [Accessed 11 October 2016]).

\subsubsection{Increase data on non-state action, in particular on targets and impact}

More data and analysis are needed to fully understand the scope of non-state actions. More and better greenhouse gas and energy-use inventories for cities, companies and other non-state actors would be especially useful ${ }^{34}$.

A clearer definition of the goals and targets of the initiatives is needed, ideally indicating levels of ambition and additionality in relation to other actions. Less than a third of the initiatives have quantitative targets. Analysing the emission reductions potential of initiatives that only have qualitative commitments is even more challenging ${ }^{35}$.

The Global Climate Action Agenda calls on non-state actor initiatives to set targets that are consistent with the long-term goals of the Paris Agreement, and to achieve the commitments they make ${ }^{36}$. Monitoring, reporting and verification procedures are instrumental in this process, but they vary widely among initiatives. Only a small, but increasing, number of initiatives evaluate their impact ${ }^{37}$.

One-third of the initiatives registered in the Climate Initiatives Platform regularly report on progress toward meeting their goals and targets. For most of the initiatives, the extent to which regular reporting of implementation occurs is unclear ${ }^{38}$. Nonetheless, the trend appears to be a positive one, and some non-state actor actions apply what could be qualified as good practice in reporting ${ }^{39}$.

\subsubsection{Further issues}

Studies of the lessons learned from the initiatives are scarce (see, for example, CISL and Ecofys, 2015). Both new and existing initiatives could benefit from this kind of analysis in the formulation of commitments and the establishment of effective governance structures.

Further research is needed to understand the reasons behind the geographic imbalance in non-state action leadership. At present, the focus is on short-term mitigation potentials. Chan et al. (2016) emphasize the importance of smaller-scale innovative solutions that - initially - may only offer limited mitigation potential, but have large mitigation potential in the longer term - that is, 2050 and beyond.

34 The Global Reporting Initiative has made some headway toward achieving this.

35 It is worth noting that the emission reductions potential of non-state actor actions with qualitative commitments may, in principle, be large.

36 Additional information about the Global Climate Action Agenda is available online at: http://newsroom.unfccc.int/climate-action/global-climate-actionagenda/ [Accessed 11 October 2016]

37 It is worth noting that such evaluations are challenging to undertake, particularly in the case of initiatives involving multiple diffuse sources of emissions.

38 It is worth noting that what constitutes 'good reporting practice' may be very different from one sector to another.

39 For example, Graichen et al. (2016) find that the Bonn Challenge, the New York Declaration on Forests and RE100, among others, follow above-average reporting practices. They provide detailed descriptions of the initiatives, and the members' activities and targets, in addition to preparing their own estimate of impact, and making available reporting guidance for potential new members. 


\section{Chapter 5}

\section{Bridging the gap - the role of energy efficiency}

Lead Authors (alphabetical): Subash Dhar (UNEP DTU Partnership), Timothy Clifford Farrell (UNEP DTU Partnership), Rana Ghoneim (United Nations Industrial Development Organization) and Diana Urge-Vorsatz (Central European University)

Contributing authors (alphabetical): Elisabeth Boles (Massachusetts Institute of Technology), Benigna Boza-Kiss (Central European University), Marco Matteini (United Nations Industrial Development Organization), Jyoti Painuly (UNEP DTU Partnership), Minal Pathak (CEPT University), Ksenia Petrichenko (UNEP DTU Partnership), Bettina Schreck (United Nations Industrial Development Organization) and PR Shukla (Indian Institute of Management, Ahmedabad)

\subsection{Introduction}

Improving energy efficiency is essential to meeting the objectives of the Paris Agreement and is a greenhouse gas mitigation option offering many economy-wide benefits (IEA, 2014; IPCC, 2014; von Stechow et. al., 2015). Out of the 189 countries that submitted Intended Nationally Determined Contributions (INDCs), 168 countries included energy efficiency as one of their priorities (Fenhann, 2016). Countries that already have strong energy efficiency policies can testify to the multiple benefits, including improved air quality, increased social welfare, competitiveness and the creation of jobs (IEA, 2014; Puig and Farrell, 2015).

Investments in energy efficiency have shown a positive net return for governments, businesses and households. Importantly, end-use energy efficiency investments release upstream cost reductions in power supply systems, with examples of: 300 per cent return on investments from national benefits in appliance standards and labelling programmes (4E, 2016); electricity companies achieving 240 per cent return on customer energy efficiency investments from reduced upstream costs in generation, transmission and peak supply costs (IEA, 2014). Despite falling global oil, gas and coal energy prices, global investments in energy efficiency increased by 6 per cent to US\$221 billion between 2014 and 2015 (IEA, 2016a). If access to credit and bond markets is increased, and transaction costs are lowered, even more investment will be mobilized, especially if the climate benefits can also be capitalized upon in the investments, such as through climate financing or internalized cost of carbon (for example, reinvested carbon taxes).

Energy efficiency policies struggle to work effectively against a context of energy price subsidies, as low energy prices undermine the essential economics of energy efficiency. Global fossil fuel subsidies were estimated at US\$490 billion in 2014
(IEA, 2015a), with a growing number of countries committing to reforming these subsidies. Some countries with direct or indirect energy subsidies should explore options to shifting subsidies from energy supply to end-use services.

This chapter offers policy makers an assessment of selected policies that have been proven to accelerate energy efficiency gains in three key sectors: buildings, industry and transport. In 2010, the buildings sector accounted for around 32 per cent of final energy use and annual emissions of 8.8 gigatonnes carbon dioxide $\left(\mathrm{GtCO}_{2}\right)$ (direct and indirect); the industry sector accounted for around 28 per cent of final energy use and emissions of $13 \mathrm{GtCO}_{2}$, (direct and indirect, as well as process emissions); while the transport sector accounted for 27 per cent of final energy use and emissions of $6.7 \mathrm{GtCO}_{2}$ (IPCC 2014).

If scaled-up, globally, the assessed energy efficiency policies can dramatically reduce energy use and greenhouse gas emissions in these key sectors. Sector-specific estimates of emission reduction potentials are highly dependent on the underlying assumptions and approaches. Therefore, studies often result in different estimates of the potentials offered by energy efficiency options. Numbers from two studies have been included to illustrate the scale of the possible reductions for each sector.

The Fourth Assessment Report of the Intergovernmental Panel on Climate Change (IPCC, 2007) shows that for a cost range of between US\$20 and 100 per tonne of carbon dioxide $\left(\mathrm{CO}_{2}\right)$, the estimates of both direct and indirect emissions reduction potentials in 2030 are (in $\mathrm{GtCO}_{2}$ e) 5.9 for buildings, 4.1 for industry and 2.1 for transport (Ürge-Vorsatz and Novikova, 2008). The authors note that these estimates are conservative and the real potential in each sector is likely bigger. A more recent analysis in 
the World Energy Outlook's (IEA, 2012) efficient world scenario ${ }^{1}$ indicates that the cumulative direct and indirect emissions estimates in 2035 are (in $\mathrm{GtCO}_{2}$ e) 30 for buildings, 22 for industry and 12 for transport. The two studies are not comparable due to basic differences in approaches, but collectively illustrate the significant potential in the three sectors.

Efficiency gains are evidently also possible in the energy supply sector with, for example, more efficient generators, transmission, and distribution systems. This chapter does, however, focus on end-use efficiency because emissions reductions are generally more cost-effective for demand-side investments.

The chapter first assesses experience with key policy options in the three sectors: buildings, industry and transport. These are then followed by sections focusing wider on systems thinking and integration, and emerging opportunities.

In addition to the mitigation effects, improved energy efficiency offers other important benefits, for instance by playing an important role in the achievement of many of the Sustainable Development Goals (SDG). Goal seven specifically aims to 'ensure access to affordable, reliable, sustainable and modern energy for all', and includes an energy efficiency target

1 The core assumption in the Efficient World Scenario is that policies are put in place to allow the market to realise the potential of all known energy efficiency measures which are economically viable. This scenario includes the full range of available energy efficiency policies and measures but no carbon price is expressed in the results (IEA, 2012). These estimates aren't potentials (like Ürge-Vorsatz and Novikova (2008) based on a carbon price) but rather scenarios of what is achievable under the economic conditions the World Energy Outlook runs. (to double the global rate of improvement in energy efficiency by 2030). Achievement of goal seven impacts the delivery of many other goals, such as good health and well being, sustainable cities and communities, responsible consumption and production, and climate action. This is further discussed in Chapter 6.

As an example of the importance of energy efficiency in the implementation of the various goals, the benefits of energy efficiency related to goal eleven, sustainable cities and communities, are presented in box 5.1.

\subsection{Building sector}

The building sector offers major opportunities to bridge the emissions gap, due to its large share in global energy use, the dynamics of population growth, urbanization and housing needs, and its large cost-effective mitigation potentials (IEA, 2013; IPCC, 2014). In 2013, the 212 billion square metres $\left(\mathrm{m}^{2}\right)$ of global building stock accounted for almost 125 Exajoules of final energy use (IEA, 2016b), up from 102 Exajoules in 2000 (IPEEC, 2015). Thermal energy uses, including heating, cooling, and water heating, comprise the largest energy service, with 55 per cent of total building energy use (IEA, 2016b).

Top-down estimates, obtained using integrated assessment models, often show limited potential for energy savings up to 2050. Conversely, bottom-up studies conclude that major savings (up to 75 per cent in 2050, compared to a reference scenario) are possible due to recent advances in technology, architecture and know-how - mainly with regard to heating

\section{Box 5.1: Examples of the multiple benefits of energy efficiency that support SDG 11 (Sustainable Cities and Communities).}

Energy savings. Jakarta, Indonesia. The Jakarta Green Building Code was introduced in 2012 to reduce energy consumption in large commercial and high-rise residential buildings. It is expected to cut 2.7 million tonnes of $\mathrm{CO}_{2}$ emissions per year by 2020 (IFC, 2016).

Improvements in air quality. Curitiba, Brazil. Integrated urban planning that encouraged high density commercial and residential development, combined with the city's public transportation network, reduced traffic congestion and enhanced air quality (Suzuki et al., 2010).

Impacts on public budgets. Los Angeles, United States of America (USA). Over a four-year period, the LED Streetlight Replacement Programme has replaced over 140,000 existing streetlights in the city with LED units. It cost US\$57 million, but now saves US\$9 million a year in energy costs and 60,000 tonnes of $\mathrm{CO}_{2}$ emissions, with a payback of six to seven years. Excess capacity freed up by the investment is being used to power as many as 100 electric charging stations (Davies, 2016).

Creation of jobs. Melbourne, Australia. The city of Melbourne launched a 1200 Buildings Programme in 2010, to improve the energy and water consumption of 1,200 commercial buildings. An analysis of the economic benefits estimated that, by 2020 , it could increase employment by 5,800 to 11,800 (Lawler, no date).

Improvement in human health and well being. Bogota, Colombia. The TransMilenio Bus Rapid Transit system in Bogota has replaced 2,100 old public service buses with ones that have improved operational efficiencies. The Bus Rapid Transit system has delivered 40 per cent reduction in air emissions, 92 per cent reduction in accidents, and delivered fuel savings of 47 per cent (ESMAP, 2009).

Increased access to energy and reduced fuel poverty. Tyrol, Austria. A 2007 housing subsidy was introduced that provides funding for social housing to overcome the additional costs of a passive design. Tyrol has the highest density of passive houses in the world, with a 21 per cent share in 2014 (Passive House Institute, 2015).

Benefits to energy providers. Johannesburg, South Africa. The city of Johannesburg has partnered with City Power to reduce peak load and household electricity consumption. About 65,000 smart meters have been deployed to monitor consumption in real-time and alert high energy-using households to reduce consumption (Writer, 2015). 


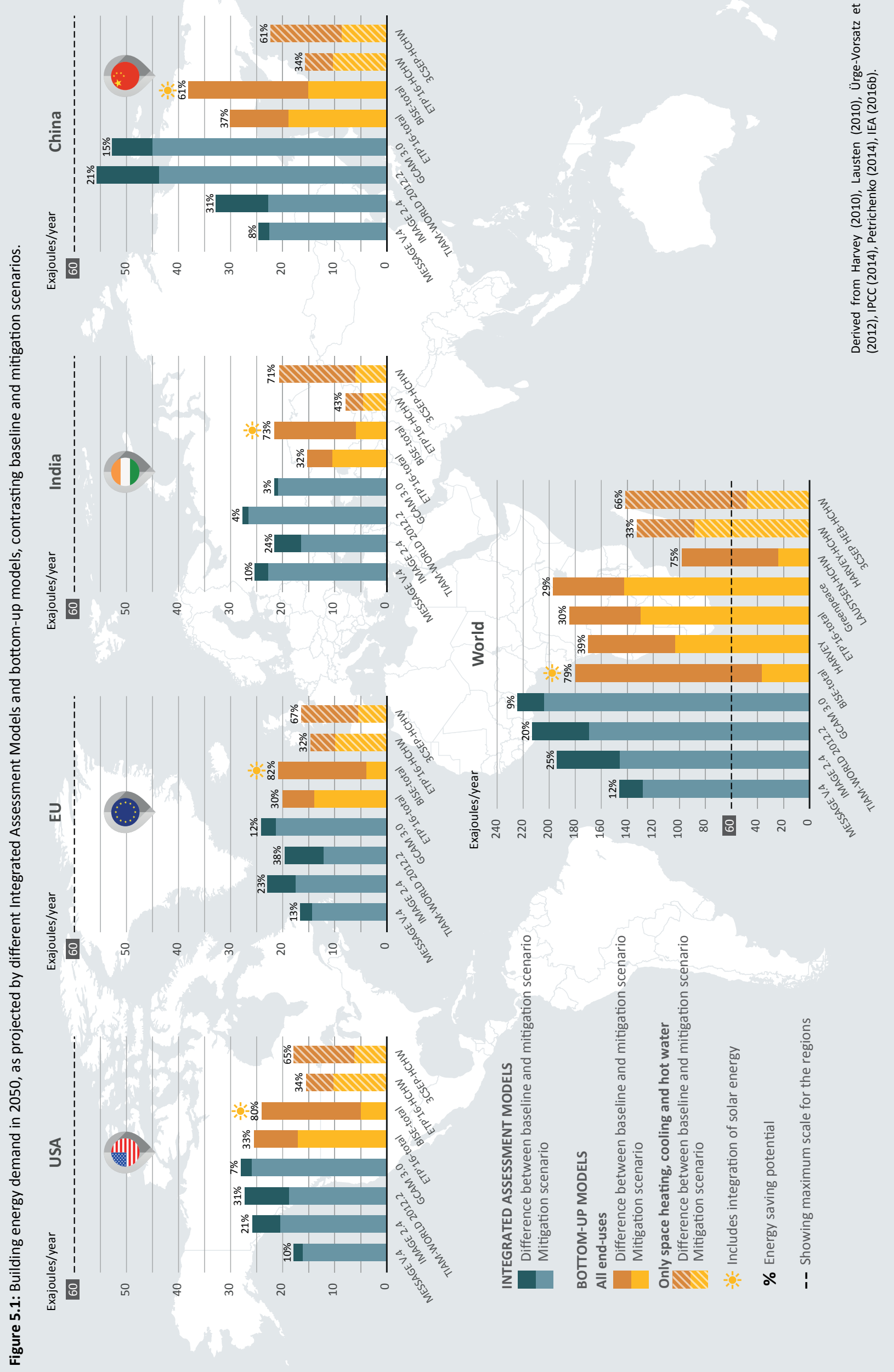


and cooling (figure 5.1). The difference between these two types of analysis lies in the coverage of mitigation options, and the assumed rate of up-take. Bottom-up estimates are mainly driven by technical and economic potentials, whereas top-down estimates mostly reflect assumed market adoption rates for certain technologies and investment dynamics.

With the sector orientation here, focus is on bottom-up studies where well-designed policy packages are critical to achieving the stated potentials combining building energy codes, building energy certification programs, together with appropriate incentives and information campaigns (Boza-Kiss et al., 2013a).

\subsubsection{Building energy codes}

Building energy codes and standards are among the most cost-effective instruments for reducing building-related emissions (Boza-Kiss et al., 2013b). These regulatory tools set minimum requirements for parameters determining building energy demand, such as energy performance or resource use in new and/or existing buildings (Boza-Kiss et al., 2013b; Becqué et al., 2016). A strong and well implemented building energy code will take the building stock to a higher energy performance, and will be able to avoid locking-in obsolete solutions and high-emitting technologies, especially in rapidly developing regions (Becqué et al., 2016).

Building energy codes are increasingly being applied worldwide. In late 2015, mandatory and/or voluntary building energy codes were in place in over 60 countries at either national or subnational levels (IEA, 2016c), making this one of the most widely used energy efficiency policy instruments ${ }^{2}$. Building energy codes are expanding their coverage from new construction to renovations of existing buildings, which is particularly important for regions with mature building stocks. For instance, the European Directive on the Performance of Buildings requires energy performance improvements for major retrofits throughout the European Union (EU) (European Parliament, 2010) ${ }^{3+4}$. Building energy codes have also been expanding in their coverage of requirements - moving towards more complex, whole-building approaches, and requiring the integration of renewable energy generation (IEA, 2013).

However, the existence of a building energy codes alone does not guarantee emission reductions. To ensure their

2 California provides an excellent example of how building energy codes can drive emission reductions. Between the 1970s and 2016 the state's thermal building energy use (and thus the corresponding emissions) has been reduced by more than 90 per cent. California continues to increase the stringency of its building regulations aiming at achieving zero net energy performance by 2020 for new residential buildings, and by 2030 for new non-residential buildings (Shirakh et al., 2015).

3 However, countries such as Germany also set energy performance requirements for minor retrofits (CA EPBD, 2015). Hong Kong also uses similar requirements to upgrade the energy performance of existing buildings undergoing major retrofits (Chan et al., 2014).

4 There are also building energy codes for "retro-commissioning", which require periodic mandatory audits, followed by obligatory improvement of energy performance for low-performing buildings. Such a regulation (Local Law 87) is in place in New York City, where buildings over 50,000 gross square feet must undergo selected measures as part of a retro-commissioning process (Becqué et al., 2016). Austin, Texas also requires efficiency improvements in the case of low-performing multi-family buildings. effectiveness, the following principles need to also be adopted:

- Compliance monitoring and enforcement are essential (Boza-Kiss et al., 2013a; GBPN, 2014) Typically, limited human and financial resources for this activity will be a key barrier to the successful implementation of building codes.

- The design of building energy codes should follow a holistic approach, covering energy performance, quality and safety, and utilization of renewable energy (Boza-Kiss et al., 2013b).

- The stringency of building energy codes should be regularly revisited and strengthened. Leapfrogging to very high efficiency performance standards have also been demonstrated and avoid lock-in.

Building energy codes are a key policy instrument, but may not be sufficient in overcoming all the barriers to thermal energy efficiency improvements in buildings. Capacity building activities, supply-chain development, and other policy instruments - like credible building performance information or energy certification and financial incentives - all complement building codes. In fact, more integrated policy packages can often better overcome the many diverse barriers prevailing in this sector (Brown and Sovacool, 2011).

\subsubsection{Building information and energy performance certification}

Certification of building energy performance is currently being used in at least 35 countries, worldwide (IEA, 2016d $)^{6}$. Labelling schemes enable policy makers to tailor incentive schemes and other policy instruments, fostering a market transformation towards high-energy performance building stock. Certification may exist with or without a label, and can be combined with the provision of a set of recommendations for improvement (Boza-Kiss et al., 2013a). Mandatory schemes are expected to have a higher overall impact, while voluntary schemes can be considered as information measures. Voluntary schemes may enhance the effectiveness of other policies, or be a transitional step towards a mandatory system. The effectiveness of certification and labelling schemes also depends on effective monitoring and enforcement, which should be an integral part of their design.

Many countries have developed their own building energy performance certification schemes, like the Home Energy Rating (Chile), Greenship (Indonesia) and Green Mark (Singapore). Many other countries have adapted international certification systems to the local conditions. However, many of these schemes were developed before a stringent climate goal was universally accepted and, therefore, operate with less ambitious energy, or emissions performance levels than would be consistent with the global goal. Therefore, it is important that countries, before adopting energy performance certification programmes

5 Nevertheless, compliance is often problematic. For instance, in some states of the USA the compliance rate was as low as 20 per cent, and in Japan about 30 per cent (Liu et al., 2010). Even in established building energy codes regimes, such as the EU, compliance rate ranges between 60-97 per cent for new buildings and $45-93$ per cent for retrofits (ICF, 2015).

6 Most of these schemes are voluntary. In the case of the European Union, its mandatory Energy Performance Certification is required when buildings are sold or rented, or when they undergo major renovations. 
for buildings developed in the past, carefully examine their stringency from the perspective of carbon lock-in, and the energy and emissions performance requirements are brought as close to the state-of-the-art as possible (BozaKiss et al., 2013b).

\subsubsection{Highly energy efficient buildings}

The passivehaus standard. In terms of energy performance, one of the most ambitious building energy certification schemes is the so-called "Passivehaus" standard". This standard encourages very low-energy buildings from a heating and cooling perspective, with low thermal losses and optimized thermal gains (Schnieders, 2003; Feist et al., 2005). The Passivehaus standard has been adapted to different climate zones worldwide and further developed with the common target that annual final energy use for heating and cooling - not exceeding 15 kilowatt hour (kWh) per $\mathrm{m}^{2}$ per year ${ }^{8}$. This target represents a reduction of up to 90 per cent in energy demand for heating and cooling for most existing buildings (Feist et al., 2005). The standard has become popular in several countries, and is experiencing a dynamic market adoption in several regions. The global floor area of Passivehauses has grown from 10 million $\mathrm{m}^{2}$ in 2010 to 46 million $\mathrm{m}^{2}$ in 2016 , with the most activity occurring in Europe (personal correspondence: Passive House Institute and Gunter Lang). Presently, the price premium for new Passivehauses in several countries is comparable to standard construction costs (Treberspurg and Djalili, 2013).

Net-zero energy buildings. The minimal remaining energy needs of highly efficient buildings can often be supplied with on-site renewable energy, thus creating a net zero energy building (Torcellini and Crawley, 2006). The global market of this type of building reached US\$630 million in 2014, and is expected to continue its growth, to reach US\$1.4 trillion by 2035 (Navigant Research, 2014). Numerous examples of net zero energy buildings exist around the world (IEA, 2013; Erhorn and Erhorn-Kluttig, 2014; New Buildings Institute, 2016) ${ }^{9}$.

Energy positive (or e+) buildings. These are buildings that generate more (renewable) energy on-site than they use. Examples can be found in a number of countries, including Australia, France, Germany, Norway, the UK and the USA. These highly efficient buildings can play an important and more active role in the overall energy system, since they can act as potential micro-energy hubs, supplying energy to local neighbourhoods through peer-to-peer networks. This offers opportunities to generate and store renewable energy (both

7 Passivehaus originated in Germany, with the pilot project launching in 1990 (Ebel and Feist, 1997).

8 The average building stock levels in most developed countries score well above 100-150 kWh per $\mathrm{m}^{2}$ (Schnieders et al., 2015).

9 The concept can also be applied at a scale that is greater than individual buildings. For example, in 2015 California established its first net zero energy community ('Sierra Crest'), consisting of 20 NZEBs (Movellan, 2015). thermal and electric) on-site, as well as deliver significant distributed demand response(De Groote et al., 2016) ${ }^{10}$.

Recognizing the promise of highly energy efficient buildings and their societal co-benefits (Treberspurg Djalili, 2013; Schnieders and Hermelink, 2006), some jurisdictions are now recommending or mandating them as standards for different building types. For instance, since 2010, in Brussels (Belgium) all new public buildings are mandated to be built to the Passivehaus standard, and as of January 2015 it is a mandatory requirement for all new buildings and major retrofits (EnEffect, 2014). Hanover, Germany does not have mandatory Passivehaus policies, however the local housing market has transformed to offer high efficiency as a standard option, and approximately one-third of all new construction voluntarily conforms to the Passivehaus standard (Passive House Institute, 2015).

\subsection{Industry}

Industrial energy demand, leading to 2030, is expected to increase at a rate of 1.3 per cent annually, primarily in emerging economies (IEA, 2015a). Decision making priorities differ significantly between the building and industry sectors where short-term energy prices for industries often have a large impact on energy efficiency decisions, particularly at the point of in-plant investment (Steinbuks and Neuhoff, 2014).

\subsubsection{Energy Management, ISO 50001 and Energy Performance Monitoring}

Energy management systems help to reduce energy use by optimizing energy consumption across the entire production process through a suite of procedures and practices that ensure systematic tracking, analysis, and planning of energy use. This is done while keeping up with core industry priorities such as reduced costs, increased productivity, environmental compliance, and enhanced competitiveness. Energy management systems are an essential tool for sustaining continuous energy efficiency improvements in small- and medium-sized enterprises, as well as in large process-intensive industries (IEA, 2015b). ISO 50001 is the globally accepted standard for energy management systems.

Many governments mandate large energy end-users to implement energy management systems ${ }^{11}$. The recent Clean Energy Ministerial meeting in June 2016 put forward the aspirational goal of achieving global ISO 50001 certifications by $2020^{12}$, providing a new momentum to the promotion of energy management. Early pilot implementation of ISO 50001 showed that for companies with no existing energy management system, the average energy performance gains

10 Demand response is the ability to shift energy demand by reducing peak consumption and grid imbalance.

11 Most countries in Europe have made energy management central in their energy efficiency programmes. In Germany, companies implementing energy management and obtaining ISO 50001 may apply for a tax reduction. This has driven the adoption of ISO 50001 by the German industry, which accounts for more than 50 per cent of the 6,778 certificates issued in 2014 (ISO, 2014).

12 The CEM estimates that the worldwide implementation of ISO 50001 by large energy-using organizations could achieve cumulative energy savings of 62 Exajoules by 2030, cost savings of US\$600 billion, and 6,500 Mt of avoided $\mathrm{CO}_{2}$ emissions (CEM, 2016). 


\section{Box 5.2: Steam systems in China.}

In 2012, the economic emission reductions potential associated with industrial coal-fired steam systems in China was 1,687 PJ (or 23 per cent of the total fuel used in industrial coal-fired steam systems in the country in 2012). This corresponds to savings in $\mathrm{CO}_{2}$ emissions of 165,817 kilotonnes of $\mathrm{CO}_{2}$ (UNIDO, 2014). Optimization of the entire steam system (as opposed to boilers only) would result in much larger energy savings.

in the first one-to-two years ranged between 10 and 20 per cent of baseline consumption (UNIDO, 2015).

\subsubsection{Energy performance standards for industrial equipment}

Many industrialized countries already have mandatory minimum energy performance standards in place for a range of energy consuming equipment within industry. Emerging economies are following suit with the introduction of similar standards for motors and boilers (box 5.2) (13 $^{13}$.

While individual efficient components may often only bring about gains of up to 5 per cent, system optimization measures can attain more durable average efficiency gains of 20 to 30 per cent. The payback period for operational energy efficiency projects is often less than two years (UNIDO and UN Energy, 2010). This broader potential requires policy support, such as awareness raising, technical support and capacity building, which can break down the barriers for optimizing energy efficiency in the design, operation and maintenance of industrial systems.

\subsubsection{Delivering industrial energy efficiency through energy service companies}

An energy service company is a business that provides a range of energy services, including implementation of energy efficiency technologies and projects. In the industry sector, the most significant energy service company activities tend to focus on buildings.

Utility programmes for industrial energy efficiency provide an additional avenue for identifying projects that energy service companies could implement ${ }^{14}$. A good example is in Denmark, where utilities are responsible for actively seeking projects improving the energy efficiency of their end-users ${ }^{15}$.

13 Electric motors use two-thirds of the electrical consumption in industry (IEA, 2011), whereas steam generation represents 30 per cent of global final industrial energy use (UNIDO, 2014).

14 Unlike the ratepayer-funded programmes that are popular for households and commercial users, a utility programme for industrial energy efficiency should: (i) provide low-cost technical assistance in terms of training, networking and sharing of knowledge and best practices; (ii) offer a package of incentives providing both technical and financial support to industrial users; and (iii) develop long-term relationships/agreements with the industrial users to deliver sustained energy improvements.

15 Large industrial end-users are obliged to conduct energy audits and implement all energy efficiency projects with a payback period of up to four years. The Danish Energy Agency provides links to approved consultants and standards for the audits. It also compiles and shares best practice case studies.

\subsection{Transport}

In developed countries, passenger transport demand grows with income, until a certain income threshold has been reached (Dhar and Shukla, 2015), while freight transport demand appears to grow as a function of the type of commodity concerned. Demand for both passenger and freight transport in developing countries is likely to follow a similar trend.

To date, transport has relied almost exclusively on fossil fuels. Given likely trends in demand for transport in developing countries, emissions from the sector in these countries could grow substantially. For this reason, implementing sustainable transport solutions is critical.

Seventy-seven percent of the INDCs submitted before the $21^{\text {st }}$ Conference of the Parties to the United Nations Framework Convention on Climate Change identified transport as a key target sector for mitigation (Gota et al., 2015). Interventions quoted in these INDCs focus on actions to "improve" (141 INDCs), "shift" (66) or "avoid" (17), compared to current transport forms (Gota et al., 2015). Across national submissions, policy options like fuel economy standards, regulations for cleaner fuels, and reorienting development plans, play a key role.

\subsubsection{Vehicle Fuel Economy Standards and $\mathrm{CO}_{2}$ emissions}

Standards that specify fuel economy (average fuel consumption, for example, expressed as litre (L) per 100 $\mathrm{km}$ ) and/or $\mathrm{CO}_{2}$ emissions for new vehicles have been implemented in most industrialized countries and several developing countries (table 5.1). These policies have generally been successful, and the average fuel economy of new vehicles sold has improved significantly. However, standards are most effective when complemented with user charges that reflect actual road and environmental costs, levied according to vehicles' usage and emissions intensity performance.

Compliance monitoring and enforcement are necessary to ensure that the purported performance levels are being achieved (IEA, 2016c), and consumers can have confidence in energy efficiency. Fuel economy improvements will also deliver benefits related to improved public health from better air quality, reduced fuel costs, and increased energy security.

Regulations on fuel economy and emissions have also helped promote other types of vehicles, such as Battery 
Table 5.1: $\mathrm{CO}_{2}$ Emission targets and fuel economy standards for cars.

\begin{tabular}{|c|c|c|c|c|}
\hline Country & $\begin{array}{l}\text { Emission standards }{ }^{1} \\
\text { (grams of } \mathrm{CO}_{2} / \mathrm{km} \text { ) }\end{array}$ & $\begin{array}{l}\text { Fuel economy standards }{ }^{1} \\
(\mathrm{~L} / 100 \mathrm{~km})\end{array}$ & $\begin{array}{l}\text { Average fuel economy } 2013^{2} \\
\text { of new vehicles }(\mathrm{L} / 100 \mathrm{~km})\end{array}$ & $\begin{array}{l}\text { Reduction 2005-2013' } \\
(\mathrm{L} / 100 \mathrm{~km})\end{array}$ \\
\hline Japan & & $\begin{array}{l}5.95 \text { by } 2015 \\
4.93 \text { by } 2020\end{array}$ & 4.9 & -1.4 \\
\hline Canada & $\begin{array}{l}135 \text { by } 2016 \\
98 \text { by } 2025\end{array}$ & & 8.2 & -1.3 \\
\hline European Union & $\begin{array}{l}130 \text { by } 2015 \\
95 \text { by } 2021\end{array}$ & & 6.8 & -1.5 \\
\hline USA & $\begin{array}{l}132 \text { by } 2017 \\
89 \text { by } 2025\end{array}$ & $\begin{array}{l}6.4 \text { by } 2016 \\
4.2 \text { by } 2025\end{array}$ & 8.6 & -1.7 \\
\hline China & & $\begin{array}{l}6.9 \text { by } 2015 \\
5.0 \text { by } 2021\end{array}$ & 7.3 & -0.1 \\
\hline Republic of Korea & 97 by 2020 & 4.2 by 2020 & 6.0 & -2.7 \\
\hline India & $\begin{array}{l}130 \text { by } 2017 \\
113 \text { by } 2021\end{array}$ & 2016 & 5.6 & +0.2 \\
\hline
\end{tabular}

Source: ${ }^{1}$ UNEP, 2010, The International Council on Clean Transportation, 2016, ${ }^{2} \mathrm{GFEI}, 2016$.

Electric Vehicles and Plug-in Hybrid Electric Vehicles. Similarly, higher fuel and road taxes have encouraged the purchase of more efficient vehicles. Labelling, to inform consumers about the fuel consumption and $\mathrm{CO}_{2}$ emissions of a vehicle, thus allowing them to make more informed purchasing decisions, is implemented in the EU, the USA and other countries (Haq and Weiss, 2016). Vehicle maintenance, low rolling resistant tyres, tyre pressure, road maintenance, and driver behaviour, all influence the fuel efficiency of a vehicle. Combining policies and measures, as has been done in France, for example, makes it possible to achieve results in a more cost-effective manner.

\subsubsection{Electric Mobility for Passenger Transport}

In 2015, the global stock of electric cars was 1.26 million (IEA, 2016e). Electric vehicles use energy 70 per cent more efficiently than non-electric vehicles (Sims et al., 2014). However, when power generation losses are taken into account, the overall system efficiency balance needs to be considered on a case-by-case basis. In the long-term, electric vehicles are an important mitigation option through both end-use efficiency and decarbonization of electricity supply (Dhar et al., 2016). They also bring about substantial cobenefits, such as improved urban air quality.

In 2015, to increase the up-take of electric vehicles, a range of enabling policies were in place in 16 selected countries
(IEA, 2016e). Policies that help increase the up-take of electric vehicles can be grouped in three areas:

- Economic incentives: purchase incentives (France, Germany, Japan, UK, USA); tax exemptions, including waivers on excise tax (China); lower purchase tax, or lower registration tax (Netherlands, Portugal); and differential taxation on the basis of emissions.

- Urban initiatives: e-mobility plans in cities; increased network of charging stations; incorporation of electric vehicles in urban plans and bylaws; waivers on parking charges; and priority in urban traffic.

- Policy continuity: An important lesson from the success of Norway was that in addition to strong incentives, there was effective policy sequencing over many years (box 5.3).

Globally, the movement of electrification has been transitioning into other transport modes, including two-wheelers, three-wheelers and public transport. Electrification of transport has grown rapidly in China and India, where electric two-wheelers and three-wheelers are increasingly common, highlighting a need to offer diverse efficient travel modes and vehicles. China leads with around 200 million electric two-wheelers (IEA, 2016e). The sale of electric scooters in China started rising due to a ban on conventional vehicles in cities, to reduce air pollution. Other

\section{Box 5.3: Incentives for electric vehicles in Norway.}

Norway has one of the most ambitious programmes to foster the adoption of electric vehicles. In 2015, battery electric vehicles represented 18 per cent of the total car sales, which has been achieved through: (i) collaboration between government, private players and non-government organizations, (ii) publicly-supported charging stations (Figenbaum et al., 2015), and (iii) strong incentives for purchase and ownership of battery vehicles (Bjerkan et al., 2016). The case for decarbonization from electric vehicles is strong, as over 95 per cent of the electricity in Norway is supplied by hydroelectric power. The Norwegian government has supported the transition to electric mobility on a continuous basis and adjusted the policies with time to encourage adoption of electric cars. 
contributing factors were policies to allow e-bikes up to a certain weight limit to share right-of-way on bicycle lanes, and investments in charging stations in cities. The Chinese government has also implemented aggressive policies and incentives for electrification of public transport, including subsidies and investments in charging infrastructure for buses. Presently, China has over 170,000 electric buses (IEA, 2016e). Recently, India has announced policies and incentives to enable the adoption of electric vehicles.

The near-term challenges for electric vehicles include the currently high up-front costs, compared to conventional vehicles, and addressing the technical issues related to battery capacity, reuse and recycling. Battery costs have undergone significant reduction, from nearly US\$1,000 per kWh in 2007, to nearly US\$300 per kWh in 2015 (Nykvist and Nilsson, 2015), and are expected to further decease to less than US\$150 per kWh in the future (Bruce et al., 2012). Estimated cost reductions for cars could be nearly 50 per cent for battery electric vehicles, and 60 per cent for plug-in hybrid electric vehicles (Wolfram and Lutsey, 2016). These lower battery costs will significantly reduce the cost of electric vehicles and the amount of subsidies required in the future. Further improvements in battery technologies and vehicle performance are expected to ease the existing limitations of driving range and battery costs. The driving range issue is also being addressed by local governments through the provision of charging infrastructure. Efforts are also underway to find solutions for the re-use and recycling of batteries, including utilization of used car batteries as a source of storage within electric grids.

\subsubsection{Sustainable logistics/freight transportation}

Freight transport accounted for 45 per cent of transport sector energy demand in 2009 (Sims et al., 2014), and a similar share of $\mathrm{CO}_{2}$ emissions. More than 50 per cent of freight-related $\mathrm{CO}_{2}$ emissions come from road transport, especially heavy-duty vehicles (IPCC, 2014; Sims et al., 2014). Efficiency of freight transport can be improved through better utilization of freight capacity, decisions regarding siting of logistics facilities, routing of freight corridors, and a shift to more efficient and cleaner modes of transport, such as rail or water-borne transport. A modal shift away from road to rail can lead to substantial emissions reductions, since the emissions from rail are only a fraction per $\mathrm{km}$, compared to heavy-duty vehicles (Sims et al., 2014). This modal shift can deliver additional benefits, in the form of reduced local air pollution and accidents (Machado-Filho, 2009). India's Dedicated Freight Corridor project is an example of an integrated plan that aims to increase efficiency of freight transport, while ensuring overall economic development (box 5.4).

\subsection{Opportunities through systems thinking and integration}

Some mitigation opportunities are difficult to cover in a sectoral breakdown, but can still be very important. In general, the opportunities for increasing energy efficiency are moving from perfecting individual products to optimizing systems. This section highlights a couple of such opportunities.

\subsubsection{Urban systems: efficient settlement forms}

Cities are one of the biggest consumers of energy in the world, representing almost two-thirds of global primary energy demand, and accounting for 70 per cent of greenhouse gas emissions in the energy sector (IEA, 2016b). While most emissions in cities originate from the building, industry and transport sectors, a sizable share of these emissions could be avoided through city-level mitigation options, such as spatial planning (to ensure connectivity, accessibility, mixed land-use, and a certain level of density), improving transit options, increasing and co-locating employment and residential densities, and increasing green spaces. A growing number of cities are joining various non-state actor partnerships, in an effort to become more efficient, sustainable and low emitting. The growing role of non-state actors is discussed in Chapter 4.

\subsubsection{Lifestyles, behaviour, culture and consumption patterns}

More sustainable lifestyles in the form of changes in behaviour and consumption patterns, along with embedded cultural traditions and habits, are increasingly in focus as important means to achieving climate goals that cut across sectors. While policy making has traditionally focused on technological and economic solutions, changes in behaviour can often result in large energy savings (Allcott and Mullainathan, 2010; EEA, 2013).

Most studies agree that mitigation strategies involving lifestyles and behaviour do not need to imply compromises in living standards. Recent research points out that domestic

\section{Box 5.4: Dedicated freight corridors in India.}

The Indian government is prioritizing policies that help to shift freight transport from road to rail. This ambition was highlighted in India's INDC as an important strategy for decarbonizing the transport sector (UNFCCC, 2015). The INDC specifies a target of increasing the share of rail in land transportation (from 36 to 45 per cent by 2030) through investment in Dedicated Freight Corridors. These corridors will develop separate rail networks for freight transport (DFCCIL, 2016). India's INDC estimates that these corridors could reduce emissions by about 457 million tonnes of $\mathrm{CO}_{2}$ over 30 -years, a figure that could increase if electricity were decarbonized. 
energy saving potentials through behavioural measures range from 20-30 per cent, but could be substantially larger in the longer term (Karlin et al., 2015) ${ }^{16}$.

While both the understanding of and the policy toolbox addressing behavioural and lifestyle changes as mitigation strategies are very rudimentary, a few conclusions can be derived. Policies that can influence the choices of consumers typically focus on price signals (notably: subsidies, tax rebates, and taxes) and information disclosure - for example, mandated energy labels (Allcott and Mullainathan, 2010).

\subsection{Emerging opportunities}

Advances in information communication technology, including the internet, big data, smart technologies and systems, and shared economy platforms, social media, are revolutionising human activities and, consequently, energy consumption. While the impact of these is still being understood, it appears as though the economic emissions reduction potential is high, if these trends can be intelligently guided and opportunities seized.

\subsubsection{Circular and sharing economy}

Recent developments enable opportunities to utilise capacities to a much higher degree, which in turn helps the world move towards a more "shared economy", as people are increasingly using assets such as cars, bicycles, and apartments on a regular basis ${ }^{17}$. Similarly, dematerialization can shift manufacturing away from a linear to a circular economy.
The concept, based on a regenerative design principle, turns goods that are at the end of their service life into resources for others, closing loops in industrial ecosystems and minimizing waste (Stahel, 2016) ${ }^{18}$. Companies engaging in these production paradigms are inherently drawn to efficient production, distribution, recycling and materials supply chain practices. Large economies, such as the EU, are on their way to adopting the circular economy as the standard approach to material production and use.

\subsubsection{Information and communication technology} New information and communication technologies are expected to improve the efficiency of services with minimal environmental impacts, and also imply a certain degree of automation in decision making. Such systems can be applied to buildings to control heating, cooling, ventilation, lighting and utilities ${ }^{19}$, as well as in the industry and transport sectors. In the industry sector, instantaneous tracking of energy performance and a real-time measurement of energy use and savings allows for significant reduction in energy use. In transport, real-time access to traffic information allows for safer and more efficient uses of transport networks ${ }^{20}$.
16 Based on the review of behavioural measures across the EU, it was found that behavioural measures could achieve around 5-20 per cent reduction in energy consumption compared to previous consumption (EEA, 2013). A meta-analysis found that of the 29 energy feedback studies they surveyed with sample sizes over 100 , energy savings ranged from 0.5 to 13 per cent of previous consumption (Ehrhardt-Martinez et al., 2010).

17 For example, in 2015 , 980 cities globally had some type of public bikesharing programme (May, 2016). Public bike-sharing is the fastest growing mode of public transportation and has grown at an annual growth rate of 37 per cent since 2009 (Campbell et al., 2016). Similarly, many mainstream car manufacturers are promoting sharing electric vehicles, such as Daimler's Car2Go, BMW's Drivenow, among others.
18 Several developed countries including Germany, Japan and the USA have comprehensive regulations in place. Sharing and recycling are closely linked to behaviour and cultural issues, therefore, incentives for energy saving behaviour, including tax breaks, market levers and government support, will encourage higher adoption. In the last decade, China has taken initiatives to promote recirculation of waste materials through targets, policies, financial measures and legislation (Mathews and Tan, 2016).

19 Smart buildings can help deliver 10-15 per cent reduction in building energy use in the USA (Agarwal et al., 2010). Digitalization and building integrated modelling can help to design buildings with optimized material use and energy savings through the entire life cycle (WEF and Boston Consulting Group, 2016).

20 Increasingly, Information and Communication Technology is defining the need for travel through online shopping and ride-sharing, and has the potential to deliver emission reductions. For instance, online shopping could reduce $\mathrm{CO}_{2}$ emissions by 22 per cent from shopping trips in Sweden in 2030 compared to 2012 (Rosqvist and Hiselius, 2016). 


\title{
Chapter 6
}

\section{Bridging the gap - the Sustainable Development Goals and climate change mitigation}

\author{
Lead authors: Frank Sperling (University of Oxford), Ilmi Granoff (Overseas Development Institute)
}

Contributing authors: Eliza Northrop (World Resources Institute), Anne Olhoff (UNEP DTU Partnership), Andrew Scott (Overseas Development Institute)

\subsection{Introduction}

The international development agenda for the next 15 years was defined by the 2030 Agenda for Sustainable Development (the 2030 Agenda), adopted by 193 countries at the United Nations General Assembly in 2015 (UN, 2015). The agenda succeeds the United Nations Millennium Declaration, which established the Millennium Development Goals, and represents a considerable expansion in scope and ambition. It comprises 17 Sustainable Development Goals (SDGs) (see figure 6.1) and 169 associated targets, and takes a global perspective - seeking to provide a comprehensive, strategic direction to the economic, social and environmental dimensions of development.

Acknowledging the interdependence of the challenges, the SDGs are to be regarded as "integrated and indivisible", according to paragraph 18 of the 2030 Agenda (UN, 2015). The need for an integrated approach to the SDGs is nowhere more relevant than in the context of climate change. This chapter provides a brief overview of the challenges climate change poses to the SDGs. It then gives an initial qualitative assessment of key areas of alignment, trade-offs and opportunities between the SDGs and the climate change mitigation objectives of the Paris Agreement, focusing on selected SDGs and associated targets.

SDG13 constitutes the 2030 Agenda's climate change goal. It does not provide concrete mitigation targets or proposed limits to global warming. It, instead, targets strengthening the resilience to climate-related hazards, mainstreaming climate change into policy and strategic planning processes, awareness building and capacity development, and funding. For more concrete and measurable mitigation and adaptation objectives, the 2030 Agenda expressly recognizes the United Nations Framework Convention on Climate Change (UNFCCC) as the authoritative body for defining global policies on climate change (see UN, 2015).
The Paris Agreement, thereby, frames a boundary condition for the implementation of the SDGs.

\subsection{The SDG-mitigation nexus}

During the period of dialogue and negotiation for the SDGs, a number of studies sought to catalogue the interrelationships, synergies and trade-offs between the proposed goals and climate change (WWF and CARE, 2015; Scott and Picot, 2014; Picot and Moss, 2014; Munro, 2014; Marston, 2014; Leong, 2015; Ansuategi et al., 2015). These studies considered relevance from both SDG impacts on climate, and climate impacts on the SDG, with a range of methodologies and results. Some studies focused on the explicit mentioning and recognition of climate change in the target formulation of different SDGs, while others placed stronger emphasis on sector specific linkages.

\subsubsection{Climate change jeopardizes maintenance of progress against the SDGs}

The Intergovernmental Panel on Climate Change (IPCC) assessment reports have identified the human impacts of climate change with increasing confidence (IPCC 2001, 2007, 2014a). This has led to growing concern for the long-term sustainability of development progress, and impacts on the poor, in particular, in the absence of appropriate risk management practices and steep reductions in greenhouse gas emissions (see for example AfDB et al., 2003; Stern Review, 2007; World Bank, 2010; Hallegatte et al., 2016; Granoff et al., 2015).

The need to strengthen resilience to climate change is a repeated concern in the SDGs. It is not only reflected in SDG13 on climate change, but also under several other goals, such as those related to ending poverty (SDG1), ending hunger (SDG2), building infrastructure (SDG9), and improving cities and human settlements (SDG11). Adaptation 
to climate change is a necessary, complementary measure to mitigation, but does not substitute for closing the emissions gap, as with progressive levels of warming, adaptive capacities of several natural and human systems may no longer be able to cope with the rate and magnitude of change, and the risk of crossing tipping points with large-scale irreversible consequences may increase (Schneider et al., 2007; Lenton et al., 2008; Schleussner et al, 2016).

Among the chief findings of analyses to date is that the impacts of climate change may undermine our ability to deliver the SDGs by 2030. Analysis by the World Bank (Hallegatte, 2016) estimates that absent, rapid and inclusive development practices, climate change could result in an additional 100 million people living in extreme poverty by 2030, slowing progress against SDG1.

Ansuategi et al. (2015) assessed the risk of failure to achieve the SDGs under high- and low-ambition climate change agreement outcomes at Paris. Their analysis identified a medium risk, even under the high-ambition scenario, of failing to achieve the SDGs related to health (SDG3); gender equality (SDG5); clean water and sanitation (SDG6); sustainable consumption and production (SDG12); life below water (SDG14); and life on land (SDG15). With the low-ambition scenario there would be a high risk of failing to achieve 10 of the 17 SDGs.

As impacts become increasingly certain in the post-2030 period, they also become highly likely to undermine the ability to maintain progress against many of the SDGs beyond 2030. Looking only at the best understood pathways by which climate change impacts poverty targetsagricultural productivity, climate extremes, and corollary childhood malnutrition and developmental stuntingGranoff et al. (2015) found that these factors alone could impact up to 750 million people in extreme or moderate poverty by 2050 .

Climate-exacerbated extreme weather events will also likely impact urban populations severely. Half of humanity lives less than 60 kilometres $(\mathrm{km})$ from the coast, and three-quarters of all large cities are located in coastal areas (UNEP, 2016). Urban impacts of climate change have been well noted, if less well quantified (Hallegatte, 2016), but clearly interfere directly with targets to improve infrastructure (SDG9) and develop sustainable cities (SDG11), and will have consequent drags on poverty eradication (SDG1) and other goals.

Figure 6.1: The Sustainable Development Goals (Source: UN, 2015).
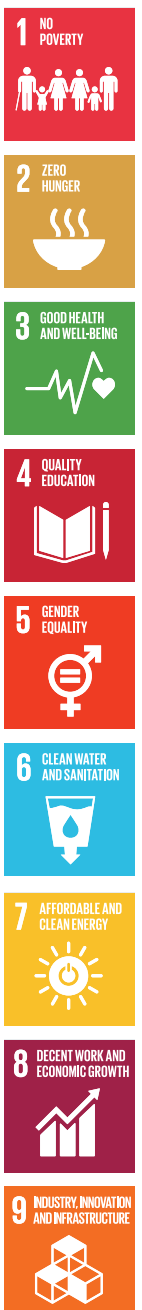

End poverty in all its forms everywhere

End hunger, achieve food security and improved nutrition and promote sustainable agriculture

Ensure healthy lives and promote well-being for all at all ages

Ensure inclusive and equitable quality education and promote lifelong learning opportunities for all

Achieve gender equality and empower all women and girls

Ensure availability and sustainable management of water and sanitation for all

Ensure access to affordable, reliable, sustainable and modern energy for all

Promote sustained, inclusive and sustainable economic growth, full and productive employment and decent work for all

Build resilient infrastructure, promote inclusive and sustainable industrialization and foster innovation

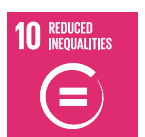

Reduce inequality within and among countries

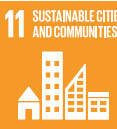

Make cities and human settlements inclusive, safe, resilient and sustainable

Ensure sustainable consumption and production patterns
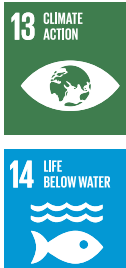

15 OIfLEN
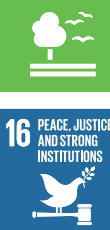

17 PARINERHHPS

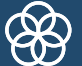

Take urgent action to combat climate change and its impacts*

Conserve and sustainably use the oceans, seas and marine resources for sustainable development

Protect, restore and promote sustainable use of terrestrial ecosystems, sustainably manage forests, combat desertification, and halt and reverse land degradation and halt biodiversity loss

Promote peaceful and inclusive societies for sustainable development, provide access to justice for all and build effective, accountable and inclusive institutions at all levels

Strengthen the means of implementation and revitalize the Global Partnership for Sustainable Development
Notes: The SDGs are global goals on the economic, social and environmental dimensions for sustainable development. They are further specified through 169 associated targets.

* Acknowledging that the United Nations Framework Convention on Climate Change is the primary international, intergovernmental forum for negotiating the global response to climate change. 


\subsection{The role of the SDGs in reducing greenhouse gas emissions: path- alignment and path-contingency}

While the SDGs are highly interdependent, the relationships are not always inherently mutualistic (Nilsson et al., 2016). Prior authors have emphasized the potential for conflict between certain SDGs and climate change objectives. The remainder of this chapter explores a complementary approach, analysing the SDGs particularly relevant for mitigation, divided into two key areas: agriculture, forestry and other land-uses, and energy-related emissions. Certain goals and associated targets are defined in ways that are synergistic, or "path-aligned". Their achievement will generally facilitate the achievement of the mitigation objectives of the Paris Agreement. Others are defined in ways that may or may not be antagonistic with these mitigation objectives, depending on how they are pursued.

Table 6.1: Path-alignment and path-contingency of selected SDGs

\begin{tabular}{|c|c|c|c|}
\hline SDG & Topic & Alignment & Analysis \\
\hline SDG2 & $\begin{array}{l}\text { Hunger and food } \\
\text { security }\end{array}$ & Path-contingent & $\begin{array}{l}\text { Target } 2.4 \text { emphasizes the need for alignment of improvements in sustainability and } \\
\text { productivity, and pursuit of hunger and food security objectives, and increases in } \\
\text { agricultural productivity envisioned in targets } 2.3 \text { and } 2 \text {.a have the potential to materially } \\
\text { increase emissions if they lead to extensification, soil degradation and other effects at odds } \\
\text { with reduction of agriculture, forestry and other land-use emissions. Alternatively, these } \\
\text { could align effectively with climate goals if pursued in an integrated fashion with target } 2.4 \text {, } \\
\text { and taking into account the opportunities to reduce food losses and improve distributional } \\
\text { considerations. Impacts of improvements to productivity depend on technology, policy and } \\
\text { context significantly, and thus alignment of the SDG is contingent upon these factors. }\end{array}$ \\
\hline SDG7 & $\begin{array}{l}\text { Sustainable Energy } \\
\text { Access }\end{array}$ & Path-aligned & $\begin{array}{l}\text { The specific energy demands of universalizing energy access under target } 7.1 \text { are low, } \\
\text { and there is formidable evidence that the preponderance are best served by low-carbon } \\
\text { distributed technologies. The risk of potential trade-offs between expanded energy } \\
\text { consumption and climate objectives are embedded within other SDGs, such as SDGs } 8 \text { and } \\
9 \text { discussed below. Targets } 2.2 \text { and } 2.3 \text { aim to promote increases in renewable energy and } \\
\text { energy efficiency, and greater success against these targets directly serves the mitigation } \\
\text { objectives of the Paris Agreement. }\end{array}$ \\
\hline SDG8 & $\begin{array}{l}\text { Growth and } \\
\text { employment }\end{array}$ & Path-contingent & $\begin{array}{l}\text { Historic economic growth has been strongly correlated with greenhouse gas emissions. } \\
\text { While the goal heading itself makes reference to sustainability, the only target level } \\
\text { reference to sustainability is with respect to "sustained growth" under target } 8.1 \text {, leaving } \\
\text { open the mitigation implications of growth pathways on its face. Target } 8.4 \text { discusses } \\
\text { decoupling of growth from environmental degradation generally but focusing on the } \\
\text { sustainability of consumption and production as per SDG15. Growth's historic correlation } \\
\text { with increased greenhouse gas emissions underscores that the compatibility of this SDG } \\
\text { with the mitigation objectives of the Paris Agreement hinges on the ability of growing } \\
\text { economies to accelerate the decoupling economic output from emissions. }\end{array}$ \\
\hline SDG9 & $\begin{array}{l}\text { Infrastructure, } \\
\text { industrialization, } \\
\text { and innovation }\end{array}$ & Path-contingent & $\begin{array}{l}\text { Targets } 9.1,9.4 \text { and 9.a focus on the expansion of infrastructure. Infrastructure } \\
\text { development is paradoxically a strong correlate of emissions growth, and a critical } \\
\text { requirement to decarbonization. This is because incumbent infrastructure choices have } \\
\text { been associated with increases in energy demand and intensity and land use change: } \\
\text { decarbonization will require both the replacement of incumbent infrastructure and } \\
\text { expansion of infrastructure services through low-carbon options. Some infrastructure locks } \\
\text { in patterns of inefficiency, other choices lead to decarbonization, energy efficiency, and } \\
\text { pollution reduction. The result of these targets on emissions will be highly contingent on } \\
\text { the nature of these infrastructure choices. } \\
\text { Targets } 9.2 \text { and 9.3. focus on the promotion of industrialization. While target } 9.2 \\
\text { does acknowledge the need for "sustainable" industrialization, historic processes of } \\
\text { industrialization have been drivers of emissions growth. New paths of industrialization, } \\
\text { particularly if enabled by innovation promoted under targets } 9.5,9 . b \text { and supplied with } \\
\text { low-carbon energy sources, have the potential change this historical pattern if innovation } \\
\text { is geared toward decarbonizing technologies and processes. The emissions implications of } \\
\text { the target are therefore contingent upon realizing this potential. }\end{array}$ \\
\hline SDG11 & Sustainable Cities & Path-aligned & $\begin{array}{l}\text { The } 10 \text { targets of the goal are generally well-aligned as seven of the ten targets as-drafted } \\
\text { focus on measures that expressly improve the resource efficiency of urban form, and thus } \\
\text { also ones that benefit climate: factors to achieve them would be policies that improve, } \\
\text { for example, compactness, public transport, and other efficiency inducing measures. } \\
\text { Target } 11.1 \text { on access to housing does leave open the possibility of climate-conflicting } \\
\text { approaches, but the goal taken as a whole emphasizes that improvements to urban form } \\
\text { entail measures that are sustainability enhancing. }\end{array}$ \\
\hline SDG12 & $\begin{array}{l}\text { Sustainable } \\
\text { consumption and } \\
\text { production }\end{array}$ & Path-aligned & $\begin{array}{l}\text { Improving the resource-use efficiency of production, reducing pollution and promoting } \\
\text { more sustainable consumption patterns diminish the pressure on the environment, } \\
\text { including impacts on the climate. This makes the targets under this goal well aligned with } \\
\text { SDG14. Achievement of these targets will also further the scope for the climate-alignment } \\
\text { of agricultural production, industrialization, and corollary economic growth under SDGs 2, } \\
8 \text { and 9, respectively. }\end{array}$ \\
\hline SDG15 & $\begin{array}{l}\text { Terrestrial } \\
\text { Ecosystems }\end{array}$ & Path-aligned & $\begin{array}{l}\text { Terrestrial ecosystems, particularly forests, hold large carbon stocks that, if disrupted, } \\
\text { could have severe consequent emissions. The halting of deforestation is an important lever } \\
\text { for agriculture, forestry and other land-use mitigation. While carbon stock preservation } \\
\text { does not necessarily serve all of the objectives of terrestrial ecosystems preservations } \\
\text { found in SDG 15's targets, the targets are largely salutary to mitigation efforts. }\end{array}$ \\
\hline
\end{tabular}


Hence, they are considered to be "path-contingent". With these goals and targets, strategic choices matter. Once these choices about how to achieve these SDGs are made, they may be difficult or costly to reverse.

Table 6.1 identifies SDGs that fall under each category, with a brief rationale. The approach focuses on the specific definition of SDG goals and targets, and what this means for their ability to align or conflict with the mitigation objectives of the Paris Agreement. Goals are regarded as path-aligned, where both the overarching SDG and individual targets are expressly defined in a way that reinforces the mitigation objectives of the Paris Agreement. Goals are also regarded as path-aligned if several associated targets are synergistic to mitigation objectives and others primarily neutral -that is, collective progress on the goal does not impede simultaneous progress towards the mitigation objectives of the Paris Agreement. Goals are regarded as path-contingent, where either the goal or one or more targets are defined in a way capable of undermining the mitigation objectives of the Paris Agreement, depending on how it is pursued.

\subsubsection{SDG implications for agriculture, forestry and other land-use based greenhouse gas emissions}

Agriculture, forestry and other land-uses account for around 25 per cent of annual global greenhouse gas emissions (Smith et al., 2014). The goals and targets related to universal food security (SDG2) and sustainable management of terrestrial ecosystems (SDG15) are specific examples of areas where multiple interests in the land-use context converge. How these interests are integrated in development policies and practice will have implications for progress towards the mitigation objectives of the Paris Agreement.

\section{Hunger and food security (SDG2): Path-contingency}

Food security improved during the Millennium Development Goals, but close to 800 million people continue to suffer from hunger, and the global community fell short of the stated Millennium Development Goal ambition of halving the proportion of chronically undernourished people between 1990 and 2015 (FAO, IFAD and WFP, 2015).

While ending extreme hunger and achieving food security remain central concerns of the SDGs, SDG2 also represents an expansion in scope. The goal now targets the eradication of all forms of malnutrition, taking both undernourishment and nutritional quality into account. It also targets the improvement of agricultural productivity, especially for small-scale producers (target 2.3, UN, 2015), and provides strategic guidance on how to achieve this, assigning particular importance to sustainable food production systems and resilience of agriculture practices (target 2.4, UN, 2015).

How societies decide to meet food security and nutrition targets will have direct implications for agriculture-related emissions, and indirect implications through agriculture's impact on maintaining forests and sustaining terrestrial ecosystem functions (SDG15). While more quantitative understanding of SDG interactions is needed, early results from integrated assessments highlight that single sector policies may harbour considerable policy trade-offs, while a system's perspective informing policy formulation can help anticipating and minimizing these (Obersteiner et al, 2016; see also von Stechow et al, 2016 on climate and energy related SDGs). For example, Obersteiner et al. (2016) show that for land-use decisions, the interactions between environmental and food security outcomes are more tightly associated with each other than population and economic growth scenarios ${ }^{1}$. Furthermore, an emphasis on measures that reduces energy and other consumption demand, generally benefits overall development concerns by freeing up solution space for other SDGs, including on food security and infrastructure (Obersteiner et al., 2016; von Stechow et al., 2016).

Alexandratos and Bruinsma (2012) project substantial increases in global food consumption accompanied with structural changes in diets, expecting that by 2050 around 52 per cent (or 4.7 billion people) of the world population will live in countries with a national average of 3,000 kilocalories per person per day in comparison to 28 per cent (1.9 billion people) today. How malnourishment-related to both overand under-consumption-is addressed through agricultural practices, land-use choices and distributional choices will have implications for aligning mitigation efforts with the objectives of the Paris Agreement. The choice of policies and measures that integrate productivity demands with an advancement of sustainable agricultural practices will influence the level of emissions from land-use (Valin et al., 2013), as well as the pressure on biodiversity, natural ecosystems, and forests (SDG15).

As Section 3.2 showed, almost all 1.5 and $2^{\circ} \mathrm{C}$ pathways currently available assume negative emission technologies during the second half of the century. This has consequences for available land-use options and, hence, the ability to achieve other SDGs that depend on the ecosystem goods and services provided by land. Land-use based technologies, such as bioenergy carbon capture and storage, afforestation and reforestation, and biochar are among the most promising negative emission technologies. Depending on the type and scale of negative emission technologies deployed, there may be synergies or trade-offs with land demand for food security and environmental conservation targets. For example, soil carbon sequestration and biochar applications can be applied on existing agricultural lands, do not require specific land-use changes, and are also considered to have beneficial impacts on soil nutrients and land productivity, while having negligible impacts on water-use and albedo (Smith, 2016). By contrast, increased deployment of bioenergy carbon capture and storage, as well as afforestation and reforestation activities, may require land-use changes. Locally, their deployment may conflict with certain means to achieve food security targets, and vice versa (Hasegawa et al., 2015).

1 The existing literature on the food-energy-water-environment nexus offers further insights on policies and practices aimed at managing interactions in the land-use space (Biggs et al., 2015; Howells et al., 2013; Ringler et al., 2013). 
The supply-side mitigation options focusing on changes in technologies and practices in the land-use context, discussed above, may support or compete with food security. Demandside measures addressing consumption levels, by contrast, are expected to synergistically address both food security and climate change concerns, but require large-scale behavioural change if their potential is to be realized (Smith et al., 2013).

Hence, the consequences of pursuing SDG2 will be pathcontingent. The multiple objectives in the land-use context need to be carefully integrated, taking into account development needs, livelihood security and environmental sustainability.

\section{Sustainable management of terrestrial ecosystems (SDG15): Path-alignment}

SDG15 on sustainable management of terrestrial ecosystems emphasizes reversing and halting trends in forest loss, land degradation and biodiversity (UN, 2015). The advancement of the specific targets of the goal are well aligned with enabling progress towards the mitigation objectives of the Paris Agreement.

Target 15.2 stipulates that by 2020 deforestation should be stopped, and accompanied by restoration of degraded forests and an increase in the global area under afforestation or reforestation. Target 15.2 is unusual in aiming for completion of the target a decade earlier than most SDGs. Its timely achievement will be critical for the SDG on climate change, in light of the important role that forests play as stores of terrestrial carbon (Smith et al., 2014; UNEP, 2015), and the importance of early action outlined in Chapters 2 and 3 of this report.

While well aligned with mitigation objectives, SDG15 also leaves some challenges to be resolved. The target implies zero deforestation on a global scale, but does not specify whether this is achieved by conservation of existing forest stocks, or by achieving zero "net" deforestation through offsetting afforestation and reforestation. The world community is called upon to realize a "substantial increase afforestation and reforestation globally" (see target 15.2, UN, 2015). However, it is not specified what a "substantial" increase means, and the extent to which there is a differentiation between primary and secondary forest is similarly unclear.

Target 15.5 is focused on reducing the degradation of natural habitats, halting the loss of biodiversity and, by 2020, protecting and preventing the extinction of threatened species (UN, 2015). While there are regional differences, there is generally a strong association between natural forests and high levels of biodiversity and carbon stocks (Strassburg et al., 2010). This makes achievement of target 15.5 further the goal of avoiding emissions related to land-use conversion from forest stocks. However, SDG15 also illustrates that targets need to be considered collectively: while highbiodiversity forest protection may help achieve SDG13, a focus on forest cover and afforestation for mitigation value, alone, may overlook important biodiversity considerations.

\subsubsection{Implications of SDGs for energy-related emissions}

Energy-related emissions are responsible for just over threequarters of global greenhouse gas emissions (IPCC, 2014a; also see Chapter 2). Energy is also critical for development. In addition to SDG7 on energy, a number of other goals have substantial energy and, therefore, climate change mitigation implications. In particular, these include SDG8 on growth and employment, SDG9 on infrastructure, industrialization, and innovation, SDG11 on sustainable cities, and SDG12 on sustainable consumption and production. The following sections look at where energy-intensive SDGs are path-aligned or path-contingent with climate change mitigation objectives.

\section{Universal access to affordable, reliable, sustainable and} modern energy (SDG7): Path-alignment

SDG7 comprises a universal access target, a renewable energy target and an energy efficiency target (see also Chapter 5). Given the importance of energy to climate change, SDG7 is closely interdependent with the mitigation objectives of the Paris Agreement.

Target 7.1 aims to achieve universal access to affordable, reliable, sustainable and modern energy by 2030 . One in six people lack access to modern electricity services, and two in five lack access to modern cooking services (IEA and World Bank, 2015). Although delivering basic access to energy for poor people-defined for electricity as 250 kilowatt hours annually for rural households, and 500 kilowatt hours annually for urban households-will result in an increase in energy consumption by people currently living below the poverty line, achieving the target will not have material implications for global emissions. Flat economies of scale for renewable energy (unit costs change relatively little for installations below a few megawatts) means that they are effective at delivering electricity services with small, off-grid or distributed installations appropriate to the rural areas where most of those lacking access today live. This flexibility, along with the rapid decline in costs, has made sustainable distributed energy open a tremendous opportunity to achieve universal access, even before 2030 (Power for All, 2016). Aggressive strategies for universal electricity access are climate compatible, since they require much greater investment in the diffusion of flexible, easily distributed, and predominantly renewable energy technologies, like minihydro, solar-pv, and solar-diesel hybrids (IEA, 2011; Szabó et al., 2011). The objective of universal access to safe, modern and reliable energy services by 2030 is, therefore, aligned with the promotion of low-carbon, renewable technologies, particularly decentralized ones (Hogarth and Granoff, 2015). Even if universal access to modern energy services was achieved using older carbon intensive technologies, the International Energy Agency estimates that it would result in a modest increase in global greenhouse gas emissions of 0.7 per cent (IEA, 2011).

Targeting universal access focuses on a benchmark of basic access to ensure that no one is left behind, much like benchmarking against extreme poverty or hunger 
goals. This, of course, does not capture the broader energy demands associated with development across the full range of SDGs. Most projected growth in energy demand is driven by consumption from wealthier income groups, and for industrial and commercial uses in emerging economies. In 1990, consumption in high-income countries accounted for 63 per cent of the world's total primary energy supply. By 2014 this share had fallen to 48 per cent, while the share of upper middle-income countries had risen to 34 per cent (IEA and the World Bank, 2015). According to the International Energy Agency's New Policies Scenario, by 2040, energy consumption in Organisation for Economic Co-Operation and Development (OECD) countries will be 3 per cent lower than it is today-all of the growth in demand is in non-OECD countries (IEA, 2015a; also see Section 3.4 and Chapter 5). However, per capita energy consumption in these countries will still be less than half the OECD average. The energy consumption of this cohort of middle-income countries, and the growing middle class and industries within them, will be very important for meeting climate targets. In this context, the transformation of the energy sector toward low-carbon and renewable supply will also be critical, as will improvements in energy efficiency that dampen demand growth for the same or better energy services.

Targets 7.2 and 7.3 aim at the material increase of renewable energy and energy efficiency, respectively. Both avenues to mitigation have been identified by the IPCC as critical for the energy sector (IPCC, 2014b). Therefore, achieving these goals is entirely aligned with, albeit not alone sufficient for, the transformation of the energy system necessary for achieving the mitigation objectives of the Paris Agreement.

Target 7.2 does not specify a measureable objective, but most countries have adopted the objective of the Sustainable Energy for All initiative, launched in 2011 and supported by most governments. It aims to double the proportion of renewables in the global energy mix, between 2010 and 2030 (IEA and World Bank, 2015). Although generation capacity, globally, is still dominated by incumbent high-carbon technologies, the use of low-carbon energy is growing rapidly. Renewables accounted for about half of new power generation capacity in 2014 (Frankfurt SchoolUNEP Centre and BNEF, 2016); over half (53.6 per cent) of the capacity installed in 2015 was in renewables (BNEF, 2016). In 2014, 85 per cent of the increase in power generated was from renewables (IEA, 2015a). Sustainable Energy for All estimates that between 2010 and 2012, the share of renewable energy in total final energy consumption globally increased from 17.8 per cent to 18.1 per cent. However, this rate of increase is well below what will be required to achieve the Sustainable Energy for All target, which is equivalent to a renewables share of 36 per cent (IEA and the World Bank, 2015). Only eight of the 20 largest energyconsuming countries increased their renewables share between 2010 and 2012 (IEA and the World Bank, 2015). Comparing projections to 2030, the International Renewable Energy Agency concluded that, "even ambitious scenarios aimed to drastically mitigate emissions and climate change leave significant gaps if compared to the Sustainable Energy for All objectives" (IRENA, 2013).

The SDG energy efficiency target (7.2) implies a 2.6 per cent annual rate of reduction in energy intensity (IEA and World Bank, 2015). According to the International Energy Agency, energy intensity globally reduced by 2.3 per cent in 2014, which was more than double the average over the previous decade (IEA, 2015b). To drive higher rates of improvement in energy efficiency, the Global Commission on the Economy and Climate recommend the convergence across countries of the current best energy efficiency standards for appliances, transport, buildings and industry (Bishop, 2015).

\section{Growth and employment (SDG8) and infrastructure, industrialization and innovation (SDG9): Path-contingency}

Energy, and concomitant climate impacts, is implicit but critical to two other SDGs: growth and employment (SDG8) and infrastructure, industrialization and innovation (SDG9). The implications of achieving the targets under these goals are largely conditional on the pathway by which those goals are achieved. At a global level, the link between economic output and greenhouse gas emissions has weakened (IEA, 2015b), suggesting the potential for low-carbon economic growth (see Chapters 2 and 3). For developed countries, the rate at which they can decouple their economic output from emissions will be critical to meeting SDG8, together with SDG13. The energy intensity of economic growth must decline by 4 to 10 per cent per year between now and 2050 (Loftus et al., 2015).

For low- and middle-income economies, the industrialization and urbanization associated with economic transformation have generally been linked with increases in emissions, primarily via increases in energy consumption and intensity. Declines in emissions associated with industrialization and urbanization tend to be related to high-income countries ( $\mathrm{Li}$ and Lin, 2015). The difference between these two effects has been attributed to the energy implications of durable infrastructure development and structural changes to less energy-intensive sectors (Li and Lin, 2015). This, in turn, leads to the path-contingent implications of infrastructure targets. Development of low-carbon infrastructure is regarded as critical to most mitigation scenarios, and yet infrastructure development is most closely associated with increased emissions, as countries have historically developed.

The mitigation challenge for infrastructure is that it will need to meet both demand growth and the replacement of legacy high-carbon infrastructure stocks at an accelerated pace (Granoff et al., forthcoming). This challenge occurs in the context of a global infrastructure gap, with infrastructure falling short of optimal levels by 70 per cent (IMF, 2014). Most governments face political hurdles to allocating sufficient resources - by raising revenue or financing - to meet infrastructure needs, while poor countries face an inadequate tax base and little ability to raise debt. 
Evidence, however, suggests that future economic growth, underpinned by urbanization, industrialization and associated infrastructure development, is enhanced by lowcarbon pathways (New Climate Economy, 2014). Historic patterns have occurred in a context of vastly different technological options. Consider, for example, the limited availability of low-carbon technologies at the time of France's rapid decarbonization, compared to the wider range of available technologies today. Further, close analysis of the relationship between urbanization and industrialization show the potential for each to be associated with either increases or declines in energy intensity (Sadorsky, 2013).

Further progress with respect to the energy goal (SDG7), by improving low-carbon energy supply and diminishing energy intensity through efficiency measures, would expand the "operating space" for progress on growth and employment (SDG8) and infrastructure, industrialization and innovation (SDG9) in a manner more compatible with achieving the mitigation objectives of the Paris Agreement. Likewise, though, the alignment of SDG8 and SDG9 with climate goals is contingent on the emissions intensity of energy consumption implicit within those goals.

\section{Sustainable cities and consumption and production (SDG11 and SDG12): Path-alignment}

SDG11 addresses issues central to any long-term mitigation strategies, focusing on affordable housing, universal access to public transport, reducing the per capita environmental impact of cities, and providing access to safe, inclusive, and accessible green and public spaces. SDG12 on sustainable consumption and production is similarly path-aligned with the mitigation objectives of the Paris Agreement through a focus on improving the resource-use efficiency of production, reducing pollution and promoting more sustainable consumption patterns. Not only will achievement of these targets reduce emissions, but also further the scope for alignment between agricultural production, industrialization, and economic growth under SDGs 2, 8 and 9, respectively. The two goals are inextricably interlinked. SDGs 11 and 12 aim to address demand-side emission reductions by transforming the way people live, and how they produce and consume.

Cities and human settlements are critical to emissions reductions, as well as to adaptation and building resilience to climate impacts. Cities consume $60-70$ per cent of the world's energy supply, and account for 70-80 per cent of total global carbon dioxide $\left(\mathrm{CO}_{2}\right)$ emissions due to energy generation, transport, industry, and biomass use (Tsay and Herrmann, 2013). In 2014, the commitments made by 228 global cities (representing 436 million people) were estimated to result in cumulative emissions reductions of 6.1 gigatonnes carbon dioxide equivalents $\left(\mathrm{GtCO}_{2} \mathrm{e}\right)$ by 2030 and $13 \mathrm{GtCO}_{2}$ e by $2050^{2}$ (ARUP and C40 Cities, 2014; see also Chapter 4). Harnessing these commitments will be crucial to achieving the mitigation goals of the

2 This corresponds to annual emission reductions of $0.402 \mathrm{GtCO}_{2} \mathrm{e} /$ year in 2030 and $0.43 \mathrm{GtCO}_{2} \mathrm{e} /$ year in 2050 as reported in Chapter 4.
Paris Agreement (Articles 2 and 24, UNFCCC, 2015). Transport in particular, much of it in urban areas, is a key sector for climate change mitigation. In 2010, the transport sector accounted for 27 per cent of final energy use, and emissions of $6.7 \mathrm{GtCO}_{2}$ (IPCC, 2014). The World Energy Council warns that, without strong global action, car ownership worldwide is on track to more than double, to over two billion vehicles by 2050 , with a correlated increase in the demand for diesel and fuel oil of up to 200 per cent (World Energy Council, 2011). According to the Paris Process of Mobility and Climate (2015) nearly three-quarters of countries prioritize the transport sector and 61 per cent include transport sector specific mitigation measures in their Intended Nationally Determined Contributions (INDCs) under the Paris Agreement.

SDG11 comprises 10 targets, of which nine are well aligned with the mitigation objectives of the Paris Agreement. Seven of them are drafted with express attention to sustainability and efficiency considerations, while two of the remaining address disasters and impacts on cultural and natural heritage sites. Of the 10 targets, only one relating to ensuring universal access to housing and basic services has the potential for material climate implications without making specific reference to sustainability considerations. The challenge for achieving this and other targets relating to universal and inclusive access to housing, sustainable urbanization and safe green and public spaces in a manner that is path-aligned with SDG is to reconcile the short-term demand with longer-term sustainability requirements. Governments must adopt approaches that support the construction of homes and urban spaces using green building techniques in suitable locations that also provide a range of transportation choices to avoid undermining the achievement of other targets under SDG11. Implementation of the targets under SDG11 must be undertaken holistically to avoid perverse outcomes, such as building affordable homes in areas vulnerable to climate impacts like rising seas or extreme weather events, or in dispersed housing development lots.

Transforming consumption and production patterns under SDG12 is also a core component of the goal under the Paris Agreement to reach net zero emissions in the second half of this century (Article 4, UNFCCC, 2015). According to the Food and Agriculture Organization of the United Nations, the energy used for the global production, harvesting, transporting and packaging of wasted food generates 4.4 $\mathrm{GtCO}_{2} \mathrm{e}$ annually, or about 8 per cent of total anthropogenic greenhouse gas emissions (FAO, 2016). This means that the contribution of food wastage emissions to global emissions is almost equivalent to that of global road transport (IPCC, 2014a), which emphasizes the central importance of both SDG11 and SDG12 to achieving the mitigation objectives of the Paris Agreement.

The final target under SDG12 addresses the market distortions that prevent a shift to sustainable patterns of consumption and production, and calls for rationalizing inefficient fossil fuel subsidies (target 12.c, UN, 2015). In 
2015, around 13 per cent of global energy-related $\mathrm{CO}_{2}$ emissions were from subsidized fossil fuels (IEA, 2015b). The International Energy Agency estimates that this provides an average incentive to emit $\mathrm{CO}_{2}$ of US\$115 per tonne of $\mathrm{CO}_{2}$. According to the IEA (2015b) efforts have been made in developing countries to reduce consumption subsidies, and in developed countries to reduce producer subsidies for investment in fossil fuel extraction. Fossil fuel subsidies remain a significant impediment to sustainable development and climate change mitigation.

\subsection{Summing up}

This chapter has outlined how selected SDGs and associated targets are aligned, while others potentially conflict with the climate change mitigation objectives of the Paris Agreement. For SDGs that are path-contingent, there is often general or even specific knowledge of the "dos" and "don'ts" of particular policies and practices that can help to minimize trade-offs and maximize synergies between different interests. Previous United Nations Environment (UNEP) Emissions Gap Reports have discussed such best practices for a number of key sectors and issues including agriculture, buildings, energy, forestry, and transport (UNEP 2012, 2013, 2014 and 2015).

The need for an integrated approach to the sustainable development and the realization of the SDGs is nowhere more relevant than in the context of climate change. The potential to meet the long-term temperature objective of the Paris Agreement rests within the framework that the SDGs provide. Equally, the potential to achieve the SDGs rests with our ability to address the climate change mitigation challenge. 


\section{References}

\section{Chapter 1}

UNEP (2015) The Emissions Gap Report 2015: A UNEP Synthesis Report. Nairobi: United Nations Environment Programme (UNEP). Available at: http://uneplive.unep.org/media/docs/theme/13/EGR_2015_Technical_Report_final_version.pdf [Accessed 18 October 2015].

UNFCCC (2014) Decision -/CP.20 Lima call for climate action. Available at: http://newsroom.unfccc.int/media/167536/auv_cop20_ lima_call_for_climate_action.pdf [Accessed 18 October 2016].

UNFCCC (2015a) FCCC/CP/2015/L.9/Rev.1 Adoption of the Paris Agreement. Proposal by the President. Available at: https://unfccc. int/resource/docs/2015/cop21/eng/I09r01.pdf [Accessed 18 October 2016].

UNFCCC (2015b) FCCC/CP/2015/7 Synthesis report on the aggregate effect of the intended nationally determined contributions. Note by the secretariat. Available at: http://unfccc.int/resource/docs/2015/cop21/eng/07.pdf [Accessed 18 October 2016].

\section{Chapter 2}

BAPPENAS (2015) Sekretariat RAN-GRK. Available at: http://ranradgrk.bappenas.go.id/rangrk/component/content/article/92bahasa/informasi-sektoral/193-hasil-indc [Accessed 31 October 2015].

Belenky, M. (2016) Achieving the U.S. 2025 Emissions Mitigation Target: January 2016 Update. Climate Advisers. Available at: http://www.climateadvisers.com/wp-content/uploads/2016/02/US-Achieving-2025-Target_Jan-2015-final.pdf [Accessed 14 October 2016].

CAIT WRI (2015) CAIT Climate Data Explorer-Pre-2020 Pledges Map. Available at: http://cait.wri.org/pledges/ [Accessed 14 October 2016].

CAT (2014) Climate Action Tracker - Brazil. Available at: http://climateactiontracker.org/countries/brazil/2014.html [Accessed 14 October 2016].

CAT (2015) Climate Action Tracker. Available at: http://climateactiontracker.org/ [Accessed 14 October 2016].

Carbon Pulse (2016) South Korea abandons 2020 GHG target, puts ETS in new hands and lifts early action credit cap. Available at: http://carbon-pulse.com/16177/ [Accessed 19 October 2016].

Clarke, L., Jiang, K., Akimoto, K., Babiker, M., Blanford, G., Fisher-Vanden, K., Hourcade, J.C., Krey, V., Kriegler, E., Löschel, A., McCollum, D., Paltsev, S., Rose, S., Shukla, P.R., Tavoni, M., van der Zwaan, B.C.C. and van Vuuren, D.P. (2014) 'Assessing Transformation Pathways'. In Edenhofer, O., R. Pichs-Madruga, Y. Sokona, E. Farahani, S. Kadner, K. Seyboth, A. Adler, I. Baum, S. Brunner, P. Eickemeier, B. Kriemann, J. Savolainen, S. Schlömer, C. von Stechow, T. Zwickel and J.C. Minx (eds.) Climate Change 2014: Mitigation of Climate Change. Contribution of Working Group III to the Fifth Assessment Report of the Intergovernmental Panel on Climate Change. Cambridge, United Kingdom and New York, NY, USA: Cambridge University Press.

den Elzen, M.G.J., Fekete, H., Admiraal, A., Forsell, N., Höhne, N., Korosuo, A., Roelfsema, M., van Soest, H., Wouters, K., Day, T., Hagemann, M., Hof, A, Mosnier A. (2015) Enhanced policy scenarios for major emitting countries. Analysis of current and planned climate policies, and selected enhanced mitigation measure. PBL Netherlands Environmental Assessment Agency, Bilthoven, the Netherlands. Available at: http://www.pbl.nl/sites/default/files/cms/publicaties/pbl-2015-enhanced-policy-scenarios-formajor-emitting-countries_1631.pdf [Accessed 14 October 2016].

Department of Environment Australia (2016) Tracking to 2020 - April 2016 update. Department of the Environment. Australian Government. Available at: https://www.environment.gov.au/system/files/resources/a977b3b6-ee21-45dd-87cbc108e0de91dd/files/factsheet-tracking-2020-april-2016-update.pdf [Accessed 14 October 2016].

Department of Environmental Affairs Republic of South Africa (2011a) South Africa's Second National Communication under the United Nations Framework Convention on Climate Change. Available at: http://unfccc.int/resource/docs/natc/zafnc02.pdf [Accessed 14 October 2016].

Department of Environmental Affairs Republic of South Africa (2011b) Explanatory note: Defining South Africa's Peak, Plateau and Decline Greenhouse Gas Emission Trajectory. SA Government Position on Climate Change. Available at: http://www.climateaction. org.za/cop17-cmp7/sa-government-position-on-climate-change [Accessed 31 October 2015].

Department of Environment and Energy Australia (2016) National Inventory Report 2014 (revised) Volume 1, Commonwealth of Australia 2016. Available at: http://unfccc.int/files/national_reports/annex_i_ghg_inventories/national_inventories_ submissions/application/zip/aus-2016-nir-09aug16.zip [Accessed 14 October 2016]. 
EEA (2014) Annual European Union greenhouse gas inventory 1990-2012 and inventory report 2014. European Environment Agency. Available at: http://www.eea.europa.eu/publications/european-union-greenhouse-gas-inventory-2014 [Accessed 14 October 2016].

EEA (forthcoming) Trends and projections in Europe 2016 - Tracking progress towards Europe's climate and energy targets. European Environment Agency. Available at: http://www.eea.europa.eu/publications/trends-and-projections-in-europe-2016 [Accessed 19 October 2016].

Garg, A., Shukla, P.R. and Bhushan K. (2014) India Report on Alternate Development Pathways for India: Aligning Copenhagen Climate Change Commitments with National Energy Security and Economic Development. Low Climate Impact Scenarios and the Implications of Required Tight Emission Control Strategies [LIMITS]. Indian Institute of Management, Ahmedabad, India. Available at: http://www.feem-project.net/limits/docs/limits_india\%20report_iim.pdf [Accessed 14 October 2016].

Government of Brazil (2010) Decreto No. 7390, de 9 de dezembro de 2010. Available at: http://www.planalto.gov.br/ccivil_03/_ Ato2007-2010/2010/Decreto/D7390.htm [Accessed 14 October 2016].

Government of Canada (2016) Canada's Second Biennial Report on Climate Change. Available at: http://unfccc.int/files/national_ reports/biennial_reports_and_iar/submitted_biennial_reports/application/pdf/canadas_2nd_biennial_report.pdf [Accessed 14 October 2016].

Government of Japan (2016) Japan's Second Biennial Report Under the United Nations Framework Convention on Climate Change. Available at: http://unfccc.int/files/national_reports/biennial_reports_and_iar/submitted_biennial_reports/application/pdf/ japan_br2_revised.pdf [Accessed 14 October 2016].

Government of Mexico (2012) Programas para mitigar el cambio climático. Available at: http://www2.inecc.gob.mx/publicaciones/ libros/685/programas2.pdf [Accessed 10 November 2015].

Government of Mexico (2015) Intended Nationally Determined Contribution. Available at: http://www4.unfccc.int/submissions/ INDC/Published\%20Documents/Mexico/1/MEXICO\%20INDC\%2003.30.2015.pdf [Accessed 14 October 2016].

Government of Russia (2014) First Biennial Report of the Russian Federation. Available at: http://unfccc.int/files/national_reports/ biennial_reports_and_iar/submitted_biennial_reports/application/pdf/1br_rus_unoffical_translation_eng.pdf [Accessed 14 October 2016].

Government of Russia (2015) Second Biennial Report of the Russian Federation. In Russian. Available at: http://unfccc.int/files/ national_reports/biennial_reports_and_iar/submitted_biennial_reports/application/pdf/2br_rus.pdf [Accessed 14 October 2016].

Greenblatt, J. and M. Wei (2016) 'Assessment of the climate commitments and additional mitigation policies of the United States'. Nature Climate Change (September 2016). Advance online publication. Available at: http://www.nature.com/nclimate/journal/ vaop/ncurrent/full/nclimate3125.html [Accessed 14 October 2016].

IEA (2016) World Energy Statistics and Balances online data service 2016 edition. Available at: https://www.iea.org/statistics/ relateddatabases/worldenergystatisticsandbalances/ [Accessed 14 October 2016].

IPCC (1995) IPCC Second Assessment Climate Change 1995. IPCC, Geneva, Switzerland. Available at: https://www.ipcc.ch/pdf/ climate-changes-1995/ipcc-2nd-assessment/2nd-assessment-en.pdf [Accessed 14 October 2016].

IPCC (2007) Climate Change 2007: Synthesis Report. Contribution of Working Groups I, II and III to the Fourth Assessment Report of the Intergovernmental Panel on Climate Change [Core Writing Team, Pachauri, R.K and Reisinger, A. (eds.)]. IPCC, Geneva, Switzerland, 104 pp. Available at: https://www.ipcc.ch/pdf/assessment-report/ar4/syr/ar4_syr_full_report.pdf [Accessed 14 October 2016].

IPCC (2014a) Climate Change 2014: Synthesis Report. Contribution of Working Groups I, II and III to the Fifth Assessment Report of the Intergovernmental Panel on Climate Change [Core Writing Team, R.K. Pachauri and L.A. Meyer (eds.)]. IPCC, Geneva, Switzerland, $151 \mathrm{pp}$. Available at: https://www.ipcc.ch/pdf/assessment-report/ar5/syr/SYR_AR5_FINAL_full.pdf [Accessed 14 October 2016].

IPCC (2014b) Climate Change 2014: Mitigation of Climate Change. Contribution of Working Group III to the Fifth Assessment Report of the Intergovernmental Panel on Climate Change. In Edenhofer, O., R. Pichs-Madruga, Y. Sokona, E. Farahani, S. Kadner, K. Seyboth, A. Adler, I. Baum, S. Brunner, P. Eickemeier, B. Kriemann, J. Savolainen, S. Schlömer, C. von Stechow, T. Zwickel and J.C. Minx (eds.). Cambridge University Press, Cambridge, United Kingdom and New York, NY, USA. Available at: http://www.ipcc.ch/ pdf/assessment-report/ar5/wg3/ipcc_wg3_ar5_full.pdf [Accessed 13 October, 2016].

Jackson, R.B., Canadell, J.G., Le Quere, C., Andrew, R.M-, Korsbakken. J.I., Peters, G.P- and Nakicenovic, N. (2016) 'Reaching peak emissions'. Nature Climate Change 6:7-10.

JRC/PBL (2014) Emission Database for Global Atmospheric Research (EDGAR). Version 4.2FT2012. European Commission, Joint Research Centre (JRC) / PBL Netherlands Environmental Assessment Agency. Available at: http://edgar.jrc.ec.europa.eu/overview. php [Accessed 14 October 2016].

Kuramochi, T. (2014) GHG Mitigation in Japan: An Overview of the Current Policy Landscape. Working Paper. Washington, DC: World Resources Institute. Available at: http://www.wri.org/sites/default/files/wri_workingpaper_japan_final_ck_6_11_14.pdf [Accessed 14 October 2016].

Larsen, J., K. Larsen, W. Herndon, S. Mohan (2016) Taking Stock: Progress Toward Meeting US Climate Goals. New York, NY: Rhodium Group. Available at: http://rhg.com/wp-content/uploads/2016/01/RHG_Taking_Stock_of_US_Climate_Goals_Jan28_2016.pdf [Accessed 14 October 2016].

The Law National Information Center (2016) Presidential Decree 27180 of 24 May, 2016 (enforced 1 June, 2016); partial amendment of the Enforcement Decree of the Framework Act on Low Carbon, Green Growth. The Law National Information Center, Korea Ministry of Government Legislation. Available at: http://www.law.go.kr/lsInfoP.do?lsiSeq=183314\&efYd=20160601\#AJAX [Accessed 16 October 2016].

Le Quéré, C., Moriarty, R., Andrew, R.M., Canadell, J.G., Sitch, S., Korsbakken, J.I., Friedlingstein, P., Peters, G.P., Andres, R.J., Boden, T.A., Houghton, R.A., House, J.I., Keeling, R.F., Tans, P., Arneth, A., Bakker, D.C.E., Barbero, L., Bopp, L., Chang, J., Chevallier, F., Chini, L.P., Ciais, P., Fader, M., Feely, R.A., Gkritzalis, T., Harris, I., Hauck, J., Ilyina, T., Jain, A.K., Kato, E., Kitidis, V., Klein Goldewijk, K., Koven, C., Landschützer, P., Lauvset, S.K., Lefèvre, N., Lenton, A., Lima, I.D., Metzl, N., Millero, F., Munro, D.R., Murata, A., S. Nabel, J.E.M., Nakaoka, S., Nojiri, Y., O’Brien, K., Olsen, A., Ono, T., Pérez, F.F., Pfeil, B., Pierrot, D., Poulter, B., Rehder, G., Rödenbeck, C., Saito, S., Schuster, U., Schwinger, J., Séférian, R., Steinhoff, T., Stocker, B.D., Sutton, A.J., Takahashi, T., Tilbrook, 
B., van der Laan-Luijkx, I.T., van der Werf, G.R., van Heuven, S., Vandemark, D., Viovy, N., Wiltshire, A., Zaehle, S. and Zeng, N. (2015) 'Global Carbon Budget 2015'. Earth System Science Data 7:349-396. Available at: http://www.earth-syst-sci-data. net/7/349/2015/essd-7-349-2015.pdf [Accessed 13 October 2016].

Ministry of Environment, Forest and Climate Change,India (2015) India: First Biennial Update Report to the United Nations Framework Convention on Climate Change. Available at http://unfccc.int/resource/docs/natc/indbur1.pdf [Accessed 14 October 2016].

Ministry of Environment Indonesia (2010) Indonesia Second National Communication under the UNFCCC. Jakarta: Ministry of Environment, Republic of Indonesia. Available at: http://unfccc.int/files/national_reports/non-annex_i_natcom/submitted_ natcom/application/pdf/indonesia_snc.pdf [Accessed 14 October 2016].

Ministry of Environment and Forestry Indonesia (2015) First Biennial Update Report. Jakarta: Ministry of Environment and Forestry, Republic of Indonesia Available at: http://unfccc.int/resource/docs/natc/idnbur1.pdf [Accessed 14 October 2016].

Ministry of Environment Japan (2015) Chapter 4: Renewable energy deployment potential. In: 'Heisei 26nendo 2050nen saiseikanou enerugii nado bunsangata enerugii fukyuukanousei kenshoukentou houkokusho' (FY2013 report on the assessment of deployment potential for renewable energy and other distributed energy technologies). In Japanese. Tokyo: Ministry of the Environment. Available at: http://www.env.go.jp/policy/ [Accessed 10 November 2015].

Ministry of the Environment and Sustainable Development Argentina (2015) Tercera Comunicación Nacional. Ministry of the Environment and Sustainable Development, Argentina. In Spanish. Available at: http://ambiente.gob.ar/tercera-comunicacionnacional/ [Accessed 4 August 2016].

NCCS (2013) National Climate Change Strategy. 10-20-40 Vision. Mexico: Federal Government of Mexico. Available at: http:// mitigationpartnership.net/sites/default/files/encc_englishversion.pdf [Accessed 14 October 2016].

Olivier, J.G.J., Janssens-Maenhout, G., Muntean, M., Peters and J.A.H.W. (forthcoming) Trends in global CO2 emissions: 2016 Report. Bilthoven: PBL Netherlands Environmental Assessment Agency.

PBL (2015) PBL Climate Pledge INDC tool. Bilthoven: PBL Netherlands Environmental Assessment Agency. Available at: http:// infographics.pbl.nl/indc/ [Accessed 14 October 2016].

PBL (2016) Updated calculations. Bilthoven: PBL Netherlands Environmental Assessment Agency (personal communication).

People's Republic of China (2012) Second National Communication on Climate Change of the People's Republic of China. Beijing: National Development and Reform Commission Available at: http://unfccc.int/resource/docs/natc/chnnc2e.pdf [Accessed 14 October 2016].

Planning Commission Government of India (2011) Low Carbon Strategies for Inclusive Growth: An Interim Report. New Delhi: Planning commission. Available at: http://www.moef.nic.in/downloads/public-information/Interim\%20Report\%20of\%20 the\%20Expert\%20Group.pdf [Accessed 14 October 2016].

Planning Commission Government of India (2014) The Final Report of the Expert Group on Low Carbon Strategies for Inclusive Growth. New Delhi: Planning Commission. Available at: http://planningcommission.nic.in/reports/genrep/rep_carbon2005.pdf [Accessed 14 October 2016].

Potsdam Institute for Climate Impact Research (2016) PRIMAP emissions module. Available at: https://www.pik-potsdam. $\mathrm{de} / \mathrm{research} / \mathrm{climate}$-impacts-and-vulnerabilities/research/rd2-flagship-projects/primap/emissionsmoduledocumentation [Accessed 13 October 2016].

Republic of Korea (2014) First biennial update report of the Republic of Korea. Available at: http://unfccc.int/resource/docs/natc/ rkorbur1.pdf [Accessed 14 October 2016].

Republic of Korea (2015) Intended Nationally Determined Contribution. Available at: http://www4.unfccc.int/submissions/INDC/ Published\%20Documents/Republic\%20of\%20Korea/1/INDC\%20Submission\%20by\%20the\%20Republic\%20of\%20Korea\%20 on\%20June\%2030.pdf [Accessed 14 October 2016].

Republic of Turkey Ministry of Environment and Urbanisation (2016) Turkey's Joint First and Second Biennial Report under the United Nations Framework Convention on Climate Change. Available at: http://unfccc.int/files/national_reports/biennial_ reports_and_iar/submitted_biennial_reports/application/pdf/turkey_joint_first_and_second_biennial_report.pdf [Accessed $1 \overline{4}$ October 2016$]$.

Reputex (2016) White Paper: Framing Australia's Energy \& Climate Policy to 2030. Available at: http://www.reputex.com/researchinsights/framing-australias-2030-energy-climate-policy-mix/ [Accessed 14 October 2016].

Rogelj, J., McCollum, D.L., O'Neill, B.C. and Riahi, K. (2013) '2020 emissions levels required to limit warming to below $2^{\circ} \mathrm{C}^{\prime}$. Nature Climate Change, 3(4):405-412. Available at: http://www.nature.com/nclimate/journal/v3/n4/abs/nclimate1758.html [Accessed 10 November 2015].

Sha, F., Ji, Z. and Linwei, L. (2015) An Analysis of China's INDC. Beijing: China National Center for Climate Change Strategy and International Cooperation. Available at: http://www.chinacarbon.info/wp-content/uploads/2010/12/Comments-on-ChinasINDC.pdf [Accessed 14 October 2016].

UNEP (2012) The Emissions Gap Report 2012. Nairobi: United Nations Environment Programme (UNEP). Available at: http://www. unep.org/pdf/2012gapreport.pdf [Accessed 14 October 2016].

UNEP (2013) The Emissions Gap Report 2013. Nairobi: United Nations Environment Programme (UNEP). Available at: http://www. unep.org/pdf/UNEPEmissionsGapReport2013.pdf [Accessed 14 October 2016].

UNEP (2014) The Emissions Gap Report 2014. Nairobi: United Nations Environment Programme (UNEP). Available at: http://www. unep.org/publications/ebooks/emissionsgapreport2014/portals/50268/pdf/EGR2014_LOWRES.pdf [Accessed 14 October 2016].

UNEP (2015) The Emissions Gap Report 2015. Nairobi: United Nations Environment Programme (UNEP). Available at: http://www. unep.org/emissionsgapreport2015/ [Accessed 14 October 2016].

U.S. Department of State (2015) 2016 second biennial report of the United States of America. Available at: http://unfccc.int/files/ national_reports/biennial_reports_and_iar/submitted_biennial_reports/application/pdf/2016_second_biennial_report_of_ the_united_states_.pdf [Accessed 14 October 2016]. 


\section{Chapter 3}

Australian Government. Department of the Environment and Energy (2015) Australia's emissions projections 2014 -15. Canberra: Department of the Environment and Energy. Available at: http://www.environment.gov.au/system/files/resources/f4bdfc0e9a05-4c0b-bb04-e628ba4b12fd/files/australias-emissions-projections-2014-15.pdf [Accessed October 14 2016].

Belenky, M. (2015) Achieving the U.S. 2025 Emissions Mitigation Target. Washington, D.C.: Climate Advisers. Available at: http:// www.climateadvisers.com/wp-content/uploads/2013/12/US-Achieving-2025-Target_May-2015.pdf [Accessed 14 October 2016].

Bonsch, M., Humpenöder, F., Popp, A., Bodirsky, B., Dietrich, J.P., Rolinski, S., Biewald, A., Lotze-Campen, H., Weindl, I., Gerten, D. and Stevanovic, M. (2016) 'Trade-offs between land and water requirements for large-scale bioenergy production'. GCB Bioenergy, 8(1):11-24. Available at: http://onlinelibrary.wiley.com/doi/10.1111/gcbb.12226/full [Accessed 14 October 2016].

Boyd, R., Stern, N. and Ward, B. (2015) What will global annual emissions of greenhouse gases be in 2030, and will they be consistent with avoiding global warming of more than 2C? London: ESRC Centre for Climate Change Economics and Policy and Grantham Research Institute on Climate Change and the Environment. Available at: http://www.Ise.ac.uk/Granthamlnstitute/wp-content/ uploads/2015/05/Boyd_et_al_policy_paper_May_2015.pdf [Accessed 14 October 2016].

Clarke, L., Jiang, K., Akimoto, K., Babiker, M., Blanford, G., Fisher-Vanden, K., Hourcade, J.C., Krey, V., Kriegler, E., Löschel, A., McCollum, D., Paltsev, S., Rose, S., Shukla, P.R., Tavoni, M., van der Zwaan, B.C.C. and van Vuuren, D.P. (2014) 'Assessing Transformation Pathways'. In Edenhofer, O., R. Pichs-Madruga, Y. Sokona, E. Farahani, S. Kadner, K. Seyboth, A. Adler, I. Baum, S. Brunner, P. Eickemeier, B. Kriemann, J. Savolainen, S. Schlömer, C. von Stechow, T. Zwickel and J.C. Minx (eds.) Climate Change 2014: Mitigation of Climate Change. Contribution of Working Group III to the Fifth Assessment Report of the Intergovernmental Panel on Climate Change. Cambridge, United Kingdom and New York, NY, USA: Cambridge University Press.

Climate Action Tracker (2015) Climate Action Tracker. Available at: http://climateactiontracker.org/ [Accessed 14 October 2016].

Climate Equity Reference Project (2015) Fair Shares: A Civil Society Equity Review of INDCs. Climate Equity Reference Project. Available at: http://civilsocietyreview.org/wp-content/uploads/2015/11/CSO_FullReport.pdf [Accessed 14 October 2016].

Climate Interactive (2015) Climate Scoreboard. Climate Interactive. Available at: https://www.climateinteractive.org/programs/ scoreboard/ [Accessed 14 October 2016].

Creutzig, F., Ravindranath, N.H., Berndes, G., Bolwig, S., Bright, R., Cherubini, F., Chum, H., Corbera, E., Delucchi, M., Faaij, A., Fargione, J., Haberl, H., Heath, G., Lucon, O., Plevin, R., Popp, A., Robledo-Abad, C., Rose, S., Smith, P., Stromman, A., Suh, S. and Masera, O. (2015) 'Bioenergy and climate change mitigation: an assessment'. GCB Bioenergy, 7(5):916-944. Available at: http:// onlinelibrary.wiley.com/doi/10.1111/gcbb.12205/pdf [Accessed 14 October 2016].

DEA (2015) Analyzing the 2030 emissions gap. Copenhagen: Danish Energy Agency (DEA).

Dellink, R., Chateau, J., Lanzi, E. and Magné, B. (2016) 'Long-term economic growth projections in the Shared Socioeconomic Pathways'. Global Environmental Change. Available at: http://www.sciencedirect.com/science/article/pii/S0959378015000837 [Accessed 14 October 2016].

den Elzen, M., Admiraal, A., Roelfsema, M., van Soest, H., Hof, A.F. and Forsell, N. (2016) 'Contribution of the G20 economies to the global impact of the Paris agreement climate proposals'. Climatic Change, 137(3):655-665. Available at: http://link.springer.com/ article/10.1007/s10584-016-1700-7 [Accessed 14 October 2016].

den Elzen, M., Fekete, H., Admiraal, A., Forsell, N., Höhne, N., Korosuo, A., Roelfsema, M., van Soest, H., Wouters, K. and Day, T. (2015) Enhancing ambition in the major emitting countries. PBL Netherlands Environmental Assessment Agency. Available at: http://www.pbl.nl/en/publications/enhancing-mitigation-ambitions-in-the-major-emitting-countries-analysis-of-current-andpotential-climate-policies [Accessed 14 October 2016].

Department of Environmental Affairs (2014) South Africa's Greenhouse Gas (GHG) Mitigation Potential Analysis. Pretoria: Department of Environmental Affairs, South Africa.

Dubash, N.K., Khosla, R., Rao, N.D. and Sharma, K.R. (2015) Informing India's Energy and Climate Debate: Policy Lessons from Modelling Studies. New Delhi: Centre for Policy Research. Available at: http://cprindia.org/sites/default/files/Informing\%20 India's\%20Energy\%20and\%20Climate\%20Debate_CPR-IIASA.pdf [Accessed 14 October 2016].

EEA (2014) Trends and projections in Europe 2014. Luxembourg: European Environment Agency (EEA). Available at: http://www. eea.europa.eu/publications/trends-and-projections-in-europe-2014 [Accessed 14 October 2016].

Fawcett, A.A., Iyer, G.C., Clarke, L.E., Edmonds, J.A., Hultman, N.E., McJeon, H.C., Rogelj, J., Schuler, R., Alsalam, J., Asrar, G.R., Creason, J., Jeong, M., McFarland, J., Mundra, A. and Shi, W. (2015) 'Can Paris pledges avert severe climate change?'. Science, 350(6265):1168-1169. Available at: http://climate.envsci.rutgers.edu/climdyn2015/slides/Science-2015-Fawcett-1168-9.pdf [Accessed 14 October 2016].

Garg, A., Shukla, P.R. and Kankal, B. (2014) Low Climate Impact Scenarios and the Implications of Required Tight Emission Control Strategies: India Report on Alternate Development Pathways for India; Aligning Copenhagen Climate Change Commitments with National Energy Security and Economic Development. Ahmedabad: Indian Institute of Management. Available at: http://www. feem-project.net/limits/docs/limits_india\%20report_iim.pdf [Accessed 14 October 2016].

Geels, F.W., Berkhout, F. and van Vuuren, D.P. (2016) 'Bridging analytical approaches for low-carbon transitions'. Nature Climate Change, 6:576-583.

Government of Canada (2014) Canada's Emissions Trends. Gatineau: Environment Canada. Available at: https://ec.gc.ca/ges-ghg/ E0533893-A985-4640-B3A2-008D8083D17D/ETR_E\%202014.pdf [Accessed 14 October 2016].

Government of China (2012) Second national communication on climate change of the People's Republic of China. Beijing: National Development and Reform Commission. Available at: http://unfccc.int/resource/docs/natc/chnnc2e.pdf [Accessed 10 November 2015].

Hausker, K., Igusky, K., Gasper, R., Aden, N. and Obeiter, M. (2015) Delivering on the U.S. Climate Commitment: A 10-Point Plan Toward a Low-Carbon Future. Washington, DC: World Resource Institute. Available at: http://www.wri.org/publication/ delivering-us-climate-commitment-10-point-plan-toward-low-carbon-future [Accessed 14 October 2016].

Hof, A.F., den Elzen, M. and Mendoza Beltran, A. (2016) 'The EU 40 \% greenhouse gas emission reduction target by 2030 in perspective'. International Environmental Agreements: Politics, Law and Economics, 16(3):375-392. Available at: http://link. springer.com/article/10.1007\%2Fs10784-016-9317-x [Accessed 14 October 2016]. 
Höhne, N., den Elzen, M. and Escalante, D. (2014) 'Regional greenhouse gas mitigation targets based on equity principles: a comparison of studies'. Climate Policy, 14:122-147. Available at: http://dx.doi.org/10.1080/14693062.2014.849452 [Accessed 14 October 2016].

IEA (2014) World Energy Outlook 2014. Paris: International Energy Agency (IEA). Available at: http://www.worldenergyoutlook.org/ weo2014/ [Accessed 14 October 2016].

IEA (2015) World Energy Outlook 2015. Paris: International Energy Agency (IEA). Available at: http://www.worldenergyoutlook.org/ resources/energyandclimatechange/ [Accessed 14 October 2016].

IPCC (2014a) Climate Change 2014: Synthesis Report. Contribution of Working Groups I, II and III to the Fifth Assessment Report of the Intergovernmental Panel on Climate Change [Core Writing Team, R.K. Pachauri and L.A. Meyer (eds.)]. Geneva : IPCC. Available at: https://www.ipcc.ch/pdf/assessment-report/ar5/syr/SYR_AR5_FINAL_full.pdf [Accessed 14 October 2016].

IPCC (2014b) Climate Change 2014: Mitigation of Climate Change. Contribution of Working Group III to the Fifth Assessment Report of the Intergovernmental Panel on Climate Change [Edenhofer, O., R. Pichs-Madruga, Y. Sokona, E. Farahani, S. Kadner, K. Seyboth, A. Adler, I. Baum, S. Brunner, P. Eickemeier, B. Kriemann, J. Savolainen, S. Schlömer, C. von Stechow, T. Zwickel and J.C. Minx (eds.)]. Cambridge and New York: Cambridge University Press. Available at: http://www.ipcc.ch/pdf/assessment-report/ ar5/wg3/ipcc_wg3_ar5_full.pdf [Accessed 13 October, 2016].

Jiang, K., Zhuang, X., Miao, R. and He, C. (2013) 'China's role in attaining the global $2^{\circ} \mathrm{C}$ target'. Climate Policy, 13:55-69. Available at: http://www.tandfonline.com/doi/abs/10.1080/14693062.2012.746070 [Accessed 14 October 2016].

JRC/PBL (2014) Emission Database for Global Atmospheric Research (EDGAR). Version 4.2FT2012. European Commission, Joint Research Centre (JRC) / PBL Netherlands Environmental Assessment Agency. Available at: http://edgar.jrc.ec.europa.eu/overview. php [Accessed 14 October 2016].

King Abdullah University of Science and Technology (2014) Appraisal and Evaluation of Energy Utilization and Efficiency in the Kingdom of Saudi Arabia. Volume 2: Energy Efficiency Audit: Case Studies. King Abdullah University of Science and Technology.

Kitous, A. and Keramidas, K. (2015) Analysis of scenarios integrating the INDCs. Sevilla: Joint Research Centre. Available at: https:// ec.europa.eu/jrc/sites/jrcsh/files/JRC97845.pdf [Accessed 14 October 2016].

Kitous, A., Keramidas, K., Vandyck, T. and Saveyn, B. (2016) GECO2016. Global Energy and Climate Outlook. Road from Paris. Joint Research Centre. Available at: http://ec.europa.eu/jrc/en/geco [Accessed 14 October 2016].

Krey, V., Luderer, G., Clarke, L. and Kriegler, E. (2014) 'Getting from here to there - energy technology transformation pathways in the EMF27 scenarios'. Climatic Change, 123(3):369-382. Available at: http://link.springer.com/article/10.1007/s10584-013-09475 [Accessed 14 October 2016].

Kriegler, E., Weyant, J.P., Blanford, G.J., Krey, V., Clarke, L., Edmonds, J., Fawcett, A., Luderer, G., Riahi, K., Richels, R., Rose, S.K., Tavoni, M. and van Vuuren, D.P. (2013) 'The Role of Technology for Achieving Climate Policy Objectives: Overview of the EMF 27 Study on Technology and Climate Policy Strategies'. Climatic Change, 123(3):353-367. Available at: http://link.springer.com/ article/10.1007/s10584-013-0953-7 [Accessed 14 October 2016].

Kuramochi, T. (2014) GHG Mitigation in Japan: An Overview of the Current Policy Landscape. Washington, DC: World Resources Institute. Available at: wri.org/publication/ghg-mitigation-policy-japan [Accessed 14 October 2016].

Le Quéré, C., Moriarty, R., Andrew, R.M., Canadell, J.G., Sitch, S., Korsbakken, J.I., Friedlingstein, P., Peters, G.P., Andres, R.J., Boden, T.A., Houghton, R.A., House, J.I., Keeling, R.F., Tans, P., Arneth, A., Bakker, C.E., Barbero, L., Bopp, L., Chang, J., Chevallier, F., Chini, L.P., Ciais, P., Fader, M., Feely, R.A., Gkritzalis, T., Harris, I., Hauck, J., Ilyina, T., Jain, A.K., Kato, E., Kitidis, V., Goldewijk, K.K., Koven, C., Landschützer, P., Lauvset, S.K., Lefèvre, N., Lenton, A., Lima, I.D., Metzl, N., Millero, F., Munro, D.R., Murata, A., Nabel, J.E., Nakaoka, S., Nojiri, Y., O’Brien, K., Olsen, A., Ono, T., Pérez, F.F., Pfeil, B., Pierrot, D., Poulter, B., Rehder, G., Rödenbeck, C., Saito, S., Schuster, U., Schwinger, J., Séférian, R., Steinhoff, T., Stocker, B.D., Sutton, A.J., Takahashi, T., Tilbrook, B., van der Laan-Luijkx, I.T., van der Weerf, G.R., van Heuven, S., Vandemark, D., Vioy, N., Wiltshire, A., Zaehle, S. and Zeng, N. (2015) 'Global Carbon Budget 2015'. Earth System Science Data, 7:349-396. Available at: http://www.earth-syst-sci-data.net/7/349/2015/essd-7-349-2015.pdf [Accessed 14 October 2016].

Luderer, G., Pietzcker, R.C., Bertram, C., Kriegler, E., Meinshausen, M. and Edenhofer, O. (2013) ‘Economic mitigation challenges: how further delay closes the door for achieving climate targets'. Environmental Research Letters, 8. Available at: http://iopscience.iop. org/article/10.1088/1748-9326/8/3/034033/pdf [Accessed 19 October 2016].

Meinshausen, M. (2015) INDC Factsheets. Melbourne: Australian-German Climate and Energy College / University of Melbourne. Available at: http://www.climate-energy-college.net/indc-factsheets [Accessed 19 October 2016].

Meinshausen, M., Jeffery, L., Guetschow, J., Robiou du Pont, Y., Rogelj, J., Schaeffer, M., Höhne, N., den Elzen, M., Oberthür. S. and Meinshausen, N. (2015) 'National post-2020 greenhouse gas targets and diversity-aware leadership'. Nature Climate Change, 5:1098-1106. Available at: http://www.nature.com/nclimate/journal/v5/n12/abs/nclimate2826.html [Accessed 14 October 2016].

NCCS (2013) National Climate Change Strategy. 10-20-40 Vision. Mexico: Federal Government of Mexico. Available at: http:// mitigationpartnership.net/mexico-2013-national-climate-change-strategy-10-20-40-vision [Accessed 14 October 2016].

Obersteiner, M., Azar, Ch., Kauppi, P., Mollersten, K.. Moreira, J., Nilsson, S., Read, P., Riahi, K., Schlamadinger, B., Yamagata, Y., Yan, J. and van Ypersele, J.-P. (2001) 'Managing Climate Risk'. Science, 294(5543):786-787. Available at: http://science.sciencemag.org/ content/294/5543/786.2 [Accessed 14 October 2016].

O’Neill, B.C., Kriegler, E., Ebi, K.L., Kemp-Benedict, E., Riahi, K., Rothman, D.S., van Ruijven, B.J., van Vuuren, D.P., Birkmann, J., Kok, K., Levy, M. and Solecki, W. (2015) 'The roads ahead: Narratives for shared socioeconomic pathways describing world futures in the 21st century'. Global Environmental Change, In Press, pp. 1-12. Available at: http://www.sciencedirect.com/science/article/ pii/S0959378015000060 [Accessed 14 October 2016].

O’Neill, B.C., Kriegler, E., Riahi, K., Ebi, K.L., Hallegatte, S., Carter, T., Mathur, R. and van Vuuren, D.P. (2014) 'A new scenario framework for climate change research: the concept of shared socioeconomic pathways'. Climatic Change, 122:387-400. Available at: http:// link.springer.com/article/10.1007/s10584-013-0905-2 [Accessed 14 October 2016].

Riahi, K., Kriegler, E., Johnson, N., Bertram, C., den Elzen, M., Eom, J., Schaeffer, M., Edmonds, J., Isaac, M., Krey, V., Longden, T., Luderer, G., Méjean, A., McCollum, D.L., Mima, S., Turton, H., van Vuuren, D.P., Wada, K., Bosetti, V., Capros, P., Criqui, P., HamdiCherif, M., Kainuma, M. and Edenhofer, O. (2015) 'Locked into Copenhagen pledges - Implications of short-term emission targets for the cost and feasibility of long-term climate goals'. Technological Forecasting and Social Change, 90(Part A):8-23. Available at: http://www.sciencedirect.com/science/article/pii/S0040162513002539 [Accessed 14 October 2016]. 
Riahi, K., van Vuuren, D.P., Kriegler, E., Edmonds, J., O’Neill, B.C., Fujimori, S., Bauer, N., Calvin, K., Dellink, R., Fricko, O., Lutz, W., Popp, A., Cuaresma, J.C., KC, S., Leimbach, M., Jiang, L., Kram, T., Rao, S., Emmerling, J., Ebi, J., Hasegawa, T., Havlik. P., Humpenöder, F., Da Silva, L.A., Smith, S., Stehfest, E., Bosetti, V., Eom, J., Gernaat, D., Masui, T., Rogelj, J., Strefler, J., Drouet, L., Krey, V., Luderer, G., Harmsen, M., Takahashi, K., Baumstark, L., Doelman, J.C., Kainuma, M., Klimont, Z., Marangoni, G., LotzeCampen, H., Obersteiner, M., Tabeau, A. and Tavoni, M. (2016) 'The Shared Socioeconomic Pathways and their Energy, Land Use, and Greenhouse Gas Emissions Implications: An Overview'. Global Environmental Change, In Press, pp. 1-16. Available at: http:// www.sciencedirect.com/science/article/pii/S0959378016300681 [Accessed 14 October 2016].

Rogelj, J., den Elzen, M., Höhne, N., Fransen, T., Fekete, H., Winkler, H., Schaeffer, R., Sha, F., Riahi, K. and Meinshausen, M. (2016) 'Paris Agreement climate proposals need a boost to keep warming well below $2{ }^{\circ} \mathrm{C}$ '. Nature, 534:631-639. Available at: http:// www.nature.com/nature/journal/v534/n7609/abs/nature18307.html [Accessed 19 October 2016].

Rogelj, J., Gunnar, L., Pietzcker, R.C., Kriegler, E., Schaeffer, M., Krey, V. and Riahi, K. (2015) 'Energy system transformations for limiting end-of-century warming to below $1.5^{\circ} \mathrm{C}^{\prime}$. Nature Climate Change, 5:519-527. Available at: http://www.nature.com/ nclimate/journal/v5/n6/full/nclimate2572.html [Accessed 14 October 2016].

Rogelj, J., Mccollum, D.L., O'Neill, B.C. and Riahi, K. (2013a) '2020 emissions levels required to limit warming to below ${ }^{\circ} \mathrm{C}^{\prime}$. Nature Climate Change, 3:405-412. Available at: http://www.nature.com/nclimate/journal/v3/n4/full/nclimate1758.html [Accessed 14 October 2016].

Rogelj, J., Mccollum, D.L., Reisinger, A., Meinshausen, M. and Riahi, K.(2013b) 'Probabilistic cost estimates for climate change mitigation'. Nature, 493:79-83. Available at: http://www.nature.com/nature/journal/v493/n7430/full/nature11787.html [Accessed 14 October 2016].

Schleussner, C.-F., Rogelj, J., Schaeffer, M., Lissner, T., Licker, R., Fischer, E.M., Knutti, R., Levermann, A., Frieler, K. and Hare, W. (2016) 'Science and policy characteristics of the Paris Agreement temperature goal'. Nature Climate Change, 6:827-835. Available at: http://www.nature.com/nclimate/journal/v6/n9/full/nclimate3096.html [Accessed 14 October 2016].

Sha, F., Ji, Z. andLinwei, L. (2015) An Analysis of China's INDC. Beijing: China National Center for Climate Change Strategy and International Cooperation (NCSC). Available at: http://www.chinacarbon.info/wp-content/uploads/2015/07/Comments-onChinas-INDC.pdf [Accessed 14 October 2016].

Smith, P., Davis, S.J., Creutzig, F., Fuss, S., Minx, J., Gabrielle, B., Kato, E., Jackson, R.B., Cowie, A., Kriegler, E., van Vuuren, D.P., Rogelj, J., Ciais, P., Milne, J., Canadell, J.G., Mccollum, D., Peters, G., Andrew, R., Krey, V., Shrestha, G., Friedlingstein, P., Gasser, T., Grübler, A., Heidug, W.K., Jonas, M., Jones, C.D., Kraxner, F., Littleton, E., Lowe, J., Moreira, J.R., Nakicenovic, N., Obersteiner, M., Patwardhan, A., Rogner, M., Rubin, E., Sharifi, A., Torvanger, A., Yamagata, Y., Edmonds, J. and Yongsung, C. (2016) 'Biophysical and economic limits to negative $\mathrm{CO} 2$ emissions'. Nature Climate Change, 6:42-50. Available at: http://www.nature.com/nclimate/ journal/vaop/ncurrent/full/nclimate2870.html [Accessed 14 October 2016].

Tavoni, M., Kriegler, E., Riahi, K., van Vuuren, D., Aboumahboub, T., Bowen, A., Calvin, K., Campiglio, E., Kober, T., Jewell, J., Luderer, G., Marangoni, G., McCollum, D., van Sluisveld, M., Zimmer, A. and van der Zwaan, B. (2015) 'Post-2020 climate agreements in the major economies assessed in the light of global models'. Nature Climate Change, 5(2):119-126. Available at: http://eprints. Ise.ac.uk/62727/1/Post_2020.pdf [Accessed 14 October 2016].

Tavoni, M. and Socolow, R. (2013) 'Modeling meets science and technology: an introduction to a special issue on negative emissions'. Climatic Change, 118:1-14. Available at: http://link.springer.com/article/10.1007/s10584-013-0757-9 [Accessed 14 October 2016].

UNEP (2014) The Emissions Gap Report 2014. Nairobi: United Nations Environment Programme (UNEP). Available at: http://www. unep.org/publications/ebooks/emissionsgapreport2014/portals/50268/pdf/EGR2014_LOWRES.pdf [Accessed 14 October 2016].

UNEP (2015) The Emissions Gap Report 2015. Nairobi: United Nations Environment Programme (UNEP). Available at: http:// uneplive.org/theme/index/13\#indcs [Accesssed 14 October 2016].

UNFCCC (2016a) INDCs as communicated by Parties. Available at: http://www4.unfccc.int/submissions/indc/Submission\%20Pages/ submissions.aspx [Accessed 14 October 2016].

UNFCCC (2016b) National Reports. Available at: http://unfccc.int/national_reports/items/1408.php [Accessed 14 October 2016].

UNFCCC (2016c) Submitted National Communications. Available at: http://unfccc.int/nationalreports/annexinatcom/ submittednatcom/items/7742.php [Accessed 14 October 2016].

UNFCCC (2016d) Submitted National Communications from non-Annex I Parties. Available at: http://unfccc.int/nationalreports/ non-annexinatcom/submittednatcom/items/653.php [Accessed 14 October 2016].

UNFCCC (2016e) FCCC/CP/2016/2 Aggregate effect of the intended nationally determined contributions: an update. - Synthesis report by the Secretariat. Available at: http://unfccc.int/resource/docs/2016/cop22/eng/02.pdf [Accessed 14 October 2016].

US Environmental Protection Agency (2012) Global Anthropogenic Non-CO2 Greenhouse Gas Emissions: 1990-2030: Revised Version 2012. Available at: http://www3.epa.gov/climatechange/Downloads/EPAactivities/EPA_Global_NonCO2_Projections_Dec2012. pdf [Accessed 17 October 2016].

West, J.J., Smith, S.J., Silva, R.A., Naik, V., Zhang, Y., Adelman, Z., Fry, M.M., Anenberg, S., Horowitz, L.W. and Lamarque, J.-F. (2013) 'Co-benefits of mitigating global greenhouse gas emissions for future air quality and human health'. Nature Climate Change, 3:885-889. Available at: http://www.nature.com/nclimate/journal/v3/n10/full/nclimate2009.html [Accessed 14 October 2016].

Williamson, P. (2013) 'Emissions reduction: Scrutinize CO2 removal methods'. Nature, 530:153-155. Available at: http://www. nature.com/news/emissions-reduction-scrutinize-co2-removal-methods-1.19318 [Accessed 14 October 2016].

WRI (2015) Paris Contributions Map. CAIT Climate Data Explorer. Available at: http://cait.wri.org/indc/ [Accessed 14 October 2016].

\section{Chapter 4}

Andonova, L.B., Betsill, M.M. and Bulkeley, H. (2009) ‘Transnational Climate Governance'. Global Environmental Politics, 9(2):52-73. Available at: http://www.mitpressjournals.org/doi/abs/10.1162/glep.2009.9.2.52?journalCode=glep\#.V_z41_myNHw [Accessed 11 October 2016].

ARUP and C40 Cities (2014) Global Aggregation of City Climate Commitments. Available at: http://www.c40.org/researches/ working-together-global-aggregation-of-city-climate-commitments [Accessed 11 October 2016]. 
Bansard, J.S., Pattberg, P.H. and Widerberg, O. (2016) 'Cities to the rescue? Assessing the performance of transnational municipal networks in global climate governance'. International Environmental Agreements: Politics, Law and Economics, pp. 1-18. Available at: http://link.springer.com/10.1007/s10784-016-9318-9 [Accessed 11 October 2016].

Betsill, M., Dubash, N.K., Paterson, M., van Asselt, H., Vihma, A. and Winkler, H. (2015) 'Building Productive Links between the UNFCCC and the Broader Global Climate Governance Landscape'. Global Environmental Politics, 15(2):1-10. Available at: http:// www.mitpressjournals.org/doi/pdf/10.1162/GLEP_a_00294 [Accessed 11 October 2016].

Bulkeley, H., Andonova, L., Backstrand, K., Betsill, M., Compagnon, D., Duffy, R., Kolk, A., Hoffmann, M., Levy, D., Newell, P., Milledge, T., Paterson, M., Pattberg, P. and VanDeveer, S. (2012) 'Governing climate change transnationally: assessing the evidence from a survey of sixty initiatives'. Environment and Planning C: Government and Policy, 30:591-612. Avaiable at: http://munkschool. utoronto.ca/egl/files/2015/01/Governing-climate-change-transnationally.pdf [Accessed 11 October 2016].

Bulkeley, H., Andonova, L.B., Betsill, M.M., Compagnon, D., Hale, T., Hoffmann, M.J., Newell, P., Paterson, M., Roger, C. and VanDeveer, S.D. (2014) Transnational Climate Change Governance. Cambridge: Cambridge University Press. Available at: https://www.cambridge.org/core/books/transnational-climate-change-governance/44AC553A1719681F5BD1D8C91B5DD999 [Accessed 11 October 2016].

CDP and We Mean Business (2016) The Business End of Climate Change. Available at: https://newclimate.org/2016/06/28/thebusiness-end-of-climate-change/ [Accessed 11 October 2016].

Chan, S., van Asselt, H., Hale, T., Abbott, K.W., Beisheim, M., Hoffmann, M., Guy, B., Höhne, N., Hsu, A., Pattberg, P., Pauw, P., Ramstein, C. and Widerberg, O. (2015) 'Reinvigorating International Climate Policy: A Comprehensive Framework for Effective Nonstate Action'. Global Policy, 6(4):466-473. Available at: http://doi.wiley.com/10.1111/1758-5899.12294 [Accessed 11 October 2016].

Chan, S., Brandi, C. and Bauer, S. (2016) 'Aligning Transnational Climate Action with International Climate Governance: The Road from Paris'. Review of European, Comparative \& International Environmental Law, 25(2):238-247. Available at: http://doi.wiley. com/10.1111/reel.12168 [Accessed 11 October 2016].

Circle Economy and Ecofys (2016) Implementing circular economy globally makes Paris targets achievable. Available at: http:// www.ecofys.com/files/files/circle-economy-ecofys-2016-circular-economy-white-paper.pdf [Accessed 11 October 2016].

CISL and Ecofys (2015) Better Partnerships: Understanding and increasing the impact of private sector cooperative initiatives. Available at: http://www.ecofys.com/files/files/ecofys-cisl-2015-wtg-better-partnerships.pdf [Accessed 11 October 2016].

Compact of Mayors (2015) Climate Leadership at the Local Level: Global Impact of the Compact of Mayors. Available at: http://www. bbhub.io/mayors/sites/14/2016/01/BR_AggregationReport_Final_SinglePages-FINAL-2016.pdf [Accessed 11 October 2016].

Durham University (2016) Transnational Climate Change Governance. Available at: http://community.dur.ac.uk/tccg/downloads/ [Accessed 12 October 2016].

Erickson, P. and Tempest, K. (2014) Advancing Climate Ambition: How city-scale actions can contribute to global climate goals. Working paper no. 2014-06. Stockholm: Stockholm Environment Institute. Avavileable at: https://www.sei-international.org/ mediamanager/documents/Publications/Climate/SEI-WP-2014-06-C40-Cities-mitigation.pdf [Accessed 11 October 2016].

Fabius, L. (2015) Paris Scientific Conference Closing Speech. Available at: http://newsroom.unfccc.int/lima/laurent-fabius-scientificconference-closing-speech-our-common-future/ [Accessed 12 October 2016].

Galvanizing the Groundswell of Climate Actions (2015) Lima-Paris Action Agenda Independent Assessment Report. Available at: https://static1.squarespace.com/static/552be32ce4b0b269a4e2ef58/t/56673b3cb204d59deb517d8d/1449605948836/LPAA_ Assessment_Report_7DEC15.pdf [Accessed 11 October 2016].

German Development Institute and the London School of Economics (2016) Galvanizing the Groundswell of Climate Action. Available at: http://www.climategroundswell.org/blog-test/2015/7/16/galvanizing-a-groundswell-of-solutions-to-supportcop21 [Accessed 12 October 2016].

Graichen, J., Healy, S., Siemons, A., Höhne, N., Kuramochi, T., Gonzales-Zuñiga, S., Sterl, S., Kersting, J. and Wachsmuth, J. (2016) Climate initiatives, national contributions and the Paris Agreement. Draft Discussion Paper.Berlin: Öko-Institut e.V. Available at: https://newclimate.org/2016/05/23/climate-initiatives-national-contributions-and-the-paris-agreement/ [Accessed 11 October 2016].

Hale, T. (2016) “'All Hands on Deck”: The Paris Agreement and Nonstate Climate Action'. Global Environmental Politics, 16(3):12-22. Available at: http://www.mitpressjournals.org/doi/pdf/10.1162/GLEP_a_00362 [Accessed 11 October 2016].

Höhne, N., Sterl, S. and Fekete, H. (2015) How much more could Germany achieve through non-state action? Quantifying the impact of subnational and international cooperative initiatives on the future greenhouse gas missions of Germany. Cologne: NewClimate Institute. Available at: https://newclimate.org/2015/11/25/how-much-more-could-germany-achieve-through-non-state-action/ [Accessed 11 October 2016].

Hsu, A., Moffat, A.S., Weinfurter, A.J. and Schwartz, J.D. (2015) 'Towards a new climate diplomacy'. Nature Climate Change, 5:501503. Available at: http://www.nature.com/doifinder/10.1038/nclimate2594 [Accessed 11 October 2016].

Hsu, A.Cheng, Y., Weinfurter, A., Xu, K. and Yick, C. (2016) 'Track climate pledges of cities and companies'. Nature, 532:303306. Available at: http://www.nature.com/polopoly_fs/1.19764!/menu/main/topColumns/topLeftColumn/pdf/532303a.pdf [Accessed 11 October 2016].

ICAT (2016) Initiative for Climate Action Transparency. Available at: http://www.climateactiontransparency.org/ [Accessed 12 October 2016].

IVM and FORES (2015) Non-state actors in a Paris agreement: are cities and companies bridging the ambition gap? Policy Brief. Amsterdam: Institute for Environmental Studies, Free University Amsterdam. Available at: http://fores.se/wp-content/ uploads/2015/05/NSA_Policy_brief_Bonn2.pdf [Accessed 11 October 2016].

Jacobs, M. (2016) ‘High PressureforLowEmissions:HowCivilSocietyCreatedtheParisClimateAgreement’.Juncture, 22(4):314. Available at: $\quad$ http://www.ippr.org/juncture/high-pressure-for-low-emissions-how-civil-society-created-the-paris-climate-agreement [Accessed 11 October 2016].

Khan, F. and Sovacool, B.K. (2016) 'Testing the efficacy of voluntary urban greenhouse gas emissions inventories'. Climatic Change, pp. 1-14. Available at: http://link.springer.com/article/10.1007/s10584-016-1793-z [Accessed 11 October 2016]. 
Roelfsema, M., Harmsen, M., Olivier, J. and Hof, A. (2015) Climate Action outside the UNFCCC: Assessment of the impact of international cooperative initiatives on greenhouse gas emissions. PBL Policy Brief. The Hague: PBL Netherlands Environmental Assessment Agency. Available at: http://www.pbl.nl/sites/default/files/cms/pbl-2015-climate-action-outside-the-unfccc_01188. pdf [Accessed 11 October 2016].

The Climate Group (2015) Compact of States and Regions - Disclosure report 2015: The first global account of climate action from leading states, provinces and regions. Available at: https://www.cdp.net/CDPResults/Compact-of-States-and-Regions-DisclosureReport-2015.pdf [Accessed 11 October 2016].

UN (2014) 2014 Climate Change Summit - Chair's Summary. Available at: http://www.un.org/climatechange/summit/wp-content/ uploads/sites/2/2014/05/Climate-Summit-Chairs-Summary_26September2014CLEAN.pdf [Accessed 11 October 2016].

UNEP (2015) Climate commitments of subnational actors and business: A quantitative assessment of their emission reduction impact. Nairobi: United Nations Environment Programme (UNEP). Available at: http://apps.unep.org/publications/pmtdocuments/Climate_Commitments_of_Subnational_Actors_and_Business-2015CCSA_2015.pdf.pdf [Accessed 11 October 2016].

UNFCCC (2016a) Global Climate Action Agenda. Available at: http://newsroom.unfccc.int/climate-action/global-climate-actionagenda/ [Accessed 12 October 2016].

UNFCCC (2016b) Lima-Paris Action Agenda. Available at: http://newsroom.unfccc.int/lpaa/about/ [Accessed 12 October 2016].

UNFCCC (2016c) Momentum for Change. Available at: http://unfccc.int/secretariat/momentum_for_change/items/6214.php [Accessed 12 October 2016].

UNFCCC (2016d) NAZCA Accelerating Climate Action. Available at: http://climateaction.unfccc.int/ [Accessed 12 October 2016].

UNFCCC (2016e) Portal on Cooperative Initiatives. Available at: http://unfccc.int/focus/mitigation/items/7785.php [Accessed 12 October 2016].

UNFCCC (2016f) Road Map for Global Climate Action. Available at: http://newsroom.unfccc.int/media/658505/high-levelchampions-climate-action-roadmap.pdf [Accessed 12 October 2016].

UNFCCC (2016g) Technical Examination Process on Mitigation. Available at: http://unfccc.int/focus/mitigation/technical_expert_ meetings/items/8179.php [Accessed 12 October 2016].

UNFCCC (2016h) FCCC/CP/2015/10/Add.1. Report of the Conference of the Parties on its twenty-first session, held in Paris from 30 November to 13 December 2015. Addendum. Part two: Action taken by the Conference of the Parties at its twenty-first session. Available at: http://unfccc.int/resource/docs/2015/cop21/eng/10a01.pdf [Accessed 12 October 2016].

UNEP and UNEP DTU Partnership (2016) Climate Initiatives Platform. Available at: http://climateinitiativesplatform.org/index.php/ Welcome [Accessed 12 October 2016].

Widerberg, O. and Pattberg, P. (2015) 'International cooperative initiatives in global climate governance: Raising the ambition level or delegitimizing the UNFCCC?'. Global Policy, 6(1):45-56. Available at: http://onlinelibrary.wiley.com/doi/10.1111/17585899.12184/abstract [Accessed 11 October 2016].

Widerberg, O. and Stripple, J. (2016) 'The expanding field of cooperative initiatives for decarbonization: a review of five databases'. Wiley Interdisciplinary Reviews: Climate Change, 7(4):486-500. Available at: http://doi.wiley.com/10.1002/wcc.396 [Accessed 11 October 2016].

Yale University (2015) Scaling up: Local to Global Climate Action. Geneva: R20 Regions of Climate Action. Available at: http://www. stanleyfoundation.org/publications/report/WhitePaperScalingUp12-2015.pdf [Accessed 11 October 2016].

\section{Chapter 5}

4E (2016) 2015 Annual Report. IEA Technology Collaboration Programme on Energy Efficiency End-Use Equipment (4E). Available at: http://www.iea-4e.org/files/otherfiles/0000/0354/4E_Annual_Report_2015_FINAL.pdf [Accessed 12 October 2016].

Agarwal, Y., Balaji, B., Gupta, R., Lyles, J., Wei, M. and Weng, T. (2010) ‘Occupancy-driven energy management for smart building automation', BuildSys '10: 2nd ACM Workshop on Embedded Sensing Systems for Energy-Efficiency in Building. Zurich, Switzerland 2 November 2010. New York: ACM, pp. 1-6. Available at: http://mesl.ucsd.edu/yuvraj-old/research/documents/Agarwal_ BuildSys10_Occupancy.pdf [Accessed 12 October 2016].

Allcott, H. and Mullainathan, S. (2010) 'Behaviour and Energy Policy'. Science, 327:1204-5. Available at: http://scholar.harvard.edu/ files/sendhil/files/behavior_and_energy_policy.pdf [Accessed 12 October 2016].

Becqué, R., Mackres E., Layke, J., Aden, N., Liu S., Managan, K., Nesler, C., Mazur-Stommen, S., Petrichenko, K. and Graham. P. (2016) Accelerating Building Efficiency: Eight Actions for Urban Leaders. World Resources Institute. Available at: http://publications.wri. org/buildingefficiency/ [Accessed 12 October 2016].

Bjerkan, K.Y., Nørbech, T.E. and Nordtømme, M.E. (2016) 'Incentives for promoting Battery Electric Vehicle (BEV) adoption in Norway'. Transportation Research Part D: Transport and Environment, 43:169-180. Available at: http://www.sciencedirect.com/ science/article/pii/S1361920915002126 [Accessed 12 October 2016].

Boza-Kiss, B., Moles-Grueso, S. and Petrichenko, K. (2013a) Handbook of Sustainable Building Policies: Composing Building Blocks. Paris, France: United Nations Environment Programme (UNEP), Division of Technology, Industry and Economics (DTIE). Available at: http://www.unep.org/sustainablebuildingpolicies/pdfs/SPoD-Handbook\%20final-Full.pdf [Accessed 12 October 2016].

Boza-Kiss, B., Moles-Grueso, S. and Urge-Vorsatz, D. (2013b) 'Evaluating policy instruments to foster energy efficiency for the sustainable transformation of buildings'. Current Opinion in Environmental Sustainability, 5(2):163-176. Available at: https:// www.infona.pl/resource/bwmeta1.element.elsevier-60783940-595c-3bd4-8234-7813c2c313f2/tab/summary [Accessed 12 October 2016].

Brown, M.A. and Sovacool, B.K. (2011) Climate Change and Global Energy Security: Technology and Policy Options. Cambridge: MIT Press. Available at: https://mitpress.mit.edu/books/climate-change-and-global-energy-security [Accessed 12 October 2016].

Bruce, P.G., Freunberger, S.A., Hardwick, L.J. and Tarascon, J.M. (2012) 'Li-O2 and Li-S batteries with high energy storage'. Nature Materials, 11(1):19-29. Available at: http://www.nature.com/nmat/journal/v11/n1/abs/nmat3191.html [Accessed 12 October 2016].

CA EPBD (2015) Implementing the Energy Performance of Buildings Directive (EPBD). Lisbon: Concerted Action Energy Performance of Buildings (CA EPBD). 
Campbell, A.A., Cherry, C.R., Ryerson, M.S. and Yang, X. (2016) 'Factors influencing the choice of shared bicycles and shared electric bikes in Beijing'. Transportation Research Part C: Emerging Technologies, 67:399-414. Available at: http://www.sciencedirect. com/science/article/pii/S0968090X16000747 [Accessed 12 October 2016].

CEM (2016) World's Energy and Business Leaders Announce Actions to Accelerate Global Deployment of Technologies at Seventh Clean Energy Ministerial. Clean Energy Ministerial (CEM). Available at: http://www.cleanenergyministerial.org/News/worldsenergy-and-business-leaders-announce-actions-to-accelerate-global-deployment-of-technologies-at-seventh-clean-energyministerial-68632 [Accessed 12 October 2016].

Chan, C., Chan, H.W. and Qian, Q.K. (2014) 'Building Regulatory Control in Facing the Challenge of Climate Change: a case of Hong Kong'. World Sustainable Building Conference, Barcelona 28-30 October 2014. Barcelona: World SB14 Barcelona Scientific Committee. Available at: https://www.irbnet.de/daten/iconda/CIB_DC28252.pdf [Accessed 12 October 2016].

Davies, A. (2016) LA's Using Energy Savings from LED Streetlights to Charge Electric Vehicles. WIRED. Available at: https://www. wired.com/2016/06/las-using-energy-savings-led-streetlights-charge-electric-vehicles/ [Accessed 12 October 2016].

De Groote, M., Fabbri, M., Rapf, O. and D’Angiolella, R. (2016) 'Buildings as micro energy hubs delivering climate solutions'. The REHVA European HVAC Journal, 53(3):53. Available at: http://bpie.eu/wp-content/uploads/2016/08/Buildings-as-micro-energyhubs-delivering-climate-solutions_Final_ng.pdf [Accessed 12 October 2016].

DFCCIL (2016) Dedicated Freight Corridor Corporation of India Ltd. Available at: http://dfccil.gov.in/dfccil_app/home.jsp [Accessed 12 October 2016].

Dhar, S. and Shukla, P.R. (2015) 'Low carbon scenarios for transport in India: Co-benefits analysis'. Energy Policy, 81:186-198. Available at: http://www.sciencedirect.com/science/article/pii/S030142151400634X [Accessed 12 October 2016].

Dhar, S., Pathak, M. and Shukla, P.R. (2016) 'Electric vehicles and India's low carbon passenger transport: a long-term co-benefits assessment'. Journal of Cleaner Production. June 2016. Available at: https://www.researchgate.net/publication/303780947_ Electric_vehicles_and_India's_low_carbon_passenger_transport_A_long-term_co-benefits_assessment [Accessed 12 October 2016].

Ebel, W. and Feist, W. (1997) 'Electricity Consumption results from the Darmstadt Kranichstein Passive House'. Saving Electricity in the Passive House. 7.

EEA (2013) Achieving Energy Efficiency through Behaviour Change: What Does It Take? Luxembourg: European Environment Agency. Available at: http://www.eea.europa.eu/publications/achieving-energy-efficiency-through-behaviour [Accessed 12 October 2016].

Ehrhardt-Martinez, K., Donnelly, K. and Laitner, J.A. (2010) Advanced Metering Initiatives and Residential Feedback Programs: A Meta-Review for Households Electricity-Savings Opportunities. Washington, D.C.: American Council for an Energy Efficiency Economy. Available at: https://www.smartgrid.gov/files/ami_initiatives_aceee.pdf [Accessed 12 October 2016].

EnEffect (2014) The Success Model of Brussels: Case Study. EnEffect. Available at: http://nypassivehouse.org/wp-content/ uploads/2014/12/Detailed-description-of-the-Success-Model-of-Brussels.pdf [Accessed 12 October 2016].

Erhorn, H. and Erhorn-Kluttig, H. (2014) Selected examples of Nearly Zero-Energy Buildings. Concerted Action Energy Performance of Buildings. Available at: http://www.epbd-ca.eu/wp-content/uploads/2011/05/CT5_Report_Selected_examples_of_NZEBsfinal.pdf [Accessed 12 October 2016].

ESMAP (2009) Good Practices in City Energy Efficiency. Energy Sector Management Assistance Program (ESMAP) https://www. esmap.org/sites/esmap.org/files/CS_Bogota_020310_0.pdf [Accessed 12 October 2016].

European Parliament (2010) Directive 2010/31/EU of the European Parliament and of the Council of 19 May 2010 on the energy performance of buildings. Article 7. Available at: http://eur-lex.europa.eu/legal-content/en/TXT/?uri=celex\%3A32010L0031 [Accessed 12 October 2016].

Feist, W., Schnieders, J., Dorer, V. and Haas, A. (2005) 'Re-inventing air heating: Convenient and comfortable within the frame of the Passive House concept'. Energy and Buildings, 37(11)1186-1203. Available at: https://www.researchgate.net/ publication/223418821_Re-inventing_air_heating_Convenient_and_comfortable_within_the_frame_of_the_Passive_House_ concept [Accessed 12 October 2016].

Fenhann, J. (2016) Pledge Pipeline. Copenhagen: United Nations Environment Programme (UNEP). Available at: http://unep.org/ climatechange/pledgepipeline/ [Accessed 12 October 2016].

Figenbaum, E., Assum, T. and Kolbenstvedt, M. (2015) 'Electromobility in Norway: Experiences and Opportunities'. Research in Transportation Economics, 50:29-38.

GBPN (2014) Designing and implementing best practice building codes: insights from policy makers. Paris: Global Buildings Performance Network. Available at: http://www.gbpn.org/sites/default/files/05_Design\%20and\%20implementation\%20of\%20 best\%20practice\%20building\%20codes_1.pdf [Accessed 12 October 2016].

GFEI (2016) Fuel Economy State of the World 2016. London: Global Fuel Economy Initiative (GFEI). Available at: http://www. globalfueleconomy.org/media/203446/gfei-state-of-the-world-report-2016.pdf [Accessed 12 October 2016].

Gota, S., Huizenga, C., Peet, K. and Kaar, G. (2015) Intended Nationally-Determined Contributions (INDCs) Offer Opportunities for Ambitious Action on Transport and Climate Change. Partnership on Sustainable Low Carbon Transport. Available at: http:// ppmc-cop21.org/wp-content/uploads/2015/06/INDC-Report-Final-Version-2015-11-25-unformatted-2.pdf [Accessed 12 October 2016].

Haq, G. and Weiss, M. (2016) 'CO labelling of passenger cars in Europe: Status, challenges, and future prospects'. Energy Policy, 95:324-335. Available at: http://ac.els-cdn.com/S0301421516302129/1-s2.0-S0301421516302129-main.pdf?_tid=a86544168e71-11e6-b52c-00000aacb35f\&acdnat=1476053129_112047959894f59379da03130bce5822 [Accessed 12 October 2016].

Harvey, L.D.D. (2010) Energy and the New Reality 1: Energy Efficiency and the Demand for Energy Services. London: Earthscan.

ICF (2015) Energy Performance of Buildings Directive (EPBD) Compliance Study. Brussels: European Commission. Available at: https://ec.europa.eu/energy/sites/ener/files/documents/MJ-04-15-968-EN-N.pdf [Accessed 12 October 2016].

IEA (2011) Energy-efficiency policy opportunities for electric motor-driven systems. Paris: International Energy Agency (IEA). Available at: https://www.iea.org/publications/freepublications/publication/EE_for_ElectricSystems.pdf [Accessed 12 October 2016].

IEA (2012) World Energy Outlook. Paris: International Energy Agency (IEA). Available at: https://www.iea.org/publications/ freepublications/publication/WEO2012_free.pdf [Accessed 12 October 2016]. 
IEA (2013) Modernising Building Energy Codes to Secure our Global Energy Future. Paris: International Energy Agency (IEA). Available at: https://www.iea.org/publications/freepublications/publication/PolicyPathwaysModernisingBuildingEnergyCodes. pdf [Accessed 12 October 2016].

IEA (2014) Capturing the multiple benefits of energy efficiency. Paris, France: International Energy Agency (IEA). Available at: http:// www.iea.org/publications/freepublications/publication/capturing-the-multiple-benefits-of-energy-efficiency.html [Accessed 12 October 2016].

IEA (2015a) World Energy Outlook. Paris: International Energy Agency (IEA). Available at: http://www.worldenergyoutlook.org/ weo2015/ [Accessed 12 October 2016].

IEA (2015b) Accelerating Energy Efficiency in Small and Medium-sized Enterprises. Powering SMEs to catalyse economic growth. Paris: International Energy Agency (IEA). Available at: http://www.iea.org/publications/freepublications/publication/SME_2015. pdf [Accessed 12 October 2016].

IEA (2016a) World Energy Investment. Paris: International Energy Agency (IEA). Available at: https://www.iea.org/investment/ [Accessed 12 October 2016].

IEA (2016b) Energy Technology Perspectives. Paris: International Energy Agency (IEA). Available at: http://www.iea.org/ bookshop/719-Energy_Technology_Perspectives_2016 [Accessed 12 October 2016].

IEA (2016c) Tracking Clean Energy Progress 2016. Energy Technology Perspectives 2016 Excerpt IEA Input to the Clean Energy Ministerial. Paris: International Energy Agency (IEA). Available at: http://www.iea.org/publications/freepublications/publication/ TrackingCleanEnergyProgress2016.pdf [Accessed 12 October 2016].

IEA (2016d) Building Energy Efficiency Policies. International Energy Agency (IEA). Available at: https://www.iea.org/ beep/?type\%5B\%5D=Codes\&keywords [Accessed 12 October 2016].

IEA (2016e) Global EV Outlook 2016: Beyond one million electric cars. Paris: International Energy Agency (IEA). Available at: https:// www.iea.org/publications/freepublications/publication/Global_EV_Outlook_2016.pdf [Accessed 12 October 2016].

IFC (2016) Green Buildings. Available at: http://www.ifc.org/wps/wcm/connect/topics_ext_content/ifc_external_corporate_site/ cb_home/sectors/green_buildings_governments [Accessed 12 October 2016].

IPCC (2007) 'Climate change. Fourth Assessment Report of the IPCC'. Cambridge: Cambridge University Press. Available at: https:// www.ipcc.ch/pdf/assessment-report/ar4/wg3/ar4_wg3_full_report.pdf [Accessed 12 October 2016].

IPCC (2014) Climate Change 2014: Mitigation of Climate Change. Contribution of Working Group III to the Fifth Assessment Report of the Intergovernmental Panel on Climate Change [Edenhofer, O., Pichs-Madruga, R., Sokona, Y., Farahani, E., Kadner, S., Seyboth, K., Adler, A., Baum, I., Brunner, S., Eickemeier, P., Kriemann, B., Savolainen, J., Schlömer, S., von Stechow, C., Zwickel, T., and Minx, J.C. (eds.)]. Cambridge University Press, Cambridge, United Kingdom and New York, NY, USA. Available at: https://www.ipcc.ch/ pdf/assessment-report/ar5/wg3/ipcc_wg3_ar5_full.pdf [Accessed 12 October 2016].

IPEEC (2015) Delivering Energy Savings in Buildings: International Collaboration on Building Energy Code Implementation. Paris: International Partnership for Energy Efficiency Cooperation (IPEEC). Available at: http://www.ipeec.org/upload/publication_ related_language/pdf/1.pdf [Accessed 12 October 2016].

ISO (2014) The ISO Survey of Management System Standard Certifications. Available at: http://www.iso.org/iso/iso_survey_ executive-summary.pdf [Accessed 12 October 2016].

Karlin, B., Zinger, J.F. and Ford, R. (2015) 'The Effects of Feedback on Energy Conservation: A Meta-Analysis. Psychological Bulletin 141(6):1205-27. Available at: https://www.apa.org/pubs/journals/releases/bul-a0039650.pdf [Accessed 12 October 2016].

Lausten, J. (2010) The Factor Four Model Supporting Policies to Reduce Energy Use in Buildings by a Factor of Four. Paris, France: International Energy Agency (IEA).

Lawler, G. (no date) Green Buildings. City of Melbourne. Available at: http://www.icnvic.org.au/media/grand\%20prix\%20invitations/ grand\%20prix\%20presentations/geoff\%20lawler\%20presentation.pdf [Accessed 12 October 2016].

Liu, F., Meyer, A.S. and Hogan, J.F. (2010) Mainstreaming Building Energy Efficiency Codes in Developing Countries: Global Experiences and Lessons from Early Adopters. Washington, D.C.: The World Bank. Available at: http://documents.worldbank.org/curated/ en/284341468324865236/pdf/578770PUBOMain101public10BOX353783B.pdf [Accessed 12 October 2016].

Machado-Filho, H. (2009) 'Brazilian low-carbon transportation policies: opportunities for international support'. Climate Policy, 9(5):495-507.

Mathews, J.A. and Tan, H. (2016) 'Circular economy: Lessons from China'. Nature, 531(7595):440-442.

May, A.D. (2016) 'Editorial: Mobility and the sharing economy'. Transport Policy, pp. 1-2.

Movellan, J. (2015) California's First Zero Net Energy Community Opens on Earth Day to Support Bold State Goals. Renewable Energy World. Available at: http://www.renewableenergyworld.com/articles/2015/04/californias-first-zero-net-energy-communityopens-on-earth-day-to-support-bold-state-goals.html [Accessed 12 October 2016].

Navigant Research (2014) Zero Energy Buildings. Navigant Research. Available at: http://www.navigantresearch.com/research/ zero-energy-buildings [Accessed 12 October 2016].

New Building Institute (2016) Zero Net Energy. Available at: http://newbuildings.org/hubs/zero-net-energy/ [Accessed 12 October 2016].

Nykvist, B. and Nilsson, M. (2015) 'Rapidly falling costs of battery packs for electric vehicles'. Nature Climate Change, 5(4):329-332.

Passive House Institute (2015) Passive House Regions with Renewable Energies. Available at: http://bu7.cmsdrupal.eu/pl/ node/45339?gid=6106 [Accessed 12 October 2016].

Petrichenko, K. (2014) Net-Zero Energy Buildings: Global and Regional Perspectives. Doctoral dissertation. Budapest: Department of Environmental Sciences and Policy, Central European University.

Puig, D. and Farrell, T.C. (2015) 'The multiple benefits of measures to improve energy efficiency'. Copenhagen: UNEP DTU Partnership. Available at: http://kms.energyefficiencycentre.org/publication-report/multiple-benefits-measures-improve-energy-efficiency [Accessed 12 October 2016].

Rosqvist, L.S. and Hiselius, L.W. (2016) 'Online shopping habits and the potential for reductions in carbon dioxide emissions from passenger transport'. Journal of Cleaner Production, 13:163-169. Availabe at: https://www.infona.pl/resource/bwmeta1. element.elsevier-03dafbab-1045-3b2a-892e-014f7fe362c3 [Accessed 12 October 2016]. 
Schnieders, J. (2003) CEPHEUS - measurement results from more than 100 dwelling units in passive houses. Darmstadt: Passive House Institute.

Schnieders, J. and Hermelink, A. (2006) 'CEPHEUS results: measurements and occupants' satisfaction provide evidence for Passive Houses being an option for sustainable building'. Energy Policy, 34(2):151-171.

Schnieders, J., Feista, W. and Rongenc, L. (2015) 'Passive Houses for different climate zones'. Energy and Buildings, 105:71-87.

Shirakh, M., Bozorgchami, P. and Strait, P. (2015) 2016 Building Energy Efficiency Standards. Available at: http://www.energy. ca.gov/title24/2016standards/rulemaking/documents/2015-06-10_hearing/2015-06-10_Adoption_Hearing_Presentation.pdf [Accessed 12 October 2016].

Sims, R., Schaeffer, R., Creutzig, F., Cruz-Núñez, X., D’Agosto, M., Dimitriu, D., Figueroa Meza, M.J., Fulton, L., Kobayashi, S., Lah, O., McKinnon, A., Newman, P., Ouyang, M., Schauer, J.J., Sperling, D. and Tiwari, G. (2014) 'Transport'. In: Climate Change 2014: Mitigation of Climate Change. Contribution of Working Group III to the Fifth Assessment Report of the Intergovernmental Panel on Climate Change [Edenhofer, O., Pichs-Madruga, R., Sokona, Y., Farahani, E., Kadner, S., Seyboth, K., Adler, A., Baum, I., Brunner, S., Eickemeier, P., Kriemann, B., Savolainen, J., Schlömer, S., von Stechow, C., Zwickel T. and Minx J.C., (eds.)]. Cambridge University Press, Cambridge, United Kingdom and New York, NY, USA. Available at: https://www.ipcc.ch/pdf/assessment-report/ar5/wg3/ ipcc_wg3_ar5_chapter8.pdf [Accessed 12 October 2016].

Stahel, W.R. (2016) 'The circular economy'. Nature, 531(7595):435-438.

Steinbuks, J. and Neuhoff, K. (2014) 'Assessing Energy Price Induced Improvements in Efficiency of Capital in OECD Manufacturing Industries'. Journal of Environmental Economics and Management, 68:340-356.

Suzuki, H., Dastur, A., Moffatt, S., Yabuki, N. and Maruyama, H. (2010) Eco2 Cities: Ecological Cities as Economic Cities. World Bank. Available at: http://siteresources.worldbank.org/INTURBANDEVELOPMENT/Resources/336387-1270074782769/Eco2_Cities_ Book.pdf [Accessed 12 October 2016].

The International Council on Clean Transportation (2016) Global passenger vehicle standards. Available at: http://www.theicct.org/ info-tools/global-passenger-vehicle-standards [Accessed 12 October 2016].

Torcellini, P.A. and Crawley, D.B. (2006) 'Understanding Zero-Energy Buildings'. ASHRAE Journal, pp. 1-7.

Treberspurg, M. and Djalili, M. (2013) 'Passive House - best practice examples of cost effective building solutions with high-quality living'. Third International Symposium on Life-Cycle Civil Engineering.

UNEP (2010) Global Fuel Economy Initiative. Available at: http://www.globalfueleconomy.org/ [Accessed 12 October 2016].

UNFCCC (2015) India's Intended Nationally Determined Contribution. UNFCCC. Available at: http://www4.unfccc.int/submissions/ INDC/Published\%20Documents/India/1/INDIA\%20INDC\%20TO\%20UNFCCC.pdf [Accessed 12 October 2016].

UNIDO (2014) Energy Efficiency Potentials in Industrial Steam Systems in China. Development of a steam systems energy efficiency cost curve. Vienna: United Nations Industrial Development Organization (UNIDO). Available at: https://www.unido.org/ fileadmin/user_media_upgrade/What_we_do/Topics/Energy_access/EE_Potentials_Steam_Systems_China_.pdf [Accessed 12 October 2016].

UNIDO (2015) The UNIDO Programme on Energy Management System Implementation in Industry. Vienna: United Nations Industrial Development Organization (UNIDO). Available at: https://www.unido.org/fileadmin/user_media_upgrade/What_we_ do/Topics/Energy_access/11._IEE_EnMS_Brochure.pdf [Accessed 12 October 2016].

UNIDO and UN Energy (2010) Motor Systems Efficiency Supply Curves. United Nations Industrial Development Organization (UNIDO) and UN Energy. Available at: https://www.unido.org/fileadmin/user_media/Services/Energy_and_Climate_Change/Energy_ Efficiency/CCS/UNIDO\%20-\%20UN-Energy\%20-\%202010\%20-\%20Motor\%20Systems\%20Efficiency\%20Supply\%20Curves\%20 (2).pdf [Accessed 12 October 2016].

Ürge-Vorsatz, D. and Novikova, A. (2008) 'Potentials and costs of carbon dioxide mitigation in the world's buildings'. Energy Policy, 36(2):642-661. Available at: https://www.researchgate.net/publication/223164036_Potentials_and_costs_of_carbon_dioxide_ mitigation_in_the_world\%27s_buildings [Accessed 12 October 2016].

Ürge-Vorsatz, D., Eyre, N., Graham, P., Harvey, D., Hertwich, E., Jiang, Y., Kornevall, C., Majumdar, M., McMahon, J.E., Mirasgedis, S., Murakami, S., Novikova, A., Janda, K., Masera, O., McNeil, M., Petrichenko, K. and Tirado Herrero, S. (2012) 'Energy End-Use: Buildings'. In Johansson, T.B., Patwardhan, A., Nakicenovic, N. and Gomex-Echeverri, L. Global Energy Assessment: Toward a Sustainable Future. Cambridge: Cambdrige University Press.

von Stechow, C., McCollum, D., Riahi, K., Minx, J.C., Kriegler, E., van Vuuren, D.P., Jewell, J., Robledo-Abad, C., Hertwich, E., Tavoni, M., Mirasgedis, S., Lah, O., Roy, J., Mulugetta, Y., Dubash, N.K., Bollen, J., Ürge-Vorsatz, D. and Edenhofer, O. (2015) 'Integrating global climate change mitigation goals with other sustainability objectives: A synthesis'. Annual Review of Environment and Resources, 40:363-394.

WEF and Boston Consulting Group (2016) Shaping the Future of Construction: A Breakthrough in Mindset and Technology. World Economic Forum (WEF) and Boston Consulting Group. Avialable at: http://www3.weforum.org/docs/WEF_Shaping_the_Future_ of_Construction_full_report_.pdf [Accessed 12 October].

Wolfram, P. and Lutsey, N. (2016) Electric vehicles: Literature review of technology costs and carbon emissions. The International Council of Clean Transportation (ICCT). Available at: http://www.theicct.org/sites/default/files/publications/ICCT_LitRvw_EVtech-costs_201607.pdf [Accessed 12 October 2016].

Writer, S. (2015) City of Joburg to introduce power 'load limiting'. Business Tech. Available at: http://businesstech.co.za/news/ general/84943/city-of-joburg-to-introduce-power-load-limiting/ [Accessed 12 October 2016].

\section{Chapter 6}

AfDB, ADB, DFID, DGIS, EC, BMZ, SDG, UNDP, UNEP and the World Bank (2003) Poverty and Climate Change: Reducing the Vulnerability of the Poor through Adaptation. Available at: http://www.unpei.org/knowledge-resources/publications/poverty-and-climate-changereducing-the-vulnerability-of-the-poor-through-adaptation-african-db-asian-db-dfid-ec-federal-ministry-for-economic-cooperationand-development-germany [Accessed 17 October 2016].

Alexandratos, N. and J. Bruinsma (2012) World agriculture towards 2030/2050: the 2012 revision. ESA Working paper No. 12-03. Rome, FAO. Available at: http://www.fao.org/docrep/016/ap106e/ap106e.pdf [Accessed 20 October 2016] 
Ansuageti, A., Greño, P., Houlden, V., Markandya, A., Onofri, L., Tsarouchi, G.-M. and Walmsley, N. (2015) The impact of climate change on the achievement of the post-2015 sustainable development goals. London: HR Wallingford, Metroeconomica and Climate and Development Knowledge Network. Available at: http://cdkn.org/resource/technical-report-climate-and-sdgs/?loclang=en_gb [Accessed 17 October 2016].

ARUP and C40 Cities (2014) Global Aggregation of City Climate Commitments. Available at: http://www.c40.org/researches/workingtogether-global-aggregation-of-city-climate-commitments [Accessed 11 October 2016].

Biggs, E.M., Bruce, E., Boruff, B., Duncan, J., Horsley, J., Pauli, N., McNeil, K., Neef, A., van Ogtrop, F., Curnow, J., Haworth, B., Duce, S. and Imanari, Y. (2015) 'Sustainable development and the water-energy-food nexus: A perspective on livelihoods'. Environmental Science and Policy, 54:389-397. Available at: http://www.sciencedirect.com/science/article/pii/S1462901115300563 [Accessed 17 October 2016].

Bishop, R. (2015) Raising Energy Efficiency Standards to the Global Best. Global Commission on the Economy and Climate. New Climate Economy - Working Paper. Available at http://newclimateeconomy.report/workingpapers/wp-content/uploads/sites/5/2016/04/ NCE_Raising-energy-efficiency-standards-to-the-global-best1.pdf [Accessed 21 October 2016].

FAO (2016) Food wastage footprints \& Climate Change. Available at: http://www.fao.org/3/a-bb144e.pdf [Accessed 26 October 2016]."

FAO, IFAD and WFP (2015). The State of Food Insecurity in the World 2015. Meeting the 2015 international hunger targets: taking stock of uneven progress. Rome: FAO. Available at: http://www.fao.org/3/a-i4646e.pdf [Accessed 18 October 2016].

FrankfurtSchool-UNEPCentreandBNEF(2016)GlobalTrendsinRenewableEnergyInvestment2016. Frankfurt:FrankfurtSchool-UNEPCentre. Available at: http://fs-unep-centre.org/sites/default/files/publications/globaltrendsinrenewableenergyinvestment2016lowres_0.pdf [Accessed 21 October 2016)

Granoff, I., Eis, J., McFarland, W., Hoy, C., Watson, C., de Battista, G., Marijs, C., Khan, A. and Grist, N. (2015) Zero poverty, zero emissions: eradicating extreme poverty in the climate crisis. London: Overseas Development Institute (ODI). Available at: https://www.odi.org/ publications/9690-zero-poverty-zero-emissions-eradicating-extreme-poverty-climate-crisis [Accessed 17 October 2016].

Granoff, I, Hogarth, J.R. and Miller, A. (forthcoming) 'Nested Barriers to low-carbon infrastructure investement'. Nature Climate Change. Hallegate, S., Bangalore, M., Bonzanio, L., Fay, M., Kane, T., Narlock, U., Rozenberg, J., Treguer, D. and Vogt-Schilb, A. (2016) Shockwaves: Managing the impacts of climate change on poverty. Washington, DC.: Climate Change and Development Series, World Bank. Available at: https://openknowledge.worldbank.org/handle/10986/22787 [Accessed 17 October 2016].

Hasegawa, T., Fujimori, S., Shin, Y., Tanaka, A., Takahashi, K. and Masui, T. (2015) 'Consequence of climate mitigation on the risk of hunger'. Environmental Science \& Technology, 49 (12), pp. 7245-7253.

Hogarth, R. and Granoff, I. (2015) Speaking truth to power: how Africa can deliver energy access and reduce poverty. London: Overseas Development Institute (ODI). Available at: https://www.odi.org/sites/odi.org.uk/files/odi-assets/publications-opinion-files/9641.pdf [Accessed 17 October 2016].

Howells, M., Hermann, S., Welsch, M., Bazilian, M., Segerström, R., Alfstad, T., Gielen, D., Rogner, H., Fischer, G., Van Velthuizen, H., Wiberg, D., Young, C., Roehrl, R.A., Mueller, A., Steduto, P. and Ramma, I. (2013) 'Integrated analysis of climate change, land use, energy and water strategies'. Nature Climate Change, 3:621-6. Available at: http://www.nature.com/nclimate/journal/v3/n7/abs/ nclimate1789.html [Accessed 17 October 2016].

IEA (2011) World Energy Outlook 2011. Paris: International Energy Agency (IEA). Available at: http://www.worldenergyoutlook.org/ weo2011/ [Accessed 17 October 2016].

IEA (2012) World Energy Outlook 2012. Paris: International Energy Agency (IEA). Available at: http://www.worldenergyoutlook.org/ weo2012/ [Accessed 20 October 2016].

IEA (2014) Africa Energy Outlook - A focus on energy prospects in sub-Saharan Africa. Paris: International Energy Agency (IEA). Available at: https://www.iea.org/publications/freepublications/publication/WEO2014_AfricaEnergyOutlook.pdf [Accessed 17 October 2016].

IEA (2015a) World Energy Outlook. Paris: International Energy Agency (IEA). Available at: http://www.worldenergyoutlook.org/weo2015/ [Accessed 12 October 2016].

IEA (2015b) Energy and Climate Change. World Energy Outlook Special Report. Available at: http://www.worldenergyoutlook.org/ energyclimate/ [Accessed 20 October 2016].

IEA and the World Bank (2015) Sustainable Energy for All 2015: Progress Toward Sustainable Energy. Washington, D.C.: World Bank. Available at: http://trackingenergy4all.worldbank.org/reports [Accessed 17 October 2016].

IMF (2014) World Economic Outlook - Legacies, Clouds and Uncertainties. Washington, D.C.: International Monetary Fund (October). Available at: http://www.imf.org/external/pubs/ft/weo/2014/02/pdf/text.pdf [Accessed 20 October 2016].

IPCC (2001) Climate Change 2001: Synthesis Report. A Contribution of Working Groups I, II, and III to the Third Assessment Report of the Integovernmental Panel on Climate Change [Watson, R.T. and the Core Writing Team (eds.)]. Cambridge University Press, Cambridge, United Kingdom, and New York, NY, USA, 398 pp. Available at: http://www.grida.no/publications/other/ipcc_tar/ [Accessed 18 October 2016].

IPCC (2007) Climate Change 2007: Synthesis Report. Contribution of Working Groups I, II and III to the Fourth Assessment Report of the Intergovernmental Panel on Climate Change [Core Writing Team, Pachauri, R.K and Reisinger, A. (eds.)].Geneva: IPCC. Available at: http://www.ipcc.ch/pdf/assessment-report/ar4/syr/ar4_syr_full_report.pdf [Accessed 18 October 2016].

IPCC (2014a) Climate Change 2014: Synthesis Report. Contribution of Working Groups I, II and III to the Fifth Assessment Report of the Intergovernmental Panel on Climate Change [Core Writing Team, R.K. Pachauri and L.A. Meyer (eds.)]. Geneva: IPCC. Available at: https://www.ipcc.ch/pdf/assessment-report/ar5/syr/SYR_AR5_FINAL_full.pdf [Accessed 14 October 2016].

IPCC (2014b) Climate Change 2014: Mitigation of Climate Change. Contribution of Working Group III to the Fifth Assessment Report of the Intergovernmental Panel on Climate Change. In Edenhofer, O., R. Pichs-Madruga, Y. Sokona, E. Farahani, S. Kadner, K. Seyboth, A. Adler, I. Baum, S. Brunner, P. Eickemeier, B. Kriemann, J. Savolainen, S. Schlömer, C. von Stechow, T. Zwickel and J.C. Minx (eds.). Cambridge University Press, Cambridge, United Kingdom and New York, NY, USA. Available at: http://www.ipcc.ch/pdf/assessmentreport/ar5/wg3/ipcc_wg3_ar5_full.pdf [Accessed 13 October, 2016].

IRENA (2015) IRENA REMAP 2030: Doubling the Global Share of Renewable Energy: A Roadmap to 2030. Abu Dhabi: IRENA. Available at: https://www.irena.org/DocumentDownloads/Publications/IRENA\%20REMAP\%202030\%20working\%20paper.pdf [Accessed 21 October 2016] 
Lenton, T.M., Held, H., Kriegler, E., Hall, J.W., Lucht, W., Rahmstorf, S. and Schellnhuber, H. (2008) 'Tipping elements in the Earth's climate system'. Proceedings of the National Academy of Sciences of the United States of America, 105(6):1786-1793. Available at: http://www.pnas.org/content/105/6/1786.abstract [Accessed 17 October 2016].

Leong, A.K. (2015) Connecting the Dots between the UNFCCC and the SDGs. Available at: https://papers.ssrn.com/sol3/papers. cfm?abstract_id=2702831 [Accessed 17 October 2016].

Li. K. and Lin, B. (2015) 'Impacts of urbanization and industrialization on energy consumption/CO2 emissions: Does the level of development matter?' Renewable and Sustainable Energy Reviews, 52:1107-1122. Available at: http://www.sciencedirect.com/ science/article/pii/S1364032115008321 [Accessed 20 October 2016].

Loftus, P.J., Cohen, A.M., Long, J., and Jenkins, J.D. (2015) 'A critical review of global decarbonization scenarios: what do they tell us about feasibility?'. Wiley Interdisciplinary Reviews: Climate Change, 6(1):93-112. Available at: http://onlinelibrary.wiley.com/ doi/10.1002/wcc.324/full [Accessed 17 October 2016].

Marston, A. (2014) Doubling Climate Ambition: How the Post 2015 and UNFCCC Processes Complement Each Other. Discussion paper. London: CAFOD. Available at: http://www.climatenetwork.org/publication/doubling-climate-ambition-how-post-2015-and-unfcccprocesses-complement-each-other [Accessed 17 October 2016].

Munro, K. (2014). The right climate for development: why the SDGs must act on climate change. London: Christian Aid, CAFOD, Greenpeace, Oxfam GB, WWF-UK, Practical Action and CARE International. Available at: http://insights.careinternational.org.uk/ media/k2/attachments/SDGs-climate-change-Sept-2014.pdf [Accessed 17 October 2016].

New Climate Economy (2014) Financing a Low-Carbon Future: Better Growth, Better Climate: The Synthesis Report. Global Commission on the Economy and Climate. Available at: http://static.newclimateeconomy.report/wp-content/uploads/2014/08/NCE-SYNTHESISREPORT-web-share.pdf [Accessed 20 October 2016].

Nilsson, M., Griggs, D. and Visbeck, M. (2016) 'Map the interactions between Sustainable Development Goals'. Nature, 534(7607):320322. Available at: http://www.nature.com/news/policy-map-the-interactions-between-sustainable-development-goals-1.20075 [Accessed 17 October 2016].

Obersteiner, M., Walsh, B., Frank, S., Havlik, P., Cantele, M., Liu, J., Palazzo, A., Herrero, M., Lu, Y., Mosnier, A., Valin, H., Riahi, K., Kraxner, F., Fritz, S. and van Vurren, D. (2016) 'Assessing the land resource-food price nexus of the Sustainable Development Goals'. Science Advances, 2(9). Available at: http://advances.sciencemag.org/content/2/9/e1501499.full [Accessed 17 October 2016].

Paris Process on Mobility and Climate (2015) Emission Reduction Potential in the Transport Sector by 2030. Available at: http://ppmccop21.org/wp-content/uploads/2015/08/Emission-Reduction-Potential-in-the-Transport-Sector-by-2030.pdf [Accessed 20 October 2016].

Picot, H. and Moss, N. (2014) The Sustainable Development Goals: Will they deliver climate compatible development for vulnerable countries? Working Paper. London: Climate and Development Knowledge Network. Available at: http://cdkn.org/wp-content/ uploads/2014/08/CDKN_SDGs_WP_final_low-res.pdf [Accessed 17 October 2016].

Power for All (2016) Decentralized Renewables: The Fast Track to Universal Energy Access. Available at: http://static1.squarespace.com/ static/532f79fae4b07e365baf1c64/t/578d7f206b8f5bebe7f47444/1468890916501/Power_for_All_POV_May2016.pdf [Accessed 17 October 2016].

Ringler, C., Bhaduri, A. and Lawfor, R. (2013) 'The nexus across water, energy, land and food (WELF): potential for improved resource efficiency?' Current Opinion in Environmental Sustainability, 5(6):617-624.

Sadorsky, P. (2013) ‘Do urbanization and industrialization affect energy intensity in developing countries?’ Energy Economics 37:52-59.

Schleussner, C.-F., Lissner, T.K., Fischer, E.M., Wohland, J., Perrette, M., Golly, A., Rogelj, J., Childers, K., Schewe, J., Frieler, K., Mengel, M., Hare, W. and Schaeffer, M. (2016) 'Differential climate impacts for policy-relevant limits to global warming: the case of $1.5^{\circ} \mathrm{C}$ and $2{ }^{\circ} \mathrm{C}^{\prime}$. Earth System Dynamics Discussions, 6(2):2447-2505. Available at: http://www.earth-syst-dynam.net/7/327/2016/ [Accessed 17 October 2016].

Schneider, S.H., Semenov, S., Patwardhan, A., Burton, I., Magadza, C.H., Oppenheimer, M., Pittock, A.B. , Rahman, A., Smith, J.B. and Suarez, A. (2007) 'Assessing key vulnerabilities and the risk from climate change'. In: Parry, M.L., Canziani, O.F., Palutikof, J.P., van der Linden, P.J. and Hanson, C.E. (Eds.) Climate Change 2007: Impacts, Adaptation and Vulnerability. Contribution of Working Group II to the Fourth Assessment Report of the Intergovernmental Panel on Climate Change. Cambridge, UK: Cambridge University Press.

Scott, A. and Picot, H. (2014) Integrating climate change in the post-2015 development agenda. London: Climate and Development Knowledge Network. Available at: http://cdkn.org/wp-content/uploads/2014/03/Integrating-climate-change-into-the-post-2015development-agenda.pdf [Accessed 17 October 2016].

Smith, P. (2016) 'Soil carbon sequestration and biochar as negative emission technologies'. Global Change Biology, 22(3):1315-1324. Available at: http://onlinelibrary.wiley.com/doi/10.1111/gcb.13178/abstract [Accessed 17 October 2016].

Smith, P., Bustamante, M., Ahammad, H., Clark, H., Dong, H., Elsiddig, E.A., Haberl, H., Harper, R., House, J., Jafari, M., Masera, O., Mbow, C., Ravindranath, N.H., Rice, C.W., Robledo Abad, C., Romanovskaya, A., Sperling, F. and Tubiello, F.N. (2014) 'Agriculture, Forestry and Other Land Use (AFOLU)'. In: Edenhofer, O., Pichs-Madruga, R., Sokona, Y., Farahani, E., Kadner, S., Seyboth, K., Adler, A., Baum, I., Brunner, S., Eickemeier, P., Kriemann, B., Savolainen, J., Schlömer, S., von Stechow, C., Zwickel, T. and Minx, J.C. (eds.). Climate Change 2014: Mitigation of Climate Change. Contribution of Working Group III to the Fifth Assessment Report of the Intergovernmental Panel on Climate Change. Cambridge, United Kingdom and New York, NY, USA: Cambridge University Press.

Smith, P., Haberl, H., Popp, A., Erb, K.H., Lauk, C., Harper, R., Tubiello, F.N., de Siqueira Pinto, A., Jafari, M., Sohi, S., Masera, O., Böttcher, H., Berndes, G., Bustamante, M., Ahammad, H., Clark, H., Dong, H., Elsiddig, E.A., Mbow, C., Ravindranath, N.H., Rice, C.W., Robledo Abad, C., Romanovskaya, A., Sperling, F., Herrero, M., House, J.I. and Rose, S. (2013) 'How much land-based greenhouse gas mitigation can be achieved without compromising food security and environmental goals?' Global Change Biology, 19(8):2285-2302. Available at: http://onlinelibrary.wiley.com/doi/10.1111/gcb.12160/abstract [Accessed 17 October 2016].

Strassburg, B., Kelly, A., Balmford, A., Davies, R.G., Gibbs, H.K., Lovett, A., Miles, L., Orme, D.L., Price, J., Turner, R.K. and Rodrigues, A.S. (2010) 'Global congruence of carbon storage and biodiversity in terrestrial ecosystems'. Conservation Letters, 3(2):98-105. Available at: http://onlinelibrary.wiley.com/doi/10.1111/j.1755-263X.2009.00092.x/abstract [Accessed 17 October 2016].

von Stechow, C., Minx, J.C., Riahi, K., Jewell, J., McCollum, D.L., Callaghan, M.W., Bertram, C., Luderer, G. and Baiocchi, G. (2016) '2 ${ }^{\circ} \mathrm{C}$ and SDGs: united they stand, divided they fall?' Environmental Research Letters, 11 (3).

Stern Review (2007) The Economics of Climate Change. Cambridge University Press. Available at: http://mudancasclimaticas.cptec.inpe.

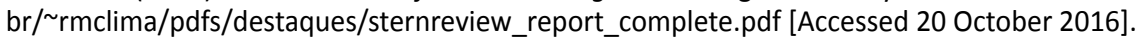


Szabó, S., Bodis, K., Huld, T., and Moner-Girona, M. (2011) 'Energy solutions in rural Africa: mapping electrification costs of distributed solar and diesel generation versus grid extension'. Environmental Research Letters, 6(3)1-9.

Tsay, S., and Herrmann, V. (2013) Rethinking Urban Mobility: Sustainable Policies for the Century of the City. Washington, D.C.: Carnegie Endowment for International Peace. Available at: http://carnegieendowment.org/files/urban_mobility.pdf [Accessed 20 October 2016].

UN (2015) A/RES/70/1 Transforming our world: the 2030 Agenda for Sustainable Development. Available at: https:// sustainabledevelopment.un.org/content/documents/21252030\%20Agenda\%20for\%20Sustainable\%20Development\%20web.pdf [Accessed 17 October 2016].

UNEP (2012) The Emissions Gap Report 2012: A UNEP Synthesis Report. Nairobi: United Nations Environment Programme (UNEP). Available at: http://www.unep.org/publications/ebooks/emissionsgap2012/ [Accessed 17 October 2016].

UNEP (2013) The Emissions Gap Report 2013: A UNEP Synthesis Report. Nairobi: United Nations Environment Programme (UNEP). Available at: http://www.unep.org/publications/ebooks/emissionsgapreport2013/ [Accessed 17 October 2016].

UNEP (2014) The Emissions Gap Report 2014: A UNEP Synthesis Report. Nairobi: United Nations Environment Programme (UNEP). Available at: http://www.unep.org/publications/ebooks/emissionsgapreport2014/ [Accessed 17 October 2016].

UNEP (2015) The Emissions Gap Report 2015: A UNEP Synthesis Report. Nairobi: United Nations Environment Programme (UNEP). Available at: http://uneplive.unep.org/theme/index/13\#indcs [Accessed 17 October 2016].

UNEP (2016) Cities and Coastal Areas. Available at: http://www.unep.org/urban_environment/issues/coastal_zones.asp [Accessed 17 October 2016].

UNFCCC (2015) FCCC/CP/2015/L.9.Rev.1. Adoption of the Paris Agreement. Available at: http://unfccc.int/resource/docs/2015/cop21/ eng/10a01.pdf [Accessed 17 October 2016].

Valin, H., Havlík, P., Mosnier, A., Herrero, M., Schmid, E. and Obersteiner, M. (2013) 'Agricultural productivity and greenhouse gas emissions: trade-offs or synergies between mitigation and food security?' Environmental Research Letters, 8 (3).

World Energy Council (2011) Global Transport Scenarios 2050. London: World Energy Council. Available at: https://www.worldenergy. org/wp-content/uploads/2012/09/wec_transport_scenarios_2050.pdf [Accessed 20 October 2016].

WWF and CARE (2015) Twin Tracks: Developing sustainably and equitably in a carbon-constrained world. London: WWF and CARE International. Available at: http://careclimatechange.org/wp-content/uploads/2015/06/twin_tracks_developing_sustainably_and_ equitably.pdf [Accessed 17 October 2016].

World Bank (2010) World Development Report 2010: Development and Climate Change. Washington, D.C. Available at: http:// siteresources.worldbank.org/INTWDR2010/Resources/5287678-1226014527953/WDR10-Full-Text.pdf [Accessed 18 October 2016]. 


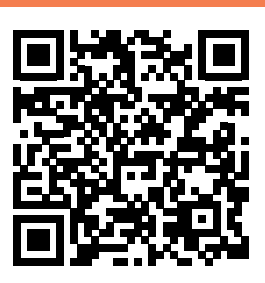

\section{www.unep.org}

United Nations Environment Programme P.O. Box 30552

Nairobi, 00100 , Kenya

Tel: (+254) 207621234

E-mail: publications@unep.org

Web: www.unep.org 